\title{
Ernst Wolff Political Responsibility for a Globalised World After Levinas' Humanism
}


Ernst Wolff

Political Responsibility for a Globalised World 


\section{Editorial}

Globalization demands for setting up new cultural orientations. Different traditions and forms of life struggle for recognition throughout the world and have to meet the necessity of values and norms with universal validity. Similarities and differences in understanding the world have to be analyzed and recognized which requires a new reflection on what it means to be a human being concerning its anthropological universality, but also its diverseness and changeability.

The books of the series Being Human: Caught in the Web of Cultures - Humanism in the Age of Globalization are committed to a new Humanism, which not only highlights humaneness in its cultural and historical varieties but also presents it as a transculturally valid principle of human interaction in all cultural life-forms.

The series is edited by

Jörn Rüsen (Essen), Chun-chieh Huang (Taipei), Oliver Kozlarek (Mexico City) and Jürgen Straub (Bochum), Assistant Editor: Henner Laass (Essen).

Advisory board:

Peter Burke (Cambridge), Chen Qineng (Beijing), Georg Essen (Nijmegen), Ming-huei Lee (Taipei), Surendra Munshi (Calcutta), Erhard Reckwitz (Essen), Masayuki Sato (Yamanashi), Helwig SchmidtGlintzer (Wolfenbüttel), Zhang Longxi (Hong Kong)

Ernst Wolff (Prof.) teaches philosophy at the University of Pretoria (South Africa) and is fellow of the Kulturwissenschaftliches Institut in Essen (Germany). His research covers hermeneutics, social and political philosophy and the philosophy of technology. 
ERnSt WolfF

Political Responsibility for

a Globalised World

After Levinas' Humanism

[transcript] 
In Cooperation with the Institute for Advanced Study in the Humanities, Essen, the Institute for Advanced Studies in Humanities and Social Sciences, National Taiwan University, the Faculty of Humanities of the University Duisburg/Essen.

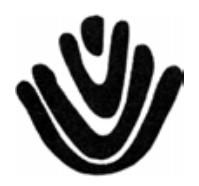

Humanism in the Era of Globalization An Intercultural Dialogue on Humanity, Culture, and Value sponsored by Stiftung Mercator of libraries working with Knowledge Unlatched. KU is a collaborative initiative designed to make high quality books Open Access for the public good.

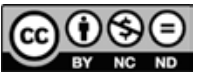

This work is licensed under the

\section{Creative Commons Attribution-NonCommercial-NoDerivs 3.0 (BY-NC-ND).}

which means that the text may be used for non-commercial purposes, provided credit is given to the author. For details go to http://creativecommons.org/licenses/by-nc-nd/3.0/.

\section{Bibliographic information published by the Deutsche Nationalbibliothek}

The Deutsche Nationalbibliothek lists this publication in the Deutsche Nationalbibliografie; detailed bibliographic data are available in the Internet at http://dnb.d-nb.de

All rights reserved. No part of this book may be reprinted or reproduced or utilized in any form or by any electronic, mechanical, or other means, now known or hereafter invented, including photocopying and recording, or in any information storage or retrieval system, without permission in writing from the publisher.

(C) 20II transcript Verlag, Bielefeld

Cover layout: Kordula Röckenhaus, Bielefeld

Proofread by Pam Apps, Izan Zybrands, Fritz Wolff

Typeset by Martin Hanke

Printed by Majuskel Medienproduktion $\mathrm{GmbH}$, Wetzlar

ISBN 978-3-8376-I694-I

ISBN 978-3-8394-I694-5 
Pour Luce, Madeleine et les autres 



\section{Table of contents}

Preface $\mid 11$

INTRODUCTION

Chapter 1

Doing justice to responsibility:

The primordial political nature

of Levinas' philosophy $\mid 17$

1 Orientation: Levinas as political philosopher | 17

2 "There are always at least three...":

Urgency and primacy of the political relation $\mid 19$

2.1 The constitution of political meaning | 21

2.2 Politics: the indispensable translation of the Saying to the Said $\mid 23$

3 Clarifications on the title $\mid 28$

\section{PART 1}

ETHICS AFTER THE COLONIES:

THE GLOBAL SCOPE

OF LEVINAS' POLITICAL THOUGHT |33

\section{Chapter 2}

Ethnography, atheism, decolonisation | 35

1 Lucien Lévy-Bruhl, or the use of ethnography for ontology and politics $\mid 36$

1.1 "To be is to participate"| 36

1.2 Heidegger, nostalgia, cruelty and the eclipse of monotheism $\mid 42$

1.3 Ethnography, ontology and socio-political criticism $\mid 45$

2 Claude Lévi-Strauss, decolonisation and indifference $\mid 50$

3 Conclusion: the politics of Levinas' philosophy of alterity $\mid 55$

\section{Chapter 3}

The range of the political:

Decolonisation as a case in point $\mid 59$

1 From situated thought to global consequences | 59

2 Decolonisation, colonisation: figures of the global $\mid 61$

3 For a globalised world $\mid 68$ 


\section{PART 2}

\section{LEVINAS' POST-ANTI-HUMANIST HUMANISM}

\section{AND AFTER $\mid 77$}

\section{Chapter 4}

\section{Humanism and anti-humanism}

\section{in Levinas' reflection on Jewish education | 83}

1 "For a Hebraic humanism"| 84

2 "Anti-humanism and education" $\mid 93$

3 Universalism and authority: an uncertain conclusion | 100

4 Changing of the guards: Talmudic humanism and a philosophical post-anti-humanist humanism | 102

\section{Chapter 5}

Levinas' post-anti-humanist humanism:

\section{Humanism of the other $\mid 105$}

1 First attempts at a political and ontological formulation of the problem | 107

2 The crisis of humanism | 114

2.1 End of the subject| 116

2.2 Questioning the rationality of the animal rationale $\mid 117$

2.3 Cultural relativity or the death of God $\mid 118$

3 Humanism and ethicity $\mid 121$

4 "Ethical culture" and the "cultural and aesthetic notion of meaning"| 127

5 "Real humanism": an un-likely family portrait | 134

5.1 Sartre: humanism as existentialism | 136

5.2 Heidegger: "humanism" in the extreme sense | 138

5.3 Althusser: humanism as ideology $\mid 142$

\section{Chapter 6}

\section{After Levinas:}

The risk of irresponsible responsibility | 147

1 Universalism and particularism: Marion and Bernasconi | 147

2 Responsibility and irresponsibility | 151

2.1 Can a Levinasian kill? From the original contradiction to the participation of practice in the meaning of the ethical | 152

2.2 Infinite responsibility and the polysemy of transgression | 157

2.3 Mediation: the irreducible political condition of responsibility | 162

3 After Levinas | 166 


\section{PART 3}

Political RESPONSIBILITY

FOR A GLOBALISED WORLD | 175

\section{Chapter 7}

Levinas and Max Weber

on being called for politics | 179

1 An inhospitable world: disenchantment and polytheism in Weber and Levinas | 179

2 Levinas: a Gesinnungsethiker or a Verantwortungsethiker?|183

2.1 The prima facie case for Levinas as "ethicist of principle"| 184

2.2 Levinas as political "ethicist of responsibility"| 189

2.3 Responsibility elevated to principle or principle elevated to responsibility?|200

\section{Chapter 8}

Towards a post-Levinasian understanding

of responsibility: the Weberian contribution of Apel | 205

1 Justification: Apel and the unavoidability of responsibility | 205

2 From a Weberian Apel to a Weberian Levinas | 209

3 Four objectives for a theory of political responsibility $\mid 213$

\section{Chapter 9}

\section{Ricoeur's contribution to a notion} of political responsibility for a globalised world $\mid 221$

1 Ricoeur's political paradox and appropriation of Weber $\mid 222$

2 From the political paradox to its integration in the "Little ethics"| 234

3 Political action between capacities and conflict $\mid 237$

4 Responsibility, prudence, collaboration, equity $\mid 244$

4.1 Remarks on the resources: Levinas and Ricoeur | 245

4.2 Ambiguity concerning Ricoeur's use of the notion of responsibility $\mid 248$

4.3 Towards a political responsibility for a globalised world $\mid 253$

\section{CONCLUSION}

FOR A “GOOD ENOUGH” JUSTICE | 267

\section{Bibliography | 273}

1 Abbreviations $\mid 273$

2 General Bibliography|277 



\section{Preface}

At the threshold of this book a few remarks concerning its origin and nature might be helpful to clarify its intention and thus prevent misunderstandings in this respect.

In 2006 Jörn Rüsen, the president at that time of the Kulturwissenschaftliches Institut (KWI) in Essen, launched an interdisciplinary project under the title "Humanism in an era of globalisation - an intercultural dialogue on culture, humanity and values". ${ }^{1}$ This project was never intended to provide a defence for a number of pre-established theses concerning humanism; in fact, it explicitly re-examined the viability of traditional Western and other humanisms and involved itself in the quest to overcome their defects. For this purpose, the project included a thorough revision of the entire dossier on the historical debates concerning humanism as support for an inter-cultural reflection on the orientation of people's action - wherever they may be interacting in this globalising world. Consequently an examination of the long history of the criticism of humanism formed an integral part of the project. $^{2}$

It is within this framework that I was requested to contribute a monograph to the project in order to clarify Levinas' position on humanism. I acquit myself of this task in Part 2 of the book. The aim of this reading of Levinas is, in accordance with the spirit of the project, neither to demonstrate Levinas' fidelity to a particular idea of humanism, nor to provide an apology for Levinas' philosophy, but to propose a balanced interpretation of what Levinas understands by the "humanism of the other (human)". The title chosen for my book testifies to the very favourable impression

1 At the time of the finalisation of this book the project description was accessible in http://www.kwi-humanismus.de/en/k3.Humanismusprojekt.htm.

2 See also the Foreword to Shaping a human world-Civilizations, Axial Times, Modernities, Humanisms, ed. by Oliver Kozlarek, Jörn Rüsen and Ernst Wolff. Bielefeld: Transcript, 2011. 
that the global dimension of the KWI project has made on me; its formative influence on the entire content will be evident.

As readers of Levinas know, the central tenets of his humanism of the other are similar to those found elsewhere in his philosophy. For this reason, a number of remarks are warranted about the manner in which this reading of the humanism of the other will be submitted to criticism and embedded in the larger design of the present book. Given the critical position that I defended in De l'éthique à la justice ${ }^{3}$ with respect to both Levinas' philosophy of the signification of alterity and his idea of political justice that is rooted in it, no obvious way forward in reading Levinas presented itself to me. Levinas is a great philosopher - one cannot easily dismiss his work, nor can one simply step into it with a few corrections. Consequently, the present study serves the purpose of looking for a way of engaging with Levinas after the criticism of his philosophy formulated in my above-mentioned book. The reader will therefore find in these pages an attempt, an essay, or an exploration in thinking "after Levinas", rather than an introduction to his work. ${ }^{4}$ Such an undertaking requires a lot of preparatory exegetical work. Since parts of the relevant work in this regard can be found in De l'éthique à la justice, I shall, where necessary, refer to, summarise or reformulate the argument, as required in each case. As response to my earlier book, the present book presents the next step in my reflection on Levinas and on those matters which concerned him.

This is then the meaning of the "after Levinas" in the subtitle of the book. I have purposely chosen the word "after" for its ambiguity. When it is said that somebody is after money, it means that that person pursues money, just like when somebody runs after someone else. In this sense I follow Levinas, since, despite my criticism, there are a number of key aspects of his philosophy that I do consider worthy of following (an exposition of these aspects will be given in Chapter $6, \S 3$ ). But because of the seriousness of my earlier criticism of Levinas, something essential to his work has to be left behind and in this other sense that which is undertaken in this book is reflection after Levinas. The title of the book represents both of these two meanings: on the one hand, this study is Levinasian in the central position it accords to the notion of responsibility; on the other hand, the span, the means, the conditions and the beneficiary of this responsibility all indicated by the phrase "globalised world" - represent my concern to pursue thought on responsibility in a different way to that of Levinas.

3 De l'éthique à la justice. Langage et politique dans la philosophie de Lévinas (Phaenomenologica 183). Dortrecht: Springer, 2007; henceforth De l'éthique à la justice.

4 This does not exclude the fact that I have tried to present especially the Part on humanism in such a manner as to give access to Levinas' thought for the non initiated. 
The adjective "political" in the title indicates that I delimit my reflection, as far as is practical, to the question of the political implications of Levinas' philosophy and assign a relatively minor position to the issue of signification and the debate about ontology and ethicity. However, I definitely do not intend to indicate by "political responsibility" an exploration on the duties of political office bearers, which was the earliest sense in which the word responsibility was used. "Political", as used in the title, doesn't refer to the particular social sphere of politics, but rather, in accordance with Levinas' own use of the term, is used to designate the dimension of action with and toward the plurality of others. Political responsibility refers here to responsibility as it is integrated into the political, and thus has consequences for issues like power, strategy, and institutions in politics, but also elsewhere. In fact, Chapter 1 is devoted to advocating that for Levinas already the adjective "political" is always attributed "pleonastically", as it were, to responsibility, and to placing this conviction in the centre of my interpretational strategy for this book. If I then retain the pleonastic doubling of "responsibility" by "political" in the title, it is exactly to insist on this perspective that I adopt on Levinas' work and that will remain the direction in which I shall attempt to think "after Levinas". The book is intended for specialists of Levinas and phenomenology, however scholars of the ethics of responsibility, of post-colonial studies and of the issues engaged with in the humanism/anti-humanism debate, as well as readers of political thought in Weber, Apel and Ricoeur, will hopefully find the book useful too.

A number of people who have discussed this project with me while the manuscript was in preparation deserve special mention: Olivier Abel, Jeffrey Barash, Rodolphe Calin, Michel Deguy, Maria Dimitrova, Alfred Hirsh and Jörn Rüsen. While thanking them cordially for their input, I need to exculpate them in the same breath from any complicity in the creation of the insufficiencies that the reader will probably find in the text.

I would like to thank three institutions and three persons for their practical support in creating and providing favourable circumstances in which to prepare this manuscript: the Kulturwissenschaftliches Institut in Essen, where Jörn Rüsen hosted me as visiting fellow in the autumn of 2009, the Ecole des Hautes Etudes en Sciences Sociales in Paris, where Olivier Abel received me as visiting researcher in the spring of 2010 and the University of Pretoria, to which I am affiliated and in particular my former head of department, Deon Rossouw.

My thanks are also extended to Izan Zybrands, Fritz Wolff, Pam Apps, as well as to Angelika Wulff, Martin Hanke and Birgit Klöpfer who have been helpful in different ways in the prepartation and publication of the book. 

INTRODUCTION 



\section{Chapter 1 \\ Doing justice to responsibility: The primordial political nature of Levinas' philosophy}

\section{ORIENTATION: LEVINAS AS POLITICAL PHILOSOPHER}

Emmanuel Levinas today enjoys wide recognition as one of the most original and important thinkers of the Western philosophical tradition on the ethical. Through the changes in his manner of thought over the six decades during which he wrote, developed his central concern, namely to argue that, and show how, we are not duped by ethics, rather, it is the ethical that sets the tone for our entire human existence. The best-known analysis that evokes the core of Levinas' work, and that could be considered his philosophical signature, is the idea of the face of the other, by which the self is affected in a sui generis manner, namely ethically.

By far the largest part of his philosophical work is devoted to the question of the self and the other, to the vis-à-vis, to the for-the-other. That being the case, when one writes about Levinas, one has to write about this, and the present book is no exception in this regard. However, as justified and as common as this perspective on Levinas' work might be, it is of crucial importance to see how Levinas relativises the place of the face-to-face, of the intimate ethical relation to the single other, by the relation to the third, i.e. to the plurality of others. In other words, one has to see that the reflections on the ethical find their place within reflection on the political. 
The political importance and even the intrinsic political nature of Levinas' thought have not always been recognised. That this is the case is to a certain extent Levinas' own doing and to some degree due to good reasons. Is his point not after all that it is hopeless to start contemplating the political if the essence of the ethical has not been determined? And since it is already an enormously ambitious project to determine the meaning of the ethical, most of Levinas' attention by far is devoted to it. The dominance of the analyses of the relation between self and the single other should not mislead us though:

"[t]here are always at least three people. [...] As soon as there are three people, the ethical relation to the other becomes political",

says Levinas, and this will be the recurrent theme throughout this book. The tension between the ethical and the political in Levinas' philosophy is betrayed by the contradiction between the two adverbs "always" (toujours) and "as soon as" (dès que) in this citation: the political introduces something new to a relation that exists before it ... but there is no before, since the plurality of others was always there and thus the relation to the other had always been political. ${ }^{2}$ And this is exactly where the concern of the current book is situated. My entire reading of, and dialogue with, Levinas is guided by the conviction of the crucial place of the political in his thought.

Having stated the general orientation of this study, the place of the political in Levinas' thought has to be traced more clearly in order to justify the political perspective with reference to Levinas' argument and with respect to his work on the ethical. ${ }^{3}$

1 "Ethics of the infinite", in Dialogues with contemporary Continental thinkers. The phenomenological heritage. Richard Kearney. Manchester: Manchester University Press, 1984, pp. 49-69 / "Il y a toujours au moins trois personnes. [...] Dès qu'il y a trois personnes, la relation éthique à l'autre devient politique" in "De la phénoménologie à l'éthique", in Esprit 234, 1997, pp. 121-140, citation, p. 129 (my emphasis, translation modified).

2 See De l'éthique à la justice 338-344. This idea will be developed below, as well as in Chapter $6(\$ 2)$ and Chapter 7.

3 In the entire book, the emphasis of the exploration of Levinas' political thought will be on his later work. This is justified to a certain extent by the fact that the larger part of the themes explored in this book is situated in Levinas' later works (of these themes the exegesis of the humanism of Humanism of the other in Chapter 5 takes a central place). Furthermore, the central issue of the third is simply not well developed in Levinas' earlier work. Finally, the exploratory nature of the argument that I present in this book serves as further justification for this strategy. This choice for the later philosophy is not principled and therefore, in subsequent 


\section{2 "There ARe always at Least three...": URGENCY AND PRIMACY OF THE POLITICAL RELATION ${ }^{4}$}

One of the most articulate expressions of the intention and ambition that Levinas had for his philosophy is to be found in the essay Ethics as first philosophy and this intention again clearly situates his work with respect to the tradition of Western philosophy:

"In this essay we wish to ask whether thought understood as knowledge, since the ontology of first philosophy, exhausts the possibilities of the meaning of thought and whether, beyond knowledge and its hold on being, there doesn't emerge a more urgent wisdom [une sagesse plus urgente].",

In opposing these two possibilities the aim is not to replace the tradition of philosophy (or ontology) with the more urgent wisdom that Levinas proposes, but to relativise the former by reference to the latter. If the Western tradition of philosophy is not to be abandoned, what then, in Levinas' mind, motivates the quest for a new philosophy, and even a different kind of first philosophy? What is it that makes Levinas' first philosophy a "more urgent wisdom"? The particularity of Levinas' notion of a first philosophy, and the justification for his claim to its urgency, resides in what it identifies as the first question of philosophy. This first question is not

“"[w]hy being rather than nothing?', but how being can be justified [or justify itself]?”,

As is well known, this question, according to Levinas, is not one of mere curiosity or even of methodological rigour, it is a question of one's own life $^{7}$ and of its justification:

elaborations of the current study, Levinas' earlier philosophy will have to be accorded its rightful place.

4 What follows here (\$2) is the first part of the essay announced in De l'éthique à la justice 372 as forthcoming under the title "The ambiguous meaning of politics in Levinas." The second half is to be found in $\S \S 2.1$ and 2.2 of Chapter 6.

5 LR 78 / EPP 77, translation modified.

6 LR 86/EPP 109, translation modified.

7 This is also what Husserl, in a text on responsibility and first philosophy, claims for his own version of first philosophy: "we realize that such a philosophy could be no theoretical hobby of humanity, that a philosophical life should rather be understood as a life out of absolute self-responsibility: the personal single subject, as subject of personal life, wants in its entire life, in all of its praxis to make up its mind genuinely freely, that is that it can at any time justify the right of its decision for itself.", "Meditation über die Idee eines individuellen und Gemeinschaftslebens in absoluter Selbstverantwortung", in Edmund Husserl, Erste Philosophie 
"One has to respond to one's right to be, not by referring to some abstraction and anonymous law, or judicial entity, but in fear for the others [...] as if I had to answer for the other's death even before I had to $b e . " 8$

More explicitly then, the death or the vulnerability of the other in general, imposes the question that sets first philosophy in motion.

It is for this reason that the phenomenon of tyranny represents a major point of orientation in Levinas' work. Tyranny is not only indicative of the extremes of violence to which people may be subjected, it is also the condition in which people are most at risk of being incapacitated to respond for their own being by answering for the fragile being, mortality and death of others. As such, tyranny could be considered the culmination of everything against which Levinas developed his thought and one could perhaps say, as he said of Plato, that his philosophy is "as it were obsessed by the threat of tyranny". 9 This political obsession drives first philosophy. It is because of the threat of tyranny and a myriad of other forms of violence that "may well have to be challenged according to the criterion of our ethical responsibility to the other" that "ethical philosophy should remain first philosophy", as Levinas explains in a remark that will retain our attention later. ${ }^{10}$

Thinking radically, Levinas' opposition to tyranny does not limit itself to an opposition to historical instances of political oppression, dictatorship, totalitarianism and genocide - of which, alas, it is not difficult to list examples. Rather, "politics left to itself bears a tyranny in itself", 11 that is to say, "the element of violence in the State, in the hierarchy, appears even when the hierarchy functions perfectly" 12 or again, the finality of justice behind the institution of the State is "soon unrecognized in the deviations imposed by the practicalities of the state". ${ }^{13}$ It follows naturally from this conviction

(1923/1924), Zweiter Teil: Theorie der phänomenologischen Reduktion, Husserl Gesammelte Werke Band VIII. Rudolf Boehm (ed.). Haag: Martinus Nijhof, 1959, pp. 193-202 (citation, p. 197).

That Levinas' notion of first philosophy shares much more with the Husserlian notion thereof than with the Aristotelian first philosophy has at least been indicated in Jean Greisch's and Jacques Rolland's "Présentation" to the volume Emmanuel Lévinas. L'éthique comme philosophie première. Paris: Cerf, 1993, pp. 7-10, of which they were the editors, and later by Jacques Rolland in "L'humain dans l'homme. Quelques notes", in Esprit 234, 1997, pp. 111-120, in particular p. 115.

8 LR 82, 83 / EPP 93, 98, translation modified.

9 CPP 16/LC 36.

10 "De la phénoménologie à l'éthique", op. cit. p. 137 (my translation) / "Ethics of the infinite", op. cit. p. 66. See Chapter 6, § 2.2.

11 T\&I 300/ TI 334-335.

12 BPW 23/LC 97.

13 OS $123 /$ HS 167. 
that Levinas' philosophy should be characterised by a profound interest in politics, at the very least in politics as problem. In fact, it would not be exaggerated to claim that behind the description of the essential nature of politics in these citations also lies an implicit reference to that which urged their author to reflect on it: he who writes that "politics left to itself, carries in itself a tyranny", does not want to leave politics to its own devices, does not want politics to function perfectly according to its own inherent logic, and cannot accept that justice is traded for mere practical expediency. Ethics as first philosophy can only be called "urgent", if this driving intention of it is borne in mind.

But what does it mean not to leave politics to its own devices by writing philosophy? In order to answer this question one needs to inspect Levinas' strategy for speaking about the political. This will be done in two parts: arguing, first, that on the most profound level politics is constituted by the non-ontological meaning, that is, by ethics; and second, that ethics necessarily passes into politics, or in fact, that ethics has always already passed into politics.

\subsection{The constitution of political meaning}

In order not to leave politics to itself, Levinas tackles this problem at the most basic level known to him, namely that of meaning. Two completely different sources are identified: phenomenology or ontology and ethics. ${ }^{14}$

Firstly, as Levinas summarises the most important lesson he learned from Sein und Zeit, the whole human being is ontology: ${ }^{15}$ with my whole existence I am a logos about Being, because I am the ontological difference. Levinas calls this logos the Said in his later philosophy and describes it as a conatus in suo esse perseverandi, the exertion to persevere in one's own being (Spinoza). If this is all there is to being human and to meaning then, according to Levinas right from "Some reflections on the philosophy of

14 "I would maintain, against Heidegger, that philosophy can be ethical as well as ontological, can be at once Greek and non-Greek in its inspiration. These two sources of inspiration coexist as two different tendencies in modern philosophy and it is my own personal task to identify this dual origin of meaning - der Ursprung des Sinnhaften - in the interhuman relationship." "Ethics of the infinite", op. cit. p. 57 / "De la phénoménologie à l'éthique", op. cit. p. 129. Similarly GDT $126 \mathrm{f}$ / DMT 143f, formulated closely to OB xlii / AE X.

15 "The whole human being is ontology." (ENT 2, translation modified) / "Tout l'homme est ontologie." (EN 13). In Levinas' adoption of the notion of "first philosophy" one should probably see a continuation of the polemics with Heidegger as summarised by the question of the famous article "Is ontology fundamental?". 
Hitlerism" (1934), ${ }^{16}$ there is no escaping the fire of war burning always in Being itself: ${ }^{17}$ the being that is characterised by the fact that he/she belongs to Being (what Heidegger calls mineness, Jemeinigkeit) would be a warrior. This is the first, the ontological, source of meaning.

But, secondly, Levinas learned a perspective on reality from Husserl in which one's natural attitude is suspended in order to gain an understanding of the originary phenomena that constitute meaning behind the subject's back and that could be thematised only later in reflection. ${ }^{18}$ In Levinas' later philosophy, reduction leads (re-ducere) the Said back to its constituting Saying, which is the second source of meaning, namely the ethical. Just as in the study of the pragmatics of language, but here with a completely different import, the Saying belongs to the Said: the Saying is the Saying of a Said, but the significance of the Saying exceeds that of what is Said - by being directed at someone, by being a Said for someone. One could rephrase this idea in more ontological terms: the being that I am has a significance that exceeds that which can be attributed to its always understanding Being, always being ontology, always being Said - and this by being for the other.

Emblematic of these two sources of meaning - of the ethical difference between the Saying and the Said with which the Saying associated is the phenomenon of ageing: ${ }^{19}$ the more I persevere in my existence, the more I lose my life; the conatus cannot be dissociated from a passivity of which I am not in any sense the agent. Levinas analyses this passivity as the proximity of the other. In proximity, my exposition to the other is a giving of myself to the other, to the point of substituting myself for the other. I am being made a sign for the other. ${ }^{20}$ This sign is the testimony, that I give to the other, of being absolutely under the influence of the other, in the sense of having the totality of my being directed to the other. ${ }^{21}$ The sign that I am as given to the other, the Saying of the Said that I am, is a kind of meaning that is not ontological, and Levinas wagers that it can thus only be an ethical meaning, namely my election or assignation to be re-

16 IH $23-33$.

17 T\&I $21 /$ TI 5.

18 DEHH 131, OB 20 / AE 38-39. Cf. also OB 53 / AE 91: "The movement back to the Saying is the phenomenological Reduction, in which the indescribable is described." (translation modified).

19 Cf. OB 59-94 / AE 86-94. The discussion of ageing will be resumed and expanded in Chapter 5, $\S 3$.

20 Cf. OB 49 / AE 83, GDT 198-199 / DMT 231-232 and the exposition of the theme in De l'éthique à la justice 257-259.

21 GCM 74/DVI 121-122. 
sponsible for the other. ${ }^{22}$ The passivity of losing or ceding my life for the other is so decisive that I can only react to it, or respond to it, and this in the ethical sense, namely to take responsibility for it.

It is of the greatest importance to underline the most salient characteristics of this responsibility as presented by Levinas. (1) My life is the "ethical difference" (cf. ageing), the difference between the Saying and the Said and this difference marks an absolute asymmetry between myself and the other. This asymmetry consists of owing the other my devotion, or rather responsibility, without there being any contract that establishes this obligation; this obligation precedes all contracts, agreements or legal status between people. (2) This responsibility is an infinite imperative - the more I answer the other, the more I obey the originary imperative, the more I still have to do so. I owe the other everything. (3) This imperative has no content. The injunction "thou shalt not kill" by which Levinas often designates this imperative, is to be interpreted as just a formal absolute imperative not to infringe on the mortality of the other, ${ }^{23}$ not to act in such a way as to reduce the other to mere being, but to give yourself for the other. The Saying remains unsayable or unspeakable (indicible). ${ }^{24}$ (4) This responsibility is the principle of heteronomy. I am the assigned or elected one or the hostage of the others' imperative. (5) In the face of this imperative nobody can answer for the other in my place. Responsibility radically singularises the subject.

All of this comes to the fore under reduction. Most of Levinas' philosophical effort goes into pointing out and reflecting on the Saying, arguing that we are not duped by it. However, there is never a question of a Saying which is not a Saying of a Said. The subject might be passively constituted by its exposition to the other, but he/she lives in an ontological world. The Saying has meaning only as Saying of a Said.

\subsection{Politics: the indispensable translation of the Saying to the Said}

There is continuity between the unspeakable Saying and the Said of which it is the Saying. But the Saying goes beyond the Said and the Said

22 OB 47 / AE 80: "saying is to respond to another" (in italics in the text).

23 The face is sometimes defined by the non-phenomenalisable mortality of the other: "This discovery of his/her death [the death of the other - EW], or this hearing of his/her appeal, I call the face of the other", in Racismes. L'autre et son visage. Grands entretiens réalisés par Emmanuel Hirsch. Paris: Cerf, 1988, citation p. 94.

24 OB 7/ AE 19. 
never exhausts the Saying. ${ }^{25}$ The clearest way to express Levinas' perspective on the relation between the Saying and the Said is by referring to the pair translation/treason:

"The correlation of the Saying and the Said, in other words the subordination of the Saying to the Said, to the linguistic system and to ontology is the price asked for its manifestation. In language as Said, everything is translated in front of us albeit at the price of a treason. Language as servant and thus indispensable."26

Thus, there is no automatic, unproblematic transition between the two sources of meaning identified by Levinas. The translation of the Saying into a Said is always imperfect. Yet, it is this indiscreet translation of the unspeakable ethical imperative of Saying into the sayable, audible and ontological language of the Said that serves to let the ethical meaning of the Saying appear in the ontological world. That is why the translation is indispensable even if its service comes at the price of a partial treason.

The paradigmatic situation in which Levinas identifies and describes the Saying or the proximity of the other, is one in which the other is alone in front of me. The vast majority of his texts on this issue follow the pattern of a subject face-to-face with one other. But this is an abstraction: life is life with many, also for Levinas. And it is this fact that necessitates and complicates the translation of the Saying into the Said. If there were just two people, I and the other, my responsibility would have entailed the direct, immediate and complete giving of myself to the other. But there are always at least three: I, the other and another other of the first two of us. ${ }^{27}$ I find myself in the proximity of a plurality of others, each of which constitutes me as subject beyond my ontological existence, each of which elects me to infinite responsibility. What is the relation between this plurality of expositions that constitute me, in the face of which I answer every time: "Here I am"? According to Levinas, this relation is one of contradiction:

"The third introduces a contradiction in the Saying whose signification before the other until then went in one direction. This is, in itself, the limit of responsibility, birth of the question: What do I have to do in justice?"28

25 OB 57 / AE 96.

26 'La corrélation du dire et du dit, c'est-à-dire la subordination du dire au dit, au système linguistique et à l'ontologie est le prix que demande la manifestation. Dans le langage comme dit, tout se traduit devant nous - fût-ce au prix d'une trahison. Langage ancillaire et ainsi indispensable." (AE 17-18, my translation / OB 6).

27 OB 157 / AE 245.

28 OB 157 (translation modified); "Le tiers introduit une contradiction dans le Dire dont la signification devant l'autre allait, jusqu'alors, dans un sens unique. C'est, 
The plurality of appeals made to me, troubles the apparent unambiguity of the ethical imperative and creates the question in me: who comes before whom and how? Ethics now demands justice.

The moment this question arises, consciousness is born, but always born as bad consciousness, as bad conscience (mauvaise conscience). The first "break with passivity", ${ }^{29}$ the first moment of conatus, the commencement of the Said, of the ontological difference, the Da of Dasein, is that question concerning the thirds: who comes before whom? This is the question of justice and in the mindset of Levinas the birth of politics. Hence the decisive remark by Levinas (cited above):

"There are always at least three people. [...] As soon as there are three people, the ethical relation to the other becomes political and enters into the totalizing discourse of ontology.",30

This conclusion summarises the vital point that the Levinasian subject, always faced with the plurality of ethical others, is constituted as a political subject, as a subject whose being consists of having to translate (at the risk of treason) ethics in the world of ontology, that is the world of political co-existence. In other words, there is no aspect of the existence of the Levinasian subject that is not always confronted by the question about and the obligation to realise justice, because the subject is always already taken up in the concern for the plurality of others, that is, the political concern. Therefore, the implication of Levinas' philosophy of the plurality of others is that all responsibility has to be borne politically; "political responsibility" is a pleonasm. All the readings of Levinas that see in him a non-political philosopher miss this central point. ${ }^{31}$

de soi, limite de la responsabilité naissance de la question: Qu'ai-je à faire avec justice?" (AE 245, my emphasis).

29 OB 62 / AE 101.

30 "Ethics of the infinite", op.cit. pp. 49-50 / "De la phénoménologie à l'éthique", op. cit. p. 129.

31 Although Didier Frank (L'un-pour-l'autre. Levinas et la signification. Paris: Presses Universitaires de France, 2008) exposes difficulties in the "transition" from ethics to justice in a way different from what I have done in De l'éthique à la justice (Chapter $8, \S 4$ ) or from what I am doing here, we do concur that "if the third looks always in the face and the eyes of others, then substitution - supposing that the presence of the third doesn't make substitution inaccessible, or even completely impossible and this is exactly the entire problem - is always from the outset measured or weighed [mesurée]" (p. 229), where "measured" means the same as "entered into the calculation of justice", i.e., the practice of politics (cf. De l'éthique à la justice 346-349). From this Frank derives the necessary "anteriority of justice" in relation to ethics (p. 240). It might be that the conclusion of an "an- 
Levinas is notoriously skimpy on what this political condition of the subject consists of and, as already indicated, it is the objective of the current study to make a contribution to this issue. However, it is appropriate to render the most important indications given by Levinas of the changes that take place when the Saying is translated into the Said in the company of the third. (1) There is (at least, according to Levinas) a correction of the asymmetry between me and the other(s); the other is looked at or even defaced (dé-visagé), ${ }^{32}$ that means, consideration of the other is henceforth integrated in the ontological world. (2) Why is this asymmetry corrected? It happens on the basis of the mutual contradiction between the thirds. The State is the condition in which my infinite responsibility for the others is limited. (3) This means that instead of being immediately infinitely responsible for this or that particular other, I have to think, weigh, compare and measure. The others become brothers, citizens and I also may become an other, I may become important, because the actualisation of justice depends on my capacity to actualise it. Thus the State is the institutionalised rendering of people's answer to the question of justice: who comes before whom? (4) But no institutionalisation of any idea of justice could ever be complete. I am called to act as a prophet in order to call the State to greater justice, to respond to the other beyond the call of law. (5) This extreme justice asks of me to unsay the Said: firstly, the Said in the form of a currently institutionalised system of justice, but secondly, also the Said that I am myself, that is, to continue to give my life for the other up to the point of saying à-Dieu to the ontological world - to the point of becoming saintly - but this, always only in so far as this call for saintliness is limited by the initial question of justice: which of the others should come before the other others?

What then is the political scenario to which these considerations will lead, or rather, how does Levinas interpret the political implications of his philosophy of meaning and of the constitution of the subject? According to him, my efforts of answering the initial question of justice will lead to prophetic and even saintly acts. These are acts by which the ethico-political subject will attempt to achieve as well as possible an answer to the plurality of infinite appeals made to him/her, that is, he/she will do whatever is possible to actualise justice. This is the political model of Jerusalem. But that same subject will have to question the efficiency and durability of these

teriority" over-states the case; it would probably be more prudent to consider ethics and justice to be "contemporaneous". This does not, however, exclude the claim for the primacy of the political that I make in the present Chapter.

32 OB $158 /$ AE 246. 
efforts of justice and therefore, in the face of all the thirds, there is an equality that arises between the subject and the others. Out of this relation, institutions and the law grow too, all of which would then ideally attempt to safeguard a particular idea of what justice entails. This is the political model of Athens. ${ }^{33}$ And since every institutionalisation of justice is imperfect, Levinas believes in the "liberal State", that is, a State that is always capable of improving legislation and justice. ${ }^{34}$ This perspective on politics could be summarised as follows:

"Usually the State is preferable to anarchy - but not always. In certain cases, in fascism or totalitarianism for instance, the political order of the State may well have to be challenged according to the criterion of our ethical responsibility to the other. That is why ethical philosophy should remain first philosophy."

In other words, the State as an institutionalised endeavour of realizing justice will always have to be called upon to improve justice; the indiscretion and partial betrayal committed to the plurality of Sayings in an attempt to translate them as truly as possible, should be unsaid (dédit) by the prophetic or saintly intervention (by Jerusalem) in order to create an even more just Athens. By developing this theory of justice (Said) that depends on the Saying (therefore, ethics as first philosophy), Levinas would have contributed to his initial task, namely not leaving politics to itself, not letting politics unfold itself by its own logic, and not abandoning the ethical finality of the State to oblivion.

Up to this point, this reading of Levinas' later political thought should be considered as uncontroversial. Levinas' philosophy is one of demanding ethics, one of remaining responsible for the other even up to the point of unsaying the Said that you are yourself, that is, up to the point of giving yourself in saintliness to the other. In the pages that follow, I shall further explore, explain and criticise these points. The nature of the ethical intervention in politics will also have to be reconsidered in view of answering the difficult question: is the kind of politics that Levi-

33 BPW 24 / LC 99-100.

34 "Socialité et argent", in Emmanuel Lévinas. Cahier de l'Herne. Catherine Chalier and Miguel Abensour (eds.). Paris: Editions de l'Herne, 1991, pp. 106-112, reference p. 111.

35 'L'Etat est d'habitude préférable à l'anarchie - mais pas toujours. Dans certains cas, dans le fascisme ou le totalitarisme, par exemple, l'ordre politique de l'Etat peut devoir être défié d'après le critère de notre responsabilité éthique à l'autre. C'est pourquoi la philosophie éthique doit rester la philosophie première." "De la phénoménologie à l'éthique", op. cit. 137 (my translation) / "Ethics of the infinite", op. cit. p. 66. 
nas had in mind as actualisation of his ethics the only Levinasian politics conceivable? (see especially Chapters 6 and 7).

\section{Clarifications on the title}

This preliminary presentation of Levinas as a political philosopher should suffice to justify the line of research of this book. Those interpreters of his work that are convinced that his sole concern was with a philosophical presentation of the ethical and that it would therefore be impermissible or at least besides the point to interrogate his work on the practical, political implications thereof, will probably be frustrated by my line of exploration and discussion of the work of Levinas. To such scholars it should of course be conceded that by far the biggest part of Levinas' work is devoted to finding a credible and intelligent discourse on the ethical, that Levinas didn't spend much time on the practical implications of his work and besides that he didn't consider the elaboration on the practical implications of his thought to impact significantly on the discourse on the ethical. However, it should be borne in mind that the person who wrote Levinas' books - Emmanuel Levinas himself - was, by doing so, already responding not to the appeal of an other, but to the appeals of the plurality of others and thus, by so doing, was looking for the realisation of justice - that is, if we follow his own philosophy. One has to measure what it means when he claims that the Saying is not only the meaning of being, but "the very signifyingness of signification [la signifiance même de la signification]", ${ }^{36}$ in other words, the significance of Being. How could signifiance (significance and meaning) be significant, if it is nothing more than a meaning (that remains unspeakable, indicible) and if nothing can be said of this significance? What is significance, if one can have no discussion about this weight? Also what does it mean - as in the citation above - if Levinas calls ontology ancillary or servant and thus indispensable (ancillaire et ainsi indispensable) ${ }^{37}$ to ethics, if one should simply dispense with the question of how it is ancillary and indispensable? That is why restricting Levinas to contemplation on the ethical alone, is condemning him to a performative contradiction and rendering the urgency with which he regards first philosophy unintelligible. 
This brings me to the justification of the title of this Chapter - doing justice to responsibility. ${ }^{38}$ Levinas is a philosopher of ethics of the greatest importance. But the centre of gravity of all of his thought seems to be political: there is no relation to the other that is not politically mediated, since all relations to the other involve relations to the plurality of others. For this reason, if Levinas is a philosopher of ethics, of responsibility, he is so by being a philosopher of justice: the only thing that one could responsibly do out of responsibility for the others in the plural, is to relativise the responsibility for each one of them, by the call for justice. This is the first sense in which justice should be done to responsibility: it means that recognition should be given to the fact that the relations of responsibility to the others are plural and that this fact calls for a reflection appropriate to this plurality, which means considering responsibilities from their import of justice. Responsible responsibility is justice. But the quest for justice towards which responsibilities naturally lead, transforms them, it does something to those responsibilities, but only thus could they remain responsible. Only by submitting responsibility to this transformation can it remain true to itself; only thus could justice be done to responsibility - which is the second sense of the title. Responsibility without justice is irresponsible.

When the theme and approach to Levinas in this book is indicated in the title as that of "political responsibility", the relationship between these two terms should consequently be understood as explained here: it is only by taking the political dimension of responsibility seriously that justice can be done to responsibility. Even though a lot of my effort will be devoted to analysing and responding to the limits and weaknesses of Levinas' own contribution to this question, it can certainly not be claimed that the question concerning the relationship between the ethical and the political in responsibility is foreign to Levinas. Since it is, then, the explicit aim of the present study to approach Levinas from this tail-end of his philosophy, much less will be said about language, alterity, face-to-face, proximity and other more central notions of Levinas' philosophy. Instead, the question concerning the political will be pursued with the objective of seeing how to go beyond Levinas - as per the purposely ambiguous subtitle of the book how to reflect on political responsibility "after Levinas".

38 I came across this very appropriate phrase in the title of a book review by William S. Hamrick, "Doing justice to responsibility", in Human Studies 26/3, 2003, pp. 401-407; the specific content given to the phrase is derived from my interpretation of Levinas' ethico-political project, rather than from that review. 
This objective will be pursued while constantly keeping in mind the second part of the title of the book: "for a globalised world". This is certainly the most unexpected part of the title of this book and of its content. It will be the objective of Chapters 2 and 3 to shed light on this dimension of responsibility. However, a few remarks by way of introduction are in order. Whereas it is quite obvious that Levinas was not a theoretician of globalisation or international relations, one has to concede that such questions are not completely absent from his work. Consider for instance the significance of political catastrophes for Levinas, of which most had an international or global dimension:

"The 1914 War, the Russian Revolution refuting itself in Stalinism, fascism, Hitlerism, the 1939-45 War, atomic bombings, genocide and uninterrupted war. [...] A liberal politics and administration that suppresses neither exploitation nor war; a socialism that gets entangled in bureaucracy.",39

It is noteworthy that Levinas placed on the same level those instances of catastrophe that took place very far from his lived experience and those of which he was personally a victim, at least as far as they merit reflection on the ethical. If it is further taken into account that these catastrophes practically always have an international dimension, then one could reasonably claim that, for Levinas, what happens on an international level concerns individual ethical subjects, at least in the sense that it poses or enforces the question concerning the ethical. ${ }^{40}$ If we then ask "what is it in our day and time that could be considered worthy of serious reflection concerning the ethical?", would it not be such international or global historical phenomena as the genocide in Rwanda or the global network of exploitative labour relations or again the inhumanity of some humanitarian aid after the earthquake in Haiti? If the global extent of the events that enforce the question concerning the political is to be affirmed, should it not at least be regarded as a legitimate question to see if the response to the world - the responsibility taken for the world - has to take on the same scale?

The notion of responsibility for a globalised world is not entirely foreign to Levinas' way of thinking. But even if it were, would that prevent us from enquiring into Levinas' thought as fitting contribution to an issue that wasn't his? The reference to a "globalised world" in the title of the book thus stands for the deliberate attempt to appropriate Levinas, or to

39 DF 281 / DL 390-391, similarly PN 3 / NP 9, A\&T 132 / AT 139, ENT 97 / EN 107.

40 These international and global implications of Levinasian thought on responsibility will be developed in more detail in Chapter 3 , especially $\S 3$. 
put his philosophy to the test, for a context that was not at the centre of his preoccupations. This approach seems to me justifiable in itself, but also called for by the change in context from that of Levinas to that of the present author. Whereas I don't dispute the right of people outside of Europe or the West to read and comment on works of European authors and to do so in the terms of the authors they comment on (e.g., I respect the right of anybody outside of France to become a Levinas scholar in the narrow sense of the word), it seems equally acceptable for us, writing from different contexts to those of the author commented on, to engage seriously with these authors, but with a different agenda.

If this book is intended as reflection on political responsibility for a globalised world, then the ambition is not to develop an ethics for globalisation and international politics. Rather the last half of the title of the book refers to the extent and context of relevance of responsible action. Furthermore, the insistence on a globalised world also serves to underscore the importance of reflection on the contemporary state of the means by which responsible action is undertaken. This means that the question of responsibility will be considered as it takes profile in an era of globalisation, with the means available to people living in such a world and for a world in which the geopolitical dimension of action is its ultimate horizon. "For" refers to the context of relevance and to the beneficiary. But these themes will be addressed in detail in the Chapters that follow. 



\section{PART 1}

\section{Ethics after the colonies:}

\section{The global scope of Levinas' political thought}

The title chosen for the first Part of the book may seem like a misnomer: Levinas the post-colonial and international political theorist! I do recognise that the terms chosen for the current exploration give a greater indication of the aim of the present study than of the texts of Levinas that will be commented on in pursuing that aim. Yet, the point of departure and central concern is a study of what Levinas wrote. The aim is not to make something of Levinas that he wasn't but to exploit what is allowed for and even suggested by his work. In order to justify this title and to anchor, as it were, this Part, I propose the following passage from the book to which I shall devote a careful study in Chapter 5 and which the title shows should be situated very near to the core concern of my study: Humanisme de l'autre homme, Humanism of the other or of the other human being. This guiding citation gives us a keyhole view, not only of this particular book of Levinas, but also of the largest part of his philosophy:

"The most recent, most audacious and most influential ethnography, maintains the plurality of cultures on the same level. The political work of decolonisation is in this way linked to an ontology - thought on Being, thought that is interpreted from multiple and multivocal cultural signification. And this multiple-interpretability of the meaning of Being, this essential disorientation - is, perhaps, the modern expression of atheism."

1 'L'ethnographie la plus récente, la plus audacieuse et la plus influente, maintient sur le même plan les cultures multiples. L'œuvre politique de la décolonisation se trouve ainsi rattachée à une ontologie - à une pensée de l'être, interprétée à partir de la signification culturelle, multiple et multivoque. Et cette multivocité du sens 
Whereas the questions concerning ontology and the multiple meanings of Being will be examined in detail in Chapter 5, three interrelated terms from this passage deserve detailed examination at this stage in order to appreciate the suggestion that Levinas makes: ethnography, decolonisation, atheism. What is the most recent ethnography and what did it, according to Levinas, bring about that is significant? What does the apparent category of personal or private conviction, namely atheism, have to do with politics? What does Levinas exactly claim concerning decolonisation as a symptom of a regrettable situation of (ontological) disorientation? In Chapter 2 the coordination of these three terms will be examined; Chapter 3 is devoted to a further exploration of colonisation and decolonisation in Levinas, with a view on the global range of responsible action.

de l'être, cette essentielle désorientation - est, peut-être, l'expression moderne de l'athéisme." (HO 20 / HH 33-34, my translation). 


\section{Chapter 2 Ethnography, atheism, decolonisation ${ }^{1}$}

It hardly needs to be recalled that when ethnography is evoked, we speak immediately about much more than merely one of the human sciences, since the practice of this discipline is one of the privileged windows on the unfolding of the relationship between Europe and its others. ${ }^{2}$ Since Levinas concurs with this opinion, albeit in a self-styled Heideggerian way, rather than in the often strongly Foucauldian inspired way seen especially in post-colonial studies, we need to examine his statement further.

Levinas' point in the guiding citation is to refer to a state of consensus in (at least "the most audacious") ethnography, namely that it maintains the

1 This Chapter is a considerably extended version of $\S \S 2$ and 3 of my article "The State and politics in a post-colonial, global order. Reconstruction and criticism of a Levinasian perspective", in SA Publiekreg / SA Public Law 24/2, 2009, pp. 352369. Part of the introduction to this Part has also been drawn from it; likewise the discussion of Levinas' Dostoyevsky citation (used in Chapter 5, §2.3) was used as $\$ 1$ of that article.

2 To cite but one perspective on the historical situation in which ethnography tended to be organically linked with colonialism: "These anthropological productions, often commissioned after military invasion of an African territory or after a rebellion against occupying European powers, were intended to provide the European administrations and missionary-cultural workers with information about the 'primitive' both to guarantee efficient administration and to provide knowledge of the 'African mentality', so that, while demonizing and repressing African practices, the 'superior' European values and attitudes could be effectively inculcated into the African conscience. From the transformations in the African economies and politics to religion and the educational institutions, the goal was to maximize European profit, secure the total domination and subjection of the colonial territory to the metropole, and reproduce Europe and European values not only in the material lives, but also in the cultural and spiritual lives and expressions of the Africans." Emmanuel Eze, "Introduction: Philosophy and the (post)colonial", in Postcolonial African philosophy. A critical reader. Emmanuel Eze (ed.). Oxford and Cambridge (Mass.): Blackwell, 1997, pp. 1-21, citation p. 10. 
equal value of different cultures. Who the ethnographers of this ethnography could be, and what Levinas really got from them, is of no slight importance. In fact, an exploration of two ethnographers to whom Levinas could possibly refer is of crucial importance to understanding some of the most intense concerns of his work. In other words, my aim is not a mere philological hypothesis on the name(s) to be filled into the general box of "ethnography" in the guiding citation; rather, by considering two likely candidates that Levinas could have had in mind, one could learn a lot about his philosophical project, but starting this time not from the face of the other, but from the relationships between people from different cultural settings. The two ethnographers that I shall consider in turn are Lucien Lévy-Bruhl and Claude Lévi-Strauss. In each case, I shall ask what could have been the decisive ideas that struck Levinas in the work of these authors.

\section{LUCIEN LÉVY-BRUHL, OR THE USE OF ETHNOGRAPHY FOR ONTOLOGY AND POLITICS}

Although I do not think that Levinas had Lévy-Bruhl in mind when he wrote the cited passage, there are three reasons why it would be useful for us to consider him in this regard. First, he is by far the ethnographer to whom Levinas refers most and he is the only ethnographer to whom Levinas has dedicated an entire study. ${ }^{3}$ Second, the link that is made in the citation between ethnography and atheism recalls Levinas' reading of Lévy-Bruhl since, as will be pointed out, the question of atheism is often referred to when Levinas writes about Lévy-Bruhl. Third, one sees illustrated very clearly from Levinas' first appropriation of the work of the ethnographer, that ethnography and ontology are used to interpret each other mutually.

What did Levinas retain from Lévy-Bruhl?

\section{1 "To be is to participate"}

From his earliest references to Lévy-Bruhl, it is the notion of "participation" that draws Levinas' attention. Being is incommunicable for a human being, in other words, human beings are characterised by an ontological solitude. LévyBruhl's presentation of participation in so-called "primitive" cultures seems, however, to suggest an alternative possibility of existence, namely transitive ${ }^{4}-$

3 "Lévy-Bruhl and contemporary philosophy" (ENT 39-51 / EN 49-63).

4 TO $43 /$ TA 22. 
an existence in which a human being is not merely directed at the other, but is the other. This is for Levinas more important than what Lévy-Bruhl has to contribute on the apparent pre-logicial or mystical character of the "primitive mentality" (mentalité primitive). ${ }^{5}$ If such a transitive form of existence is possible, this would entail an existence by which one is fused, through participation, into a general, ecstatic, ontological monism. ${ }^{6}$ Ontological solitude and participation would be two divergent historically conditioned forms of existence.

By the time Levinas wrote down this discovery (1946/47), calling "existing" (exister) a transitive verb, is long since philosophically innocent. In an essay on Heidegger in 1932 (that is, before Levinas began to distance himself from Heidegger), it is explained that

“[o]ne could perhaps say that Heidegger's entire philosophy consists in considering the verb 'to exist' as a transitive verb"7

and accordingly the existentials (Existentialien) of Dasein could be considered as adverbs of this transitive verb. ${ }^{8}$ This fact should be pointed out so that we can from the outset pay attention to the Heideggerian and ontological overtones that Lévy-Bruhl's notion of participation has in Levinas' reading thereof. When we examine participation, we reflect on the modes of being of the human being or rather, of Dasein.

This first qualification of participation as an existence in a fused ontological monism with other people can be developed by considering the subsequent description of participation as "impersonal vigilance" (vigilance impersonnelle). ${ }^{9}$ Participating in Being as the "primitives" do, according to Lévy-Bruhl, is like when one suffers insomnia: I remain awake despite being exhausted: this vigilance, the failure to fall asleep, is not an action of the subject, rather, it remains awake in the subject (ça veille). ${ }^{10}$ Similarly, participation is the mode of existence in which one has no private existence (or no "ontological solitude" as in Time and the other), but existence "returns to an undifferentiated background". "This "fond indistinct" is what Levinas calls the il $y a$, the "there is". The il $y a$ is pure Being or existence, or in the grammatical metaphors that Levinas uses, it is in-finite "to be", it is anony-

5 TO $42 / \mathrm{TA} 22$.

6 TO $43 / \mathrm{TA} 22$.

7 DEHH 80. Levinas' use of "exister" instead of "être" is not an existentialist misreading of Heidegger, but is chosen to avoid the strangeness that the translated Heideggerian terminology had. Cf. ENT 48 / EN 59.

8 GDT 58/DMT 68.

9 E\&E 60/EE 98.

10 E\&E 66/EE 111.

11 E\&E 61/EE 99. 
mous or impersonal, since no being has taken hold of it, there is no being that has "conjugated" it yet, as it were.

The impersonal vigilance of participation that characterises, according to Lévy-Bruhl, the "primitive mentality" is haunted by or subject to a horror before the sacred, since the sacred is exactly this impersonal Being (être) without beings, this capricious impersonal flux of events (il y $a$ ) in which people defencelessly participate:

"The impersonality of the sacred in primitive religions $[\ldots]$ describes a world where nothing prepares for the apparition of a God. Rather than to God, the notion of the there is [il y a] leads us to the absence of God, to the absence of every being. Primitive people are absolutely before Revelation, before the light." ${ }^{\prime 12}$

In this sense the effective mood of horror provoked in the "primitives" by the sacred, testifies to the possibility of an existence in which one is absolutely fused with or diluted into the flux of being to the point of Being depersonalised, ${ }^{13}$ that is to say, in which one participates in pure being to such an extent that there is no exit from this identity with Being. Any intervention from outside or interruption of this flux of Being is precluded. In this sense participation is an atheistic existence. We shall see in Chapter $5(\S 1)$ that this is for the younger Levinas typical of human existence in general: human existence is fatally diluted into Being and in need of an escape; but it is also a form of existence that can be celebrated in disdain for this need of an escape or interruption - with disastrous political consequences (see also $\$ 1$ of Chapter 5).

Ten years after Time and the other and Existence and existents, Levinas comes back to Lévy-Bruhl in two texts that are again very instructive. In his essay "Lévy-Bruhl and contemporary philosophy" (1957), Levinas' perspective on the ethnographer's work is taken from a shift in the latter's own conviction concerning the relationship between "primitive" culture and modern culture. Following the development of Lévy-Bruhl's thought in the Carnets, ${ }^{14}$ Levinas argues that the ethnographer gradually abandoned his famous distinction between pre-logical, "primitive" thought and modern scientifically formed thinking for a vision of the unity, in other words for the universal similarity, of the human spirit. ${ }^{15}$ But what becomes then of the studies of the "primitive mentality"? They serve to uncover structures of the human

12 E\&E 61 / EE 99, translation modified.

13 E\&E $61 / 100$.

14 Published as Les carnets de Lucien Lévy-Bruhl (with a preface by Maurice Leenhardt). Paris: Presses Universitaires de France, 1949.

15 ENT $40 /$ EN 50. 
mind in general. ${ }^{16}$ This is then Levinas' objective with his essay on LévyBruhl: to point out how Lévy-Bruhl's ethnography teaches us something that is universally valid about human existence, to show where some of the fundamental concepts of human existence come from ${ }^{17}$ and how these prepare or enforce developments in contemporary philosophy. The essential point of similarity is to be found in the insistence, by both Lévy-Bruhl and contemporary philosophy, on the originary, non-representational mode of existence of human beings, which Lévy-Bruhl refers to as "participation".

What does this pre-representational participation entail? "To be is to participate [Etre, c'est participer]", cites Levinas from the Carnets, and comments:

"The participation that comes into play in the affective category of the supernatural in no way leads from an imprecise physical phenomenon toward metaphysical being, but from the given thing toward a power that no longer has the solid framework of being, toward the diffuse presence of an occult influence."

In other words, "participation" describes the primordial mode of existence in which the human being is situated not yet among things, but in a flux of powers. This would be the primordial access to the world: not as an individual separated from the things, but as a participator in an atmosphere or a climate, in which that which will later on become substance is still "desubstantialised"19 and to the power of which one is exposed. ${ }^{20}$ In this, Lévy-Bruhl is very close to "contemporary philosophy" - meaning, first and foremost Heidegger's - for whom, according to the rendering of Levinas, existence replaces the subject ${ }^{21}$ in the sense that as (a) being (étant) existence is first and originally a present participle of Being (être): first

16 Such is also the more recent conviction expressed by the historian of anthropology, Frédéric Keck, when opening his essay "Causalité mentale et perception de l'invisible. Le concept de participation chez Lucien Lévy-Bruhl" (in Revue philosophique 3/2005, pp. 303-322) by stating categorically: "The oeuvre of Lucien Lévy-Bruhl can be reread today, no longer in the framework of an analysis of the thought of 'primitive societies', since all contemporary anthropology has deconstructed the belief in the existence of such societies, but with a view to questioning the nature of the mind [la nature du mental]." (p. 303). This essay places the work of Lévy-Bruhl, and in particular the notions of mentality and participation, within the historical development of epistemology in anthropology and provides a more detached (and superbly historically informed) perspective on Lévy-Bruhl's position, than the engaged perspective of Levinas of which I trace the contours here.

17 ENT 41 / EN 51.

18 ENT 45-46/EN 56.

19 ENT $47 /$ EN 57.

20 ENT $48 /$ EN 57.

21 ENT 48f / EN 59. 
verbal, with adverbial traits, before being substantive with qualities. In this ontological description,

"the $I$, thus delivered up to Being, it is thrown out of its abode into an eternal exile, losing its mastery over itself, overwhelmed by its own being. Henceforth, it is a prey to events that have already determined it. [...] being-in-the-world is the exemplary fait accompli. Being that is about to be is already Being that has traversed you through and through. [...] the I that is in their grasp decides, is engaged, takes hold of itself., ${ }^{, 2}$

Such would be, then, the conclusion of an existential, ontological (in the Heideggerian sense) rendering of the central findings of Lévy-Bruhl's ethnography.

The importance of pre-representational participation as the essential mode of being of human beings allows for the use and understanding of the word mentality. Now, the word does not serve to distinguish the cognitive events of "primitive" peoples over against the rationality of "the healthy adult white male [l'homme blanc, adulte et bien portant]". ${ }^{23}$ Rather, a description of the "primitives" helps us to see something that is at work in all human beings. This something is the "mentality" behind, and thus the prerepresentational situatedness, of the representational mind. It is the mentality behind the mens (mind).

"The notion of mentality consists in affirming that the human mind does not depend solely on an exterior situation - climate, race, institution, or even contracted mental habits that would pervert the natural illumination. Mentality is in itself dependence; it emerges from an ambivalent possibility of turning toward conceptual relations or of remaining in relationships of participation. Prior to representation it is strikingly engaged in Being; it orients itself in Being., 24

That the subject is pre-representationally or pre-reflectively engaged is exactly what is ascribed by Heidegger to human existence: human existence, or more correctly Dasein, is engaged in existence in the sense that its own being is lived as a transitive verb, that means (as Levinas would paraphrase) that by conjugating the verb "to be", human existence is inseparably linked or attached to Being. ${ }^{25}$ Furthermore, this transitiveness by which Dasein is its own being, is engaged in that its own being is to it as a task: Dasein has to be. ${ }^{26}$ Master of its

22 ENT 47 / EN 58, translation modified.

23 ENT $39 /$ EN 49.

24 ENT 50/EN 61, translation modified.

25 ENT 50 / EN 62

26 See Martin Heidegger, Being and time. John Macquarrie and Edward Robinson (transl.). Oxford: Basil Blackwell, [1962] 1988, pp. 173, 321, 346 / Sein und Zeit. Tübingen: Max Niemeyer Verlag [1927] 1993, pp. 134, 276, 300. 
existence by conjugating Being, Dasein is at the same time played by Being, as in the citation above:

"As for the $I$, thus delivered up to Being, it is thrown out of its abode into an eternal exile, losing its mastery over itself, overwhelmed by its own being. Henceforth, it is a prey to events that have already determined it., ${ }^{27}$

That this phenomenological and ontological appropriation of Lévy-Bruhl's notion of participation also has consequences for the co-existence of people is underlined by Levinas at the end of his essay. He suspects that the idea that separate individuals merge into one social entity (the "social body [corps social]") ${ }^{28}$ could explain and even partially justify "the modern feeling of existence". ${ }^{29}$ Levinas speculates on the possibility that the era in which he wrote this essay is one of philosophy in which the first intuition concerning being is derived from such a fusional experience of society. ${ }^{30}$ Not only could it be possible that contemporary experience of social existence is justified by such a fusional feeling of society, but it is possible that work such as that of LévyBruhl has contributed to flatter or encourage "a nostalgia for outdated and retrograde forms". ${ }^{31}$ Instead of merely enlarging our understanding of reason by extending it to the modes of thinking of people that would otherwise or formerly be suspected of lacking in rationality - as Levinas appraises the positive contribution of Lévy-Bruhl - the new appreciation for the mode of thinking of the "primitive mentality", justified as it may be in the face of the shortcomings and catastrophes provoked by technical reasoning, risks entailing "a reversion to primitive mentality pure and simple". ${ }^{32}$ This situation of a return to the primitive mentality - of which the essence seems to be for Levinas the fusional or participational experience of social existence - as well as the failure of technical rationality, is described by Levinas as a crisis. But if we enquire as to what constitutes this crisis, we obtain only the last question of the essay:

"But is monotheistic civilization incapable of responding to this crisis by an orientation liberated from the horrors of myths, the confusion of thought they produce, and the acts of cruelty they perpetuate in social customs?"33

27 ENT $47 /$ EN 58.

28 ENT $51 /$ EN 62.

29 ENT 51 / EN 62. Here, Levinas uses the word "modern" for "contemporary" or "fairly recent".

30 ENT 51 / EN 62-63.

31 ENT $51 /$ EN 63.

32 ENT $51 /$ EN 63.

33 ENT $51 /$ EN 63. 
This socio-cultural diagnosis with which the essay on "Lévy-Bruhl and contemporary philosophy" concludes, draws up two opposing visions of what contemporary "European" culture or civilisation is supposed to be: one is dominated by its monotheistic roots, the other by the horror of myths and participation; the latter would be characterised by a nostalgia that leads to cruelty, the former is questioned about its capability to resist or subvert the latter. ${ }^{34}$

\subsection{Heidegger, nostalgia, cruelty and the eclipse of monotheism}

The terms of this diagnosis - nostalgia, cruelty, and the eclipse of monotheism - would remain vague, if it was not for the fact that one finds them in the other text of 1957 in which Levinas refers to Lévy-Bruhl. ${ }^{35}$ In a thematic overview of the two dominant truth strategies of Western philosophy, ${ }^{36}$ Levinas explains that most often philosophers have opted against truth as an encounter with the transcendent other, that maintains the philosopher in a heteronomous relation to the other and leads ultimately to a metaphysics enquiring about the divine, and for an approach by which the other has to be incorporated into the self/same (même) - knowledge consists in the autonomous action of the self that identifies the diversity of the others in itself. ${ }^{37}$ Affirming strongly the freedom and autonomy of the knowing subject (the same/self) seemed the best manner to overcome the disturbing fusion and confusion of opinion as is described for the mythical stage of sociality by Lévy-Bruhl's notion of par-

34 Levinas may well have been influenced by Franz Rosenzweig in this opposition, considering what Rosenzweig calls the "world historical opposition (Welthistorischer Gegensatz) of mythology and revelation" - see "Atheistische Theologie" in Der Mensch und sein Werk. Gesammelte Schriften 3, Zweistromland. Kleinere Schriften zu Glauben und Denken. Reinhold and Annemarie Mayer (eds.). Dordrecht: Martinus Nijhoff, 1984, pp. 687-697, especially p. 693. In this essay, Rosenzweig objects to the mythological interpretation of both Christianity and Judaism as a reduction of the faith content of these religions to what is explicable in purely human terms. It is probably not irrelevant to recall that the essay on LévyBruhl was published only two years before Levinas' important paper on Rosenzweig: "“Between two worlds'. The way of Franz Rosenzweig" (1959) (DF 181-201 / DL 252-281).

35 Apart from Rosenzweig's thoughts alluded to above as an external aid to illuminate Levinas' thought here, another form of clarification, in particular the link between monotheism and the benefits of its secularisation of society, can be obtained from the 1956 essay "For a Hebraic humanism", which will be discussed in detail in Chapter $4, \S 1$.

36 CPP 47-48 / DEHH 165-166.

37 CPP 48/DEHH 166. 
ticipation. ${ }^{38}$ Whatever one might think of this all too hasty typology of truth strategies and the all too cryptic reference to Lévy-Bruhl, Levinas seems to consider this opposition of a philosophical strategy of the affirmation of the freedom of the self over and against the tyranny of the other a positive development, in as far as it overcomes the blind and harmful influence of the others over the self under a regime of tyranny or of the mythical stage of human existence. However, in the rest of the same essay, the full élan of his critical energy is directed at the "narcissism" inherent in the "primacy of the self/same", 39 especially since, in its most eminent form - that of the philosophy of Heidegger - it reverts to all that is violent in the primitive participation: ${ }^{40}$ it conquers, dominates and possesses ${ }^{41}$ whatever it encounters, it is fundamentally atheistic, since it cannot tolerate the thought of ideas coming into its domain that it had not placed there by reason itself, ${ }^{42}$ it draws its strength from capturing the particular individuality by means of neutral, general notions, and implicitly it considers itself naturally justified in confrontation with the other. ${ }^{43}$ Rarely in Levinas' entire oeuvre is his judgement formulated as severely as in this text, when he explains his conviction that this strategic supremacy of the self over the other is fully maintained in the philosophy of Heidegger. ${ }^{44}$ It is in his judgement that one sees not only a criticism of another philosopher, but a development of a social strategy for which the name of Heidegger is often in Levinas a synecdoche.

In Heidegger one encounters Dasein as possessed by freedom rather than Dasein disposing of freedom. In this way the freedom is not questioned, ${ }^{45}$ since

"[b]eing is inseparable from the comprehension of Being; Being already invokes subjectivity. But Being is not a being. It is a Neuter [as in the critique of the strategy of the same - EW] which orders thought and beings, but which hardens the will instead of

38 CPP 48/DEHH 166.

39 CPP 49/DEHH 167

40 In fact, the reference of Levinas to Lévy-Bruhl is not clear and my interpretation of it, apart from being guided by my previous reading of Levinas' longer essay on the ethnographer, is based on what Levinas says of Heidegger: "Heidegger does not only sum up a whole evolution of Western philosophy. He exalts it by showing in the most pathetic way its anti-religious essence become a religion in reverse" (CPP 53 / DEHH 171). It seems to be implied here that Western philosophy entails an escape from and eventual reverting to something similar to the "primitive mentality".

41 CPP 48 / DEHH 167.

42 CPP 49/DEHH 167.

43 CPP 49-51 / DEHH 167-169.

44 CPP 51ff / DEHH 169ff.

45 CPP 51, 52 / DEHH 169, 170. 
making it ashamed. The consciousness of his finitude does not come to man from the idea of infinity [this is the form of the excluded other - EW] that is, its not revealed as an imperfection, does not refer to the Good, does not know itself wicked. ${ }^{, 46}$

By so doing, Heidegger's philosophy

"continues to exalt the will to power, whose legitimacy the other alone can unsettle, troubling good conscience", 4

he "maintains a regime of power more inhuman"48 than that of the technical power issued from Greek thought. This "regime of power", speculates Levinas, finds its historical expression in Nazism, that could well be based on

"peasant enrootedness and a feudal adoration of subjugated men for the masters and lords who command them". 49

Whereas the Nietzschean colouring of this criticism of a nostalgia for a life of plenty in the motherland ${ }^{50}$ is clear, it should be pointed out that the "enrootedness" (in the citation above ${ }^{51}$ ) is the Heideggerian equivalent of Lévy-Bruhl's participation. Once this has been noticed, it becomes easier to see what Levinas has in mind when he calls this "peasant enrootedness" "a pagan existing",52 and explains that

"[a]nonymous, neuter, [Being] directs [building and cultivating], ethically indifferent, as a heroic freedom, foreign to all guilt with regard to the other". ${ }^{53}$

One finds in these words a parallel exclusion to that found earlier in the "primitive mentality":

"The impersonality of the sacred in primitive religions [...] describes a world where nothing prepares for the apparition of a God. Rather than to God, the notion of the there is [il y $a$ ] leads us to the absence of God, to the absence of every being. Primitive people are absolutely before Revelation, before the light. ${ }^{, 54}$

Desubstantialisation, whether it is in the "primitives" or in Heidegger, leads to people being overpowered by an impersonal, anonymous power that excludes them from being affected by anything that would transcend it.

46 CPP 52/DEHH 170.

47 CPP 52 / DEHH 170.

48 CPP 52/DEHH 170.

49 CPP 52 / DEHH 170.

50 Later in the same text, Levinas describes the inverse attitude, namely the desire for the other in the following terms: "It does not refer to a lost fatherland or plenitude; it is not homesickness, not nostalgia" (CPP 57 / DEHH 175).

51 And again CPP 53 / DEHH 171.

52 And see CPP 52f / DEHH 171: "atheism and paganism".

53 CPP 53 / DEHH 170.

54 E\&E 61 / EE 99, cited above. 
But again, the point is not to criticise the political engagement of one individual. The "peasant enrootedness", this

"earth-maternity determines the whole Western civilization of property, exploitation, political tyranny, and war.",55

And Heidegger is not only the summary and summit of Western philosophy, but in the manner that he is presented by Levinas, represents the "outcome of a long tradition of pride, heroism, domination, and cruelty". ${ }^{56}$ Thus, the terms of the social criticism at the end of Levinas' essay on Lévy-Bruhl ${ }^{57}$ nostalgia, cruelty, and the eclipse of monotheism - have all found their historical referents. They have also been elaborated on by the traits of a specific form of contemporary "participation" that is not only responsible for an unfortunate period of German history, but characteristic of the entirety of Western civilisation: possession, exploitation, tyranny in politics, and war.

\subsection{Ethnography, ontology and socio-political criticism}

This is incidentally also the high point of Levinas' use of Lévy-Bruhl; since the remaining references ${ }^{58}$ to the ethnographer entail no significant interpretation of his work, one could say that Levinas' use of LévyBruhl comes to an end in 1957. We therefore have to take stock of what has been gained by this overview of Levinas' use of Lévy-Bruhl's work.

It should be clear that Lévy-Bruhl could not be the author of the ethnography to which Levinas refers in our guiding citation (page 33, above): not only was Lévy-Bruhl not considered contemporary any more in 1964, he could not be considered as an ethnographer that "maintains the plurality of cultures on the same level" (in most of his work). Also, where there are indications of a levelling of Lévy-Bruhl's regard for different cultures (according to Levinas' reading of the ethnographer's Carnets) the question of cultural plurality is of no importance to Levinas, rather it is the matter of participation and what it implies that is the focus of his attention. It should also be remarked that in the commentaries that Levinas wrote on Lévy-Bruhl, the question of decolonisation, and indeed of colonisation, is absent. However through the exploration of Levinas' readings of Lévy-Bruhl a number of valuable insights have been gained.

55 CPP 53/DEHH 171.

56 CPP 52/DEHH 170.

57 ENT $51 /$ EN 63.

58 T\&I 234, 276/ TI 260, 309, A\&T 129/ AT 136. 
(1) Levinas' take on Lévy-Bruhl means that his texts on the ethnographer read like an introduction to (especially Heideggerian) phenomenology. ${ }^{59}$ In these texts one finds a good number of the basic elements of Heidegger's Daseinsanalyse. These basic elements are the following: At the centre of all philosophical questions is the difference between Being as the verb "to be" and being as beings that are. Understanding of the verb "to be" happens only in that being (Dasein) that is the place where the differentiation between "to be" and the beings take place. This understanding of "to be" is a matter of pre-predicative or pre-representational existence, rather than a series of episodes of conscious cognition. Existing means for Dasein to understand "to be" or Being. In fact, existing is a continuous understanding or interpreting event. Hence the importance of analyses of the different modes by which Dasein factically exists. ${ }^{60}$ All of these elements of Heidegger's philosophy have been taken over and appropriated by Levinas. This should be stated emphatically because, for all his criticism of Heidegger, Levinas is a profoundly Heideggerian philosopher and it is only after this has been recognised, that his criticism of Heidegger, as well as his modifying appropriation of parts of Heidegger's philosophy, can be appreciated. But what does this contribute to our understanding of the guiding citation in the introduction to this Part?

(2) The implicit claim of our guiding citation (page 33) is that ethnography is ontologically significant and instructive. Through the overview of Levinas' readings of Lévy-Bruhl we have seen how Levinas as a scholar in phenomenology knows how to identify noteworthy aspects of the ethnographical descriptions for considerations, not merely about the "primitives", but about people in general. This is not an obviously correct procedure, since the analyses of Dasein do not constitute an anthropology. I would even claim that one of the purposes of Levinas' phenomenological hermeneutics of ethnography is to use the ethnography in order to provide a more anthropologising reading of phenomenology, and in particular of Heideggerian ontology. Thus, the characteristics of the life of "primiti-

59 This is also the justification for pointing out, from the beginning, the Heideggerian resonances of Levinas' reading of Lévy-Bruhl. However, the relation between Levinas' reading of Lévy-Bruhl and phenomenology is much more complex than could be given account of here, since at the time that Levinas was developing this reading, Lévy-Bruhl had already received a favourable reception by Husserl and Sartre; Merleau-Ponty would do so round about the same time as Levinas (cf. Frédéric Keck, "Causalité mentale et perception de l'invisible", op. cit. p. 320f). Comparing Levinas to such other phenomenological readers of Lévy-Bruhl would reveal more of the intricacy of this matter.

60 Cf. De l'éthique à la justice 5-7. 
ves", interpreted with the aid of Heidegger, helps us to return to Heidegger in order to find the anthropological import of his claims about $D a$ sein's ontological existence. This doesn't mean that the ontology of Heidegger is simply collapsed, but that it is accompanied by a parallel discourse, by a path that is indicated from Dasein, through anthropology, to political or social criticism. This is the strategy by which Levinas develops a discourse that always has political overtones when it is explicitly ontological, and has an ontological tenor, when it is explicitly political. This is how he could assert that in the ethnographic claim to the equality of cultures, the connection between a political event (decolonisation) and an ontology (one of plurality) becomes visible.

(3) The climax of this coupling of the ontological with the political is situated in the political implications of an ontology that would reduce the other to the same, that fuses or constrains the other to participate in the flow of the same. Although we have seen how Levinas exposes this violence of ontology, ${ }^{61}$ especially in connection with his reading of Lévy-Bruhl in 1957, it should be noted here already that this has been a part of his work from very early on. In De l'évasion (On escape - 1935) for instance, Levinas proposes his own project explicitly in terms of a renewal of the question of "Being as 'to be' [l'être en tant qu'être]", ${ }^{2}$ i.e., in the terms of Heideggerian ontology, and inquires if Being or "to be", understood in this manner, is not perhaps "the sign of a certain civilisation that is installed in the fait accompli of Being ${ }^{63}$ and incapable to get out of it" ${ }^{, 64}$ and he warns (or already diagnoses?) that

"every civilization that accepts Being, the tragic despair that it entails and the crimes that it justifies, deserves the name of barbaric." ${ }^{, 65}$

61 I shall not enter here into the legitimate question as to the validity of Levinas' criticism of Heidegger. My concern is only with Levinas' interpretation and the implications thereof.

62 EV 99.

63 Above, we found the idea of being as "fait accompli" too, namely where Levinas referred to "being-in-the-world is the exemplary fait accompli." (ENT 47 / EN 58).

64 EV 99.

65 EV 127. But here too, the reference to the question of paganism/atheism and monotheism is not impossible to indicate. In a (confessional and philosophical) text from the same year Levinas writes: "Paganism is neither the negation of spirit, nor ignorance of a unique God. The mission of Judaism would be only very modest if it brought monotheism to all the peoples on earth. It would be to instruct those that know. Paganism is a radical inability to exit the world. It does not consist of negating spirits and gods, but of situating them in the world." (cited after Roland in EV 153-154). Monotheism is thus opposed to a form of incapacity to be affected by something from outside of this world and that carries in religious terminology the 
In Chapter $5(\S 1)$, the early formulation of the coupling of ontological and political violence will be examined in more detail.

(4) When the matter of the violence of Western civilisation is placed on the agenda, and especially in connection with the work of LévyBruhl, the issue of decolonisation is spontaneously evoked. In fact, in contemporary African philosophy, Lévy-Bruhl is often named as the colonial ideologue par excellence. ${ }^{66}$ The categorical formulation of Kebede is telling in this regard:

"No need to go into fussy research to lay hands the method used to invent the 'white man'. All the ingredients are found in the thinker who is universally believed to have codified the colonial discourse, namely Lucien Lévy-Bruhl., ${ }^{, 67}$

Now, it is clear that the political fate of the "primitives" as well as that of their colonised and decolonised descendants is not the matter of concern for Levinas as a reader of Lévy-Bruhl. What he appreciates most is the ethnographer's ideas in which the distinction between Western rationality and the "primitive mentality" has already withered away and the notion of the pre-logical has been abandoned to make place for an equivalence of two manners of thinking in minds that are in essence the same ${ }^{68}-$ Levinas' ethnographer is neither one of a hierarchy of differences (as the earlier Lévy-Bruhl would be), nor of an indifference to differences (as the ethnography in our guiding citation). Rather, Levinas relates cultural differences in a phenomenological manner by arguing that what is constitutive of the "primitive mentality" is equally constitutive of the mentality of (at least some of) his contemporaries. It is the participatory aspect of the constitution of human beings' mentality that is criticised by Levinas, not the alleged inferiority of either of the two as such. What will be decisive in his work are the arguments that allow for the denunciation of violence in both of these "mentalities". And let it immediately be added that, the instance of authority for the judging of cultural expressions is not a factor of

name of paganism. But this corresponds not only with what Levinas saw in LévyBruhl's notion of participation, but also to his philosophical project in On escape of finding an escape or "excendance" from Being and the violence that it implies.

66 I say "contemporary", since the négritude philosophers, influential around the time of decolonisation, made a positive appropriation of some of Lévy-Bruhl's analyses (cf. for instance Abiola Irele on Senghor in "African philosophy, Francophone", in E. Craig (ed.). Routledge Encyclopedia of Philosophy. London: Routledge, 1998).

67 Messay Kebede, Africa's quest for a philosophy of decolonization. Amsterdam and New York: Editions Radopi, 2004, p. 1.

68 ENT 40, 49/EN 50, 61. 
rationality (nor of irrationality) and is itself worthy of being called "prelogical" "10 in what is to Levinas an eminently positive sense. It is in the name of the ethicity that Levinas will support by means of his philosophy that he is capable of denouncing the crimes, the possession, the violence and the cruelty that he considers prevalent in Western civilization. And it is on the basis of this ethical judgement, and not on the basis of the superiority of Western culture, that Levinas would also criticise whatever he deemed worthy of criticism in other cultures. ${ }^{70}$ There is no reason why the violence in colonialism would not be included in Levinas' criticism of Western civilisation's crimes, possession, violence, and cruelty and therefore this subject will be explored in more detail in Chapter 3 .

(5) In all of this, the religious terms "atheism", "paganism" and "monotheism" play a considerable role. For the moment I only state that the intention with which Levinas uses them in his philosophical texts is not simply (or perhaps, not at all) to introduce confessional categories into his philosophical discourse. If one wants to understand Levinas' stance on the matter of ethics, ontology, plurality and politics, it is of utmost importance to see that these terms are capable of carrying meanings other than confessional ones. This seems to me the appropriate interpretational approach to Levinas, independent of the question of whether one accepts what Levinas says by using these terms, or not.

(6) The thought strategy that links ethnography, ontology and atheism, accompanied by a social criticism and the question of its solution had thus been present in Levinas' work for a long time when the words of the guiding citation were formulated. Far more than a mere philological curiosity, this fact helps us to understand how a number of different strands of thought in his early work fit together, and to understand the indissoluble link between what is written on the level of ontology and its implications for a socio-political criticism. Two further advantages are to be derived from this. First, it will give us a frame of reference with which to explore the meagre references of Levinas to Lévi-Strauss. This in turn will help us to see the shift in Levinas' diagnosis of the essential sociopolitical problem from his earlier work to his later work and subsequently it will allow us to discern what is at stake in Levinas' concern with matters of cultural and political plurality and unity. Second, such a view

$69 \mathrm{HO} 53 \mathrm{f} / \mathrm{HH} 86$.

70 That he didn't hold strictly to this principle and succumbed in some places to either an idea of cultural superiority or moral superiority, will be recalled in Chapter 6 $(\S 1)$. 
on the changes of Levinas' political concerns will make it possible to give a more correct philosophical interpretation of the question of atheism and monotheism, alluded to above.

We therefore have to move on to the consideration of our second ethnographer, Claude Lévi-Strauss.

\section{Claude lévi-Strauss, DECOLONISATION AND INDIFFERENCE}

Considering Lévi-Strauss as the ethnographer that Levinas could have had in mind in the guiding citation (page 33) might at first sight seem somewhat doubtful. In Levinas' entire work, Lévi-Strauss is referred to by name only twice. ${ }^{71}$ In fact, one of these two references seems to exclude Lévi-Strauss from any serious place in Levinas' thought, since the latter confesses in a context where he speaks explicitly about Lévi-Strauss: "even today, I don't understand structuralism"72 and "probably I haven't read [Lévi-Strauss or structuralism - EW] as one should" "73 and of Lévi-Strauss he admits that "I don't at all see where is the point of his view". "However, in what follows, the correspondence with our citation is easily detectable: the "vision" of Lévi-Strauss "corresponds, certainly, from a moral point of view, to what is called decolonisation and the end of dominant Europe [...]". ${ }^{75}$ Nothing more of value is said in this passage, but the connection between Lévi-Strauss and decolonisation is decisive.

The other of the two explicit references to Lévi-Strauss in Levinas' work is at the end of his 1959 essay on Rosenzweig. This is an important place for two reasons. First, this is the essay with which Levinas has practically singlehandedly opened French studies of the author that he considered to be "the

71 I limit myself here only to the issues evoked by the guiding citation and these explicit references to Lévi-Strauss. The question concerning the relation between Levinas' idea of humanism and that of Lévi-Strauss - both of which could be said to aspire to a post-colonial and post-subjectivist notion of humanism, albeit in quite different ways - will not be dealt with here.

72 EL 161.

73 EL 162.

74 EL 161.

75 EL 161. I do not take it too seriously when Levinas says that Lévi-Strauss is "Certainly the most distinguished mind of the century" (EL 161), since on the very next page Ricoeur is called "the best [of the distinguished minds] of our era." (EL 162). Besides, it is hard to see on what basis one could sing such praise to an author that one avows one doesn't understand. 
only modern philosopher of Judaism that would be worthy of this name",76 and of whom he would later recognise that in Totality and infinity, ${ }^{77}$ his influence is too prevalent to be cited. ${ }^{78}$ Second, it indicates that Levinas had made a significant appropriation of the work of Lévi-Strauss, at the very latest around the time when his interest in Lévy-Bruhl waned. ${ }^{79} \mathrm{I}$ cite this passage at length, since it says a lot about Levinas' own manner of thinking and it will immediately fill in the image of our guiding citation (of page 33).

"There is yet another way in which history could put in question the existence of the Jewish people $[\ldots]$ there is an interpretation according to which [this existence] goes nowhere: all civilizations would be equal. Modern atheism is not the negation of God. It is the absolute indifferentism of Tristes Tropiques [of Lévi-Strauss]. I think that this is the most atheist book that has been written in our day, the absolutely disoriented and most disorientating book [...]. Rosenzweig [...] allows us, in the very name of philosophy, to resist the supposed necessities of history.,

These cryptic remarks of Levinas on Lévi-Strauss resonate with the guiding citation by (1) the issue of a non-hierarchical relationship between different cultures or civilisations, (2) the disorientation that it entails, (3) the atheism that it expresses and (4) the politics of decolonisation with which it fits. On the basis of this accord, it could be allowed to interpret "history" in the citation about Tristes tropiques, with "Being" in the guiding citation - an equivalence that is commonly used by Levinas since his earliest texts. Hence, the suspicion about Lévi-Strauss as the ethnographer of disorientation is affirmed. The fact that the guiding paragraph could accommodate other ethnographers too could be considered of no consequence, since in what is said about Lévi-Strauss Levinas' essential point is clarified. ${ }^{81}$

76 "Recension. Léon Chestov: 'Kierkegaard"', in Emmanuel Levinas, L'intrigue de l'infini. Marie-Anne Lescouret (ed.). Paris: Flammarion, 1994, pp. 87-90, citation p. 87.

77 T\&I $28 /$ TI 14

78 Cf. De l'éthique à la justice 14-22 on Levinas' reading of Rosenzweig.

79 I say "at the latest" since it cannot be excluded that it is to someone like LéviStrauss that Levinas refers at the end of his essay on Lévy-Bruhl, when he speaks of the "renewal of mythology, the elevation of myth to the rank of superior thought by secular thinkers" (ENT 51 / EN 63). Also, the claim I make here covers only what can be supported by textual references.

80 DF 201 / DL 279-280, translation modified.

81 Bernasconi's demonstration that Levinas is constantly in dialogue with MerleauPonty on the issues of culture, decolonisation and a phenomenology of meaning, and their interrelation, in the first chapter of $\mathrm{HO}$ should be considered perfectly plausible (see Robert Bernasconi, "One-way traffic: the ontology of decolonization and its ethics", in Ontology and Alterity in Merleau-Ponty. Galen A. Johnson and Michael B. Smith (eds.). Evanston: Northwestern University Press, 1990, pp. 67-80). My point is not to exclude such a role of Merleau-Ponty in this chap- 
But the importance of identifying the culprit exceeds the joy of playing philological sleuth. It enables us to identify what Levinas considers the ontological and political implications of Lévi-Strauss' ethnography to be.

(1) There would be, in Levinas' mind, ontological implications in maintaining the equivalence of the value of different cultures, as Lévi-Strauss does. If Levinas were to make a reading of Lévi-Strauss, in the same manner as he did of Lévy-Bruhl, he would have indicated what the "ontology - thought on being, thought that is interpreted from multiple and multivocal signification" entails (see the guiding citation, page 33, above). In fact, (and this is perhaps because Levinas was not sure of his reading of Lévi-Strauss) he did so, but only obliquely - we find this analysis, without reference to Lévi-Strauss in the first chapter of Humanism of the other, from which our guiding citation comes.

(2) We can elucidate the political consequences of the implied ontology by considering the two ways in which Levinas (in the citation from the essay on Rosenzweig, page 51, above) believes the Jewish people - and with them all ethical agents - to be threatened. (1) The first consists of being simply drawn along by history and history being its own exclusive judge. History (or Being) is for Levinas a totalising and identity-creating force that allows for no true judgement about the manner in which particularities disappear in the universal history (here one recognises again Levinas' criticism of Heidegger's notion of being). This is the problem of participation again, this time formulated as a historical concept rather than an ethnographic one. In this perspective, what Levinas said of the individual in a Heideggerian perspective, holds also for other peoples: "it is a prey to events that have already determined it." ${ }^{, 82}$ (2) The implicit ontology of Lévi-Strauss' ethnographic convictions poses a somewhat different problem to ethical agency: it doesn't destroy the agency by integrating it into a whole, into the flow of an identity-creating force, but by collapsing all judgement or valuation between agents, in other words, by indifference. Levinas refers to this indifference as a disorientation (in the guiding citation of page 33) - "disorientation" being synonymous here with "atheistic" and, especially when the time at which Levinas wrote it is taken into account (1964), it is not surprising to see that the political

ter of $\mathrm{HO}$ - in fact, Levinas explicitly orients his discussion of meaning on Merleau-Ponty - but to expose and exploit what is present in Levinas' relation to the ethnographer.

82 ENT $47 /$ EN 58. 
manifestation of this dis-orientation is seen in the dis-occidentalisation of the world, i.e., in the process of decolonisation. ${ }^{83}$ Strangely enough, when, in the finishing paragraphs of the essay, Rosenzweig is presented as the solution for the problem posed by Lévi-Strauss, the parameters of the problem change in such a manner that it again becomes a question of undermining the necessity of history and the issue of indifferent plurality seems to slip away. ${ }^{84}$ It is as if Levinas here finds a problem for which, at this stage, he has no solution, and can find none, not even in Rosenzweig. I shall comment on this shift below, for time being let it then be noted that there are two distinguishable threats to the continued existence of the Jewish people.

(3) Thus far, in my commentary on the essay from Difficult freedom, I have referred, without problem, to the Jewish people. This is of course imposed by reference to a text that was initially prepared for a Jewish audience (namely the Colloque d'Intellectuels Juifs de Langue Française). However, Levinas leaves ample room for the appropriation of his argument by and for non-Jews, or to put it differently, the essence of what he says applies to all people and not only to Jews. This becomes clear when one takes seriously that Levinas presents Rosenzweig's intellectual opposition to the necessity of history as allowed for in the name of philosophy, which in this case should be taken to stand for universal validity (as opposed to validity only for those that adhere to the authority of the same religion). ${ }^{85}$ One finds more explicit support for such a claim, if one accepts Levinas' conviction that

"[t]o wish to be a Jew today is therefore, before believing in Moses and the prophets, to have the right to think that the significance of a work is truer in terms of the will that wished it into being than the totality into which it is inserted". ${ }^{86}$

83 "The world created by this saraband of countless equivalent cultures, each one justifying itself in its own context, is certainly dis-Occidentalized; however, it is also disoriented [dés-occidentalisé, mais aussi un monde désorienté]." (HO 37 I HH 60).

It should be noted here that the double analysis of the most important figures of political catastrophes, as I have reconstructed them here with the help of Levinas' reading of Lévy-Bruhl and Lévi-Strauss, is also to be found elsewhere in his work. The essay "On the deficiency without care, in a new sense" [De la déficience sans souci au sens nouveau]" (GCM 43-51 / DVI 77-89, my translation) is an excellent example thereof.

84 DF 201 / DL 280.

85 That the universal validity of Rosenzweig's practice of philosophy could be questioned is not excluded here. The point, however, is to see if Levinas speaks in principle only about Jews or if his ideas apply in principle also to other people. 
In other words, what is essential in Judaism is not in the first instance the fidelity to the faith tradition but the conviction that one could - also independently from the Jewish confession - act in a manner as to infringe on the identitary and totalising power of history of Being, for it is only in this way that judgement and evaluation of action is possible. ${ }^{87}$

(4) It should at least be noted that, as far as the political tenor of Levinas' reading of Lévi-Strauss is concerned, (and apart from the question of the continued existence of the Jewish people that I have just reinterpreted as the continued existence of ethical agency) that in the 1959 passage there was no reference to decolonisation, whereas in 1964 (the guiding citation) it takes an important position as the political manifestation of ontological indifference and of atheism. Given the terseness of the references to Lévi-Strauss this could of course be mere coincidence. Let it at least be suggested that since the passage on Lévi-Strauss and the guiding citation are so similar in tenor and content, and since in both cases the reference to Lévi-Strauss is placed in a strategically important position ${ }^{88}$ for the indication of the problem, that it might perhaps be considered possible that this change in wording reflects Levinas' appropriation of the events of decolonisation that have unfolded in the meantime. ${ }^{89}$ What decolonisation meant for Levinas' thought on politics will be examined below.

(5) We have seen, in the conclusions drawn from Levinas' use of LévyBruhl, that the use of terms like "atheism" or "monotheism" in this kind of context does not have much to do with personal convictions in matters of religion. Similarly, in reflecting on the implications of Lévi-Strauss's ethnography, Levinas is concerned with an implicit ontology to which the ethnographic text testifies, and its political implications. The term "atheism", in the guiding citation and in the short remarks about Tristes tropiques, thus refers to a stance of indiffe-

87 The issue of the coordination between philosophy and reflection that is embedded in a Jewish community, as Levinas understands it, will be explored further namely in Chapter 4 (\$4) and Chapter $5(\$ 4)$.

88 In the case of the guiding citation, its importance for Humanism of the other will be shown in Chapter 5.

89 To recall just the major markers of French decolonisation: Laos, Cambodia, Vietnam, as well as Tunisia and Morocco became independent before or in 1956 and the big number of Sub-Saharan African colonies and Madagascar in 1960. The Algerian war came to an end and Algeria gained independence in 1962 when Levinas was probably already working on the essay from which the guiding citation comes (Humanism of the other, chapter 1). Djibouti and the Comoros had to wait until the second half of the 1970s for their independence. 
rence with regard to the Being-disclosing capacity of distinct cultural phenomena. An "atheistic" ethnography (or for that matter any other form of "atheistic" discourse on the same subject) is one that is in favour of a non-hierarchical relation between different cultures and even engaged in promoting an attitude by which any such hierarchisation is rejected as a political act - of this, decolonisation would be a supreme example in the time Levinas wrote - and it is in this attitude and its corresponding political practice that Levinas sees an incapacity to distinguish, to judge, to differentiate in a normative manner, or in other words, he sees in such an attitude an indifference that, if pursued consistently, would entail political disorientation. In short, here again atheism doesn't refer in the first place to a personal conviction concerning the non-reality of a transcendent person; as it referred in the discussion of Lévy-Bruhl to the impenetrability of a fused, identity-creating flux of history, here it refers to the practice (the "political work" from the guiding citation) issued from a deep acceptance of an irresolvable indifference - hence Levinas' term "indifferentism" - to which he will also refer as the "crisis of monotheism" in Humanism of the other. Whereas one could perhaps still consider the use of the word "atheism" in the citation from the essay on Rosenzweig on Tristes tropiques as made from and for a religious context, its repetition in the guiding citation from Humanism of the other is undeniably philosophical.

Having presented the detailed exegesis of Levinas' remarks on LévyBruhl and Lévi-Strauss, it is now necessary to draw a few conclusions from the two sets of remarks, considered together.

\section{Conclusion: the politics of LeVInAs' PHILOSOPHY OF ALTERITY}

In Levinas' engagement with Lévy-Bruhl and Lévi-Strauss, his primary concern is never with how the "primitives" or their descendants should be understood. The question of understanding the cultural other is approached only indirectly in both cases: ethnography informs ontology, it helps to uncover the anthropological overtones of an ontology and only in this way 
gives access to considerations concerning the relation between people(s). ${ }^{90}$ And here, the objective is not to understand the other or to give guidelines for living together, but to develop a diagnosis of the violence in the confrontation between different people. The two ethnographers each help to identify a different problem in the co-existence of people. And it is of utmost importance to see this, since Levinas' profound reflections on ontology and ethics are strongly formed by these diagnoses. I do not mean to claim that it is the reading of the ethnographers that structures Levinas work in an earlier and a later period, but that the different cultural-political diagnoses of the two main periods of his post-war work are accessible by a reading of his use of the two ethnographers.

For the sake of clarity, the main political concern reflected in each of the two major phases of Levinas' work should be schematised. ${ }^{91}$ The overwhelming political concern of Levinas' earlier philosophy is the rise of Nazism and the effects of its totalitarian violence. ${ }^{92}$ If the fact of the existence of the colonies was a concern for Levinas, then it would be only in a secondary way and in so far as their existence reflected totalitarian violence. A specific ontological strategy is called for to address this problem from a philosophical point of view: this consists of affirming a non-totalisable alterity, despite the totalising and identity-creating force of Being, in other words, affirming the other, despite the same. From the political point of view, the fact that there is a discernible later philosophy of Levinas doesn't mean that his earlier philosophy is invalid or even that it had been insufficiently treated, but that the political concern of the earlier philosophy is not the only really disturbing one faced by Levinas and his contemporaries. The political concern of Levinas' later philosophy is that of a world in which competing, contradictory claims to excellence or recognition exist directly next to each other, without any possibility of settling or resolving such claims in a noncontingent manner. The appropriate ontological strategy for countering

90 A fairly similar interpretational strategy could be indicated to be at work in (at least some of) Levinas' efforts to make insights from literature useful for ontological considerations. I have explored one such example - that of Levinas' reading of Céline's famous novel - in 'Le mal, le destin et l'éthique. Lévinas et le Voyage au bout de la nuit', in Études littéraires 41/2 2010, pp. 133-145.

91 This schematisation is justified only by the objective of developing my particular point of view. It should not be taken as a presentation of the intricacy and complexity of Levinas' thought on politics and its relation to his philosophy in general. An overview of this theme can be found in Howard Caygill's Levinas and the Political, London and New York: Routledge, 2002.

92 More will be said on this in Chapter 5. 
this problem would consist in identifying an orientation or sense of the presumably indifferent multiplicity of cultural meanings. As much as the change from the earlier to the later Levinas could be ascribed to changes in his philosophical reflection in the sense of his strategy of justifying ethicity, it seems nonetheless valid to claim that the two phases correspond also to two distinguishable political needs.

Levinas' entire philosophy is motivated by his concern about these two political risks, or even tendencies, that are both clearly present in the post-colonial world, but also elsewhere: the tendency of identity-enforcing totalitarian violence and that of indifferent plurality. Consequently his philosophical project is aimed at finding the source of a non totalisable alterity, that he also calls infinity, and to find something that is otherwise than the indifferent, multiple cultural renderings of Being. These two evidently political concerns could be summarised in the ontological terms "Totality and infinity" and "Otherwise than Being". These two formulas are of course the titles of Levinas' two most important books. The ontological register of the titles and even of the biggest part of the content should not mislead the reader to think that Levinas' ultimate concern is about the verb "to be", Sein, être, its meaning and its limits. The enormous challenge of Levinas' philosophy is to provide one satisfactory solution that could hold for both of these problems - and this, as explained in Chapter 1, confronted at the most profound level of reflection for Levinas: that of meaning. The concern with "to be", ontology, is in the service of a most radical confrontation with the problem. Levinas' philosophy will have succeeded if he could affirm convincingly at the same time that the apparent indifferent plurality of cultural manifestations has a unitary orientation and that this unitary orientation is the interruption of the totalising unitary movement of history. The continued existence of Jewish people against antiSemitic totalitarianism and the possibility of judging interaction between people despite decolonisation would be the political figures that capture this task. However, it is the survival of any oppressed other in the face of totalitarianism and the possibility of evaluation of all action in interaction that are at stake in these figures.

Having thus strengthened our initial claim concerning the political nature of Levinas' philosophical enterprise (see Chapter 1) and having explored two major figures by which the stakes of the political as philosophical problem are presented and confronted (Chapter 2), we have arrived at the conclusion that Levinas claims general validity for the philosophical dis- 
course in which he addresses these problems. It is the largest practical dimension of this general claim, which will be explored in the next Chapter. 


\section{Chapter 3}

\section{The range of the political: Decolonisation as a case in point}

\section{FROM SITUATED THOUGHT TO GLOBAL CONSEQUENCES}

Levinas' major concern is then with political events, or the threat thereof, that cause harm to the other. The origins of such events are not the ideas of social scientists or philosophers - neither those of Lévi-Strauss, nor those of Heidegger. It cannot be since - as has been shown from Levinas' reading of Lévy-Bruhl - the mens and its ideas are brought forth and depend on a more original mentality. ${ }^{1}$ Mentality belongs not to the individual but rather to a group, and it predisposes the members, that share the mentality, to certain kinds of action. Typical mentalities judged by Levinas are identitary totalisation and indifferent pluralism. It is the text of ethnographers that help to identify those mentalities - not only in "primitives" but also by projection of the studies on the "primitives" on modern societies. But although large-scale political catastrophes result from mentality, rather than from ideas, aspects of mentalities can still be enforced by the cultural influence of ideas. Levinas' accusation against Heidegger is exactly that his philosophy enforces an undesirable mentality. In the same manner intellectual support can be given for other or positive possibilities of mentalities and this is the ambition of Levinas. It is not his thought that initiates or grounds the alternative action, but it identifies and gives intellectual support to an aspect of human "mentality" (Levinas will say a form of intelligibility) that exists before and independently from the philosopher. And it is exactly the work of the phenomenolo-

1 However, it should be borne in mind that this reading of Lévy-Bruhl is dependent on Levinas' reading of Heidegger. 
gist to lead us in reflection back (that is, to practice reduction, albeit then in a particular, Levinasian sense) to the constitution of this mentality - as has been indicated in the introductory Chapter. Furthermore, if I have insisted on the fact that for Levinas writing philosophy is already a political intervention (Chapter 1), then this is at the core of his practice: to re-enforce, by affirming and analysing, the ethical aspect of the constitution of human agency, that is, of agency as constituted by its responsibility for a plurality of others, in other words, of political agency.

Levinas spent his philosophical life endeavouring to convince his readers that whatever our mentality might be, it is always already, continuously, and decisively tampered with by the other. This tampering is not in the first place the otherness that consists of a different language, physiognomy, cultural reference, or nationality but rather a tampering by the radical alterity of the ethical imperative coming from the other that has its origin neither in the subject's position within the totalising force of history, nor in the cultural particularity of the subject.

Yet, as already argued, this discourse always has political overtones and political objectives, even when it is explicitly concerned with ontology and alterity. "Political" in this context refers to the relationships between the plurality of people, where these relationships are constituted by different kinds of power and have an influence on the fate of people's existence, in such a manner that could be susceptible to judgement in terms of justice. This circumscription is Levinasian in that it does not concern only the institutions of the State or those that in one way or another strive to impact on the exercise of State power (but certainly does not exclude these either), but concerns already the difficult task of deciding about the priority and nature of action due to all other people, as well as the effective realisation of this reflection in the world. If such is the use of the term "political", it is now important to reflect on the scope of the political: how far does the relevance of Levinas' thought stretch on alterity despite the totalising force of history, and on the non-indifferent ethical meaning in a world of indifferent cultural particularity?

In order to respond to this question, let us return to the two guiding problems of political history as exemplified by the identitary violence of Nazism and the indifference reflected in decolonisation. A superficial consideration of the historical manifestation of Nazism already shows that although it is a form of nationalism and as such ideologically attached to a particular soil and blood, the energy of such a nationalism very quickly gives it an international momentum. That the identitary violence of Nazism had international and even global consequences hardly needs to be argued. But it is important to insist on the fact that even though this 
problem is initially nationally situated, it is an event of international, if not global, dimensions.

Since a lot has been written about Levinas and Nazism, I shall hence forth take it for granted that the ultimate horizon of the criticism of identitary violence is global and turn my attention to the question of decolonisation that we encountered at the beginning of this Part in the guiding citation (page 33, above). It is also important to examine Levinas' position on decolonisation (in as far as it is permissible to construct it from the very few texts on the theme), since one's first impression is that he writes about decolonisation disapprovingly and thus implicitly supports the idea of Europe's cultural superiority. But what does a closer look reveal?

\section{Decolonisation, colonisation: FIGURES OF THE GLOBAL}

From our guiding citation, it appears that it is of some importance to Levinas that the historical process of decolonisation be qualified as political. In order to appreciate what the political stakes are for him in decolonisation, we have to examine his declarations concerning decolonisation and colonisation - all of which are from his later philosophy.

In his only other usage of the term "decolonisation", 2 Levinas criticises the non-specified proponents of a non-specified anti-colonial discourse in the following terms

"[o]ne reasons as if the equivalence of cultures and the discovery of their multiplicity [foisonnement] and recognition of their riches were not themselves the effects of an orientation and an unambiguous sense in which humanity stands. One reasons as if the multiplicity [multiplicité] of cultures had always been rooted in the era of decolonization, as if misunderstanding, war, and conquest did not flow just as naturally from the proximity of multiple expressions of Being, the numerous assemblages or arrangements it takes in various civilizations. One reasons as if peaceful coexistence did not suppose that an orientation is traced in Being, endowing it with a unique sense [sens unique].",3

The triple parallel helps us to equate or at least to associate decolonisation with the idea of the equivalence of cultures and their peaceful coexistence. But all three of these elements are suggested by Levinas to be secondary to and dependent on "an unambiguous sense", "an orientation that endows a

2 The other two being the guiding citation and the remark about Lévi-Strauss in EL (both cited above).

$3 \mathrm{HO} 23 / \mathrm{HH} 39$, translation modified. 
unique sense" and it is only since this is now forgotten in the anti-colonial discourse, that one reasons as if the multiplicity of cultures always coexisted in this peaceful manner associated with, or believed to be possible in, the contemporary era of decolonisation. Over against this opinion, Levinas implicitly claims an original plurality of human cultures, as well as a non-peaceful existence between them; cultural plurality (he implicitly claims) is naturally coordinated by incomprehension, war and conquest. Levinas' point - which is also the point of his later philosophy - is that the recognition of cultural diversity in the contemporary practice and discursive support for decolonisation, betrays an implicit acceptance of a non cultural specific orientation to the plurality of cultural expressions.

Decolonisation thus stands for two things in Levinas' mind: (1) the historical fact of a plurality of cultures, without common denominator and (2) a discourse in which recognition is given to the respective values of each of these. Of course, most often this discourse is "atheistic", i.e., conducted in oblivion of the unique and one-directional meaning (sens unique). The object of his criticism is neither the fact of the plurality of cultures, nor their recognition in the political form of decolonisation, but that which, to his mind, would be a naïve forgetfulness of that which makes the claim to the possibility of peaceful coexistence between cultures possible. A celebration of diversity without consideration for an orientation to that diversity amounts to a provocation of incomprehension, war and conquest. This seems to me to be Levinas' opinion, on all levels of human interaction. However, when one speaks of "decolonisation" it is the relation between constellations of States that is evoked. I allow myself to refer to this level or reach of application of Levinas' conviction as the global.

It would be possible to expand our understanding of what Levinas has in mind with the political event of decolonisation by an examination of his use of the semantic field of colonisation, coloniser, colony, etc. Although these words are more frequently used in his work than decolonisation, this doesn't amount to a full exploration of the colonial phenomenon. My intention is not to force his remarks on this theme to form a system, but to throw light on the current subject by reference to the four most important of these remarks. From the outset it should be mentioned that the words colony, coloniser, etc., are completely absent from Levinas' earlier philosophy, in fact, they appear for the first time in the 1964 essay "Signification and sense", that later formed the first chapter of Humanism of the other and from which the notion of decolonisation has been cited twice. In each of the cases that will be examined now, something will be added to our understanding of Levinas' idea 
of colonisation, but something will also be revealed about the manner in which he opposes a facile discourse of decolonisation and the rehabilitation of a universal reference for judgement.

Referring to Merleau-Ponty's conviction that, when a universal point of judgement of cultures or a common grammar is abandoned, universality can only be lateral, Levinas explains:

"Such a conception of universality translates the radical opposition, characteristic of our times, against cultural expansion by colonization. Culture and colonization do not go together [se sépareraient foncièrement]. ${ }^{, 4}$

And thus expands on his impression of anti- or decolonising discourse: the essence of his concern is not decolonisation as such, but the abandonment of the idea of a universal judgement. This becomes even clearer when Levinas reconstructs the tradition of Western thought, from Plato to Léon Brunschwicg, as characterised by the attempt of "purifying thought of cultural alluviums and language particularisms" and by situating its own dignity in "liberating the truth from its cultural presuppositions". But since in this tradition there lurks the danger of committing violence and exploiting people in the name of such a liberation, philosophy had to unmask such hypocrisy and this had the effect of inversing the tendency of the venerable tradition: philosophy had to

"show that significations arising on the horizon of cultures, and even the excellence of Western culture, are culturally and historically conditioned. So philosophy had to join up with contemporary anthropology [ethnologie]. Behold Platonism defeated!"6

It is of crucial importance to note that Levinas shares the criticism of violence associated with the (hypocritical) use of an ideology of emancipation that is nothing other than exploitation and violence in the name of universally valid values. ${ }^{7}$ In our later discussions of Levinas' response to

$4 \mathrm{HO} 37 / \mathrm{HH} 59$.

$5 \mathrm{HO} 37 / \mathrm{HH} 59$

$6 \mathrm{HO} 37$ / HH 59. It is when Levinas subsequently (in HO 37 / HH 59) continued his line of thought by attributing this victory over politico-cultural Platonism to the generosity of Western thought, that he exposes himself to the ethno-centrist criticism developed by Bernasconi (see discussion in Chapter $6, \S 1$ ).

7 Despite appearances then, Levinas does not at all lament the decline of Europe as a global power, of "the Platonic privilege, until then uncontested, of a continent which believes it has the right to colonize the world" (DF 292 / DL 407). Rather, he seems to condemn this "entitlement to colonise" in terms that show some affinity with that of Sartre when the latter described colonialism as a system (see "Le colonialisme est un système" [1956], in Situations V. Colonialisme et néocolonialisme. Paris: Gallimard, 1964, pp. 25-48). According to Sartre, colonialism is a unificatory system in that the significant part of the advantage of the inter- 
the down-side of the loss of a point of judgement of the plurality of cultures, we shall see that Merleau-Ponty will serve as an important aid to understand the manner in which "philosophy joined up with contemporary ethnology" (at least in Humanism of the other). Also if this alliance between philosophy and ethnology amounts to a victory over Platonism, Levinas counters by formulating the objective of his own philosophical project as a support for a kind of Platonism. ${ }^{8}$

In "Signature" Levinas links this Platonism and its possible exploitative abuse explicitly with Europe and the history of colonisation:

"In spite of his intellectualism and his conviction about the excellence of the West, Husserl has thus brought into question the Platonic privilege, until then uncontested, of a continent which believes it has the right to colonize the world."

Here again something is said about the overcoming of this assumed privilege: "Husserl sought to contest that the place of Truth is in Representation." ${ }^{10}$ Levinas' own rehabilitation of Platonism will thus be one that passes through that which is learned from Husserl, namely, that what is decisive is not on the level of explicit formulations or statements

action between the colonising State and the colonised regions is concentrated in the colonising country (p. 35). From this simple principle the form of existence and the mentality of both the colonisers and the colonised are shaped (p. 40, 43), since, as Sartre explains: "the colonist is created just as much as the native is: he is created by his function and by his interests" (p. 43). Levinas would have reformulated this such that the history of colonial power imposes its totalising and identity-creating force on those that participate in it.

8 When we work through my criticism of Levinas' project later on, I shall point out the irony in Levinas' figurative usage of the term "coloniser" in his explanation of Platonism: "the world of significations precedes the language and culture that express it; it is indifferent to the system of signs that can be invented to make this world present to thought. Consequently, it dominates historical cultures. [...] there would exist a culture that consists of depreciating purely historical cultures and in a certain way colonizing the world" (HO 19 / HH 31, my italics). My criticism will consist, amongst others, of showing how the letter of this text turns against the spirit of the text. But before doing so, it could be noted that one finds the same set of ideas, affirmed in another way, in the notes that Levinas took for writing "Signification and sense" (Chapter 1 of $\mathrm{HO}$ ) and that are now available under the title "Sens et signification" in the section "Notes philosophiques diverses" in the newly published Oeuvres complètes (volume 1). The ninth point apparently establishes an equivalence or relation of mutual implication between four terms: "9 ${ }^{\circ}$ AntiPlatonism. Disorientation. Equivalence. Decolonisation." (CdC 263).

9 DF $292 /$ DL 407.

10 DF 292/ DL 406. 
(i.e., representations) of truth, but on the level of pre-representational "mentality" or intelligibility. ${ }^{11}$

In a discussion of the "bad consciousness and conscience" (mauvaise conscience) of Europe in "Peace and proximity", Levinas takes up the question of the arrogance of European reason. The latter would have promised the world peace and freedom as the consequence of its pursuit and expansion of universal reason, but it is difficult to believe in this promise after

"its millennia of fratricidal struggles, political or bloody, of imperialism, scorn and exploitation of the human being, down to our century of world wars, the genocides of the Holocaust and terrorism; unemployment and continual desperate poverty of the Third World; ruthless doctrines and cruelty of fascism and national socialism, right down to the supreme paradox of the defence of man and his rights being perverted into Stalinism."12

It is not clear if Levinas intends to place the responsibility for the terrorism and genocides (of the twentieth century), for instance, also on Europe, or if he means that Europe merely failed to prevent these catastrophes. However, what is sure is that for Levinas these events decisively question the centrality of Europe and its culture in human history. This questioning of a supposed European centrality is not simply referred to by Levinas, but he evidently subscribes to it, at least in as far as it strikes at the arrogance of European reason (as he portrayed it). Hence the understanding he shows for "the affirmation and championing of specific cultures in all corners of the globe". 13 But in accordance with Levinas' philosophical aim of salvaging the possibility of judgement of cultures, he points out the irony that the equality of all cultures is exactly claimed in the name of universalism that typifies the ageold European strategy for the encounter with the other. But now - and we shall later see how Levinas justifies this speculation - this universalism is not the child of reason, but "exaltation of a logic other than that of Aristotle, of a thought other than civilized". ${ }^{14}$ What could the origin of such a different questioning be? It could be situated in "remorse fed by the memory of colonial wars and the long oppression of those once called savages, a long indifference to the sadness of a whole world". ${ }^{15}$ This regret would then be an

11 It is also what Levinas claims in Alterity and transcendence to have learned from Lévy-Bruhl: his reflections on representation in the "mentalité primitive" (amongst others) encouraged Levinas "to reflect on thought freed of all representation [pensée libérée de la pure représentation]." (A\&T 129 / AT 137).

12 A\&T 132 / AT 139.

13 A\&T 132-133/AT 140.

14 AT 140.

15 A\&T $133 /$ AT 140. 
element of European culture by which that very culture's supposed centrality is disputed on the basis of the denunciations of its violence. It should be clear from this context in which the word "colonial" is used, that it serves as a metonymy for the whole series of violent consequences of what Levinas considers to be the arrogance of a particular form of European reason. As could be derived from the list of catastrophes evoked by Levinas, his issue is with the consequences of political organisation of societies and the relations between groups of human beings, from the local to the international and the global. We learn already from the fact that Levinas is interested in the suffering of the people concerned (much more than in the inherent value of their respective cultures), what his point of entry will be for the rehabilitation of an ethical Platonism: the fragility and mortality of people - wherever they may be. It is only in the name of the meaning of people's suffering that the violent effects of a dominating culture (and for the same price, the violent plurality of cultures) may be contested and re-directed.

It is of importance to note that this perspective is also echoed by a reflection on colonisation in one of Levinas' Talmudic readings. In Quatre lectures talmudiques Levinas explains that the ancient Israelites did not take possession of the Promised Land like a territory that is colonised, but took charge of it in order to construct a just society on it. Having stated this principle, Levinas then asks if that is not the principle by which all conquerors and colonialists justified their actions (just as we have seen him ask in the texts cited from Humanism of the other $\left.{ }^{16}\right)$. His answer is that for those who take possession of a territory under the authority of the Torah, a different orientation is valid:

"to accept the Torah is to accept the norms of a universal justice. The first teaching of Judaism is the following: a moral teaching exists and certain things are more just than others. A society in which man is not exploited, a society in which men are equal $[\ldots]$ is the very contestation of moral relativism. What we call the Torah provides norms for human justice. And it is in the name of some national justice or other that the Israelites lay claim to the land of Israel.,"17

Whether one accepts Levinas' argument here or not, what is important for the current argument is to note that he refuses a Jewish nationalism that is anchored in its territory or in ethnicity. Its true anchor, or rather,

16 The fact that the Talmud contains the same teaching as Levinas' philosophy is in my judgement not sufficient proof that he is merely translating Jewish convictions into Greek. The influence is probably stronger in the inverse direction: from philosophical ideas to his interpretation of the Talmudic text. Besides, his philosophical convictions are strong enough to stand (or fall) on their own.

17 NTR 66/QLT 141-142. 
its true orientation that points beyond all relativism is universal justice, equality of people ${ }^{18}$ and the refusal of exploitation of people. Thinking of the previous discussion on atheism and monotheism, it should strike the reader as interesting that the essence of Judaism has, according to Levinas in this passage, nothing to do with a conviction concerning the reality of a transcendent entity called God. However, God is not absent here, since this transcendent orientation, this single imperative, is God. ${ }^{19}$

It should be abundantly clear from this discussion of one passage on decolonisation and four on colonisation in Levinas, that in each case the focal point is the refusal of a cultural arrogance of whatever nation or group that imposes itself by whatever means as superior to others and thus as measure for the validity or value of others. But at the same time, Levinas refuses to abandon cultural plurality to an indifference in which no judgement would be possible. In this double concern - for which the issue of colonisation and decolonisation serves as excellent introduction - Levinas' care about the relation between the self and the other is extended to the question concerning the relation between large groups of people - States or cultural groups. It is impossible to miss that this is a geopolitical perspective on Levinas' most precious concerns. ${ }^{20}$ It is equally impossible to deny that what is at stake for Levinas in

18 The intention of the word "homme" is probably to refer to all human beings.

19 In the name of this God, certain tendencies in the contemporary State of Israel may be critically exposed - in a context where Levinas speaks of the undermining of the ideals of Judaism in the young State of Israel: "As for Israel, by dint of insisting on its significance as a State, it has been entirely reduced to political categories. But its builders found themselves abruptly on the side of the colonialists. Israel's independence was called imperialism, the oppression of native peoples, racism." (DF 222 / DL 311). From the context it seems most probable that Levinas refers here to criticism from the inside.

20 Robert Bernasconi has argued, albeit with a different strategy, for the mutual relevance of globalisation and Levinas' ethics in "Globalisierung und Hunger" (in Im Angesicht der Anderen. Levinas' Philosophie des Politischen. Pascal Delhom and Alfred Hirsch (eds.). Zürich and Berlin: Diaphanes, 2005, pp. 115-129) and his essay could certainly be considered as support for the point I am advocating here. I do differ from him when he states that globalisation is to be understood as the overcoming of spatially structured limitations and that it is therefore necessarily in conflict with what is human (p. 122). It cannot be contested that action is concentrated in the locality of the acting body, but it is not correct to consider the overcoming of this natural limitation as an infringement on our humanity. What is human is determined by, amongst others, the technology of a certain era - this has been the case ever since the dawn of humanity. The enhanced technical capacities of our era augment our capacity to do harm and good on a previously unimagined scale. Yet, I do agree that the growth in power, sophistication and complexity of technical processes exposes the process of decision making to greater uncertainty and risk. That this uncertainty has in our era the overwhelming tendency to do harm, is unfortunately true. 
each of these cases is not the vibrancy or equality of cultures, not even the interaction between a subject and a cultural other, but the suffering of countless others with whom the ethical subject would never be in direct contact. The bad conscience - a key term in Levinas' later philosophy for evoking the proximity of the other to the self - is clearly shown to emerge also from the memory or knowledge of wars, oppression and "a long indifference to the sadness of a whole world." (cited above). That this immediately also raises the question concerning the relevance for Levinas' philosophy of ethicity of the means by which people are oppressed, or the means by which one could gain knowledge of such oppression and the means by which one could hope to oppose such oppression, will be thematised later, for it will first have to be argued that such considerations concerning means are not secondary to reflection on the meaning of the ethical. But let it for now at least be suggested that, if we accept Levinas' underdeveloped idea about the global reach of the ethical, and thus of responsibility, it would in one form or another naturally have to lead to reflection concerning the means that mediate distant people, in other words the technical system of the world as we have it today.

\section{FOR A GLOBALISED WORLD}

Once this international and global dimension of the problems with which Levinas aspires to engage has been noticed, the insufficiency of a response to them that would only concern the politics of the State becomes evident. By making this claim, it is of course not denied that the reflection provided by Levinas on the liberal State, the State of which the legislation is continually challenged in the name of justice, is an essential part of the reflection on politics. My point is rather that in Levinas' thinking concerning matters political, most often the politics of the State is taken as its largest horizon and the presentation of the international or global dimension of the political remains underdeveloped. This situation invites his readers to contemplate the inevitable global dimensions of the political from a Levina-

By commenting on Levinas' response to Kant's practical philosophy, and in particular the essay on "Perpetual peace" (that is situated in contemporary geopolitical debates concerning the justification of war in the name of human rights), Alfred Hirsch also assumes and demonstrates the capacity and indeed the aptitude of Levinas' philosophy to be confronted with its global relevance. See Alfred Hirsch, "Vom Menschenrechte zum ewigen Frieden. Grenzgänge zwischen Kant und Levinas", in Im Angesicht der Anderen, op. cit. pp. 229-244. 
sian perspective and this, by starting from the sparse reflections in his work that lend themselves to such a reflection.

A first way to examine the case for such a global Levinasian view would be to consider the numerous places in which Levinas lists the human catastrophes of his lifetime. Speaking of the century of his lifetime, Levinas summarises:

"This is the century that in thirty years has known two world wars, the totalitarianism of right and left, Hitlerism and Stalinism, Hiroshima, the Gulag, and the genocides of Auschwitz and Cambodia." ${ }^{21}$

And elsewhere,

"[t]he world wars (and local ones), National Socialism, Stalinism (and even deStalinization), the camps, the gas chambers, nuclear weapons, terrorism and unemployment - that is a lot for just one generation, even for those who were but onlookers. $" 22$

From these and similar passages, it should be clear that when Levinas contemplates the catastrophes of his era that they are not simply phenomena that took place in different countries and that they could for that reason be said to constitute an international phenomenon; rather, most of them are international and sometimes global phenomena and deserve to be reflected on in that dimension, since they would be simply unintelligible without this perspective. Furthermore, as pointed out already in Chapter 1, it is remarkable that in these passages where Levinas lists the most spectacular catastrophes of his century, what happens in far away places is of ethical significance for a Levinasian subject of responsibility, even if he/she is not directly affected by such events.

This can be shown to hold also in the rare texts of direct political commentary from the pen of Levinas. ${ }^{23}$ He can hardly be more explicit about this than when he comments on the novelty introduced by the scientific and technical development of atom bombs and the threat of sparking nuclear war by the unleashing of unheard of powers of nature in "On the spirit of Geneva" (1956). ${ }^{24}$ Since the force of nuclear attack involves a human-made force that transcends the power of States that would normally be the ultimate instance of protection of people against the forces unleashed by humans,

21 ENT 97/EN 107.

22 PN $3 /$ NP 7.

23 An overview of important themes of political interest in Levinas' work is given in De l'éthique à la justice 135-136.

24 Caygill gives a detailed analysis of this essay in Levinas and the Political, op. cit. pp. 69-71. 
Levinas can summarise: "Politics is replaced by a cosmo-politics that is a physics." ${ }^{25}$ The irony with which Levinas exposes the superficiality that international political action can have, takes nothing away from the affirmation of the technically mediatedness and global dimension of this issue. This seems an elementary fact to state, but it means that if Levinas doesn't want to leave politics to its own devices (as argued for in Chapter 1), he has to aspire to have something to say for such a cosmo-politics. And he does, in fact, open such a discourse by exposing the false start of such a cosmo-politics, namely by being the response to a "physics", that is, by being nothing more than an attempt to re-arrange the blind forces of nature as remobilised by human effort. Cosmo-politics is in this sense (and in the terms exposed in Chapter 2) an "atheistic" enterprise, to which Levinas' philosophy could exactly contribute a recall to orientation by ethics. ${ }^{26}$

Similarly, in an extension of his later meditation on the injustice inherent in the obstinate claim to one's own position in Being, Levinas asks:

"My place in Being, the Da- of Dasein - isn't it already usurpation, already violence with respect to the other? A preoccupation that has nothing ethereal, nothing abstract about it: the press speaks to us of the Third World, and we are quite comfortable here; we're sure of our daily meals. At whose cost? - we my ask."27

Such a remark about the fact of being put to question by the misery of far-away others would be completely unintelligible in the context of Levinas' ethics of the face-to-face and of proximity, if one doesn't accept

25 IH 144.

26 A very noteworthy attempt to make Levinas' thoughts on ethics useful for a critical engagement with cosmopolitan political thought (in the usual sense of the term), is that of Eduard Jordaan in "Cosmopolitanism, freedom, and indifference: a Levinasian view" (Alternatives 34/2009, pp. 83-106). By deploying a Levinasian critique, Jordaan argues: "that despite the moral concern for the world's poor which cosmopolitan thought exhibits and seeks to inspire in the rest of us, the writings of some influential cosmopolitan authors contain elements that strain against greater concern for the world's poor, and, more worryingly still, might be said to entrench and even engender indifference towards the world's poor." ( $p$. 101). The result of this argument is not a "refutation" of cosmopolitan political thought, but rather a Levinasian call to greater sensitivity for the risk of indifference lurking in the limitation of the responsibility of political agents, the suppression of otherness of the other and the weaknesses in emphasising equality in cosmopolitan theory (p. 84). By restricting his use of Levinas for such a critical exposure, Jordaan shows a "negative" way to use Levinas for argumentation in global political relations. Whereas the validity of such a Levinasian approach is not questioned, it should be noted that my critique of Levinas' idea of infinite responsibility and the need to reflect on the means of responsible action (Chapters 6 and 7) will set limits to the usefulness of such an approach.

27 A\&T 179/ AT 180, translation modified. 
that for Levinas my injustice (that is, the manner in which my existence is violently integrated with the existence of others) and justice (as response to this injustice of my existence) is mediated and constituted even on a global scale. To put it bluntly, in Levinas' example, that which makes the questioning of my right to be a matter that is not abstract but very concrete is not the proximity of the other, but the newspaper or television (i.e., the socio-technical system of news reporting) through which, by mediation of which, I am questioned by the far-off other.

One could equally consider the notion of election and the particular universal interpretation that Levinas gives to it in his writings prepared for a Jewish context. As will be explained in detail in Chapter 4, the particularism of Judaism, the election of Israel, is in Levinas' view the universal asymmetry of all subjects faced with the others and thus also a figure of the obligation to respond to the suffering of all others. The global presence of both ethical agents and the suffering others seems to fit in the extension of Levinas' idea of election.

Two themes of Levinas' thought directly extend his ethics to an international political dimension through their claim to universality and desire for universal validity: human rights and humanism. Since the Universal declaration of human rights (1948), all discourse on human rights has to deal with this dimension. Having devoted a study previously to Levinas' thought on human rights, I shall not look at this issue in this book. ${ }^{28}$ There is also more than a mere affinity for the global dimension of ethics in the theme of humanism that is used in both Levinas' philosophy and his writings prepared for Jewish readerships. That humanism tends to be a discourse that should at the very least be defined by its claim to an ethical relevance for the whole of humanity, warrants the attention that will be devoted to it in the whole of Part 2 of this book.

Apart, then, from explicit references to international political issues one needs simply to reflect on key notions from Levinas' philosophy in order to realise that it is in vain that one avoids the global dimension thereof. Peace, if it is to retain any correspondence with what is commonly understood by it, that is, what is commonly yearned for by people in a state of war or violent conflict, cannot be conceived of independently from international relations - and this, even if one doesn't reduce reflection on peace to the subtle balance of warring parties, but instead refers it to the

28 See my "The quest for justice versus the rights of the other?", in In Levinas' trace. Maria Dimitrova (ed.). Sofia: Avangard Prima Publishers, 2010, pp. 101-111. 
alterity of the other, that would be more original than war. ${ }^{29}$ Food for one's hungry neighbour is a simple idea, used by Levinas, but one that obviously refers to the establishment of nutritional security and what is today called environmental justice - that is, if it is not reduced to a simplistic and moralistic handing out of sandwiches as alms (which of course doesn't exclude the sharing of sandwiches).

As has already been suggested at the end of $\S 2$ (but will be argued in detail in Chapter 7), once it is affirmed within the Levinasian context that the means of ethical conduct is significant for ethics, then the entire question regarding the "how?" of the efficient use of means, the question of the just use of means, stretches as far as the effect of the use of these means. And since ethics involves all human action, ethics thus covers all technical action, i.e., all action as it is transformed, specialised or augmented through the implementation of technical means. For this reason the question concerning the justice done to ethics is as big as the technical systems needed to realise justice or submitted to the evaluation of justice - which is the global scale. The global dimension of international relations, of media, of the economy, of marketing, of cultural exchange, of banks, transport and pollution, etc., forms the horizon within which justice should be thought through and pursued.

That this is a valid conclusion for Levinas' ethics could also be shown by transposing the question to the register of ontology and alterity. The Saying is the Saying of the Said, claims Levinas, which means that the ethical stretches as far as the ontological. As far as there is a human network of capability of "I can", so far is this capability questioned by the ethical. As far as there are beings that understand Being, but do so in interaction or exchange, albeit mediated by technical means, there is an exchange of the logos, or an interference in the logos of understanding that the different individuals carry. This is of course not, or not always on an explicit level, but very often implicit, or on the level of mentality (in the sense explained in Chapter 2). Furthermore, I can see no way in which there could be a limit in principle in the consideration of the thirds; it seems inevitable to conclude that the calculation of justice, as presented by Levinas, should at least in principle stretch as far as all the thirds, that is, the entire humanity.

29 A development of the theme of peace in Levinas from a point of view that supports my "global" perspective can be found in the already mentioned essay of Alfred Hirsch, "Vom Menschenrechte zum ewigen Frieden." op. cit. 
To conclude, it is unjustified and undesirable to think of Levinas' philosophy principally in terms of ethics (as argued in Chapter 1) and when thought of politically then it is unjustified to restrict reflection to the local, the neighbourhood or the State context. The ultimate horizon within which Levinas' ethics and theory of justice presents itself to be thought through is that of the entire humanity and the international and global relations that bring people into interaction. That Levinas didn't devote too much space to developing his thought in this direction cannot be considered an invalidation of this conclusion. Rather, his negligence in this regard should be the subject not only of our criticism, but also of our continued efforts to appropriate and engage with his thought. At the same time, my point is not to reduce the political implications of Levinas' thought to the global. Responsibility for a global world does not exclude responsibility for the local, but entails at least in principle an openness to the biggest scale in which to situate all reflection on responsibility and all evaluation of responsible action.

This international or global horizon of ethics is of course not an a-temporal aspect of ethics or implication of Levinas' thought on the ethical - the inevitable international or global fabrication of our very lifeworld and of the political structure of contemporary life is simply the condition of our contemporary world. This is true not only for people living in the advanced industrial regions of the planet, but practically for everybody. Since the creation of a world of networked societies, the global dimension is rather the rule than the exception: practically all societies are bound up in global networks and, as Manuel Castells has shown with perspicacity, marginalisation is also a form of integration into the global network. ${ }^{30}$

The historical situation in which the a-historical validity of the ethicity of Levinas has to realise itself, is implied in the very choice of the word "responsibility" for ethicity, since this prospective understanding of responsibility as the major figure for the reflection on obligation is itself the child of an era of unparalleled complexification and thus uncertainty of the causal networks of human action. Although ethicity as such is an a-historical, context-independent signification, for Levinas, ${ }^{31}$ the

30 See Manuel Castells, "The rise of the fourth world: informational capitalism, poverty, and social exclusion", in End of millennium, Oxford: Blackwell, 1998, chapter 2 .

31 However, since the ethical is only as old as the human, the question of ethicogenesis might be interesting to explore. One finds a theory of ethico-genesis in the work of another critical Heidegger student, Hans Jonas. In his work too, one has 
world in which one has to weigh the responsibility due to a plurality of others, the world in which one has to be just, is historically constituted. This might seem a very basic point to make, but with all of Levinas' insistence on the context-independent signification of the alterity of the other, this fact tends to fade into the background, not only in his own work, but also in that of a good number of his commentators.

Typical of this contemporary political condition is the frequent, constant and complex contact between people of different cultural and therefore ethico-evaluative backgrounds. ${ }^{32}$ A phenomenon that is probably as old as humanity, in our time it has taken on proportions probably never before experienced. That this is due to immigration, travelling, the increasing density of commerce, military activity, refuge seeking, sport and cultural exchanges, all of these enforced by the development of technologies of transport, of communication and of the diffusion of cultural products, could be considered general knowledge. A mixture of old and new forms of misery, and thus sources of ethical appeal and of political demands of rights or claims to recognition spontaneously ensue from this situation. At the same time claims for the universal institutionalisation of, and at worse the widespread lip-service to, a fairly established set of human rights and the establishment of international agreements or institutions of justice, on the one hand and the spread of a relatively homogeneous economic model over the globe, on the other hand, enhance the compatibility and translatability between different cultures, sometimes creating the impression of homogenising cultural plurality to dialects of one language and seeming to limit the differences of a process of multiple modernities. ${ }^{33}$ Once it is recognised that people are caught in the tension between such diversifying and unifying forces and the values they enforce in their lifeworld, one could, from this perspective, return to

to distinguish between two theories of responsibility - the one ethicity, the other responsibility for a particular context or era of human history - see my "Responsibility in an era of modern technology and nihilism. Part 2. Inter-connection and implications of the two notions of responsibility in Jonas", in Dialogue. Canadian Philosophical Review 48/4, 2009, pp. 841-866.

32 This fact, together with the preceding line of argumentation, draws the direction in which I shall attempt to think about political responsibility very close to the "social connection model" of responsibility developed by Iris Young in "Responsibility, Social connection, and Global labor justice", in Global Challenges. War, Selfdetermination, and responsibility for Justice. Cambridge and Malden: Polity, 2007, pp. 159-186.

33 See especially Shmuel Eisenstadt, "Multiple modernities" in Daedalus 129/1, 2000, pp. 1-29. 
Levinas to enquire about his contribution to ethics in such a world. This is what will be done in Part 2 of this book.

But before we turn the page, let the preceding reflection serve to bring a final articulation to the reference to a "globalised world" in the title of the book. There is in this book no ambition to make a contribution to the state of the debate about the status of globalisation or the forms of modernisation. "Globalised" is the term that marks the intention to engage as well as is possible with the world in its current situation and of which I have just recalled some salient traits. It is my intention to emphatically situate my reflection on Levinas, within this world. This is, as far as I am concerned, part of the meaning of doing justice to responsibility. Reflection on the genocide in the Second World War and on the process and intellectual interpretation of decolonisation is still of great importance to this world, but I explicitly resist a reflection that is so philologically mesmerised by the texts of Levinas' arguments, that it doesn't dare to venture further to contemplate the contemporary relevance thereof. Even more important - and that is the second justification for the choice of placing the "globalised world" in the title - is the effort to avoid the moralistic and therefore context-alien appropriation of Levinas for the contemporary world. That a discourse about globalisation and ethics can equally succumb to moralization goes without saying. Whether I succeed in avoiding this, my reader will judge. 



\section{PART 2}

\section{Levinas' post-anti-humanist humanism and after}

As a way of accessing the guiding question of this Part, I combine the two uses of the term humanitas indicated by Aulus Gellius - either as philanthropia or as paideia ${ }^{1}$ - to give an approximation of the idea of humanism. Accordingly, humanism concerns schooling - in particular schooling in what are considered the most excellent cultural products of a particular group, in other words schooling in the authoritative tradition - with the intention of cultivating people that would live more virtuously with others. Often such an intellectual position is accompanied and enforced by a cultural politics that involves the study of this tradition and the promotion of this culture, with the claim that it would contribute to moral progress and serve as an antidote for corrupting attitudes and uncivilised behaviour. The declared intention is to open a way for laudable (or humane) interaction with all people and it is exactly this humanist study that would give insight not only into what it means for some people to be human, but what it means for all to be human and what it means to be truly human in a normative sense.

This approximation ${ }^{2}$ suffices to suggest that if Levinas, at a certain stage of his intellectual trajectory, presents his own philosophy as a humanism -

1 Aulus Gellius, The Attic nights, Vol. 2. London: William Heinemann (Loeb classical library), [1927] 1982. Philanthropia is indicated by Gellius to be the common, but incorrect, meaning: "signifying a kind of friendly spirit and good-feeling towards all men without distinction". The proper, Latin meaning corresponds with paideia, which is the exclusively human pursuit of "education and training in the liberal arts". (Book XIII, xvii, pp. 457-458).

2 I insist on the orientational value of this approximation; any proper encyclopaedia of the history of ideas will reveal the complex history of cultural practices and attitudes that have been named "humanist". 
albeit then as a "humanism of the other" - then we can expect not only a claim to the universal validity of the responsibility at the core of his concern for the other, but also that we would find some indication of the kind of humanist culture, or an equivalent thereof, that would support this responsibility. Such is the working hypothesis that will be put to the test in this second Part - to be partially confirmed and partially amended and discarded. Thematically the hypothesis links Part 2 of this book, not only to the theme of politics in the Introduction and the question concerning the global range of responsibility in Part 1, but also with my own elaboration on responsibility and the means by which responsible action is supported as detailed in Part 3.

Since the diversity of humanisms and claims to the meaning of "real humanism" cannot easily be harmonised into a few general theses, it would require a particularly sophisticated knowledge of the historical development of the different species of humanism to do justice to a comparison between them and the work of Levinas. I don't claim such competence and shall opt for a different approach that would be equally legitimate for the explorative purposes of the current study. In the centre of the current study will be an examination of the use that Levinas has made of the term "humanism" and "anti-humanism". 3

Yet, even though this is a completely reasonable question to pose to the works of Levinas, it could hardly be said to be an evident question to put to it. Were it not for the fact that Levinas gave the title Humanisme de l'autre homme, "Humanism of the other (human)", to a small selection of essays in 1972, it would certainly have been less obvious to enquire about humanism in his thought. The reason for this is the fact that the question of humanism is hardly present in his work. A consultation of the Levinas concordance 4 shows that no use is made of the word "humanism" in Existence and existents or in Totality and infinity. It is barely given more than a passing mention in Otherwise than Being, and in his other books it is very infrequently used - the notable exceptions, namely the last two essays of Difficult freedom and the book that carries the word in its title, Humanism of the other, will be brought to our attention later. Of all these disparate references, it is certainly not irrelevant to

3 Since the issue here is the way in which Levinas' develops his own position, and not a reconstruction of all the implicit and explicit debates with those thinkers of the "end of man", I use "anti-humanism" in the way that Levinas does and thus without any claim from my side either of there being a unified position held by a number of authors, or reducing any of them to an anti-humanism.

4 Cristian Ciocan and Georges Hansel. Levinas concordance. Dortrecht: Springer, 2005. 
note that more pertain to anti-humanism than to humanism and in total a larger volume of discussion is set aside for presenting Levinas' agreements with anti-humanism than with humanism, or his criticism of antihumanism than his actual support for humanism.

If we suspend for a moment the two exceptions (alluded to above) to this general lack of interest in matters of humanism or even anti-humanism, one finds in the entire works of Levinas so little that is explicitly developed on humanism and anti-humanism that it cannot be credibly systematised. However, the most important theses retained in his works can be rendered fairly easily:

(1) In both the Judaic texts and the philosophical texts the heart of humanism is the human being and its value, its liberty and its material needs. This human being is in the first place the other human being. ${ }^{5}$

(2) Of pre-modern, Greco-Roman humanism we learn that it was assimilated partially by Christianity and Judaism, and is an element that facilitates dialogue between these two religions. ${ }^{6}$ It is at the same time the required defence of society against revenge and violence, but can lose its vigilance for instituted violence. ${ }^{7}$

(3) In as far as the philosophy of humanism is concerned, we hear about its socialist ${ }^{8}$ or Marxist ${ }^{9}$ versions, for which Levinas shows some support. The same affinity is expressed with regard to its existentialist articulation in Sartre ${ }^{10}$ or in Bloch's neo-Marxist reformulation. ${ }^{11}$ Sartre fares better on the all-important issue of human freedom than does Merleau-Ponty. ${ }^{12}$ This support includes the criticism formulated against previous schoolish humanism ${ }^{13}$ and of bourgeois humanism by Althusser, ${ }^{14}$ and implies some criticism of Heidegger's apparent lack of attention to the material conditions of human existence. ${ }^{15}$ That Heidegger's thought is not humanist is claimed already for Being and time, ${ }^{16}$ but of course also for the ideas expressed in the

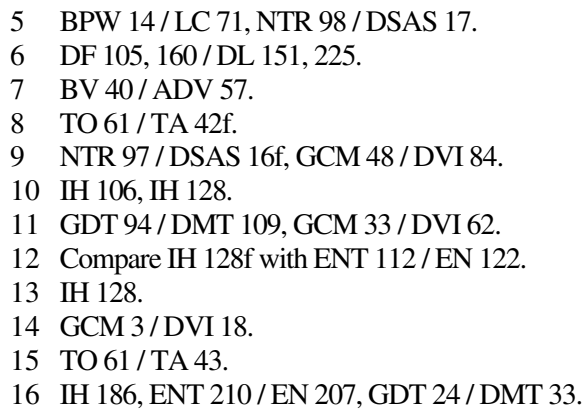


Letter on "humanism" ${ }^{, 17}$ and his later philosophy in general. ${ }^{18}$ Antihumanism is appreciated for its attention to human misery, ${ }^{19}$ for the decentring of the subject ${ }^{20}$ and to a certain extent for exposing what hypocrisy there might have been in humanist literature. ${ }^{21}$ However, it is criticised for its moral laxity and lack of orientation. ${ }^{22}$ It is associated with the death of God, the end of a certain idea of the human being and the play of language without final significance. ${ }^{23}$

(4) There exists also a special link between Judaism and humanism, ${ }^{24}$ and Judaism could be considered as the humanism of a demanding God. ${ }^{25}$ It is from Judaism that one learns in the first place about the humanism in which the other is the centre piece. ${ }^{26}$ Humanism can have the meaning of "humanitarianism" - it is, for example, appropriate to call the ancient institution of "cities of refuge" humanistic. ${ }^{27}$ The Torah and the study thereof could reanimate a humanism that has lost its vigilance. ${ }^{28}$

Taken in isolation, the single references in this catalogue of opinions regarding humanism and anti-humanism are hardly of any interest. Which is not to say that they are of no value. In their respective context these remarks make a contribution to the argument of the respective texts. Considered together, they indicate at least that Levinas showed some interest in the development of the debate about humanism and anti-humanism. However, in none of these instances is the issue a presentation or overview of humanism or a considered evaluation of whatever the main tenets of humanism might be. ${ }^{29}$

The picture changes somewhat if we turn our attention now to the texts that have thus far been left out of consideration: the two essays at the end of Difficult freedom and Humanism of the other. In doing so, it seems prudent to respect from the outset the fact that Levinas practices in them two distinct

17 GDT 24/DMT 33, 68.

18 PN 127f/SMB 10f.

19 OS $131 /$ HS 178.

20 OB 127 / AE 203, GDT 182 / DMT 213.

$21 \mathrm{PN} 14-15$ / NP 19, BV 32 / ADV 43.

22 GCM 49/DVI 86.

23 PN 4 / NP 8, ENT 61 / EN 72.

24 NTR 82/QLT 175.

25 DF 26/DL 46.

26 NTR 98/DSAS 17.

27 BV 42/ ADV 59.

28 BV 38/ADV 55.

29 This does of course not exclude the possibility of examining each of these remarks in detail, as I have done with the even rarer remarks by Levinas on ethnography or decolonisation in Part 1 of this book. But this will not be my approach here. 
discursive modes: in the first case we find a pedagogue that is concerned about the role of Jewish education in a secular (laïque) Western country and about the merits of Judaism as a religion - the writer is not insensitive to the philosophical ambiance in which he speaks about education; in the second case, the author is a philosopher who is concerned about the ethical, about finding the appropriate discourse in which to explore and advocate it, and who, while thinking, is inspired to a degree by his own understanding and practice of Judaism. One Levinas, two distinctive voices: Jewish pedagogue and French philosopher. Even though there are similarities in the two voices - as will be shown - the conclusions to be drawn from them are not identical. Since most of what has been catalogued above from the works of Levinas concerning humanism and anti-humanism can be related to these texts, I shall proceed by discussing first the two essays from Difficult freedom, before attempting a full commentary on Humanism of the other.

The first two chapters of this Part of the book are devoted to a careful exegesis and presentation of Levinas' humanism, where humanism is understood to provide a perspective on Levinas' main philosophical concerns in view of the question of the universal significance thereof (and of which Part 1 mapped the global, political significance). Accordingly, in Chapter 4 the idea of a Hebraic humanism and the opposition between the study of the Talmud and anti-humanism will be explored. Similarly, in Chapter 5 a detailed interpretation of the 1972 book, Humanism of the other, is worked out. Also, the thought exposed in that book will be situated in the development of Levinas' philosophical thought with respect to the influential views on humanism by such divergent contemporaries of Levinas as Sartre, Heidegger and Althusser. The main ideas of Levinas' later philosophy - as presented in the two preceding chapters - will be submitted to critical scrutiny especially with regard to the political implications thereof, in Chapter 6. By doing so, I expose my agreements and disagreements with Levinas and justify my quest of an understanding of political responsibility for a globalised world, after Levinas. 



\section{Chapter 4}

\section{Humanism and anti-humanism in Levinas' reflection on Jewish education}

Humanism is explicitly thematised and advocated in the last two essays of Difficult freedom, and this in two quite different ways: the first as a plea "For a Hebraic humanism" (1956), the second as a meditation on "Anti-humanism and education" (1973). The two texts, one concerned with a particular form of humanism and the other only with humanism after or through anti-humanism, share a number of important concerns. First, both are concerned with education and, in particular, the education of young Jews in the Jewish heritage or from a Jewish orientation. Second, this issue is responded to, at least formally, by an appeal to "humanism" (but the different articulations of the two essays will be pointed out later) and this in the face of the phenomenon of Jews integrating into the ambient Western cultures, especially by equating their Jewish morality with humanist ideas of the West. Third, in opposition to this tendency and in the face of the dissolution of Diaspora Judaism, Levinas proposes in both essays an education that is not merely religious education, but the transmission of competence in an entire civilisation or culture. This means not just the acquisition of a certain knowledge, but especially a practice, namely that of working through the Bible and Rabbinic literature, and where this practice links both with the rituals of the Jewish religion and the practice of ethics for the advantage of all people. Finally, in both texts the Hebrew Bible and the subsequent reflection on it in Rabbinic literature gives a privileged and decisive access to what the human being is. ${ }^{1}$

1 DF 275 and 284 / DL 383 and 395. 
If there is a distinctive tension or progression between the two essays, then this can to a large extent be attributed to a change in Levinas' attitude in associating Judaism with humanism. In order to appreciate this change with respect to the central reference to humanism, I shall now look more closely at the two essays in turn.

\section{1 “For a HEBRAIC hUMANISM"}

Against the background of Jewish assimilation and concerns about the desirability of learning Hebrew and the risk of imperilment that a $\mathrm{He}$ brew education might pose to the secular education (éducation laïque), Levinas suggests that Jewish education be rethought from the perspective of the meaning of Judaism in the contemporary world, that is, a world in which humanity is in question. ${ }^{2}$ It is, in Levinas' view, a Hebraic humanism that is required to reanimate Judaism in a manner that is relevant for the contemporary world. In order to understand this claim, one first needs to understand what is meant by humanism in general. Humanism might be a questionable term, as Levinas points out, but this much can be said for the purposes of his essay: humanism is

"a system of principles and disciplines that free human life from the prestige of myths, the discord they introduce into ideas and the cruelty they perpetuate in social customs."3

We have seen in Chapter 2 the importance of secular (desacralising) thought for Levinas, and the key role that it plays in his philosophy and social diagnoses - it is by attributing such a secularising quality to humanism in general, that Levinas derives the secular (laïque) quality of the Hebraic humanism that he advocates. This doesn't necessarily mean that for Levinas humanism can be reduced to its secularising or demythologising nature, but that this is at least one central aspect of humanism, and that this quality should, in his view, suffice to appease his readers' concern about the maintenance of secular education. To be true, there is

2 "[T]he study of Hebrew itself lends support to what can today give a meaning to Judaism. It lends support to the Jewish humanism which cannot remain indifferent to the modern world in which it seeks a whole humanity." (DF 273 / DL 381). It is because of this importance of the study of Hebrew and Hebrew texts, that I prefer to render the title of the essay as "For a Hebraic humanism" [Pour un humanisme hébraïque], rather than "For a Jewish humanism" as the English translator does. Besides, Levinas uses in the text both expressions: "Hebraic humanism" and "Jewish humanism".

3 DF 273/DL 381. 
certainly much more to Judaism than secularising thought, but this set of principles and disciplines that opposes cruelty, this secularity, is a common denominator of all forms of expression of Judaism. What makes this humanism "Hebraic" is the centre of its discipline: the study of a literature and a civilisation that turns around the commentary of the Jewish Law and that is maintained in practice.

As important as the study of texts may be, it is the practice that ensues from it, that is essential. For it is only in the practice of justice (of which this humanism is the incessant contemplation and study) that God can be seen. Indeed, according to Levinas, the monotheism of Judaism (from the Bible, throughout the Talmudic commentaries) that is the ultimate source of this Hebraic humanism, is not bent on facilitating a privileged vision of God for the faithful, but on steering them towards their work for other people. In this sense, Levinas can claim that "[m]onotheism is a humanism". ${ }^{4}$ One could paraphrase that monotheism is a secularising (including, possibly, atheistic), never-ending reflection on justice for all people through the incessant study of the Talmud. But this humanism needs its humanists to give access to its treasures. This is the importance of Jewish humanism, ${ }^{5}$ which is at least as necessary for the contemporary world as the Greco-Roman heritage of the West.

From this perspective, it should be clear that Levinas is grappling here with much more than teaching an old language. The education that he has in mind is an access to and an institutional support for a "civilisation of justice". The Jewish institutions of the Diaspora can be mobilised for an ambitious cultural programme of uniting spirit and justice, somewhat parallel to Gellius', paideia and philanthropia. And if this means that a particularity of Jews and Judaism has to be affirmed in the process, it is at the service of excavating from the Jewish heritage that which is needed for the accord amongst all people.

This, then, is Levinas' message to the Jewish community in France in 1956: continue to have your children and students study Hebrew and everything that is associated with the discipline of studying the text of the Hebraic tradition. Sure enough, this will help you to keep Judaism alive and relevant, which might be important to you for whatever personal, religious or cultural reason, but the real objective thereof is not the continued existence of a religion or even the continued service to its God, but the fate of human beings, in other words, justice. 
But since one cannot accept that the contemporary reader would simply agree with this point of view, it is important to reflect on what the structure of validation is that implicitly supports Levinas' point of view: what is required from a reader to accept what Levinas proposes in this text? Since Levinas wrote the text for Jews in the Diaspora, one could suppose that he counted on a Jewish faith or an acceptance of the authority of the Jewish religion or at least on a pro-Jewish sentiment in order to make his point. From the content of the argument it seems that non-Jews that, for whatever reason, are convinced that Judaism or the Hebraic literature makes a decisive contribution to the schooling of humanity for justice, would also be likely to accept Levinas' point. However, Levinas doesn't make such reasons explicit (beyond what is summarised above) and his essay is not very clear on this issue of the reasons for agreeing with its point about Hebraic humanism. Since Levinas did develop similar ideas or a similar perspective on Judaism in other essays from the same period and for a similar audience, it seems legitimate to receive instruction from them regarding the structure of validation that Levinas supposes as sufficient support for this "Hebraic Judaism". This regards (1) the kind of Judaism, (2) the universality of Judaism and (3) the "atheism" of Judaism.

In examining Levinas' other pleas for the importance of Talmudic studies, one is struck, on the one hand by the specificity of what is required from his readership in terms of the kind of Judaism necessary in order to "play his game", but on the other hand, by the fact that this specificity has not much to do with enthusiasm for a sectarian piety, but with the shock and horror of the fate of the Jews of Europe in the fifteen years and more preceding these essays. In "Education and prayer" Levinas expresses the conviction that, as important as prayer might be or might have been for Jews the

"Judaism of the house of prayer has ceased to be transmittable. The old-fashioned Judaism is dying off, or is already dead. This is why we must return to Jewish wisdom; this is why in our recitation of this wisdom we must reawaken the reason that has gone to sleep; this is why the Judaism of reason must take precedence over the Judaism of prayer: the Jew of the Talmud must take precedence over the Jew of the Psalms.",

The Judaism that Levinas has in mind is one that has given up the desire (or that never had it) to conquer a part of the public space by its edifices - it has

6 According to the information on Espacethique (http://espacethique.free.fr/ index.php?lng=fr, consulted 9 June 2010), this essay first appeared under the title "Philosophie de la prière" in Bulletin intérieur du Consistoire Central des Israélites de France in 1964, pp. 57-59. Written between "For a Hebraic humanism" and "Anti-humanism and education" it is probably correct to state that it reflects a long standing perspective of Levinas on Jewish spiritual life.

7 DF 271 / DL 377. 
no infrastructure that can artificially support it, it is kept from dissolution by a Jewish science of texts, the meticulous study (in Hebrew) of which is comparable to visiting cathedrals. ${ }^{8}$ Hence the particular kind of practice, textual and reflective, that Levinas advocates as an indispensable component of Judaism - that is why the "Judaism with a historic reality - Judaism, neither more nor less - is rabbinic." "However, having noted Levinas' insistence on the particularity of Judaism or a particular kind of Judaism as essential for the support of an education that is guided by the dream of a Hebraic humanism, it should be pointed out at the same time that being Jewish is actually not a specific enough requirement to go along with Levinas' idea. The centrality of the study of the Talmud in Levinas' educational programme and in his idea of Judaism, serves to lead one back to what is Jewish about Jews: not their blood, history or land, ${ }^{10}$ in fact, not a religion or even God in the first place, but rather the study of the law and the relation to other people that it mediates: the singularity of Judaism resides exactly here:

"the link between God and man is not an emotional communion that takes place within the love of a God incarnate, but a spiritual or intellectual relationship [une relation entre esprits] which takes place through an education by the Torah." 11

Justice is the essence of this teaching and of the practice that should follow from it; justice is the essence of Judaism. ${ }^{12}$

From this point Levinas can insist that the very specific particularity of Judaism doesn't obstruct, but rather furthers its universalism. ${ }^{13}$ Of this universalism, Levinas gives us a good idea in "A religion for adults" (1957). ${ }^{14}$ Jewish universalism doesn't mean the universalism of a truth that is equally valid for everybody, but it is universal because it is open to everybody. Open not in the sense of a desire to proselytise everybody, but to serve everybody. The particularity of Judaism is the flip side of this moral universalism: realising the obligation to serve particularises or singularises the person or group that realises this obligation. In this sense, the particularisation of Israel is an election, it is a setting it apart from other. But according to Levinas' under-

8 DF 257 / DL 357.

9 DF $13 / \mathrm{DL} 28$.

10 DF 176, 23 / DL 246, 40f.

11 DF 144 / DL 204, translation modified.

12 "The justice rendered to the other, my neighbour, gives me an unsurpassable proximity to God. It is as intimate as the prayer and the liturgy which without justice are nothing. [...] The pious person is the just person." (DF 18 / DL 34, translation modified).

13 DF 13/DL 27.

14 DF 11-23 / DL 24-42, in particular the ideas expressed in DF 21f / DL $38 \mathrm{ff}$ and repeated elsewhere in Difficult freedom. 
standing of election, it is not a "historical, national, local or racial"15 category; despite whatever impression might be created by the Hebrew Bible or by certain strands of interpretation of Judaism, the particularity or election of Israel has, according to Levinas, nothing to do with being the first monotheism, or having authored a certain wisdom, or being the privileged instance of a whimsical divine decision. This setting apart is proper to every human subject in his or her capacity as obliged to serve the others. A synonym for this setting apart or particularism is (moral) asymmetry. The particularity in Jewish particularism is the singularity of any human subject as situated exceptionally in an asymmetric position with regard to the others. If there is to be equality between people, it can be realised only on the basis of the assumption of this inequality or asymmetry; if there is a universality of humanity, it can be realised only on the basis of particularism (provided that particularism is understood in the sense explained here). The ethnic or historical people called Israel, is in Levinas' interpretation of Judaism, only one possible manifestation of a broader category of "Israel" to which any person may belong, and that carries the particular name "Israel" only because of the particular historical context in which the testimony of this election of all human subjects has been transmitted. But this tradition teaches that a pagan who knows the Torah - or rather a pagan that realises his or her election to serve all people - is equal to the High Priest. ${ }^{16}$ Levinas is, of course, not ignorant of the radicality of the interpretation that he gives here of Judaism, in fact, after a similar explanation of election in the Universalis article on "Judaism" $\left(1971^{17}\right)$ Levinas exclaims: "This is the extreme humanism of a God who demands much of people". 18 This exclamation is deserved, not only because of the extreme demand placed on human agents by God, according to this interpretation of Judaism, but also because of Levinas' labelling it as "humanist". The latter refers clearly to the centrality of the service due to human beings. But what then about God?

This question is answered in a radio address, "Loving the Torah more than God" $(1955)^{19}$ of which the concluding point is summarised in a similar exclamation about Judaism: "It is a complete and austere humanism, linked to a difficult adoration!"20 It is everything to understand why the adoration of such a God is difficult - it is historical circumstances that,

15 DF 22/DL 40.

16 DF 22/DL 40.

17 Date of publication confirmed on Espacethique (http://espacethique.free.fr/ index.php?lng=fr, consulted 9 June 2010).

18 DF 26/ DL 46, translation modified.

19 DF 142-145/ DL 201-206.

20 DF $145 /$ DL 206. 
whilst making a certain kind devotion to God impossible, still require a service to humanity. The suffering of Jews in the last century has made more than evident the death of a certain God:

"What can this suffering of the innocents mean? Is it not proof of a world without God, where only man measure Good and Evil? The simplest and most common answer would be atheism. This is also the sanest reaction for all those for whom previously a fairly primary sort of God had dished out prizes, inflicted punishment or pardoned sins - a God who, in His goodness, treated men like children. But with what lesser demon or strange magician have you therefore filled our heaven, you who claim that it is empty?",21

But even if by "God" Levinas has in mind the "adult's God [who] is revealed precisely through the void of the child's heaven", 22 what makes him persevere in the use of this word? It is the belief that

"[c]onfidence in a God Who is not made manifest through any worldly authority can rely only on internal evidence and the values of an education. To the credit of Judaism, there is nothing blind about this., ${ }^{, 23}$

And this loving of the Torah, more than God, would be a

"protection against the madness of a direct contact with the Sacred that is unmediated by reason. But above all it is a confidence that does not rely on the triumph of any institution, it is the internal evidence of morality supplied by the Torah."24

This concession to atheism should be added onto the appropriation of the history of secularisation that is central to Judaism:

"Judaism has decharmed [désensorcelé] the world, contesting the notion that religions apparently evolved out of enthusiasm and the sacred. [...] Monotheism marks a break with a certain conception of the sacred. It neither unifies nor hierarchizes the numerous and numinous gods; instead it denies them. As regards the divine, which they incarnate, it is merely atheism." 25

21 DF $143 /$ DL 202.

22 DF $143 /$ DL 203.

23 DF 144 / DL 204, my emphasis.

24 DF 144 / DL 204, my emphasis.

25 DF 14-15 / DL 28-29, translation modified, my emphasis. At this point the conclusion of Levinas' 1957 essay on Lévy-Bruhl should be called to mind: "But is monotheistic civilization incapable of responding to this crisis by an orientation liberated from the horrors of myths, the confusion of thought they produce, and the acts of cruelty they perpetuate in social customs?" (ENT 51 / EN 63). If the West has the capacity to resist the modern avatars of the mythical gods, then Levinas seems to claim implicitly, it is because it has emerged from monotheism, of which the excellence is also in this non-confessional context indicated to be its secularising potential. 
There is for all intents and purposes, no meaningful discourse on God possible independent from the question of ethics. Ethics is that by which God is seen; ${ }^{26}$ but what can be known about God, God's attributes, are all imperatives. ${ }^{27}$ And by this different way we arrive once again at the primacy of the Judaism that contemplates the Talmud, over the Judaism that praises the attributes of God in Psalms. ${ }^{28}$

After this detour through Difficult freedom, let us get back to the question posed at the end of our reading of "For a Hebraic humanism": what is the structure of validation assumed by Levinas' plea for a Hebraic humanism? The answer consists of three interdependent elements: (1) Talmudic study as the essence of Judaism, (2) a universalism that is both a task and a recognition to all those people of other traditions that recognise this task, and (3) an embracing of the history of secularisation, complemented by a large concession to atheism. The support that these three elements could gain stem, in turn, (1) from an inner affirmation of the validity of the texts and debates of the Talmud and the study and commentary thereof, (2) from the message of the Talmud concerning the universal reach of its meaning, as well as the capability demonstrated by people from other traditions to contribute to the debate about justice and their capability to arrange their action accordingly and (3) from the evidence imposed by world historical events that place a question mark on certain kinds of religious practice. This means, for Jews, a clear relativisation and reinterpretation of theological claims to an exceptional, God-ordained election, as well as a considerable deflation of claims about God or revelation. For non-Jews, this means a strong claim as to the importance of the study of Judaic antiquity, next to and at least on a par with, for instance, Greco-Roman antiquity (one might say, a relativisation of the inferior position accorded generally in the contemporary study of antiquity to the Hebraic heritage), as well as a claim, not only to the universal validity of its ethical demand for justice, but also to incorporating the reflection of other traditions on justice into a Talmudic debate on justice, presented as universal. This holds for the adherents of other monotheisms, ${ }^{29}$ and beyond. ${ }^{30}$ However, in this debate, the study of classical texts - a study that avoids the dead-end of mere philology, but enters the game of debate about

26 DF $17 /$ DL 33.

27 DF $17 /$ DL 33.

28 As in the citation of DF 271 / DL 377, above.

29 DF $180 /$ DL 252.

30 "Rest assured that the light is not reserved for Israel alone, and darkness for the rest of humanity." (DF 240 / DL 335-336). 
justice - is crucial and for this reason it is difficult to see what place nonscriptural religions and cultures would take in this debate.

In short, monotheism as humanism, and in particular its Hebraic version, is the quasi-atheistic study of Talmudic text, with the view to a just human practice. The last element of this circumscription - just practice is crucial and follows not only from the particular claim to universalism and a deflated theology, but - and this is dear to Levinas - from the teaching of the Talmud itself. About Jews, he can state that

"the truth - the knowledge of God - is not a question of dogma for them, but one of action [...] a Jew can communicate just as intimately and religiously with a non-Jew who practises morality $[. .$.$] as with another Jew". { }^{1}$

And this communion doesn't only require the common recognition of the monotheistic heritage, but subsequently requires recourse

"to the Greek civilization and what it engendered: logos, the coherent discourse of reason, life in a reasonable State". 32

Note that this is Levinas' conviction from a Jewish point of view. In this context, he still affirms the universality of Judaism, which has been defined as the irreplaceable responsibility for others. ${ }^{33}$ The importance of the religious tradition of Judaism is nothing more than that of having participated in the discussion about justice and in the effort to realise this responsibility for a long time. To this the Talmud bears witness and constitutes a part of the debate - it deserves a humanist discipline, not because it is Jewish, but because it speaks about the justice of humanity, which in any case was, according to Levinas, the Old Testament's main cause.

This use of other texts from Difficult freedom to clarify the nature of the Hebraic humanism pleaded for by Levinas in the education, especially, but not exclusively, of young Jews, does not only enforce our understanding of Levinas' idea of humanism, but should also guard us against a too hasty conclusion about its status. We have to do here with texts that have been written in or about the context of Jewish practice in the Diaspora; furthermore, it should be clear that when Levinas exclaims that Judaism is a humanism, his point is also to articulate the surprise of non-Jews about the importance of service to humans over against faith in theological statements (and to tease the Sartreans) and should not be reduced to a

31 DF 176/ DL 247, translation modified.

32 DF 176 / DL 246. To which Levinas will add: "That is the true terrain of all understanding." (DF 176 / DL 246) - but, as we shall see later, his esteem for the State and for Greek thought about the State, will not always be so charitable.

33 DF 177 / DL 247. 
constant concern for the establishment of a humanism. The issue is the manner in which Judaism is to continue to exist after the Shoah - any contribution to humanism is a secondary goal. "Humanism" is an important argumentative tool for Levinas, it is also a useful word to explain the study of the Talmud, next to other old traditions, but it would not be correct to say that Levinas' point in all of these texts is primarily humanistic. His point is an ethical interpretation and practice of Judaism.

Yet two aspects of his ideas about the form of existence of diasporic Judaism merit the use of the word "humanist" and thus prevent one from interpreting the use of the word as merely rhetorical. (1) When speaking here of humanism, Levinas' concern is the study of the Talmud with a universal ethical rather than theological objective, and "humanism" serves to articulate his argument for this practice. (2) Humanism is also an appropriate term to capture the spirit of Levinas' train of thought in which the discourse concerning justice across the differences of culture takes a central position. Whereas Levinas seems to indicate that the value of the Rabbinic texts can be accepted only if the difference of their message, textual practice and required interpretation strategy with respect to other traditions is accepted, this is not an insistence on particularity for the sake of maintaining and celebrating the difference with respect to other cultural expressions, but a confidence in the importance of the contribution that this particular position can make to the universal coexistence of people. If Levinas is convinced of the excellence of Jewish religious texts, this excellence is only incidental and in principle replaceable or copyable. This universalistic claim is not the universalism of "our truth should be held by all", but of "all can be the beneficiaries of our truth and all, through their own traditions, have some access to it and can discuss with us about it". One might therefore encapsulate Levinas' position in a reformulation of Terence's humanist thesis: I am an ethical subject and no concern about justice for others is alien to me.

This presentation of Levinas' Hebraic humanism of the 1950s certainly doesn't capture all of the nuances of his position, but this is of no vital concern for the current purposes. What should retain our attention is the fact that once Levinas has pleaded for this humanism - as textual practice and universal ethical reflection - in education and as a cultural political project, that he should have been quite troubled by the wave of anti-humanist philosophies from the 1960s (and of which his reading of Tristes tropiques, referred to in Chapter 2, was an early experience). The essay of 1973 testifies to Levinas' reflection on this challenge posed to his thoughts on Jewish education. 


\section{2 “ANTI-HUMANISM AND EDUCATION"}

If the last essay in Difficult freedom also aims at advocating a "true humanism"34 as the objective of Jewish education, the approach is nonetheless quite different from that of the previous essay, as the use of the word "anti-humanism" in the title already indicates. The change in perspective on how the humanistic character of Jewish education should be approached becomes clear if one considers Levinas' effort to define humanism. Humanism, that has served for a long time as the strategy for the selfjustification of Western culture, entails:

"the recognition of an invariable essence named 'man', the affirmation of his central place in the economy of the Real and of his value which engendered all values. This created respect for the person, both in itself and in the other, which made it necessary to safeguard his freedom; a blossoming of human nature, of intelligence in Science, creativity in Art, and pleasure in daily life; the satisfaction of desires without prejudice for the freedom and pleasures of other men and, consequently, the institution of a just law - that is to say, a reasonable and liberal State or, in other words, a State at peace with other states and - an important point - above all opening up for individuals as broad as possible a domain for private life, on the threshold of which the law stops. A limit to law is necessary to humanism, for humanism can perhaps see no laws other than those of the State and of nature., 35

In practice, and in the narrower sense, humanism refers to the promotion of these principles, which happens in the study of certain texts.

The first pitfall of humanism gapes in the centrality of the writing and studying of texts: the possibility of forgetting the beautiful ideas behind the texts and of becoming wrapped up in the celebration of eloquence. ${ }^{36}$ Since there is no a priori reason why this illness cannot also infect a Hebraic humanism, Levinas needs to rethink, under the pressure of the antihumanist critique of humanism, if and how to affirm his appropriation of the term "humanism" for his politics of Jewish education. It is clear, in any case, that in doing so he rejects the implicit idea that he has to measure his vision of about Jewish education against the secularised version of Judeo-Christianity. Not only does this strategy do injustice to Judaism, since it debases Judaism to a variant of Western humanism and thus compromises its particularity, but it also lacks credibility, since it doesn't consider the "crisis of humanism". If Jewish education is to have any significance, it will have to go beyond humanism, and especially

34 DF 286/DL 398.

35 DF 277 / DL 385, translation corrected.

36 Cf. also IH 80. 
beyond the humanist reduction of Judaism (i.e., the desire to measure Judaism against the standard of ambient humanist values).

As in the writings of the 1950s, Levinas cannot but start reflecting on this issue by taking his distance from a certain kind of religious discourse. Without justifying the conviction further, he states:

"This was the century in which God died - that is to say, in a very precise sense, in which a certain discourse on God became increasingly impossible."37

If it is taken into consideration that the intellectual opposition to theology had gained significant impetus in the 18th century, Levinas' reference to the 20th century most likely rather stresses the impact of the political catastrophes. However, when he then discusses these, it is done to illustrate the "crisis of humanism"; it should probably be concluded that the same events that engendered the crisis of humanism, also make a certain discourse about God impossible. The presentation of these events by Levinas is of significant importance to us, since it makes a connection between historical events, and intellectual developments in a politico-intellectual diagnosis of his times, and that will be in force also in his philosophy:

"The 1914 War, the Russian Revolution refuting itself in Stalinism, fascism, Hitlerism, the 1939-45 War, atomic bombings, genocide and uninterrupted war. On another level, a science that wants to embrace the world and threatens it with disintegration - a science that calculates the real without always thinking it, as if it were created on its own in the human brain, without man, who is reduced purely and simply to the fields in which the operations of numbers unfold. Or in a different atmosphere, the ambitious philosophical enterprise which charms many of us, the ambitious philosophical enterprise in aid of thought and against pure calculation, but subordinating the human to the anonymous gains of Being and, despite its 'Letters on humanism', bringing understanding to Hitlerism itself. A liberal politics and administration that suppresses neither exploitation nor war; a socialism that gets entangled in bureaucracy. ${ }^{, 38}$

Such are the events that have shown not only the fragility or incapacity of the humanist project to realise itself through States and to protect humanity, but the incapacity of a certain idea of the human essence to produce the values needed to prevent these disasters and finally, in addition, the increasing impossibility of a certain kind of discourse on God. Furthermore, in order to fully appreciate the critique of contemporary society and the response that Levinas will propose to it, one should notice that the three kinds of developments identified by Levinas have in common the fusion of the human being into a blind process, whether this is war and tyranny, the physical succession

37 DF 280/DL 389.

38 DF $281 /$ DL 390-391. 
of events of the cosmos or the flux of Being (être). We have seen in Chapter 2 that such a fusion is for Levinas typical of the defenceless horror of exposure to the sacred in "primitive" religions and again quintessential of the return thereof in the indifference of modern atheism; in both cases it is ethical agency that is suffocated. If a certain kind of humanism is going to be proposed as an appropriate response to this situation, such a humanism is, implicitly, once more called to a task of desacralisation. In addition to this, the global reach of this societal diagnosis (clearly traced in the citation above) should again be underscored, as was done in Chapter 3, in order to be perceptive to the implied reach of the proposed response.

As perpetual victims of the failures of Western humanism Jews have been privy to this "crisis of the human ideal" error: humanism is since its Greco-Roman inception the human ideal of the conqueror ${ }^{40}$ and doesn't exhaust the meaning of the human. It is (at least initially) out of concern for a more complete or realistic idea of the meaning of the human and out of a realisation of the reduction committed against it, that a new wave of challenge to humanism and a "suspicion regarding a certain kind of language on the human" ${ }^{, 41}$ gains momentum. Of this wave of "anti-humanism", Levinas retains the following important characteristics: first, the denunciation of literature and eloquence that hypocritically hides misery and inaction; ${ }^{42}$ second, it exposes the cracks in the humanist notion of an eternal human essence; third, in the prolongation of the previous point, as an extension of an uncovering of humans from the hold of a certain essence, is the liberation from economic, moral and legal constraints. Up to this point, Levinas clearly gives his support to the anti-humanist critique of humanism. However, he is not willing to continue too far along this line of thought: when the fight for freedom from forms of oppression risks turning into a fight without limit, Levinas insists on the need to educate children in the distinction between good and evil; ${ }^{43}$ when the liberation from traditional morals risks losing all responsibility and permitting anything, including in one's action towards others, Levinas proposes a moral orientation based on Jewish values. ${ }^{44}$ Against the complete disintegration of an idea of the human essence, Levinas poses the irreducible essence of the human being (without elaborating on it) and the supremacy of the human being according to the

39 DF 281 / DL 391.

40 See also DF 170 / DL 239.

41 DL 393, phrase missing in DF.

42 DF 282, 283/DL 393, 394.

43 DF $285 /$ DL 397.

44 DF $285 /$ DL 397. 
Old Testament. ${ }^{45}$ Against an abusive, hypocritical eloquence and literature, he advocates the study of the Talmud, the Jewish study of the Law, and the practice that ensues from it. ${ }^{46}$

If humanism as a strategy for the self-justification of the West has been shaken by these events, it seems simply naive to think that a simple religious education along traditional lines will be meaningful. Besides, submitting Jewish children and students to a religious education measured against humanism would be futile in the light of the crisis of humanism. Again the alternative that Levinas proposes is the same: the Jewish scriptures, with the Rabbinic commentary and the practices that go along with them. ${ }^{47}$ At the same time, Levinas yet again questions certain forms of Jewish expression for the relevance with which they act in the contemporary world (e.g., Jewish apologetics ${ }^{48}$ ). Whereas it is quite obvious that a humanistic study of the Talmud could succumb to the temptations of eloquence, Levinas implicitly believes that the thorough study thereof and the practice that is associated with it, would suffice to maintain this form of humanism, without succumbing to the criticism of anti-humanism. But Levinas' claim for the Jewish Law is much more encompassing. In a time of human crisis

"the Jewish wisdom of the Law, the external act, is no longer simply a reflection or pronouncement of European culture, or the pride of belonging to the oriental origins of the West. Here we have the unique means to preserve the humanity and the personality of people. This agency teaches us true humanism., ${ }^{, 49}$

What is at stake for Levinas in this crisis of humanism, that is also the crisis of a troubling era in human history, is the "rescue of the Human being [sauvetage de l'Homme]"50 of which the continued existence as person is threatened politically, intellectually and morally. An education that takes as its basis the tradition of Jewish wisdom concerning the Law and that creates the infrastructure for the maintenance and advancement of a Jewish culture ("a culture based on a word which through its elevation can be called the word of God"51), is what is needed. This is a universal obligation of Jews; in service of humanity, but not to proselytise humanity. But in the

45 DF 284/DL 395.

46 DF $283 /$ DL 394.

47 DF $280 /$ DL 389.

48 DF $283 /$ DL 394.

49 DF 286/DL 397-398, translation modified.

50 DF 286 / DL 398, my translation. This phrase should be emphasised, since we shall see that a salvaging of "the very humanity of the human being" (IH 33) is what Levinas calls for from 1934 onwards.

51 DF 286/DL 398, translation modified. 
spirit of the Judaic tradition, this entails not a war against war in order to install its own humanism of the conqueror, but rather a "humanism of patience" ${ }^{, .52}$ What Levinas has in mind with this humanism of patience is not clear. From the last cryptic remarks of his essay one gathers only the following. It is a humanism that holds to the particularism of its universal vocation and does so in the face of and in opposition to "doctrines, anthropologies, axiologies and theologies", 53 but always in communion with other people, without distinction. Since the languages in the big cities have become confused again (evoking the confusion of languages in the story of the tower of Babel), a particularism "of Abraham", ${ }^{54}$ i.e., of the father of all monotheists, is needed, in other words, a particularism of the possibility of a unifying discourse that is moral in nature. If we live in an Abrahamic time it is, according to Levinas, because

"one must accept obedience personally [pour son compte], without counting the faithful [sans compter les fidèles]. This personal acceptance is not egoist.",55

This non-egotistical obedience to the law is what excludes installing another humanism of conquerors ${ }^{56}$ and what calls for a "humanism of pa-

52 DF 287 / DL 399.

53 DF $288 /$ DL 401.

54 DF $288 /$ DL 401.

55 DF 288 / DL 401, translation modified. Levinas possibly refers to the story of Abraham's dispute with God about the number of the faithful or the just that might be living in Sodom and Gomorrah and about their salvation - it turned out that there were none and those cities were destroyed, while Abraham and his family were commanded to leave the scene without looking back. With this in mind, the "particularism of Abraham" seems to evoke the idea of being just, while suspending judgement about the justice of others or despite the injustice of others. Although not referring to this Biblical story, the clarifications concerning the "descendants of Abraham" might illuminate the ethical quality of this Abrahamic particularism: "The heirs of Abraham - people to whom their ancestor bequeathed a difficult tradition of duties toward others, which one is never done with, an order in which one is never quits. In this order, above else, duty takes the form of obligations toward the body, the obligation of feeding and sheltering. So defined, the heirs of Abraham are of all nations: any person that is truly human is no doubt of the line of Abraham. [...] There is more in the family of Abraham than in the promises of the State. It is important to give, of course, but everything depends on how it is done. It is not through the State and through the political advances of humanity that the person shall be fulfilled - which, of course does not free the State from instituting the conditions necessary to this fulfilment. But it is the family of Abraham that sets the norms." (NTR 99-100 / DSAS 19-20, translation modified). I cite at length, because this passage on the "descendants of Abraham", although not explicitly linked to the notion of humanism, is developed in the train of thought following Levinas' significant qualification of humanism as being founded in the other (NTR 98 / DSAS 17). 
tience", which would be one that is guided by the symbol of the suffering servant, ${ }^{57}$ a symbol of all the conquered and suffering of history that demand justice.

Still, this does not provide a clear image yet of what this alternative post-anti-humanist humanism is. But, in another very dense passage of an essay of the same time ("Jacob Gordin", 1972-1973), Levinas uses most of the same terms to describe an alternative humanism. Reading the two texts together can help to amplify the basics of his idea. After criticising the humanism of the conqueror Levinas explains that

"[o]ur age certainly no longer needs to be convinced of the value of non-violence. But it perhaps lacks a new reflection on passivity, and a certain weakness that is not cowardice, a certain patience that we must not preach to others, in which the ego [le Moi] must be held, one which cannot be treated in negative terms as though it were just the other side of finitude. Enough of Nietzscheanism, even when purged of its Hitlerian deformations! But who will dare to say such a thing? The humanism of the suffering servant - the history of Israel - invites us to create a new anthropology, a new historiography, and perhaps, by bringing about the end of Western 'triumphalism', a new history.",58

This much can be derived from the two texts from the beginning of the 1970s: after the bankruptcy of the "humanism of the conqueror" in the West, and with the evidence of the need to escape a kind of thinking that engenders violence, a kind of thought (philosophical or social scientific) that praises human interaction in terms of the will to power, of conflict between powerful expressions of creativity (as one would find in many variations of anti-humanism) will not do. A different humanism is needed, which is characterised by the figure of the suffering servant (which is a symbol of the history of Israel - probably meaning here the religious community, rather than the modern State - and of human suffering in general) and by a patience, or endurance of suffering, or weakness, that despite its importance is to be practised but not preached to others (supposedly, others outside of the community of Israel).

This humanism, this quest for the justice of all suffering people should be practised against the current of contemporary political and intellectual history; but in "Anti-humanism and education" nothing is said about this being an ideal for anybody outside of Judaism. ${ }^{59}$ Such a prac-

57 DF 287 / DL 399.

58 DF $171 /$ DL 239-240.

59 However, given the inclusive understanding of the particularity of the "descendants of Abraham" it cannot be excluded that the "humanism of the suffering servant" is in principle proposed to all people. 
tice doesn't entail a subjectification or spiritualisation of principles of action, ${ }^{60}$ but rather constant externalisation of reflection on it, in continuation of the debate about justice in Rabbinic thought. This might be associated with religious observance, but the practice ensuing from this dialogue about justice doesn't aim at pleasing God, but at "safeguard the human in humans". ${ }^{61}$ Levinas' advocacy of this humanism thus clearly implies a plea for a Jewish particularism, but, as previously, not for a limitation of ties to a nation, a State or fellow citizens. ${ }^{62}$

Let us look more closely at the extent or ambition of Levinas' claims in the later thought on an alternative humanism. The problem is dehumanisation and anti-humanism; Judaic schooling is the answer, but only for Jews. But this thesis brings with it a number of implications. First, as before, it implies a clear option for a certain kind of Judaism, as described above. Second, the question inevitably arises - what should non-Jews do with this? Clearly not nothing: the political and intellectual diagnosis can in principle be taken over as is. But no positive answer is given in these reflections. Third, the political catastrophes associated with humanism are particular geographically and historically specific events; likewise, the intellectual phenomenon of antihumanism is a discourse that has a limited spatio-temporal sphere of influence. Combined, these two facts entail that in order even for a Diaspora Jew to accept Levinas' point, a particular phase in French intellectual life will have to be taken, in combination with a specific configuration of prominent historical events, as background against which the option for this form of humanism becomes intelligible. In negative terms, it cannot be taken for granted that the humanism of the suffering servant or of patience is a model to be adopted by all Jews (although Levinas clearly desires this for Jews in his context) - let alone non-Jews - since they live in a historical, political and intellectual context with different demands. Furthermore, in sharp contrast to Levinas' first version of humanism, there is no suggestion of a universal participation in this conversation about a post-anti-humanist quest for justice. These observations are of considerable importance since, apart from the particularism avowed to by Levinas, this introduces another form of particularism to his plea for a humanism of patience: it is a cultural or context specific humanism. The Judaism advocated by Levinas in "Anti-humanism and education" is itself culturally specific, for other reasons than just for the fact that it is Jewish: even if the essence of this humanism of patience is accepted to be trans-historical, the

60 DF 288/DL 400.

61 DF 288/DL 401, translation modified.

62 DF $288 /$ DL 401. 
manner in which this message is expressed and the terms in which it presents itself are specific to a particular context. This context determinacy of the expression of this alternative humanism is not a secondary aspect thereof - this becomes quite clear if one again asks the question concerning what would motivate someone to accept it as valid: only two things: (1) such a humanism should be deemed in line with the message of the Hebrew Bible and the Rabbinic tradition ${ }^{63}$ and (2) the horror of the dehumanising political catastrophes and the limitless, lawless freedom as consequence of anti-humanism should be considered as significant justification for a manner of thinking that goes against it. Religious authority (that is, not the authority of the religious functionaries, but the moral - rather than theological - authority attributed to the writings transmitted by the Jewish religion) in combination with a grim politico-cultural diagnosis of a specific era seems to me to be the structure of validation supposed by this essay.

\section{UNIVERSALISM AND AUTHORITY: AN UNCERTAIN CONCLUSION}

If we look back from the 1973 essay on humanism and education to the 1956 essay on the same subject, a number of remarkable things are worth adding to the list of general similarities between the two essays given at the

63 This impression could be confirmed by the Talmudic readings of the same time - at least in as far as explicit references to humanism are made. In Beyond the verse, for instance, the Torah is presented as that which keeps learning or wisdom from becoming purely rhetorical - and in this continues the philosophical project of which the inception is already in Plato's polemics with the sophists (BV 28 / ADV 44). The style of the Talmud is itself an antidote to the "sorcery of language" - in making this statement, the original definition of humanism in Difficult freedom (1956) is joined, but reinforced by the anti-humanist critique of the hypocritical eloquence of the 1970s. Again Levinas denounces a "pure humanism, humanism without the Torah" (BV 28 / ADV 44, my translation) as that which suffocates culture. The claim is that the "real humanism" is not one that rejects Western or Greek wisdom, but one that is enforced by what is essential to human culture, namely the teaching of the Torah and the study thereof through the Talmudic tradition.

Or again, where Levinas discusses the humanism of the "cities of refuge", he comments on the form of thought of the Talmudic text: "A question that is often asked in the Gemara: what verse is to be quoted? It is not only so as not to affirm without foundation, but also so that the verse throws light for us on the spirit of the institutions attached to it." (BV 42 / ADV 59). In other words the Talmudic text does make a contribution to a certain debate, but not without some form of institutional authority. A detailed analysis of the notion of authority in Levinas' readings of the Talmud would have to complete this remark, but falls outside of the scope of the present study. 
beginning of this Chapter. Considering first the implicitly presupposed affirmations needed from his audience in order to accept the validity of his two respective presentations of humanism, we can note that the quasi-atheistic religious orientation of the earlier text is maintained in the later one and with it also the insistence on the appropriateness of a specific kind of Judaism, namely one of which the study of texts of Jewish antiquity forms the basis (not only for education, but for spiritual life in general). It is the third element of the structure of validation - universalism - that is quite different from what is supposed by the 1956 essay on humanism and education: in the later essay there is only the question of a universalism of vocation, not of a universal participation of the plurality of cultural traditions in a discourse on justice. This omission might simply be due to the practical contingencies under which the essay was written. However, it does leave a question open regarding the place of adherents of other religions and other cultural traditions. The broadest reading would be that Levinas here leaves the question in suspense; the narrow reading would be that he bases his claims about a humanism for Jews on the authority of the Hebrew Bible and the tradition that comments on it and that not much is to be said either about those that do not accept the authority of this tradition, or about an internal evidence that the teaching contained in these texts could draw from its scholars.

This is an important issue since it concerns the practices by which claims concerning just action are produced and practice itself is justified, planned and launched. I do not think that the exposition of the two texts of Difficult freedom (and those used to supplement them) suffices to establish a clear line of development in Levinas' thought on this issue. In fact, our reading of Levinas' thought on humanism in the religious context, leaves us with a question about two central issues. First, is the humanism pleaded for one that invites a universal participation by any and all people irrespective of their cultural heritage in a debate about justice, or is this humanism the roadmap for survival, exclusively for Jews, albeit in their capacity as servants of the whole of humanity and of suffering people in particular? Second, does this call to study the Talmud imply the broad claim that a collection of ancient texts testifies to a source of justice (which is not itself), which it excels in reflecting and to which all people can be invited to join, since their own reflection might give them access to the source of justice independently from the Talmud, or is the call to Talmudic studies limited to those that are linked to Judaism, either by their family history or by the acceptance of the authority of the religious texts (or probably both) and in which the scriptures themselves form the indispensable access to reflection on justice? 


\section{Changing of the guards: TALMUDIC HUMANISM AND A PHILOSOPHICAL POST-ANTI-HUMANIST HUMANISM}

Although I don't claim to render the full nuance of these texts and those of the same period, it seems reasonable to state that the nature of these writings probably doesn't allow for an absolutely clear and precise description of the evolution of Levinas' position on these issues concerning Judaism and humanism. We have seen the different manners in which Levinas would probably have responded to these questions - our reflection is, of course, limited to the two important texts about humanism written in a religious context and outlined in this study.

However, there is the philosophical text, Humanism of the other, in which humanism is again thematised. Here it is with a notably different discursive practice: as philosophical text, it constantly resubmits the authority of texts to questioning; there could be no question of referring to a "Book of all books". The same criteria for accepting the validity of his arguments cannot hold. No tie with Judaism or a wish for a contemporary vitality of the Jewish community as religious community can be taken as a point of departure (even though the arguments advanced may be of Jewish religious inspiration). This means at the same time that a key aspect of the two versions of Levinas' humanism in Difficult freedom, namely the study of the Talmud, cannot simply be required as the central piece of this philosophical humanism - or, if it is part of this philosophical humanism, then the place given to the Talmud would be next to other traditions speaking about the same concerns and certainly not on the basis of a preconceived idea of the excellence of the texts, and even less on the basis of religious authority, but only in as far as it contributes to a theme of reflection. No desire to speak or reflect about God or religion can be supposed in his general readership - especially not in France in the 1960s and 1970s. Universalism would enter the argument, not in the sense that it would be required to write from no perspective, but rather in the sense that it would be indispensable for Levinas to show that he can relativise the position from which he writes (in relation to all other positions) and be lucid about what this position brings with him to the argument.

Yet, with all of these differences with respect to the discursive practice, the essence of the theme is the same, namely responsibility for the other human being and justice. This can be shown clearly by comparing the title of the philosophy book - in which the decentring of a humanism to the concern of the "other human" is strikingly displayed in the title 
Humanism of the other - with an explicit remark in Du sacré au saint about what Levinas identifies as an essential trait of Jewish humanism:

"the person whose rights must be defended is in the first place the other human being; it is not initially myself. It is not the concept 'human' which is at the basis of this humanism; it is the other human beings." 64

Even though the other human and the responsibility and justice due to other people have been the core of all Levinas' philosophy since the war, he did not always refer to his thought as humanist. Also, after Humanism of the other Levinas never nurtured the term; particularly significant is the practical absence of any reference to humanism in Otherwise than Being, which is with Totality and infinity arguably Levinas' most important book in philosophy and was written just a few years after Humanism of the other. The justification for the adoption of the title "humanism" is to be sought elsewhere than in the will to contribute to, remain true to and extend the tradition (or one of the traditions) of European cultural life that carries that name. One finds an indication of this in the interview "Philosophy, justice, and love" (1982), where Levinas explains his ideas concerning human subjectivity as constituted by responsibility - he declares:

"My view is opposed to the tendency of one whole portion of contemporary philosophy that prefers to see in man a simple articulation or a simple aspect of a rational, ontological system that has nothing human about it [...]" ${ }^{65}$

He advances then with a short elaboration of the Heideggerian version of this tendency, highlights a trace of the same tendency in Merleau-Ponty's work and then continues his reflection on the general tendency of his time:

"In the same distrust with regard to humanism according to contemporary philosophy there is a battle against the notion of the subject. What they want is a principle of intelligibility that is no longer enveloped by the human; they want the subject to appeal to a principle that would not be enveloped by concern for human fate. On the contrary, when I say that consciousness in the relation with the other loses its first place, it is not in that sense; I mean to say that, in consciousness thus conceived, there is the awakening to humanity. The humanity of consciousness is definitely not in its power, but in its responsibility [...] I advocate, as in the title of one of my books, the 'humanism of the other'.,"66

These then are the concerns that warrant giving the title of "humanism" and particularly "humanism of the other (human)" - which is equally the essence of Jewish humanism - to one of his books (but not to his philo-

64 NTR 98 / DSAS 17, translation modified, similarly GDT 182 / DMT 213.

65 ENT $111 /$ EN 121.

66 ENT 112 / EN 122, translation modified. 
sophy in general): a dispute with contemporary philosophy about the status of the subject, and a concession about the decentring of the subject, but this by a responsibility for the other and a care for human well-being. Everything hinges on the "... of the other (human)" by which the polemical appropriation of "humanism" is qualified. And in this, the resonance with "Jewish humanism" is willed.

It is the contemporary intellectual tendency that occasions the polemical appropriation of the title "humanism", but the title is equally justified by the "anti-anti-humanist" thematic. ${ }^{67}$ One could say that the "humanism" adopted in Humanism of the other is equally circumstantial as that of Difficult freedom, except that in the former there is no question of the humanistic study of the Talmud. This fact will have to be contemplated, since if there is a humanism advocated by Levinas, that could at least in principle sidestep the study of the Talmud, while remaining true to the ideal of his Judaic humanism (namely justice towards people), one would have to know where the resources for this other philosophical humanism come from. Furthermore, if there are such Talmudic-independent resources, we will have to consider in what position it leaves the Hebraic humanism or the humanism of patience. ${ }^{68}$ Let us then without further ado turn to Humanism of the other to explore these questions.

67 See similarly PN 17 / NP 102.

68 A response will be suggested to this dilemma in the two concluding points to Chapter 5, $\$ 4$. 


\section{Chapter 5 Levinas' post-anti-humanist humanism: Humanism of the other ${ }^{1}$}

One's first impression in searching for help from Levinas in reflecting about humanism might be one of joy. Remarkable as it may be, here is a French author, well informed about his contemporaneous philosophical scene, who in 1972 publishes a book on humanism: it is entitled Humanism of the other. One's joy will be quickly attenuated, though, on opening the book. Not only is there no definition or description given of what the author understands by "humanism", not only is the anti-humanism dominant in the early 1970s French - or even simply "Parisian" as Levinas says ${ }^{2}$ - philosophical scene presented as the essential point of reference, but the aim of the book, in apparent disdain for its title, is indicated not as the foundation of a new humanism, but as a research on a kind of meaning to be found in the "proximity of the one-for-the-other" 3 of which the preface gives a brief sketch. The same kind of disappointment will be the fate of the reader seeking insight into notions like "self", "other", "identity", "culture" and a string of other notions that we so direly need to reflect on in the world that is ours and from which one would expect a humanism to provide philosophical and cultural-political guidance.

To be precise, these notions are not absent from Levinas' work. Not only are they present as terminology in his texts, but the terms (as they are traditionally used) are to be found at the very origin of the statement of Levinas' problem. What makes access to Levinas' work difficult is exactly the way in

1 A slightly different version of this Chapter (up to §4) was published under the title "Rethinking the conditions for inter-cultural interaction. A commentary on Levinas' Humanism of the other", in a thematic issue on "The interaction between self and the others in the age of globalization" (guest editor, Jörn Rüsen) in the Taiwan Journal of East Asian Studies 7/2, December 2010, pp. 113-147.

$2 \mathrm{HO} 58 / \mathrm{HH} 95$.

$3 \mathrm{HO} 3 / \mathrm{HH} 7$. 
which he uses these words. Invariably, the notions that we would like to interrogate the philosopher on are used, but while crossing out, as it were, our common understandings of these notions. What Levinas says of the introduction of his book applies too for his use of traditional philosophical terminology: just as the preface is not only a repetition of the content of the book but a first "urgent" commentary on it so as to partially undo what is said in the book, so too when he uses terminology, he uses it in such a way as to undo something of what has been said about, or by means of, those terms by the tradition of philosophical reflection. If we then want to expose ourselves to the perspective that Levinas presents on humanism, we will have to examine this way of using terms and partially undoing them at the same time. One understands Levinas when one hears how a traditional philosophical term "rings" after its ringing has been interfered with in this way.

In accordance with the general concern of Levinas' entire philosophy, one wouldn't be able to appreciate much of the after-ringing or reverberation of the notion "humanism" without that of "identity" and "alterity" or "same" and "other". This shouldn't be much of a surprise, because if it is true that the stakes of Humanism of the other are the same as those of Levinas' philosophy in general (as pointed out at the end of Chapter 4), then we need just recall what has been said about the general concern of this philosophy at the end of Chapter 2: Levinas' entire philosophy is motivated by his concern about the threat of political disasters, which tend to manifest themselves in the form of identity-enforcing totalitarian violence and that of indifferent plurality. It was argued that his philosophical project is a quest for the source of a non-totalisable alterity, which would interrupt the force of identity and give orientation to the indifferent, multiple cultural renderings of Being. Furthermore it is of considerable importance to recall that it was concluded that this double political concern is responded to in Levinas' philosophy by recourse to the big notions of metaphysics - "same" and "other" or "identity" and "alterity" - which are meditated in the register of ontology and ethics.

To appreciate Levinas' use of these terms, and thus his contribution to our subject matter, one has to consider the conditions under which the ringing of these words and the interference with them were initiated, long before writing Humanism of the other. One finds the first embryonic expression of this quest in two related essays: "Some reflections on the philosophy of Hitlerism" [Quelques réflexions sur la philosophie de l'hitlérisme] (1934 $)$ and "On escape" [De l'évasion] (1935). Read together, they reveal how Levinas situates his philosophical problem at a political as well as an ontological level, an understanding of which is indispensable for understanding what he has in mind in the humanism of the other.

4 In IH 23-33. 


\section{FIRST ATTEMPTS AT A POLITICAL AND ONTOLOGICAL FORMULATION OF THE PROBLEM}

Levinas never made a secret of the fact that his philosophical agenda was inspired by his personal experiences. ${ }^{5}$ His concerns, political as well as personal, are such that the question of the self and the other is placed firmly in the centre of his philosophy: victim of anti-Semitism in Europe, Jew amongst Christians and atheists, Russian- and Hebrew-speaking in a French and German world, and reader of the Talmud in a world of Greek thinking. In other words, Levinas lived and worked in the tension between identity and alterity on the cultural, political, religious, ethnic, intellectual and language planes. When, in the early 1930s, he observed the rise of Nazism, this tension gave birth to a philosophical problem that, through various reformulations, will remain the major concern for Levinas throughout his way of thinking. This problem concerns the relationship between the subject and his/her history or, one could say, it concerns the place to be accorded to the different narratives (cultural, religious, ethnic, etc.) that constitute the identity and the manner of being of the subject. What Levinas considers to be the decisive core of this issue is our "conception of the human being". 6 It is only when one considers this core, namely one's conception of the human being, that one is able to recognise that whenever the tension between the self and the other arises, what is at stake is the very humanity of the human being (l'humanité même de l'homme). ${ }^{7}$

Thus, what Levinas considers philosophically interesting, or disturbing rather, in the "philosophy of Hitlerism" is that its rise in the political arena confronts one with the ineluctable task of contemplating the humanity of the human being. He does so in his essay by referring to a long and multifarious tradition of liberalism in Europe. Liberalism, that encapsulates for Levinas the essence of the European tradition of the conception of the human being, will be used by him in this essay as a standard against which to measure innovation or deviation. The most salient aspect of this tradition is its care for the idea of a human subject that disposes of one or another kind of liberty or freedom. Liberty is the capacity to make a present moment; it is the opposite of being drawn along by history. In fact, as Levinas states, in absolute terms

5 See for instance the first pages of Ethics and infinity and the autobiographical essay, "Signature" in DF 291-295 / DL 405-412.

$6 \quad$ IH 27 and repeated elsewhere.

7 IH 33. Here we find again the term introduced in Chapter 4, when its echo in Difficult freedom was considered under the terms of the "rescue of the Human being" (DF 286 / DL 398, my translation). 
the free individual "has no history", 8 though it is evidently not denied that the individual makes history.

When Levinas highlights the most important moments of this liberal tradition of the West, he insists on the golden thread or "leitmotiv", 9 starting curiously ${ }^{10}$ with Judaism, running through Christianity and taken up again in modern liberalism, that situates human dignity - the dignity of every particular human being - in the capacity of the soul to disengage itself of its own history, from whatever particular narrative that could singularise it, give it its particular identity. ${ }^{11}$ Marxism seems to be a breach with this tradition in that it considers the consciousness to be determined by Being, ${ }^{12}$ meaning that the life of the soul, in the great variety of its expressions, reflects the material conditions of being of the respective classes of society. However, even in Marxism the consciousness retains the capacity to throw off the effect of the material conditions, and this capacity is situated in the act of taking cognisance of the social situation. ${ }^{13}$

A real breach with the European notion of the human being would take place only if the historical situation, attachment or identity of the human being is not taken to be secondary to the free soul, but the very basis of it. ${ }^{14}$ Such a notion of the human being would centre on the human body. Now, one should be very careful not to rashly identify the bearers of such a notion of the human being only with Hitler or the Hitlerians (as Levinas calls them). Sure enough, in the first sentence of the essay Levinas, in accordance with the title of the essay, speaks of the "philosophy of Hitler". ${ }^{15}$ But on that same page, he also claims that, in as far as this philosophy evokes the question of the relationship between the soul and reality (or history), the "philosophy of Hitlerism goes beyond the philosophy of the Hitlerians". ${ }^{16}$ Furthermore, the section of the essays that explains this new notion of the human being contains no more precise indication of its bearers than a reference to "modern

$8 \mathrm{IH} 24$.

9 IH 26

10 "Curiously", not in the sense that the Jewish roots of Western culture are ignored, but in the sense that it seems more logical to situate that root in what is today called the Middle East.

11 Cf. IH 26: "The equal dignity of all souls, independently from the persons' material or social condition, does not follow from a theory that maintains beneath the individual difference an analogy of 'psychological constitution'. Equal dignity should be attributed to the power given to the soul to free itself of what was, from all that tied it, from all that engendered it".

12 IH 27.

13 IH 28.

14 IH 28.

15 IH 23.

16 IH 23. 
Germany"17 and "the Germanic ideal of the human being". 18 No "Hitlerian" author is cited explicitly or named (though the two references to Nietzsche are probably not incidental). I insist on this point because Levinas opens up an ambiguous space in which the reader should fill in a name of a bearer of such a philosophy in which history determines the fate of the human soul and it is of crucial importance for the understanding of Levinas' entire philosophical project that one fills in the correct name: next to that of whatever Hitlerian, the name of Heidegger. This is the person from whom Levinas learned more about philosophy than from anybody else (except perhaps Husserl); it is also the person that Levinas believes provides the most illuminating perspective on his contemporary intellectual environment.

What makes it difficult to see Heidegger in this text - apart from the fact that he is never named - is that Levinas already transforms Heidegger's analysis of the human being (or rather, Dasein), at the moment he redeploys it. Levinas does what Heidegger avoided in Being and time: he identifies human existence with the fact of being a body. Between the lines of Levinas' text, one reads that it is Heidegger's philosophy of Dasein that would clarify what it means to be attached to one's body. According to Levinas

"[t]he body is not only closer and more familiar to us than the rest of the world, it doesn't only command our psychological life, our mood and our activity. Beyond these commonplace observations, there is the feeling of identity." 19

And he continues by stating that the adherence of the body to the self "is an adhesion from which one can't escape" (est une adhérence à laquelle on n'échappe pas). ${ }^{20}$ The echo of one of Heidegger's most important statements is still audible in Levinas' text:

"Dasein [Levinas says "the body" - EW] is ontically 'closest' to itself, ontologically furthest, but pre-ontologically nevertheless not foreign." 21

Just as, in the new (Germanic) conception of the human being, one is attached to one's body, ${ }^{22}$ so in Heidegger's philosophy one is attached to

17 IH 33.

$18 \mathrm{IH} 31$.

19 IH 29.

20 IH 29

21 Martin Heidegger, Being and time. John Macquarrie and Edward Robinson (transl.). Oxford: Basil Blackwell, [1962] 1988, p. 37 / Sein und Zeit. Tübingen: Max Niemeyer Verlag. [1927] 1993, p. 16 (translation modified). A similar claim is made after the introduction of the notion of mineness (Jemeinigkeit) (Being and time. op. cit. p. 67-68/Sein undZeit. op. cit. p. 41-43), to which we turn next in our text. 
one's own being; in fact, what Levinas is doing here is to reformulate the most significant ontological insight provided by the ontic specifics of human existence (as analysed in Being and time) by an introduction of the body: as far as he is concerned, your body is the way in which your being is your own. Being [Sein, être] is always yours, in such a way that you cannot rid yourself of it. This fact of "being that is always someone's", Heidegger called "mineness" (Jemeinigkeit) and this term forms the centre of Levinas' polemics with his former teacher. ${ }^{23}$ In the opening sentences of $\S 9$ of Being and time, entitled "The theme of the analytic of Dasein" Heidegger explains mineness in the following words:

"We are ourselves always the entities or beings to be analysed. The Being of this entity is at every instant mine. In their very act of being these entities are themselves related to their being. As beings of the event of Being, these entities are entrusted to or delivered to their own being. The being is the concern for these entities." 24

For Levinas this summarises the essence of the new conception of the human being, a conception that breaks with the European tradition: ${ }^{25}$ through my body, Being or history is so much mine, that I am subjected to what Being or history imposes on me, to the identity (Selbstheit, ipséité) that is historically constituted - and from this there is no escape. The

22 "[D]ans cet enchaînement au corps [...] consiste toute l'essence de l'esprit" (IH 30), says Levinas.

23 I have argued this in De l'éthique à la justice, Chapter 1.

24 Freely translated from Sein und Zeit. op. cit. p. 41-42: "Das Seiende, dessen Analyse zur Aufgabe steht, sind wir je selbst. Das Sein dieses Seienden is je meines. Im Sein dieses Seienden verhält sich dieses selbst zu seinem Sein. Als Seiendes dieses Seins ist es seinem eigenen Sein überantwortet. Das Sein ist es, darum es diesem Seienden je selbst geht." / Being and time. op. cit. p. 67-68.

The link between Levinas' essay on Hitlerism and Heidegger's idea of mineness was affirmed much later (1990), when Levinas commented on his early essay: "This article proceeds from a conviction that the source of the bloody barbarism of National Socialism [...] is inscribed in the ontology of Being, concerned to be [...]." Cited from the "Post-scriptum", in Quelques réflexions sur la philosophie de l'hitlérisme. Rivages poche (Petit Bibliothèque) 1997, p. 25.

25 It is not clear why Levinas, in this essay, puts so much emphasis on the long, continuous Western/European tradition of the liberty of the soul and condemns the breach with that tradition. One should notice that it is somewhat problematic, in that he formulates an argument for a conception of the human being that is precisely not determined by his/her history. In order to maintain the coherence of the essay one would have to take Levinas' insistence on the continuity of this European tradition not as a legitimisation of his argument, but only as the historical background to his ideas of which he approves. However, it is clear that such a benevolent reading would be somewhat forced. That Levinas had a very positive image of European culture is no secret and, as we shall see, even appeared at certain instances in the form of a Euro-centrism. 
human being's life is characterised by care (Sorge), but every caring action is one that has already been entrusted to or surrendered to Being, which draws it along. In other words: "The essence of the human being is no longer in freedom, but in a kind of enslavement [enchaînement] ${ }^{, 26}$ and one can do no more than to accept this fatality.

The political consequence of such a notion of humanity is the immediate exclusion of politics as a condition to which free spirits consent. ${ }^{27}$ Instead of the free play of ideas that would make truly human politics possible, ideas are imposed on individuals by their belonging to consanguine groups (or ethnic, cultural, religious and other groups by extension) - and this necessarily leads to expansion and war: racism seeks universalism by means of conquest, according to Levinas. Or again in other words: a particular identity spontaneously seeks to impose itself on what doesn't conform to it; identity spontaneously seeks to impose itself on non-identity, on alterity. These are, according to Levinas in 1934, the terms in which to consider the humanity of the human being that is being put at risk. ${ }^{28} \mathrm{We}$ have also seen the extension of the same line of reflection on identity and alterity in Levinas' remarks on ethnography, in Chapter 2, and on colonisation, in Chapter 3.

Levinas' reaction to this problem will not consist of simply returning to the tradition of the free soul (although his writings up to Totality and infinity could be considered to be, to a certain extent, a reworked appropriation of this tradition). His philosophical project starts from accepting the terms in which Heidegger conceives of human existence, but attempts to go beyond the fatality he sees in them. ${ }^{29}$ The first step was to advance the formulation of the problem in ontological terms. This Levinas did in the 1935 essay, On escape. Hence forth, the primary strategy by which to tackle the question of the tension between "identity" and "alterity", "self" and "other", will be a dispute with the Western tradition of thinking in which the question of Being is central. In other words, the contemplation of political catastrophes (or the threat thereof) is translated into ontological terms inherited and adopted from Heidegger.

If indeed "the essence of the human being is no longer in freedom, but in a kind of enslavement", if human existence is indeed first and foremost characterised by mineness, what would this entail for human existence? In On

$26 \mathrm{IH} 30$.

27 IH 30.

28 The most important elements of the 1934 study will reappear in Levinas' later analyses of political and cultural events. See for instance "On the deficiency without care, in a new sense" [De la déficience sans souci au sens nouveau]" (GCM 43-51 / DVI 77-89, my translation).

29 Again, it is the same notion of fatality that Levinas identified in "primitive" religion and the means by which he identified it in Heidegger - as argued in Chapter 2. 
escape Levinas provides what could be considered as a counter Daseinsanalyse (ontological analysis of the human being), in which he attempts to show some of the implications of Heidegger's idea of mineness. Being means for the human that one's identity is firstly to be considered not in terms of the reflection of the subject to itself, but in terms of continued existence (ipseity or selfness) - the perseverance in one's existence (Spinoza's conatus, that the later Levinas likes to use to gloss the ontological identity). Being means for human existence to be or to exist in such an intimate circuit of "exchange" with Being (i.e., mineness), that one always understands (prepredicatively) Being in the different ways in which one is. In fact, the entire human existence is a long happening of the understanding of Being, i.e., ontology. ${ }^{30}$ With one's whole existence at every moment, one is a logos, a "discourse", concerning the different ways in which one conjugates, as it were, the meanings of "to be", that is, ways in which one understands Being. But whereas mineness is at the source of selfness and all understanding (as a subsidiary of the understanding of being), one is at the same time tightly Levinas says brutally ${ }^{31}$ - bound to Being. There is no escape; one is attached to being without any exit - hence the title of the 1935 essay. All understanding, and hence all meaning, is imposed on humans by virtue of the circulation of understanding in which they find themselves with Being. In the terms used in Chapter 2: for Dasein, to be means to participate.

Levinas proposes no solution to this dilemma in 1935. The hermeneutics of facticity of human existence offered in the analyses of shame and nausea sets out to express the need of the human being to escape from the apparently inescapable burden of one's own identity, that is

"to break the most radical, the most inexorable, enslavement, namely the fact that the self is itself". ${ }^{2}$

The urgent problem of "finding the way out" could also be formulated as a question: "is ontology fundamental?". In these words (the title of the seminal essay of 1951), Levinas restates the question of the escape: are all forms of meaning dependent on ontology, on one's always brutally belonging to Being? Does the human being exhaust the meaning of his/her humanity and

30 This is the centre of Levinas' appropriation of Heidegger: "The whole human being is ontology [Tout l'homme est ontologie.]." (ENT 2 / EN 13, translation modified, similarly GDT 58 / DMT 68).

31 That this idea of being narrowly attached to Being is opposed to a tradition of liberalism is reaffirmed in the 1935 essay: "The revolt of traditional philosophy against the idea of Being, proceeds from the discrepancy between human liberty and the brutal fact of Being that strikes it." (EV 91).

32 "[D]e briser l'enchaînement le plus radical, le plus irrémissible, le fait que le moi est soi-même" (EV 98). 
selfness by articulating the event (Er-eignis) of being? $?^{33}$ Is there not perhaps another form of meaning that transcends my attachment to myself, to my identity, to my body, to history, and ultimately to Being?

Levinas' project will consist of arguing that, next to ontological meaning, or rather more original than ontological meaning, there is a kind of meaning that arises between people that is not ontological and he will argue that it is ethical in nature. ${ }^{34}$ The entire question of human diversity, of the tensions involved in the relation between identity and alterity is made dependent on Levinas' Heideggerian inspired notion of identity and an alterity that will infringe on that identity. Let it be stressed that the terms in which Levinas approaches this question are terms of meaning and not in the first place that of an economics or politics of difference. In fact, he explicitly states that the alterity in which he is interested, the alterity that makes an escape from the fatal violence of identity as perseverance in selfness possible, the alterity that would be at the root of a peaceful coexistence amongst the diversity of peoples, is to be understood in a very particular way: the other is other -

"[o]ther, not at all because he would have other attributes or be born elsewhere or at another time, or be of a different race [...]. It is not at all the difference that makes alterity; it is alterity that makes the difference. ${ }^{, 35}$

I rephrase: it is not at all the difference of singularising attributes of identity (of a different culture, ethnicity, religion, etc.) that constitutes what is essential to alterity; it is the ethical meaning of alterity that makes the difference with regard to the ontological meaning of the relationships between people. The solution, or rather the response, that Levinas proposes to the problematic tension between identity and alterity, will not reside in an articulation of the differences susceptible to prejudice, discrimination, stereotyping, inequity or

33 These terms are borrowed from a later text - GCM 46 / DVI 82: "man exhausts the meaning of his humanity and his ipseity in articulating the Er-eignis of being."

34 These terms are to be found in "Ethics of the infinite", in Dialogues with contemporary Continental thinkers. The phenomenological heritage. Richard Kearney. Manchester: Manchester University Press, 1984, p. 49-69, here p. 57 / "De la phénoménologie à l'éthique", in Esprit 234, 1997, pp. 121-140, here p. 129, where Levinas explicitly states that "it is my own personal task to identify this dual origin of meaning - der Ursprung des Sinnhaften - in the interhuman relationship ", these two sources of meaningfulness being phenomenological or ontological and ethical, respectively.

35 'Autre, pas du tout parce qu'il aurait d'autres attributs ou serait né ailleurs ou à un autre moment, ou parce qu'il serait de race différente. [...]. Ce n'est pas du tout la différence qui fait l'altérité ; c'est l'altérité qui fait la différence." Cited from the interview "La vocation de l'autre", in Racismes. L'autre et son visage. Grands entretiens réalisés par Emmanuel Hirsch. Paris: Cerf, 1988, p. 92. 
other forms of violence, but in indicating that there is something different to the other (and that is not reducible to the qualities of the other) and that the subject (or self) cannot be indifferent to this alterity of the other. The most profound alterity of the other is situated not in his/her perceptible difference, but in the non-in-difference that the self discovers regarding the other, whoever that other may be. This alterity as the non-in-difference that underlies all difference restores to humans the full sense of their humanity that is at risk in the ontological reduction prevalent, according to Levinas' reading, in the Western tradition of thought. In other words, reflection on the problematic tension between identity and alterity should in final analysis be referred back to what constitutes humanity, namely ethicity, and it is only from this perspective of ethicity that a measure, or common discourse, is discovered that sets a limit to the engagements imposed by what would otherwise be an absolute cultural relativism. This latter point is Levinas' major concern of the first essay in Humanism of the other, to which we now turn.

\section{THE CRISIS OF HUMANISM}

Humanism of the other is a collection of three essays (published respectively in 1964, 1968 and 1970) to which a preface has been added for the publication in 1972. It represents (especially in the first essay) Levinas' first attempts to go beyond what he considered the insufficiencies of his major work of 1961, Totality and infinity, but without rejecting the basic convictions defended in that book. Humanism of the other is part of the transition $^{36}$ to the second phase of Levinas' work in which Otherwise than Being (1974) stands in the centre and of which the central piece, the article "La substitution" (first published in 1968), is contemporaneous with Humanism of the other. However, in Humanism of the other Levinas takes up the debate with Heidegger in terms similar to those formulated three decades earlier and extends it to a debate with contemporary anti-humanism (or the crisis of humanism) in the social sciences. Let's explore this statement in more detail.

36 In situating Humanism of the other within the development of Levinas' work, it is probably most prudent to insist on its place as a transitional collection. One should especially be careful not to be guided merely by the date of initial publication of the essay of $\mathrm{HO}$, but to consider also the notes available for Chapter 1 in the recently published first volume of the Oeuvres complètes. The 28 ideas that are formulated under the title "Sens et signification" evidently prepares this Chapter and are, according to the editorial note, written on an invitation card of 1954. However, according to the editor of these notes, Rodolphe Calin, it is unlikely that they were made before 1960 (personal communication to author). 
In Humanism of the other, Levinas still considers Heidegger's philosophy as the best key to understanding what is really happening in his contemporary intellectual and even political scene. ${ }^{37}$ One could summarise Levinas' reading of Heidegger in this book as follows. Firstly, ontologically human existence is first and foremost characterised by mineness - in particular, Levinas twice cites the phrase by which Heidegger captures the essence of the identity of the human being as care: in human existence the happening of being is what is the concern for the human being. ${ }^{38}$ Secondly, the existence, consisting of understanding Being, is at the source of all meaning. ${ }^{39}$ Thirdly, Being is so much mine, that my existence brings potential meanings of being to expression; but actually, what happens (and this comes better to the fore in the second Heidegger, in Levinas' view) is that I am seized by being that expresses itself through me $\mathrm{e}^{40}$ (this seems to be the point of convergence between Merleau-Ponty and Heidegger). ${ }^{41}$ Fourthly, this perspective on human existence necessarily problematises a notion of subjectivity as interiority and reflection; the end of the subject dawns when, as apparently for Heidegger,

"the subject has nothing interior to express. It is altogether thought from Being and the truth of Being.",42

The consequence of this is that

“it is not the human being, that has an I don't know what proper vocation that would invent or seek or possess the truth. It is the truth [of Being - EW] that arouses and holds the human being (without holding any commitment to the human being).,43

37 The philosophy of after the so-called Kehre is interpreted by Levinas as an extension of implications of what is already implicit in Being and time. He refers to Heidegger's philosophy as "the most influential philosophic thought of our century, which already tries to be post philosophic." (HO 60 / HH 99). And after having reformulated what he considers the appropriate response to anti-humanism, Levinas confronts Heidegger directly so as to indicate the ambition of his reconsideration of ethics (HO 65ff / HH 107ff).

$38 \mathrm{HO}$ 25, 29/HH 41, 48 and paraphrased $\mathrm{HO} 47$ / HH 76.

$39 \mathrm{HO} 25$ / HH 41. HO 49 / HH 79: "Action, freedom, beginning, present, representation - memory and history - articulate in various ways the ontological modality that is consciousness."

40 Cf. HO 47f / HH 76 where one finds a succinct summary of Levinas' perspective on Heidegger: 'Even if man's existence - the being-there [= Dasein - EW] - consisted in existing in view of that existence itself, that ex-sistence, all those movements and reversals arousing and situating the human would be dedicated to caretaking or illuminating or obscuring or forgetting Being [l'être], which is not in the being [étant]. Subjectivity would appear, in view of its own disappearance, a moment necessary to the manifestation of the structure of Being, of the Idea."

$41 \mathrm{HO} 17 / \mathrm{HH} 29$ and cf. ENT 112 / EN 122.

$42 \mathrm{HO} 75 / \mathrm{HH} 122 \mathrm{n} 4$.

$43 \mathrm{HO} 47$ / HH 76 - translation modified - and almost the same wording in HO 59 / HH 97. 
One could call Heidegger's position, summarised in these points, as one of the end of metaphysics, as far as metaphysics depends on the idea of the individualist, reflective and autonomous or free subject. But this end of metaphysics stretches much further than just the thinking of one philosopher. In fact, it encapsulates the state of affairs in the human sciences, dominated by structuralism, at the time Levinas writes, ${ }^{44}$ in which the subject (or at least a certain notion of the subject) has commonly become suspect: just as in Heidegger, here too the subject is not considered to hold the truth, but the truth - in this case the structures directing human phenomena - expresses itself through the human being. ${ }^{45}$ The social scientific theories that are in accord with Heidegger's end of metaphysics, ${ }^{46}$ are sometimes typified as representing a same end of the subject, "end of humanism" or "anti-humanism". These could, in turn, all be considered symptoms of what is called in Nietzschean parlance the death of God. ${ }^{47}$

This anti-humanism is presented in Humanism of the other from three perspectives: (1) the end of the human being as subject, ${ }^{48}$ (2) the putting to question of the human being as a "rational animal" by the political catastrophes of the twentieth century ${ }^{49}$ and (3) the crisis of culture due to the diversity of cultural expressions without common measure for evaluation. ${ }^{50}$

\subsection{End of the subject}

The first aspect of anti-humanism - the decentring of the human subject has already been presented as an introduction to the crisis of humanism. This decentring consists of adjourning the autonomous subject with its lucid, re-

$44 \mathrm{HO} 58 / \mathrm{HH} 95$.

$45 \mathrm{HO} 47,72 \mathrm{n} 3 / \mathrm{HH} 76,118 \mathrm{n} 3$. One should be vigilant when reading Levinas' renderings of the essence of structuralism. In HO 71f / HH 118n1 he refers with approbation to the essay of Michel Serres, "Analyse symbolique et méthode structurale" (in Revue philosophique de la France et de l'étranger 171, 1967, pp. 437-452), as an illuminating interpretation of structuralism. I suspect that a detailed research into the sources of Levinas' knowledge and interpretation of structuralism would show that he owes a lot to this essay, if not perhaps as much as to Merleau-Ponty, for the development of his perspective on cultural relativism. The importance of such a research could be indicated by contrasting Levinas' remarks on the profoundest nature of structuralism in Humanism of the other with his admission in an interview of 1987 that “even today I still don't understand structuralism” (EL 161).

46 E.g., HO 61 / HH 100.

$47 \mathrm{HO} 58 / \mathrm{HH} 95$.

48 HO 58-61 / HH 95-101.

$49 \mathrm{HO} 45-46 / \mathrm{HH} 73-74$.

50 HO 9-25/ HH 17-41. 
flective vision of its own interiority, and considering the human being, consciousness and all, as subordinate to anonymous structures. The roots of this idea go back at least as far as Hegel. ${ }^{51}$ There is a substantial convergence between the (contemporary, structuralist) human sciences and Heidegger on this point, which amounts to the negation of interiority, ${ }^{52}$ reducing consciousness to an epiphenomenon (but also shepherd, poet or messenger) ${ }^{53}$ of an underlying structural process. Emblematic of this change in paradigm is the decentring of the Cartesian cogito by psychoanalysis: what was supposed to be the substantial subject as fortress against the malin génie, is now reduced to a mask, a persona ${ }^{54}$ of dark forces that has taken control of it. ${ }^{55}$ The same holds for the practice of ethnography that describes the objective structures underlying cultural phenomena, even whilst obeying such a structure. ${ }^{56}$ Of the transmitted safe fortress of interiority remains not much more than an exposure to the whims of unmasterable structures and forces. Or again in ontological terms: the subject, even whilst conjugating the verb to $b e$, is so dominated by it that every conjugation is only an apparent mastery, only a being subjugated to a meaning imposed on it by Being.

\subsection{Questioning the rationality of the animal rationale}

This dissolution of the subject as master of itself is reflected in the political scene. The subject that would, as autonomous agent, embark on realising a pre-meditated project, seems in reality to be only rushed along to tragedies for others and for itself.

"[T]hat politics and an administration guided by the humanist ideal maintain the exploitation of man by man, and war, ${ }^{, 57}$

is a paradox that invites one to disbelieve and disqualify the causality of the human agent (which amounts to the rejection of the subject as causa sui). This tragic paradox becomes almost comical when one considers the unparalleled means over which humanity in the twentieth century disposes and the ambitions formulated by people. The human being becomes ineffi-

51 HO 72n3, 60/ HH 118n3, 97.

$52 \mathrm{HO} 60,61 / \mathrm{HH} 99,100$.

$53 \mathrm{HO} 61 / \mathrm{HH} 100-101$.

54 Levinas plays with the French word "personne": meaning either "person", "somebody" or "nobody".

$55 \mathrm{Cf}$. HO 45 / HH 74, which amounts to the rejection of the subject as subiectum or hypokeimenon.

$56 \mathrm{HO} 47 / \mathrm{HH} 77$.

$57 \mathrm{HO} 59 \mathrm{f} / \mathrm{HH} 97$. 
cient to the point of being the toy of its technology and of its political programmes. ${ }^{58}$ The very idea of the human being as animal rationale is thus thrown into a crisis. ${ }^{59}$ The idea of the subject as master of his/her intentions is not capable of articulating the most pressing questions of the after war years; for Levinas' contemporaries the deepest anguish

"comes from seeing revolutions founder in bureaucracy and repression and of totalitarian violence passing for revolutions". 60

And one can imagine that when the word "totalitarianism" is used, for Levinas the reminiscence of Hitler and the camps would not be far away.

\subsection{Cultural relativity or the death of God}

Although Levinas doesn't call the third aspect of anti-humanism by this name, his presentation of it in a book on an alternative humanism as well as the exact equivalence in his way of countering it (equivalent to his response to the other elements of anti-humanism), allow us to name it antihumanist. This problem, which takes up a very big part of the book, ${ }^{61}$ also leads us to what Levinas considers the core of anti-humanism, namely the so-called "death of God".

The first chapter of Humanism of the other thematises cultural relativity. As indicated above, Levinas will tackle this problem by referring it to the constitution of meaning. He proposes a basic introduction to the question of cultural relativity by translating it into ontological terms according to which Being itself comes to expression in the multiplicity of cultural expressions; ${ }^{6}$ every cultural action or object speaks of Being. In this, according to Levinas, contemporary philosophy is radically anti-Platonic:

"for Plato, the world of significations precedes the language and the culture that express it; it [the Platonic world of meanings - EW] is indifferent to the system

$58 \mathrm{HO} 45 / \mathrm{HH} 73$.

$59 \mathrm{HO} 45,48 \mathrm{f} / \mathrm{HH} 74,78$. But one should be very careful in stating this point. Whereas Levinas remains sceptical as to the restoration of the animal rationale in the sense of mastering praxis (as set out here), his entire philosophical enterprise could be considered as rethinking the definition of the human being as zoon logon echon (of which animal rationale is the traditional Latin translation). Heidegger already undertook such an enterprise and Levinas never rejected the idea that the entire human being is a logos on being; what he did was to relativise the ontological logos that one is oneself, by another logos, spoken by the face of the other $(\mathrm{HO}$ 31 / $\mathrm{HH} 51)$.

$60 \mathrm{HO} 60 / \mathrm{HH} 98$.

$61 \mathrm{HH} 9-25 / \mathrm{HH} 17-41$ - much more than the previous two.

$62 \mathrm{HO} 18 / \mathrm{HH} 30$. 
of signs that can be invented to make this world present to thought. Consequently, it [the world of meanings - EW] dominates the historical cultures. ${ }^{\circ 3}$

Contemporary philosophy, therefore, is anti-Platonic in the sense that it rejects outright any conception of such an ultimate and authoritative world of meaning behind the diversity of cultures, and subordinates meaning to the way in which it is expressed, in other words, all meaning is dependent on the culturally specific way of its expression; without this specificity there is no meaning. If this is accepted, it would mean that there is no way to judge or evaluate cultures, or at least there is no way in which to judge particular cultures, without the judging itself being at the same time an expression of a particular culture. There would be no super-culture that transcends its expression. That this is maintained in modern ethnology and is also reflected in the politics of decolonisation (which is nothing less than the historicopolitical manifestation of the rejection of a trans-cultural access of the colonising forces to a trans-historical human ideal) has been discussed in Chapters 2 and $3 .^{64}$ Even Marxist theories that attempt to introduce a crosscultural criterion by reference to human needs, inevitably slide into this cultural relativism since the discourse on needs is motivated by the will to create a new society and, thus, the very formulation and manifestation of needs is culturally determined. ${ }^{65}$

What this leads to is what Levinas calls "the cultural, aesthetic notion of signification [la notion culturelle et esthétique de la signification]". ${ }^{66}$ Such a notion of signification or meaning inevitably slides into absurdity, according to him - not the absurdity of absence of any meaning (since every culture would still have its internal coherence of references that would serve to give meaning to every cultural act or object), but, the absence of ultimate, transcultural or super-cultural reference. Levinas certainly does not deny that one could establish criteria against which different cultures or cultural elements could be compared or graded (such as efficiency in the realisation of particular kinds of project, for instance), but such criteria would themselves be culture specific. ${ }^{67}$ Besides, such criteria would not be sufficient to determine if elements of cultures are of value at all. As far as the ontological per-

63 HO 18 / HH 31. See again Chapter 3, § 2 on Platonism and colonisation.

64 Having presented this line of thought on the anti-Platonism of contemporary culture, one could again refer to the essential equivalence that consistently guides this reflection from the moment Levinas jotted down the preparatory notes for it (now available under the "Notes philosophiques diverses"): " $9{ }^{\circ}$ Anti-Platonism. Disorientation. Equivalence. Decolonisation." (CdC 263).

65 HO 21-22 / HH 35-37.

$66 \mathrm{OH} 22 / \mathrm{HH} 38$.

$67 \mathrm{HO} 37 / \mathrm{HH} 59$. 
spective on cultural diversity is adopted no finality could be reached on the significance or importance of a culture or of the practices that constitute a culture. ${ }^{68}$ Up to this point Levinas ascribes to a cultural relativism. What is lacking from this picture, according to him, is the meaning of meaning or rather the sense of signification (in the terms of the title of $\mathrm{HO}$, chapter 1), i.e., that which would provide the cultural diversity with an orientation. This lack of orientation in the cultural diversity, which is inherent in the contemporary cultural and aesthetic notion of meaning, bears, since Nietzsche, another name in philosophy: the death of God; ${ }^{69}$ Levinas also calls it "the crisis of monotheism". ${ }^{70}$

Far from resuscitating a God from one of the world religions or one from the philosophical tradition (but not without being inspired by what he has learned from Judaism and from Western metaphysics), Levinas first contests the status of transcendence of such a "God": he ascribes to the death of a certain God, but believes that if philosophy is to surmount the problem of

68 "Absurdity does not lie in non-sense but in the isolation of countless significations, the absence of a sense that orients them. What is lacking is the sense of the senses" (HO 24 / HH 40). This statement is never justified by its author. Let it at least be noted that an interesting avenue for reconstructing a dialogue between Levinas and the Frankfurt School is opened by this remark: cf. Jürgen Habermas, "Zu Max Horkheimers Satz: "Einen unbedingten Sinn zu retten ohne Gott, ist eitel", in Texte und Kontexte, Frankfurt am Main: Suhrkamp, 1991, pp. 110-126. Levinas' constant companion in the first Chapter of Humanism of the other is Merleau-Ponty. Although no explicit reference to any text of Merleau-Ponty is made, it is not too difficult to find significant elements of the "cultural notion of meaning", for instance in Signes (Paris: Gallimard, 1960), where Merleau-Ponty elaborates not only on the unity and plurality of culture as an expression of the body (pp. 110 112 ) and the fact that one is, through culture, linked with others and even responsible for others (p. 121), but proposes nothing more than history as the judge between these different cultural expressions. Likewise, Levinas' politico-cultural diagnosis (in the absence of recognition of ethical alterity) from the first Chapter of Humanism of the other is captured succinctly in Merleau-Ponty's Sens et Non-sens (Paris: Gallimard, [1966] 1996), "In politics, finally, the experience of these thirty years obliges one also to evoke the background of non-sense against which all universal undertaking stands out and that threatens is with failure." (p. 8).

69 It should be underscored that what is at stake here is first of all a crisis of the human sciences and of contemporary European culture, and only secondarily the question of the existence of a deity. Cf. Paul van Tongeren, Reinterpreting modern culture. An introduction to Friedrich Nietzsche's philosophy, West Lafayette: Purdue University Press, 2000, of which the main point is summarised as follows: "The main problem which Nietzsche confronts us with is not so much that God is dead but that we do not understand or do not admit what this means. [...] His critique of religion is a critique of modern a-religiosity, a diagnosis of modern culture." (p. 285).

$70 \mathrm{HO} 24$ / $\mathrm{HH} 40$. 
absurdity it must revert to the notion of God or at least the infinite. ${ }^{71}$ The God whom Levinas, the philosopher, believes is dead is the God of ontology. ${ }^{72}$ The "God" that could orientate the plurality of cultures, on whom all cultures depend for the significance of their meaning, is the God of ethics.

To summarise: cultural diversity and equivalence - to which contemporary philosophy, social science and political reality attest - lead to an absurdity without any transcendent, super-cultural source of meaning that could orientate them. This lack of transcendence is rooted in the ontological existence of the human being, to be precise, in the mineness, from which, as far as one remains Heideggerian (and if Levinas' reading of him is accepted) there is no escape. The diversity of logoi that human beings are, all speak of Being (they are ontology), but without any escape from their disorientating diversity. Seeking a transcendent meaning or sense, means the same as seeking an escape from mineness, which also means the same as seeking to overcome the death of God. And this in turn means seeking to prevent humanity from getting lost by lapsing into absurdity. In the first chapter of Humanism of the other Levinas gives a formulation of his problem in terms of culture, ontology and meaning. However, in the second and third chapters of his book, he argues that it would be in vain to attempt to respond to this problem by recourse to the resources or the subject (as has been indicated above). Let it be stated clearly that Levinas accepts a good number of major anti-humanist ideas ${ }^{73}$ - as long as one leaves out of consideration what he will defend as ultimate meaning or the sense of all signification, namely ethicity.

\section{HUMANISM AND ETHICITY}

The problem, and the reason why Levinas feels himself called to write on the humanism of the other human being, is exactly that an infringement is taking place on the humanity of the self and the other. This happens in a

71 Levinas refers to the Second World War as a "hole in history - [years] when all the visible gods had abandoned us, where god was truly dead or had gone back to his irrevelation." (HO 28 / HH 46). Compare with HO 25 / HH 41: "We do not think that what makes sense can do without God [...]" and HO 36 / HH 57 where he refers to the necessity of philosophical meditation "to resort to notions such as Infinity or God."

72 Furthermore, as has been shown in his commentary on the "primitive" religions, he considers the "gods" to be dead (Chapter 2), and his reservations about certain traditional forms of Jewish expression declare the traditional monotheistic God, at least for intellectual and ethical purposes, dead (Chapter 4).

73 See also OB 127 / AE 203. 
contemporary discourse in the social sciences that is typified as antihumanist. Levinas doesn't hesitate to link this fact to the name of Hitler, ${ }^{74}$ which means that theoretical anti-humanism is not simply an academic debate, it puts in jeopardy again, as Levinas said in 1934, the very humanity of the human being (the book Humanism of the other ends on exactly the same idea as that of the essay of 1934). ${ }^{75}$ But how does Levinas justify this idea? And what does his notion of humanity consist of?

It becomes clear, right from the preface, that Levinas' concern in this book is with political and human scientific events or tendencies that do violence to the humanity of the human being. To this he attempts to give a response, which one knows from the title of the book he will identify in some way as a "humanism", in particular a "humanism of the other human".

In the preface, Levinas qualifies the project of his book by the word "inactuel" or later "intempestif". Sure enough, one could take this to mean non-topical, untimely or misplaced, and Levinas recognizes from the first page that his use of the word "humanism" could, in 1972, be considered to be out-of-date. But "inactuel" and "intempestif" are more of those words from the Western philosophical tradition that Levinas tries to provide with an overtone or a different reverberation. "Inactuel" and "intempestif" are in fact the French words with which one translates the German "unzeitgemä $\beta$ ", in particular as in the title of Nietzsche's book Unzeitgemäße Betrachtungen. Levinas implicitly presents his book Humanism of the other as an Unzeitgemäße Betrachtung, an untimely meditation or an unfashionable observation (as the title of Nietzsche's book has been translated in English). ${ }^{76}$ What is more, he will do so by opening up a new meaning of the word "inactuel", non-actual.

"Here the non-actual [l'inactuel] signifies the other of the actual [l'actuel] rather than ignorance and negation of it; the other of what, in the high Western tradition, is commonly called Being-in-act [être-en-acte] [...] the other of Being-in-act, but also its cohort of virtualities that are potentials; the other of Being, of the esse of Being, of the gesture of Being, the other of fully Being [pleinement être] [...] stated in this expression in act [en acte]; the other of Being itself - the untimely [l'intempestif] that interrupts the synthesis of presents that constitutes memorable time.,"77

$74 \mathrm{OH} 6$ / HH 11; and cf. "Hitlerism" HO 29 / HH 47 and the reference to Léon Blum's prison writings of 1941-42, $\mathrm{HO} 28$ / $\mathrm{HH} 46-47$.

75 Cf. HO 69/ HH 113.

76 It should be observed that there is no other text of Levinas in which references to Nietzsche take such a dominant place.

$77 \mathrm{HO} 3 / \mathrm{HH} 7-8$, translation modified. 
Without going into the detail of this dense statement, one should at least see that what Levinas defines as non-actual (inactuel and intempestif) and that is equivalent to "the humanism of the other human being", is that which is other to the whole Western tradition of thinking ${ }^{78}$ - from Aristotle (cf. "Being-in-act") to Heidegger (cf. "the esse of Being",79) - that places reflection on Being in its centre. As indicated above, in the book Humanism of the other, Levinas is still occupied with the fact of mineness, i.e., one's attachment to Being without any exit ("Being without issue"). ${ }^{80}$ Levinas is still concerned with the ontological issue of being drawn along fatally by Being. And his response is not of the order of Being, in fact it is foreign to Being in that he defends the case for a kind of meaning that emerges independently of ontology, ${ }^{81}$ and that is, for this reason, independent of Being-as-act, and therefore in-actual. Levinas' humanism is untimely, not because it was unfashionable in the 1970s to defend humanism in philosophy, but it is untimely since it draws its sources from what is absolutely foreign to Being as time, and thus to all ontological sources of meaning. It is in-actual with reference to the human being whose concern in being would be caring for Being. What is untimely is a consideration of humanism viewed as ethicity (or what Levinas names "ethics itself [l'éthique même]"82) that is not reducible to the logos of Being, to the cultural, social, religious, ethnic or whatever condition of the human being - as is done, for instance, in Nietzsche's On the genealogy of morals - but an untimely consideration of

78 Whereas Levinas will be inspired by another tradition - that of Judaism - his concern here is not to confront Western culture with another culture, but to confront it with what is not only the other of Western culture, but also of all other cultures, including Judaism. Though, rarely, if ever, does Levinas state it so categorically. This does, of course, not take away from the fact that Judaism could be valued as testimony to that non-cultural meaning, a possibility that in turn should not be denied a priori to any other culture.

79 Cf. "essence of Being" (HO 61, 63 / HH 100, 103, where "essence" is used as an abstract noun describing the very verbality of Being). This use of the word "essence", rather than the traditional use, is explicitly announced in the preface to Otherwise than Being.

80 As is said in $\mathrm{HO} 59 / \mathrm{HH} 97$.

81 " $[\mathrm{t}$ t means casting doubt on experience as source of sense" (HO 6 / HH 11) and HO 36 / HH 57: "the 'term' of such a movement, both critical and spontaneous [...] is no longer called Being."; HO 67 / HH 110: "Non-essence of man" (a parody of anti-humanist criticism of humanist essentialism, but Levinas of course means something different by "essence"). One here already recognises the theme that would be encapsulated in the title of the book Otherwise than Being or beyond essence.

$82 \mathrm{HO} 28 / \mathrm{HH} 46$. 
ethicity as an irreducible imperative or putting to question ${ }^{83}$ addressed by the other human being to the (mostly pre-predicatively stated) ontological identity of the self. That is, a meaning, a $\log o s$, that is not in the indicative, but in the imperative or interrogative.

If indeed such an originary ethical meaning is more than mere wishful thinking, Levinas would have to present it in such a way that this meaning is not dependent on any specific culture. ${ }^{84}$ The essence of Levinas' justification of ethics now needs to be outlined; this will be done referring mostly to Humanism of the other.

Levinas never renounces the great lesson from Heidegger, namely that meaning originates in the act of Being. What he does question is that this exhausts human access to meaningfulness. His whole project consists in demonstrating another, and more originary, source of meaning that is ethical. This twofold meaningfulness of human existence is analysed under the name of ageing (vieillissement). ${ }^{85}$ The human being might be considered to be persevering in his/her existence, or identity as selfness - of which the visible appearance is ageing - but at the same time, this perseverance is executed only despite oneself (malgré soi) or despite Being (malgré l'être), ${ }^{86}$ since the more one exists the more one consumes one's existence. In ageing one sees existence as being gained and lost at the same time. This passivity from which one's active existence cannot be detached is not the passivity of undergoing an experience (since this is, phenomenologically seen, only another form of activity), but what Levinas calls "a passivity that is more passive than any passivity". ${ }^{87}$ Levinas' wager is that this losing existence despite yourself, this extreme passivity, has its own meaning, namely one of inevitably ceding your existence to the other. What Levinas says about the contemporary consensus concerning language, and by implication about all signification, holds equally for Levinas' perspective on the human being as incarnate logos (i.e., the active aspect of existence): certainly one should insist on its hermeneutic (and therefore also its historically contingent)

$83 \mathrm{Cf}$. HO 6 / HH 11, and Levinas insists that this questioning is "a challenge of consciousness, not a consciousness of the challenge [la mise en question de la conscience et non pas d'une conscience de la mise en question]" $\mathrm{HO} 33$ / $\mathrm{HH} 53$; and a slightly different wording in $\mathrm{HO} 36 / \mathrm{HH} 57$.

$84 \mathrm{HO} 6 / \mathrm{HH} 11$.

85 It is used only in passing in $\mathrm{HO} 65$ / $\mathrm{HH} 106$, but developed in more detail in $\mathrm{OB}$ 51-56 / AE 86-94. It has already figured in our discussion in Chapter 1. I should here remind the reader of Levinas' declaration that his philosophical objective was the justification for these two sources of meaning.

86 OB 51 / AE 86, HO 68 / HH 110 or HO 51 / HH 82.

87 E.g., HO 6/HH 11. 
structure and on the cultural determinedness of all expressions, ${ }^{88}$ but, he adds, one should not forget that the logos, in all its diversity, is addressed at someone, in the sense of being exposed to the other. ${ }^{89}$ Without consideration for this directedness of the logos that one is, its meaning will remain absurd, like the meaning of a turn of speech in a dialogue in which the fact of being addressed by and responding to someone is ignored. Due to the extreme passivity of one's existence, despite yourself, your whole existence, your entire perseverance in a particular identity is exposed to or addressed to the other. This holds equally for all cultural expressions or utterances, it also holds for all actions (the ontological logos as praxis). Pre-predicatively, the human being is not only a logos, a "statement", concerning Being, but the human being is such a logos always as directed to someone in a very particular way, namely as a response to the other, as "an offering of oneself" (une offrande de soi)..$^{90}$ The other enjoys a primary place in my existence such that the logos that I am, is always only a response to the other. This aspect of responsiveness is a surplus of meaning or sense ${ }^{91}$ over and above, or rather before, the meaning of the ontological existence. This surplus in the response is therefore characterised by Levinas as not ontological, as ethical, i.e., the response-character of my whole being constitutes my being as responsibility for the other. The same idea is expressed differently from the side of the other: the face of the other speaks, ${ }^{92}$ it imposes on the self an inalienable task of responsibility. In fact the other elects the self, as it were, as unique to this responsibility. No one could replace the self in this task and the responsibility remains infinite. This ethical appeal from the other to the self invests it with the first meaning: mere formal ethicity. This non-ontological meaning is completely independent from all hermeneutic and cultural conditions, but determines the latter decisively, since these conditions come

$88 \mathrm{HO} 30 / \mathrm{HH} 49-50$.

$89 \mathrm{HO} 63$ / HH 104. "[B]efore it is celebration of Being, expression is a relation with the one to whom I express the expression and whose presence is already required so that my cultural gesture of expression can be produced. [... The other] is, primordially, sense because he [or she] lends it to expression itself, because only through him [or her] can a phenomenon such as signification introduce itself, of itself, into Being." (HO 30 / HH 50).

The subject is thus not only decentred by the structures identified by the human scientists and thus exposed to the exterior rather than collected in its own interiority (as described above), but also, and Levinas would say most importantly, one is exposed to the other. This exposure is the advent of ethicity.

$90 \mathrm{HO} 75 \mathrm{n} 4 / \mathrm{HH} 122 \mathrm{n} 4$, my translation.

91 HO 69/HH 113.

$92 \mathrm{HO} 31 / \mathrm{HH} 51$. 
only "after" ethicity. ${ }^{93}$ This is the meaning and sense of all culture, it is the "God" that Levinas believes is to be salvaged. ${ }^{94}$ The world may be deWesternized, but not dis-orientated, according to Levinas' play on words ${ }^{95}-$ a new form of Platonism is introduced in which the entire trans-cultural hinterworld consists only of the Good beyond Being. ${ }^{96}$

This ethicity thus resides in an "intrigue" or "plot" 97 that "occurs" between the self and the other: the alterity (of the other) is not to be understood as the difference of the other with respect to the self (since this would make it a relative alterity); it is the other putting to question the self (the ontological identity), making an appeal to the self for his/her responsibility, and thus investing the self with the most decisive mark of identity: being elected to respond to the other. This obligation of the self towards the other is a duty

"that did not ask for consent, that come into me traumatically, from beneath all rememorable present, an-archically [used in the etymological sense of "notfoundationally" - EW], without beginning. [The duty] came without being offered as a choice, came as an election where my contingent humanity becomes identity and unicity, through the impossibility of escaping from election. ${ }^{, 98}$

Thus is answered what the title of the book means: humanism is a discourse on humanity, but in which humanity, even though it says something about the unity of all human beings ${ }^{99}$ transcends the idea of "humanity" as indication of a genus of animal - humanity contains an inherent asymmetry: it doesn't mean the same for the other and for the self. For the other "being human" means to exert a pre-predicative imperative or questioning on the self (i.e., neglecting the ethical alterity of the other equals infringing on that person's humanity); for the self "being human" means to have one's

$93 \mathrm{HO} 36 / \mathrm{HH} 58$.

94 But there is nothing obvious in this appellation: the Good, as ultimate sense of valuation, is a value "that, by abuse of language, is named. A value that is named God." (HO 54 / HH 87 and see HO 56 / HH 89).

$95 \mathrm{HO} 37 / \mathrm{HH} 60$.

$96 \mathrm{HO} 54 / \mathrm{HH} 86$.

97 The term "intrigue" is not used in Humanism of the other, but introduced in "La trace de l'autre" (first published in 1963, DEHH 187-202) and is used to describe the originary ethicity linking the self and the other in exactly the same terms as in the last part of Chapter 1 of HO. See also the use of "intrigue" in the definition given of ethics: "We call 'ethical' a relation between terms where both are linked neither by a synthesis of understanding, nor by a relation of a subject to an object, but where the one weighs on the other or is important for the other, or is meaningful for the other, where they are linked by a plot that knowledge can neither exhaust, nor sort out [une intrigue que le savoir ne saurait ni épuiser ni démêler]." DEHH 225.

$98 \mathrm{HO} 7 / \mathrm{HH} 12-13$

$99 \mathrm{HO} 6 / \mathrm{HH} 11$ 
identity before anything else in the assignment to respond to the other (i.e., removing from the self its obligation to the other is an infringement on the humanity of the self) ${ }^{100}$ the $\log o s$ (or identity) that the self inevitably is, now is a logos addressed to the other, in response to the other, and to the benefit of the other. The identity of the self is a sign for-the-other. ${ }^{101}$ Levinas' humanism is a humanism "of the other human being" in that it could not be a humanism of the single self. It is a humanism that depends on the other, it is "anchored" in alterity, and thus it is a humanism to which the other has the right, it is the other's humanism and thus a humanism for the other. ${ }^{102}$ But the humanity of the other and the humanity of the self imply one another mutually in an inseparable way. If this is what Levinas understands under his "humanism", then it is this double decentring of humanism - its orientation from the other (rather than from the self) and from alterity (rather than from ontology) - that warrants qualifying Levinas' stance as that of a post-anti-humanist humanism.

\section{4 “ETHicAl CULTURE” AND THE "CULTURAL AND AESTHETIC NOTION OF MEANING"}

In the circumscription of humanism in the opening paragraphs of this Part the very important place of cultural products in the life of humanism has been pointed out. Yet, from the preceding discussion, in which it was shown how Levinas renews the notion of humanism with recourse to the contextindependent meaning of the appeal to responsibility, imposed by the other on the self, it is still not indicated in what way the ethical would "make sense" of the plurality of cultures. Levinas therefore needs to explicate the tensions between these two positions. To be true, Levinas doesn't conclude the discussion of the "cultural and aesthetic notion of meaning" without reinvesting the very notion of culture with a new meaning:

$100 \mathrm{HO} 66 / \mathrm{HH} 109$. One sees this asymmetrical, but linked, salvaging of the self and the other in different terms also in the preface to Totality and infinity, amongst others.

$101 \mathrm{HO} 7,75 \mathrm{n} 8 / \mathrm{HH} 13,122 \mathrm{n} 8$.

102 See also Levinas' clarification: "I don't affirm human saintliness; I say that man cannot question the supreme value of saintliness. In 1968, the year of questioning in and around the universities, all values were 'up for grabs', with the exception of the value of the 'other man', to which one was to dedicate oneself. [...] Man is the being who recognizes saintliness and the forgetting of self [l'oubli de soi]. [...] Man is not only the being who understands what beings means [...]" (A\&T 180/ AT 181). 
"We will conclude by saying that before signification is situated in Culture and Aesthetics it is situated in Ethics, presupposition of all Culture and all signification. Morality does not belong to Culture; it allows us to judge, to uncover height. Height ordains being. ${ }^{103}$

In a paper published in 1983, "The philosophical determination of the idea of culture" $" 104$ he takes this perspective on culture further by calling this ethics an "ethical Culture". This notion seems to be justified by the fact that ethics, as the fact of always responding to the other, gives rise to a new notion of spirit/mind (esprit) ${ }^{105}$ that is defined by this responsibility to the other rather than by expressions in art and poetry. It is a culture that is defined in opposition to barbarism, but where barbarism is implicitly defined by the reduction of the human being to Being (one could recall the remark of Levinas' in On escape that 'every civilization that accepts Being, the tragic despair that it entails and the crimes that it justifies, deserves the name of barbaric"). ${ }^{106}$ The culture that is ethics is the

"breach made by humanness in the barbarism of Being, even if no philosophy of history guarantees us against the return of barbarism". 107

One might perhaps reformulate that this "ethical culture" is a humanism without an optimism of progress. It would also be a humanism without any Bildung or cultural formation towards a pre-established model of an ideal human being, but rather a humanism or an ethical culture that is constantly questioned by the other's appeal to responsibility. In this respect, the humanism of Humanism of the other differs from the two essays on education and humanism in Difficult freedom (see Chapter 4) and especially the earlier one, in that the philosophical text makes no plea for a humanistic study of certain cultural traditions of reflection on ethics (although it certainly doesn't exclude it).

But Humanism of the other gives us a better, albeit surprising, idea of what such an ethical culture is, that transcends all particular cultures and in the light of which all cultural events - including all forms of relationships and interactions between the self and the other - could be judged. Like all cultures, ethical culture identifies the self. But in Levinas' notion of ethical culture this happens in a very paradoxical way. What is most intimate about one's identity, the very non-founded foundation thereof, is the unique election to be responsible for the other (and in this notion the phi-

\footnotetext{
$103 \mathrm{HO} 36 / \mathrm{HH} 58$, translation modified.

104 ENT 179-187 / EN 185-194.

105 ENT 187 / EN 193.

106 EV 127.

107 ENT 187 / EN 194.
} 
losophical re-appropriation of humanism is very close to that of the two texts from Difficult freedom). One's identity is the other in the self, to the point where the meaning of my identity depends decisively on me being for-the-other, as if I were a sign for the other. ${ }^{108}$

"To be Me/Ego, thenceforth signifies being unable to escape from responsibility, as if the whole edifice of creation stood on my shoulders."109

And this meaning that constitutes the identity decisively undermines my ontologically constituted identity. The most intimate of the identity of the self is the other that invests it with an infinite obligation. Consciousness, and for the same price, the whole existence of the self "loses its first place", ${ }^{110}$ since it is disturbed by an originary alienating proximity of the other. ${ }^{111}$ And since the other has the primacy in the identity of the self, Levinas expresses this inversion (or substitution as he also calls it) ${ }^{112}$ with a grammatical imagery, claiming that

"[t]he active I [Moi] returns to the passivity of a myself [soi], to the accusative of the $m e[s e]$ that is derived from no nominative, to the accusation prior to any misdeed." 113

This form of identity in the accusative is expressed in a Biblical formula by which to declare one's ethical availability: "Me voici!" ("here I am!"), and that Levinas frequently cites ${ }^{114}$ (the English, "Here I am!" unfortunately restores the nominative form of the personal pronoun). I am $m e$ before I am $I$, because of the originary exposure to the other.

My identity is thus not that last stronghold of my being-at-home in the world; it is rather the fact that as

"[f]oreign(er) to itself, obsessed by others, un-quiet, the I is hostage, hostage in its very recurrence of a "me" endlessly failing to itself". ${ }^{115}$

$108 \mathrm{HO} 7 / \mathrm{HH} 13$, as stated above.

$109 \mathrm{HO} 33 / \mathrm{HH} 53$.

$110 \mathrm{HO} 32 / \mathrm{HH} 53$.

111 " []$]$ the approach to others, where others are form the start under my responsibility, 'something' has overflowed my freely made decisions, has slipped into me unbeknownst to me, alienating my identity." (HO 62 / HH 102).

$112 \mathrm{HO} 6 / \mathrm{HH} 111$

113 HO 64 / HH 105, similarly HO 68 / HH 111, translation modified.

114 Although this formula is used in numerous places in the Hebrew Bible, it is perhaps not insignificant to consider the note in the Carnets de Captivité where Levinas expresses his appreciation for the place that this formula has in the story of the calling of Samuel (CdC 78, 83). The child Samuel, who had not yet learned to hear the voice of God, thinks that it is the priest Eli that calls him. Although Levinas doesn't explicitly say so, the confusion of the call of God and the call of the other, is probably what makes this passage exceptional.

$115 \mathrm{HO} 67 / \mathrm{HH} 109$, translation modified. 
In fact the self's identity consists originarily in being without identity, ${ }^{116}$ since its very identity is constituted by a difference:

"The difference that gapes between ego and self, the non-coincidence of the identical, is a thorough non-indifference with regard to people."

Levinas shares the anti-humanist liking for the line of Rimbaud "Je est un autre" ("I is another"); ${ }^{118}$ he fully embraces a decentring of the subject, but in terms of his own, claiming to be even more radical than the other anti-humanist theorists.

This is the identity with which the super-cultural ethical culture stamps all agents. ${ }^{119}$ It is also the conviction with which Levinas challenges Heidegger $^{120}$ and with him the entire Western tradition of philosophy and culture (in accordance with what has been stated from the outset - see $\S 1$, above). However, in this particular part of Chapter 3 of Humanism of the other (§IV entitled "L'étrangeté à l'être", strangeness or foreignness to Being) Levinas clearly sets up two traditions against one another: on the one hand the tradition of the pre-Socratics, Plato, Aristotle, Descartes, Heidegger (and the latter's readings of Hölderlin and Trakl) are named and referred to by the "être" (Being as a verb or to be) in the section's title; on the other hand, representing the "étrangeté à ..." (strangeness to ...) is the Bible, ${ }^{121}$ more precisely the Tanakh (that is also referred to as the Hebrew Bible or Old Testament) and the tradition of its interpretation (that echoes the citation of the Babylonian Talmud as epigraph to this chapter of Humanism of the other), of which the books of Genesis, Leviticus, Lamentations, Jeremiah and the Psalms are named. This opposition advances the idea of ethics as a strangeness to Being (that I have explained above; see also the discussion of the in-actuality of ethics, above). Not only is one's identity originarily not determined by your place in the world or in history, but since the self is a stranger to himself/herself nobody is (originarily) at home (Personne n'est chez soi). ${ }^{122}$

$116 \mathrm{HO} 68 / \mathrm{HH} 110$.

117 HO 66/ HH 108-109, translation modified.

$118 \mathrm{HO} 60$ / HH 97 and especially HO 62 / HH 103.

119 And the other is as if in the image of God - not an icon of God, but as it were, a trace of God (HO 44 / HH 69).

$120 \mathrm{HO} 65 \mathrm{ff} / \mathrm{HH} 107 \mathrm{ff}$.

121 As Levinas says in HO 66f / HH 108, 109.

$122 \mathrm{HO} 66 / \mathrm{HH} 108$. With the theme of being a stranger Levinas implicitly polemicises with Heidegger as the author of texts like Wohnen, Bauen, Denken and especially the Brief über den "Humanismus" (compare for instance the ethical strangeness with Heidegger's idea of homelessness [Heimatlosigkeit] that is constituted by a forgetting of being [Seinsvergessenheit], as expressed in P 258 / W 339). A careful comparison of these two texts on humanism would bring a myriad of such implicit references to the fore. That would, however, make a 
However, this opposition suggested by Levinas evokes two important questions: firstly, if it is true that the second of these traditions does better justice to ethical alterity, how should its relationship with the dominant Western tradition in Europe be considered? This is an intra-cultural question. The second question, which is trans-cultural, is the following: how could Levinas justify using a particular culture to present the case for the trans-cultural ethical culture?

(1) Western culture is dominated by ontology or what Levinas elsewhere calls gnoseology. ${ }^{123}$ The practice of placing this form of signification centrally and maintaining its dominance is possible only by forgetting the ethical meaning of people and veiling this meaning in philosophy. ${ }^{124}$ Levinas is probably thinking of the Jews in Europe (but not exclusively of them) when he indicates the price of this forgetting and this veiling - the meaning of their suffering, the meaning that considers ethics to be primary and of which their writings testify

"is not a philosopher's construction; it is the unreal reality of persecuted people in the everyday history of the world". ${ }^{125}$

Suppression or violence on the level of ontology, reducing ethical meaning to ontology, is reflected in violence in political reality - such is the relation of the Jewish tradition to the Western world in which it has had to cope with a long history of adversity. Yet, as significant as the suffering of Jews in Europe might be for such a reflection on the political consequences of covering up ethical meaning (a claim that seems to support Levinas" "humanism of the suffering servant" from Difficult freedom), this does not amount to any conclusion regarding the desirability of either a Hebraic humanism or a humanism of patience. In other words, the reminder of Jewish suffering in the philosophical

separate study. Behind these polemics is a favourite image of Levinas - opposing Ulysses that returns to his patria to Abraham that forever leaves his behind as symbols guiding Western civilization and Judaism respectively, but also as narrative reflection of the logic of ontology and ethics respectively.

123 OB 64 / AE 104: "Western philosophy has never doubted the gnoseological, and consequently ontological, structure of signification."

$124 \mathrm{HO} 67 \mathrm{f} / \mathrm{HH} 110$.

$125 \mathrm{HO} 67 \mathrm{f} / \mathrm{HH} 110$, translation modified. Compare with the remark in the essay in Difficult freedom on anti-humanism and education (and the discussion in Chapter 4) where Levinas underscores the fact that Jews in Europe have had a foretaste of the "crisis of the human ideal" (DF 281 / DL 391). Furthermore, the Biblical theme of the suffering servant that Levinas interprets as a symbol of all the conquered and suffering that demand justice (DF 287 / DL 399 and discussed in Chapter 4) is echoed here. 
text doesn't permit us to settle the unresolved state in which Levinas' humanism of Difficult freedom has been left at the end of Chapter 4.

(2) But Levinas' way of going about this matter should retain our attention. I have said that the third aspect of Levinas' problem with anti-humanism is that of cultural relativism and that this could be solved only if a supercultural point of orientation could be found. However, it is impossible for Levinas to do so in a way other than culturally determined: he attempts to develop a discourse on ethics that would be acceptable within the discourse of Greek thinking, i.e., Western philosophy. The choice of discursive partner or opponent is easily imposed by the historical contingency of Levinas' life, but also the dominance of Western civilisation in recent world history. He polemicises with this form of discourse exactly for its forgetting of a kind of meaning in the name of which Levinas challenges Western thinking, that is, in obedience to this primary meaning. That meaning, Levinas finds better attested to or more sensitivity shown for, in the tradition of Jewish thought. But one should be careful to understand correctly what he does. On the one hand Levinas explicitly does not want to challenge philosophy with recourse to the authority of religion. ${ }^{126}$ On the other hand, Levinas is aware that his very allegiance to the game rules of Western philosophy becomes a question in the light of the theme of his philosophy, namely the primacy of ethics. This question opens up a space for introducing "the other" (written in inverted commas, since it is meant in the minor sense of cultural difference ${ }^{127}$ ) of Western philosophy, namely Jewish thought. And why not, asks Levinas, draw on texts that are equally part of the European cultural heritage as those of Hölderlin and Trakl commented on by Heidegger, namely the books of the Jewish Bible? ${ }^{128}$ The whole question of the relation between Judaism and the West, between religion and philosophy, is put into play here. Is the other tradition of the West just associated with it by accident, is it only a monster, a historical freak, that places Judaism as an

$126 \mathrm{HO} 66$ / HH 108: "Biblical verses do not function here as proof but as testimony of a tradition and an experience." Compare this declaration with the conclusions concerning the form of authority of religious scriptures supposed by Levinas from the readers of his essays on humanism in Difficult freedom (Chapter 4, above).

127 A tension in this minor use of the term "other" should be noticed: Judaism cannot simply be considered the other of Western culture if it is at the same time claimed that it is part of the European cultural heritage. Its otherness is rather of the nature of having been partially absorbed, mostly through Christianity, into the Western heritage and in this way to a certain extent obscured. HO 66/ HH 108. 
annex to the West? ${ }^{129}$ Or is the presence of Judaism testimony to the insistence of the appeal of the other (in the context of the West), and of ethicity in the face of the other (testimony to it, but not the appeal itself $!^{130}$ )? Jewishness by its existence of living without a State (up to 1948), i.e., living the condition of being a stranger or foreigner to the world, and bearing the consequences thereof, and by its primacy accorded to ethics testifies to the non-Being or beyond Being ${ }^{131}$ suppressed by the West in culture, as in politics.

Of course there is a question of cultural specificity in Humanism of the other. But the choice of the cultural specifics of his polemics is determined by the contingency of the author's historical situation; and the choice for Judaic inspiration is never justified by a supposed superiority of that culture. For Levinas, the "Jewishness" to which the Biblical citations and Talmudic references in his philosophical thought solicits some consent, does not simply mean believing in the God of Abraham, Isaac and Jacob, it does not require being a child of Abraham, or being a protagonist for Zionism or living in the State of Israel, it doesn't mean speaking Hebrew (though it doesn't exclude these either ) - it means having in final analysis, in what ultimately counts, no identity: being someone else, being without a homeland. ${ }^{132}$ For Levinas

"Israel, beyond the Israel of flesh and blood, encompasses all people who refuse to accept the purely authoritarian verdict of History."133

129 HO 66/HH 108.

130 Although - and we shall see this problem in Chapter $6, \S 1$ as exposed by Robert Bernasconi - doesn't Levinas say that there are people (Jews as he implies) whose very existence is one of non-essence or beyond Being $(\mathrm{HO} 67 \mathrm{f} / \mathrm{HH}$ 110)? As far as this is insinuated, Levinas infringes on his own notion of the alterity of the other as not determined by ontological givens. In saying this, one should however not forget the close link between the mortality of the other (and thus his/her suffering), which is a non-ontological "phenomenon" and alterity.

131 HO 54, 67 / HH 86, 110

132 And to an important extent, this is true also for Levinas' Judaic writings - as was argued in Chapter 4. The relation between philosophy and Judaism in Levinas' work is quite complex and there exists up to now no clear consensus amongst scholars as to how one is to conceive of the articulation between the two elements. I have presented and motivated my own view on this issue, beyond what is possible to do here, in 'Giving up your place in history. The 'position' of Levinas in philosophy and Jewish thought", in Journal for Semitics 16/1, 2007, pp. $180-193$.

133 OS 65 / HS 88. This kind of expression of a universal, anonymous Israel, of which one finds also a "European" equivalent in Levinas, poses problems that will be exposed in Chapter 6. The important point is that whatever excellence can be attributed to Israel or the Jewish religious community, cannot be denied $a$ priori in other religious or cultural forms. 
And in this sense do not dwell in Being, as Heidegger would have it. But since Levinas draws his inspiration from the Jewish testimony and formulates his plea in the language of Western philosophy - both of which are manifestations of Being - he is obliged, in obedience to originary ethicity, which is the theme of his plea, to cross out as it were everything he says. Hence the central importance of the first paragraph of the preface of the book, in which this crossing-out of what follows in the book, is announced (as discussed in the introduction to the current Chapter). The text in which Levinas pleas for the recognition of the originary ethicity of the other, is inevitably expressed in a particular cultural discourse and thus constitutes the risk that it might at the very moment of testifying to the other, be the first step to its veiling and forgetting. If this holds for Levinas' philosophical text, it would likewise hold for his Talmudic readings and, in fact, for the Rabbinic literature itself. The humanism of the other, as the "ethical culture" of responsibility for the other, draws all of its meaning from a Talmudic-independent resource. No philosophical justification can be given for a Hebraic humanism or for a humanism of patience in which the study of the Talmud is central. However, if it can be argued that the Talmud testifies truly and effectively to the "unique sense" that is the ethical alterity of the other, then it can be recommended for study by all people, independent of their cultural background - but this, together with the study of any other text that could plausibly be claimed to have the same merits.

Thus we return to the preface from which the exploration of Humanism of the other was launched. Having followed the complex flow of arguments of this book, the examination of its import can be further examined by a strategy of comparison.

\section{5 “REAL HUMANISM": AN UN-LIKELY FAMILY PORTRAIT}

Already from the title of the book, it is clear that Levinas is looking for a humanism that takes full cognition of the ambient anti-humanism. This humanism should be a defence of the (other) human being or of humanity, but in such a way that it could critically respond to anti-humanism. ${ }^{134}$ Levinas' humanism is presented as a radicalisation of and a going beyond anti-humanism, since it commences as the question: 
“couldn't humanism take on some sense if we thought through to the very limit the denial that Being inflicts on freedom? [...] Couldn't this sense be found without getting pushed to the "Being of beings", to system, to matter?"135

This question could function as a point of departure, since Levinas accepts and appreciates to a certain extent the criticism of subjectivity inherent in all anti-humanism:

"Its inspired intuition is to have abandoned the idea of person, goal and origin of itself, in which the ego is still a thing because it is still a being.",136

However, his anti-humanism respecting humanism consists of conceiving differently the subject (as is programmatically stated in the preface to Totality and infinity) and the humanity of the human being.

Our understanding of Levinas' enterprise can be advanced by comparing his humanism to the ideas on the same subject in the work of some of his contemporaries - and assuming the risk that the shortness of presentation may entail simplification. ${ }^{137}$ The ideas of Sartre, Heidegger and Althusser naturally spring to mind for this kind of exploration, as these authors were some of the most significant contemporary contributors to the debate on humanism. ${ }^{138}$ The aim of this sub-chapter is not to show

$135 \mathrm{HO} 49 \mathrm{f} / \mathrm{HH} 80$.

136 OB 127f / AE 203.

137 One could certainly choose a number of different ways to situate the philosophy of Levinas in general and of Humanism of the other in particular. Phenomenology, Marxism, postcolonial studies or the liberalism-communitarianism debate could equally provide a background against which to interpret this book of Levinas.

For all that follows Tom Rockmore's Heidegger and French philosophy. Humanism, anti-humanism and being. London and New York, Routledge, 1995 (especially chapters 5, 6,7 and 9) may be consulted. The older essay of Eugenio Garin, "Quel 'humanisme'? (Variations historiques)" (Revue internationale de philosophie, 85-86/1968, pp. 263-275), gives a still very useful contemporary orientation to the humanism debate. A good overview of the French debate can be found in Sean Homer "Humanism and anti-humanism" in Encyclopedia of modern French thought. Christopher John Murray (ed.). New York and London: Fitzroy Dearborn, 2004, pp. 331-334.

138 The list is of course in no way exhaustive. For example, the position of LéviStrauss is especially interesting in this context, but, being spoiled for choice, he is left out, having already figured in Chapter 2. For a valuable overview of LéviStrauss' position on humanism see Denis Kambouchner, "Lévi-Strauss and the question of humanism (followed by a letter from Claude Lévi-Strauss)", in The Cambridge companion to Lévi-Strauss. Boris Wiseman (ed.). Cambridge, et. al.: Cambridge University Press, 2009, pp. 19-38. First markers for a comparison of humanism in Merleau-Ponty and Levinas are given by Robert Bernasconi, "One-way traffic: the ontology of decolonization and its ethics", in Ontology and Alterity in Merleau-Ponty. Galen A. Johnson and Michael B. Smith (eds.). Evanston: Northwestern University Press, 1990, pp. 67-80. 
that Levinas is always right, but simply to draw more sharply the contours of his humanism of the other human. A critical view on Levinas' thought will have to wait till Chapter 6 .

\subsection{Sartre: humanism as existentialism}

Existentialism was a humanism, and for that reason also (ever since Heidegger's Letter on "humanism") bore much of the brunt of anti-humanism. In reading Existentialism and humanism, ${ }^{139}$ it becomes clear very quickly that, compared to Sartre, Levinas is much closer to anti-humanism.

Sartrean humanism takes as its point of departure the human subject. ${ }^{140}$ This subjectivity reveals itself in action and is determined by no essence, according to the well-known formula "existence precedes essence [l'existence précède l'essence]" ${ }^{141}$ In this undeterminedness resides the most profound dignity of the human being. ${ }^{142}$ The human being is nothing but that which he/she has made himself/herself to be, ${ }^{143}$ and has therefore to take responsibility for what he/she is. ${ }^{144}$ In freedom, one doesn't only create or choose oneself, but also creates an image of what the human being could be. ${ }^{145}$ The conscious, willed project of self-creation is, however, to be executed without recourse to any pre-established set of principles. In this sense, Sartre swears his allegiance to the death of God. And since there is no God to guarantee transcendent principles, ${ }^{146}$ the human being is condemned to freedom, condemned to invent humanity at every instant of acting. ${ }^{147}$ Matters are thus as the human being decides them to be ${ }^{148}$ or again, "the destiny of the human being is in himself/herself". ${ }^{149}$

139 For an engaging reading of Sartre's earlier philosophy in which the question of humanism takes an important place, see Alain Renaut. Sartre. Le dernier philosophe. Paris: Grasset and Fasquelle, 1993.

140 E\&H 26, 44, 52 / EH 17, 63, 84.

141 E\&H 26/EH 17.

142 E\&H 28, 45 / EH 22, 65.

$143 \mathrm{E} \& \mathrm{H} 28,41,50 / \mathrm{EH} 22,55,78$.

144 E\&H $29 / \mathrm{EH} 24$.

145 E\&H 30 / EH 27. Cf. E\&H 29 / EH 24-25: "Subjectivism means, on the one hand the freedom of the individual subject and, on the other that man cannot pass beyond human subjectivity. [...] For in effect, of all the actions a man may take in order to create himself as he wills to be, there is not one which is not creative, at the same time, of an image of man such as he believes he ought to be."

146 E\&H $33 / \mathrm{EH} 35$.

147 E\&H 34 / EH 37-38.

148 E\&H 41 / EH 54.

149 E\&H 44 / EH 62. 
That such a declaration of the death of God accompanied by a strong, free, autonomously acting subject would seem, from an anti-humanist perspective, nothing more than mere lip service doesn't surprise us. In the place of the dead God arises the Sartrean subject that is (as Sartre himself recognises) in continuation with the Cartesian cogito. ${ }^{150}$ Existentialism reconstructs, in the centuries old tradition, humanism on the foundation of a metaphysics of the subject. ${ }^{151}$ The self-conscious and free subject is the basis of truth, also of the truth of existentialism as a humanism and this is the very foundation of human dignity. Sure enough, there is an attempt by Sartre to overcome what he conceives as a solipsistic pitfall in the cogito: I need the other to become conscious of myself ${ }^{152}$ and it is in a "world of intersubjectivity" that the human being decides what he/she and the others are. ${ }^{153}$ But this social cogito leaves intact the individual self. Besides, despite the absence of a universal human essence, there is a universal human condition that makes it perfectly possible for any human being of any culture to understand the projects of others of other cultures ${ }^{154}$ - cultural diversity is no obstacle in the world of inter-subjectivity. No wonder then that ethics could be envisaged from the point of authenticity, from the fact of living according to human liberty that gives morality a universal form, even though the content of it may vary. ${ }^{155}$ Such an authenticity would imply the compatibility of all people's liberties. ${ }^{156}$ Any resistance to this universally accommodating liberty would be an infringement on authenticity, i.e., acting in bad faith.

Thus Sartre rejects an older form of humanism that takes as its basis a universal human essence, ${ }^{157}$ but espouses one in which the human being is still to be created. ${ }^{158}$ Despite this apparent uncertainty, and despite the death of God, humanity is not at stake, provided that the universality of human freedom embedded in the projecting character of the cogito is recognised.

It should be clear that Levinas would consider such a humanism as irrevocably outdated. Sartre's notion of the subject lives in the naivety of before any recognition of the decentring of the subject in the human sciences. ${ }^{159}$

\author{
150 E\&H 45 / EH 64. \\ 151 E\&H 44 / EH 63. \\ 152 E\&H 45 / EH 66. \\ 153 E\&H 45 / ЕH 67. \\ 154 E\&H 46/EH 69-70. \\ 155 E\&H 52 / EH 85. \\ 156 E\&H 52 / EH 84. \\ 157 E\&H 55 / EH 92. \\ 158 E\&H 55-56/EH 92-93. \\ 159 One could characterise this perspective as "naive" in the light of Freud's famous \\ 1917 essay "Eine Schwierigkeit der Psychoanalyse", in Gesammelte Schriften
}


Sartre resuscitates God (as a unified point of reference, or foundation, for all value and meaning) under the name of the free subject. If Levinas then still declares that he considers his own humanism as a way of taking the Sartrean notion of "being condemned to be free [être condamné à être libre]"160 further, it is only to radicalise that condemnation - not in the same sense as the way in which Being or structures condemn human beings to not being free, but rather as condemned to serving the other. For this condition of condemnation to freedom, he uses the term "hostage" (otage): ${ }^{161}$ the self is the hostage of the other, the self is irremissibly in "enslavement" or "subservience" (asservissement) ${ }^{162}$ with regard to the other and this condemnation exceeds whatever liberty the self might have ${ }^{163}$ - even to the point of being responsible

for the responsibility of the other ${ }^{164}$ - in the sense of decisively determining the meaning of the liberty of the self. And it is only as such - invested and commanded by the other, "vulnerable" to the appeal of the other - that Levinas would ever contemplate the significance of the freedom of the self. There is still something of a universality in Levinas' ethics, as will be indicated later, but even if such be the case, ethics always refers back to an originary asymmetry. And it is this very asymmetry that makes of the other not a foundation of meaning, but an an-archic or non-foundational source: the other is not God, but lives in the trace of an ever already-passed "God". ${ }^{165}$

\subsection{Heidegger: "humanism" in the extreme sense}

Just like Sartre, Heidegger also distinguished two forms of humanism in his "Letter on 'humanism"” (1946). ${ }^{166}$ The deciding factor in distinguishing his

von Freud, zehnter Band. Leipzig, et al.: Internationaler Psychoanalytischer Verlag, pp. 347-356 - Sartre still considers the subject to be the "master of his/her own home".

$160 \mathrm{HO} 73 \mathrm{n} 13 / \mathrm{HH}$ 120n13, my translation.

161 HO 57, 67, 58/HH 91, 109, 110, 111.

$162 \mathrm{HO} 53 / \mathrm{HH} 85$.

163 Cf. "a responsibility overflowing freedom" (HO 53, 54 / HH 85, 86).

$164 \mathrm{HO} 68 / \mathrm{HH} 111$.

$165 \mathrm{HO} 44 / \mathrm{HH} 69$.

166 P 236-276/ W 313-364. On the historical unfolding of the conflict between Sartre and Heidegger on humanism, see Dominique Janicaud. Heidegger en France, tome I: Récit. Paris: Albin Michel, 2001, chapter 4: "L'humanisme dans les turbulences". A valuable overview of the meaning and reception of the Letter on Humanism is provided by Dirk Mende in "'Brief über den 'Humanismus." $\mathrm{Zu}$ den Metaphern der späten Seinsphilosophie", in Dieter Tomä (ed.). HeideggerHandbuch. Leben-Werk-Wirkung. Stuttgart and Weimar: Verlag J.B. Metzler, 2003, pp. 247-258. For an interpretation of this text within the broader frame- 
two forms of humanism is the question of metaphysics: typical of the history of metaphysics is that it is, according to Heidegger's reading, the history of forgetting ${ }^{167}$ and hiding the fact that Being is a verb (it happens) and not a noun (a thing). ${ }^{168}$ Subsequently there is (1) a metaphysical humanism that reduces the human being to the noun-character of Being whilst ignoring that Being is first of all a verb and (2) a non-metaphysical humanism that realises the importance of the verbal character of Being and gives it priority over the noun-character in matters human. ${ }^{169}$

In the first of these approaches to the human being, of which Sartre would be a late representative, one sees that it is exactly in the notion of the subject that one could identify the metaphysical character of the first humanism. It obstructs the urgent question of Being that determines humanity, and instead presents the human being as animal rationale, ${ }^{170}$ which inevitably leads to the error of thinking

"the human being from out of the animalitas instead of thinking towards the humanitas of the human being". ${ }^{171}$

What gets lost in the process is the "essence" of the human being. This essence is the fact that the human being is the place where the difference between the noun-character (Seiende) and the verbal character (Sein) of Being is made; this happening of differentiation in Being being called eksistence. ${ }^{172}$ This understanding of the "essence" of the human being doesn't so much negate the humanist idea of the human being as animal rationale, rather, it puts that idea in the right perspective ${ }^{173}$ by thinking more originarily about humanity. ${ }^{174}$ In fact - and this is where the second or true humanism

work of Heidegger's work and his intellectual environment, see Gianni Vattimo: "La crise de l'humanisme", in Exercises de la Patience 5, 1983, pp. 19-30.

$167 \mathrm{P} 253 / \mathrm{W} 332$.

168 P $255 / \mathrm{W} 334$.

169 Cf. P 246 / W 322. See also P 245 / W 321: "Every determination of the essence of the human being that already presupposes an interpretation of beings without asking about the truth of Being, whether knowingly or not, is metaphysical.”

170 P 246/W 322f.

171 P 246f / W 323, translation modified. Heidegger doesn't reject the Greek antecedent of the Latin animal rationale, but fears that its true meaning has been covered up by the history of metaphysics (cf. P 245f / W 322, also Being and time. op. cit. p. 208 / Sein und Zeit. op. cit. p. 165).

$172 \mathrm{P} 248 / \mathrm{W} 325$.

173 P 251/W 330.

174 Cf. "more primordially" P 267, anfänglicher, W 351. 
according to Heidegger comes in ${ }^{175}$ - the highest determination of the essence and dignity of the human being can be thought only when the human being is considered as belonging to Being. ${ }^{176}$ Heidegger's idea of true humanism consists of evacuating the place accorded by the first humanism to the subject and restoring it as the place of Being; and it is only when this perspective on the human being is adopted that real humanity comes to light: the human being lives in the proximity of Being, which means that humanity has an opening in which meaning could unfold. ${ }^{177}$ This is equivalent to saying that humanity consists originarily of being addressed by Being; ${ }^{178}$ it is Being that gives content to the formal ek-sistence of human beings. Humanity exists in the service of thinking the truth of Being. ${ }^{179}$ Language is the place in which the truth of Being unfolds itself, it is the "house of Being". 180 This address and the meaning in which the human being dwells do not lead to an ethics. Heidegger will even claim that what he is thinking is neither ontology (in the traditional sense), nor ethics. All that his considerations about humanity would lead to is a letting go with reference to the task of constructing rules and values (since these inevitably presuppose a fixed notion of the subject on which they are founded) and an existence of letting Being be. ${ }^{181}$ As such it thinkingly constructs the house of Being, ${ }^{182}$ it arranges the space in which one existingly dwells and thus, according to Heidegger, one is already busy with the original ethics. ${ }^{183}$

175 This is a "humanism" that thinks against humanism or that contradicts all previous humanisms (P 251; 263 / W 330; 345), but without falling into an inhumanity (P 265 / W 348). At the same time Heidegger claims that it restores the essence and dignity of the human being to such an extent that what he presents is nothing else than "“Humanism' in the extreme sense" ['Humanismus' im äußersten Sinn ] (P 261 / W 342 and see the following page for a definition of Heidegger's humanism). Heidegger, however, concedes that this is a humanism of a peculiar kind (P 263 / W 345).

176 P $252 / \mathrm{W} 330$.

177 P 261 / W 342-343, also P 254 / W 333-334.

178 Cf. P 246/W 323.

179 Cf. P 268/W 352.

180 Refrain of the whole Letter, e.g., P 254 / W 333. And this is Heidegger's rendering of the zoon logon echon: "the human being is not only a living creature who possesses language along with other capacities. Rather, language is the house of Being in which the human being ek-sists by dwelling, in that he belongs to the truth of Being, guarding it." (P 254 / W 333)

$181 \mathrm{P} 272 / \mathrm{W} 358$.

$182 \mathrm{P} 272 / \mathrm{W} 358$.

183 Cf. P 271 / W 356: 'If the name 'ethics,' in keeping with the basic meaning of the world éthos, should now say that ethics ponders the abode of the human being, then that thinking which thinks the truth of Being as the primordial element of the human being, as one who eksists, is in itself originary ethics." 
It would not be possible to go into the detail of the relationship between Levinas' humanism text and that of Heidegger, since even a superficial comparison would quickly show that the former was written in constant critical reference to the latter. This is no surprise if one considers on the one hand the determining influence that Heidegger has had on Levinas' way of thinking, and on the other hand, the massive wave of appropriation of Heidegger in French philosophy since the 1960s. ${ }^{184}$ What deserves our attention is that Levinas' humanism is designed to take Heidegger's criticism of humanism as a metaphysics seriously and to sidestep the pitfalls thereof. ${ }^{185}$ Levinas never lets go of the ontological difference, which he learned about from Heidegger; he claims only that this is not the most decisive thing about humanity. He does so, as we have seen, neither by restoring subjectivity, nor by rehabilitating the human being as animal rationale, but by claiming that more primordially, before the human being dwells in the truth of Being (if this is indeed the case), he/she is expelled, homeless, in a meaning imposed from beyond Being. Levinas would claim that Heidegger, whilst breaking with a certain tradition of Western thinking, perseveres in another, namely that of the forgetting of the ethical difference: the human being as the place in which the non-in-difference between the self and the other is decisive for all meaningful existence. Levinas' idea of the self is consequently stamped by heteronomy, by an imposition of responsibility by the other, and what is the most humane about humanity is not the subject, nor is it Being as Heidegger claimed, it is the other. Therefore ethics or rather ethicity is what is to be thought primarily in a consideration of humanism. And this is to be done in response and obedience to the appeal from the other. One could, thus, call Levinas' humanism a post-metaphysical humanism. And this post-metaphysical humanism directs its criticism to the Heideggerian "humanism". The latter is not only insufficient, but dangerous, for reasons that have been expounded and of which the main thrust could be summarised as follows:

184 Cf. D. Janicaud, Heidegger en France, op. cit. p. 132: "The Letter is indeed the text of Heidegger that has probably had the greatest influence in France, especially in the 1960".

185 This is clearly attested to in Levinas' lecture of 6 February 1976, entitled "The radical question: Kant against Heidegger", where Levinas presents a short interpretation of the "Letter on "humanism"" (especially GDT 58 / DMT 68). One reads his concern to take the main tenets of Heidegger's later philosophy in general seriously in PN 127f / SMB 10f. 
"There is in Heidegger the dream of nobility of blood and sword. But humanism is something completely different. It is more a response to the other that lets the other go first, that yields to the other instead of fighting the other."

\subsection{Althusser: humanism as ideology}

Putting aside the circumstances that provoked Althusser to write his 1963 essay "Marxism and humanism", ${ }^{187}$ he starts off by describing the fate of humanism in Marx's intellectual itinerary: from humanist or practitioner of a "philosophy of the human being [philosophie de l'homme]"188 to a radical anti-humanist. It is especially this second phase of Marx's philosophy and Althusser's interpretation thereof that is important to us. The anti-humanism of Marx's second phase breaks with the former thought as based on a notion of the essence of the human being in that

"the essence criticized [and by implication humanism - EW] is defined as ideology, a category belonging to the new theory of society and history." 189

Thus, according to the subsequently formulated theoretical anti-humanism, in order to understand the human world and possibly to change it, one should depart from a strategy based on a quest for the essence of the human being:

"It is impossible to know anything about men except on the absolute precondition that the philosophical (theoretical) myth of man is reduced to ashes."190

However, it is of central importance to note that this reduction of humanism to ashes, on the level of theory, doesn't mean the negation of the practical reality of humanism, namely in the form of ideology. ${ }^{191}$ Having knowledge of this ideology doesn't amount to making it evaporate. Rather, the knowledge of the ideology of humanism sought by Marx (according to Althusser) is knowledge of the conditions of the necessity thereof, conditions that also determine the Marxist response to this humanism. ${ }^{192}$

186 IH 186.

187 FM 221-247 / PM 227-248. One could consult Vincent Descombes. Le même et l'autre. Quarante-cinq ans de philosophie française (1933-1978). Paris: Minuit, 1979 (especially "La querelle de l'humanisme", pp. 124-130) for elements of a historical orientation to the anti-humanism debate in France. A useful discussion of Althusser's position is Kate Soper's Humanism and anti-humanism. London, et al.: Hutchinson, 1986, pp. 96-119.

188 FM 226/PM 232, translation modified.

189 FM 227 / PM 233-234.

190 FM 229/PM 236.

191 FM $230 /$ PM 236.

192 FM 230-231 / PM 236-237. 
Gaining knowledge of humanism as ideology in this manner entails the development of theoretical anti-humanism. Therefore, it is essential to understand what "ideology" is. An ideology, Althusser summarises,

"is a system (with its own logic and rigour) of representations (images, myths, ideas or concepts, depending on the case) endowed with a historical existence and role within a given society". ${ }^{193}$

Every society, even the ultimate communist society, bathes within ideology. ${ }^{194}$ To be precise, the "mode of existence" of ideology (and thus, by implication, of humanism as discourse based on a notion of the essence of human beings) is not a matter of consciousness, but of unconsciousness, and that in a very particular sense: ideology imposes itself on people as "structures", ${ }^{195}$ it is formed by the historical conditions in which people live. That means that the representations of which ideology is a system,

"are perceived-accepted-suffered cultural objects and act functionally on men by means of a process that escapes them. Human beings 'live' their ideologies [...] not at all as a form of consciousness, but as an object of their 'world' - as their 'world' itself.", 196

The very manner in which people live their lives and their relation to their world is ideologically mediated and incarnates ideology. This could be illustrated by a topical example:

"In the ideology of freedom, to be precise, the bourgeoisie live their relation to the conditions of their existence, in other words, their relation that is real (the law of a liberal capitalist economy) but invested in an imaginary relation (all men are free, including the free labourers). Their ideology consists of this play on the word freedom."197

From this one could see that the person, or rather the class, that uses ideology is itself being used by ideology. ${ }^{198}$ It is only by means of such a theory, an anti-humanist theory, that strategies could be adopted to transform society, to transform the conditions that produce a humanism, which functions as legitimisation of the bourgeoisie. ${ }^{199}$ And such strategies could not exclude adopting in practice one form of humanism or another.

It is clear that Althusser's anti-humanism draws the human being, consciousness and all, into the non-masterable flow of history. Agency and con-

\footnotetext{
193 FM 231 / PM 238.

194 FM 232/PM 239.

195 FM 233/PM 240.

196 FM 233 / PM 240, translation modified.

197 FM 234f / PM 241, my translation.

198 FM 235/PM 242.

199 FM 241 / PM 249 and Levinas implicitly refers to the Althusserian critique of this ideology in GCM 3 / DVI 18.
} 
sciousness are decentred, and humanism is withdrawn from anthropology and relegated to strategy. Levinas, in so far as he accords a place to ontology, would be willing to agree with this perspective, in fact, in his reading this anti-humanist theory would be nothing more than another mode of appearance of the domination of the human being by Being as described by Heidegger. As such it has, as do the other theories of the decentred subject, a descriptive potential with regard to the terrifying history of human "deficiency" in the twentieth century. ${ }^{200}$ Levinas would even agree with Althusser that if there is to be a transformation of society, it would not draw its resources from a theory of the human essence, but from a source that decentres the self. However, for Levinas, beyond the decentring of the human being by social and historical conditions, and therefore more intimate and determining for the self, is the decentring by the alterity of the other, by the ethical appeal. It is not from a theory that social transformation could be energised, but in the obedient response to the appeal for responsibility to the other. That theory, class struggle, or whatever Marxist notion of transformation could be incorporated into such an obedient response, is not excluded - neither is any other idea about social justice a priori excluded. ${ }^{201}$

200 GCM 47-49/DVI 83-85.

201 But Levinas' affinity for Marxism should not be overlooked. In an important passage from the Talmudic reading "Judaism and revolution" (BV 94-119 / DSAS 11-53), Levinas illuminates his remark "Authentic humanism, materialist humanism" (BV 97 / DSAS 16) as follows: "Our old text upholds the right of the person, as in our days Marxism upholds it. I refer to Marxist humanism, the one which continues to say that 'man is the supreme good for man' and 'in order that man be the supreme good for man he must be truly man' and which asks itself: 'How could man, the friend of man, in specific circumstances, have become the enemy of man?'[...]" (BV97f / DSAS 17). This passage ends with the decisive affirmation that the other is the basis of humanism (BV 98 / DSAS 17), an idea that will find its way to the title of Humanism of the other.

But apart from the explicit remarks, it is significant to take note of his (quite rare) reference to contemporary academic articles. A footnote after the phrase "Marxist humanism" (in the citation above) gives two essays as valuable for understanding Marxist humanism, both from the Revue internationale de philosophie 85-86/1968 - a volume that was dedicated to the question of the crisis of humanism and to which Levinas contributed the essay that became Chapter 2 of Humanism of the other "Humanism and an-archy" (pp. 323-337 in the journal). The first article recommended by Levinas is Jacques D'Hondt's, 'La crise de l'humanisme dans le marxisme contemporain" (pp. 369-378), an unambiguous rejection of Althusser's anti-humanist reading of Marx. "Would Marx have been mistaken about the meaning of his own work?" asks D'Hondt (p. 378) and thus supports the traditional humanist reading of Marx. The second article recommended by Levinas is Jean Lacroix's "L'humanisme de Marx selon Adam Schaff" (pp. 379-386). Lacroix challenges Althusser's "evocative and deep, but also questionable interpretation" of Marxism (p. 379) by recourse to that of 
Having devoted this fifth Chapter to a scrutiny of Levinas' philosophical articulation of his post-anti-humanist humanism, it should now be submitted to critical examination. This is the goal of the next Chapter.

Adam Schaff (in Le Marxisme et l'Individu: Contribution a la philosophie marxiste de l'homme, Paris, Armand Colin, 1968; Polish original published in Warsaw, 1965) that insists on Marxism as the sole integral humanism. Lacroix doesn't go as far as a critical comparison of Althusser and Schaff, but keeps to a sympathetic presentation of Schaff's humanist Marxism as a realistic and liberation-oriented theory of human existence. It is from a citation by Lacroix of Schaff that Levinas draws the "assertion of Marx that the human being [l'homme] is the highest good for humanity [pour l'homme]" (p. 386), to which he refers in the citation above.

It seems reasonable to believe from this information that Levinas finds himself in agreement with the spirit of Marxist humanism, although he questions the capacity of Marxism to provide the ultimate orientation in cultural diversity (HO Chapter 1) and although he embraced, to some extent, the notion of antihumanism. Furthermore, these references make us attentive to the fact that Levinas' reflection on humanism and anti-humanism constitutes one of the important loci for his positioning with respect to Marxism. 



\section{Chapter 6 \\ After Levinas: \\ The risk of irresponsible responsibility}

It should be clear from the preceding discussion that for Levinas the dossier on humanism could be reopened only on the condition that humanism is radically re-conceived. But how radical, how new and, above all, how desirable is Levinas' post-anti-humanist humanism? The present Chapter seeks to submit Levinas' thought on the alterity of the other the corner stone of his humanism - to critical examination. In accordance with the line of interrogation demarcated for this book, the focus will be on how the political implications of Levinas' philosophy are to be assessed. In the light of the critique that will be developed here, the question of thinking responsibility in its political dimension "after" Levinas, will ensue from this examination.

As a first orientation to the problems of gauging the political implications of Levinas' ethics, two insightful essays by two eminent Levinas readers will be presented. By juxtaposing the divergent reading of Marion and Bernasconi, the perilous nature of this undertaking will be signalled.

\section{UNIVERSALISM AND PARTICULARISM: MARION AND BERNASCONI}

Humanism, according to the conviction articulated in Humanism of the other, is the defence of the idea that all meaning is orientated by the appeal of the other, of the other that bears the alterity of not being reducible to the subject's ontologico-hermeutic existence. 
That is why the

"best way of encountering the other, is not even to notice the colour of his/her eyes! When one observes the colour of the eyes, one is not in social relationship with the other. The relation with the face can surely be dominated by perception, but what is specifically the face is what cannot be reduced to that."1

It is the face of the other - metonymy for the alterity of the other - that interferes with the sweeping flow of Being. The alterity of the other would also be what invests me with primal or originary meaning, founding my subjectivity, my identity, my self and individuality - primarily as called to respond to the other. But who exactly is the other that invests me with singular identity in this way? Since it is the face without characteristics, this means that the alterity of the other is stripped of all individualising qualities. The other that makes the ethical appeal is nobody, or at least nobody in particular. This is the insight of Jean-Luc Marion: in Levinas' philosophy the other is nothing but universal, non-particular, humanity behind the particularities of the individual person. ${ }^{2}$ The other, after having torn the self from the anonymous flux of Being, is swallowed by the anonymity of a humanity ${ }^{3}$ without qualities. The face of the other cannot say of whom it is the face, since it speaks only in the name of a trans-individual humanity. Consequently, when confronted with the question of just responsibility towards the plurality of others, Marion is convinced that the ethical anonymity of the other inevitably translates into neutralising the other (as one is neutralised in front of the law), and that the identity of the ethical subject is in the same movement compromised and neutralised, since the subject has to respond to the other in the same way as anybody else. ${ }^{4}$ In my view Marion's decision not to use the minor, but significant, theory of justice of the later Levinas ${ }^{5}$ weakens his argument since it obscures the possibility, foreseen by Levinas, of making singularising exceptions in order to call the neutrality of the law to greater justice. This will be discussed later. Let it for now be granted that from the anonymity of the face of the other, taken absolutely, one has to arrive with Marion at universality and neutrality as the essential outcome of Levinas' ethics on the plane of the political.

1 E\&I 85-86 / EI 79-80, translation modified.

2 Cf. Jean-Luc Marion, "D'autrui à l'individu", in: Emmanuel Lévinas. Positivité et transcendance. Paris: PUF (Epiméthée), 2000, pp. 287-308, in particular pp. 296300.

3 E\&I 86/EI 81.

4 Cf. "D' autrui à l'individu", op. cit. p. 300.

5 And of which the only trace in Humanism of the other is to be found in HO 76n11 / HH 123n11. 
Robert Bernasconi, ${ }^{6}$ to the contrary, demonstrated that in a number of places Levinas' alleged non-specificity of the face of the other actually manifested as a "continuity with abstract humanism and its complicity with homogenization", 7 i. e., instead of the other's alterity being devoid of any content, Levinas sometimes universalised a Western or Jewish cultural identity in such a way as to make either of them the measure for the humanity of the other or of the self. In Humanism of the other, this is blatant when Levinas, whilst insisting on the relativity of particular cultures, still maintains a specific "generosity of the Western civilisation" that not only exposed this relativity, but in so doing helped other cultures to understand themselves, which, according to Levinas, they couldn't do before the Western intervention. ${ }^{8}$ This process is claimed by Levinas to be one of generosity and is apparently dissociated from the colonising violence that he denounces. ${ }^{9}$ This perspective echoes Husserl's 1935 Vienna lectures (of which the influence on Levinas is demonstrated by Bernasconi) in which an even clearer historical teleology is developed by which cultures are hierarchically ordered according to their fidelity to the (Western) idea of the human being as rational animal. ${ }^{10}$ This complacency that Levinas exhibits regarding the notion of Western (or Jewish) superiority comes to the fore again, and more clearly, in scattered remarks in his interviews and Judaic writings.

The commentator arrives at the following conclusion:

"If at times Levinas still seems to judge other cultures simply by their proximity to his own, this should not be considered sufficient reason to dismiss his thought, before the resources of that thought have been explored. Foremost among these resources is Levinas's acknowledgement that the self-questioning that originates from the gaze of the Other always takes place as an interruption of my complacency. What disturbs the self-evidence that supports my unquestioned attachment to my own cultural values is not just the Other as such. It is the Other in his or her

6 "Who is my neighbor? Who is the other? Questioning 'the generosity of Western thought"”, in Ethics and responsibility in the phenomenological tradition. The ninth annual symposium of the Simon Silverman Phenomenological Center. Pittsburgh: Duquesne University, 1992, pp. 1-31.

7 "Who is my neighbor?...", op. cit. p. 5.

$8 \mathrm{HO} 37 / \mathrm{HH} 59-60$.

9 "But it [Platonism] is overcome in the name of the generosity of Western thought itself, which, catching sight of the abstract man in men, proclaimed the absolute value of the person, and then encompassed in the respect it bears it the cultures in which these persons stand or in which they express themselves. Platonism is overcome with the very means which the universal thought issued from Plato supplied. It is overcome by this so much disparaged Western civilization, which was able to understand the particular cultures, which never understood themselves [lesquelles n'ont jamais rien compris à elles-mêmes].” (CPP 101 / HH 59-60).

10 According to Bernasconi, "Who is my neighbor?...", op. cit. p. 11. 
specific cultural difference from me that presents a direct challenge to my own cultural adherences and calls me to respond without any certainty of the appropriate way in which to respond or the idiom in which to do so."11

It is this very last sentence which is the core of Bernasconi's reading of Levinas: the alterity of the other has a content, determined amongst others by that person's cultural or ethnic specificity - it is Levinas' erring on the side of implicitly claiming a cultural superiority that leads to this conclusion. Although I am not sure if this amounts to allowing the introduction of an "alterity-content" in the face of the other, ${ }^{12}$ it does show that (at least) in the movement of responding to the other, the same Levinas allows one to conclude that the cultural particularity of the other and of the self matters in ethical consideration, and therefore this particularity surely does matter in the interaction with the plurality of others, in politics.

It is not my intention to arbitrate between these conclusions regarding Levinas' implications for politics as neutral universality or interested particularity. In fact, in what follows, it will become evident that I think that Levinas' theory of justice (which had not been sufficiently called to aid in Marion's or in Bernasconi's essay) probably opens up the matter to the entire spectrum of possibilities between these two extremes. In Levinas' own presentation of justice, he willingly concedes that even when the contextindependent alterity of the singular other is maintained, the identity and specificity of the other do come into play once the subject is obliged to compare the plurality of others: as soon as there is a plurality of others, the subject's eyes are opened, as it were, to the particularity of the others and thus the cultural and ethnic, religious and economic, gender and age identity of the other becomes important. The subject's eyes are opened to the particularity of the suffering of the other. But the ethical responsibility of the subject to the other has not been made dependent on the particular qualities. This is of enormous importance, since it means that at any stage in my execution of my responsibilities to the others, any single other, whatever that person's identity or condition might be, could and does make an appeal to my responsibility, i.e., puts into question the manner in which I respond

11 Bernasconi, "Who is my neighbor?...", op. cit. pp. 26-27.

12 One cannot from Levinas' personal, cultural or religious convictions and the disparate abusive expressions thereof conclude that his philosophy should be changed on this matter. That is why I consider it important to let the resources of the text itself override the (conceded, important) mistakes of the author (which would harmonise with the preface of $\mathrm{HO}$ that insists on crossing out, or questioning, any expression of the alterity of the other). At the very least, it should be recognised that conceding to an alterity-content would amount to changing the very heart of Levinas' philosophy. 
to the multiplicity of others and thus calls me either to greater attention to the particularity of some or to the greater equality of everybody. For this reason Levinas' subject could be an imperialist or anarchist, a liberal or a revolutionary - provided that such a conviction is justified with reference to the efficiency of serving the others.

The juxtaposition of these two strong readings of Levinas should suffice to point out the problem of the indeterminate status of justice as it is engendered from the plurality of responsibilities of the subject in the philosophy of Levinas. In stead of solving this problem, I shall attempt to measure its depth.

\section{RESPONSIBILITY AND IRRESPONSIBILITY}

A major uncertainty seems to arise in Levinas' humanism of the other human being on the level of justice, i.e., in the face of the plurality of others (and that has been introduced in this book already in Chapter 1). Central to this situation is the investment (or election) of the self by the other: the most intimate identity of the self is its infinite responsibility to the other in which nobody could replace that subject. But we have insisted in the first Chapter on the fact that there are always at least three - the ethical subject, the other and another other - I cite again:

"There are always at least three people. [...] As soon as there are three people, the ethical relationship to the other becomes political and enters into the totalizing discourse of ontology."13

Now, when the plurality of the others comes into play, the other is drawn out of this universal anonymity (if one follows Marion) and his/her identity, singularity and particular circumstances enter into the multitude of contemporaneous and equally valid claims from all of the others on the subject, who then has to ask the question of how to distribute his/her loyalty, efforts and means; in the same movement in which the particularity of the multitude of others becomes ethically relevant, the scope of the question concerning justice extends from the restricted relation between the self and the other, to that between the self and (in principle) anybody else on the planet (see Chapter 3). This question of distribution or allocation is the question of justice, which situates the apparent context-independent appeal of the other in the context of other legitimate appeals of all the other others. This raises in my

13 "Ethics of the infinite", op. cit. pp. 57-58 / "De la phénoménologie à l'éthique", op. cit. p. 129 (translation modified). 
mind one of the most important difficulties in Levinas' philosophy: once the subject's ontological existence has been directed ethically "for-the-other", or in fact, once it has been directed by the plurality of others, how should this ontological and political existence be formed to the advantage of the others? Levinas, however, probably in an effort to take contemporary antihumanism into consideration, has so embraced its moving away from ideas of human essence and foundational ethics, that his humanism of the other has been stripped of whatever means could accompany reflectingly the question concerning that which should practically be done. Accordingly, the question of the competence of Levinas' subject to establish what justice entails in a particular context and to realise it seems to be to him of no concern - he wants the subject to be sent on his/her way of responsibility towards the others, but without even posing the question of the means. Thereby Levinas implicitly claims that considerations concerning the competence of ethical subjects and the means they develop to serve what they consider justice to be, are of negligible relevance to the meaning of the ethical.

The conviction that I defend is quite opposite: it should be considered of utmost importance to reflect on the secondary position accorded by Levinas to the competence of the ethical agent and the means deployed by the ethical agent in his/her efforts to obey the imperative to unlimited responsibility. It is when this is done that the implications of the difficult translation of ethics into justice (see Chapter 1, § 2.2) enters into our field of vision - perhaps in an unexpected and disquieting way. In order to test this issue, let us take as a theme of reflection the example of killing other people. At first glance, nothing seems further away from Levinas' thought than a legitimisation of killing. He is, after all, a philosopher of peace and of the "thou shalt not kill!" in the face of the other.

\subsection{Can a Levinasian kill? From the original contradiction to the participation of practice in the meaning of the ethical}

Does the radical ethics of Levinas, of which he sometimes captures the essence in the imperative "thou shalt not kill!", make provision for the killing of people? In order to answer this question properly, it seems appropriate to transpose the terms in which it is posed to that of the key Levinasian terms of the Saying and the Said.

It should be called to mind that this ethical imperative that emanates from the other and by which one's subjectivity is decisively constituted, is 
the Saying by which the Said of one's ontological existence is given sense. However, we also know that the prohibition against murder that, according to Levinas, is the meaning of the face of the other, is just a formal imperative and for this reason every translation of this Saying into the Said, every realisation of the imperative in acts of obedience to it, every effort to make the Saying said, is only a provisional translation, or as Levinas says, a translation that is a partial treason or betrayal ${ }^{14}$ and that for this reason needs to be unsaid. Since the Saying is ultimately unsayable or unutterable (indicible) or purely formal, it cannot be fixed in a Said and each attempt at fixing it in a Said has to be un-said (dédire). If I transpose the question concerning the possible use of killing as a legitimate ethical action to the level of discourse on the Saying and the Said, it is because very often, if not always, Levinas' commentators fail to reflect on the whole series of terms that are associated: next to Saying, unsayable, Said and unsaying (dire, indicible, dit, dédire) one has to consider contradiction (contradiction). This is what Levinas teaches:

"The third introduces a contradiction in the Saying of which the meaning before the other until then went in one direction. This is, in itself, the limit of responsibility, the birth of the question: What do I have to do in justice?"15

This is a major point. One can weigh its importance by connecting this remark with the similar one on the "entry" of the third, cited above and already commented on in Chapter 1 :

"There are always at least three people. [...] As soon as there are three people, the ethical relation to the other becomes political and enters into the totalizing discourse of ontology."

If there are always at least three people, then the third always introduces a contradiction in the Saying, and there is in the life of the subject no time before the question of justice, namely "who of the others comes before whom?". If there are always at least three people and the interrelation between the second and the third, with respect to the first person, is that of contradiction, then the original relation between the self and the others is one of contradiction. ${ }^{16}$ Contradiction of what? It is a con-

14 OB 6/ AE 17-18.

15 OB 157, translation modified. "Le tiers introduit une contradiction dans le Dire dont la signification devant l'autre allait, jusqu'alors, dans un sens unique. C'est, de soi, limite de la responsabilité naissance de la question: Qu'ai-je à faire avec justice?" (AE 245).

16 See De l'éthique à la justice 346-349, where I have exposed the methodological incongruity that allows Levinas to bracket out the alterity of the third, while discussing the alterity of the other. 
tradiction between the imperatives, the appeals to the responsibility of the subject, made with equal legitimacy by the second and the third. It is exactly because of this contradiction that one appeal infringes on another, without however, taking anything away from the validity of either. And thus the question of justice, is the question of contradiction and the question of "who comes before whom?", is the question of "who comes after whom?", in other words "whose demanding and valid appeal to my responsibility should be considered less urgent than that of another, and should therefore be sacrificed in the name of justice?".

Returning now to the dilemma of killing, it should be concluded that the prohibition to kill one person stands in a relation of "contradiction" with the same prohibition emitted by all the others. And under such a regime of contradiction, immediate and obvious obedience to any single other is not possible - all responsibility is already taken up in a complex procedure of weighing, that is, sacrificing, in search of justice, since all responsibility is political.

That is why Levinas doesn't hesitate, when he speaks of the actualisation of justice, to introduce the idea of a struggle with evil and he explicitly distances himself from "the idea of nonresistance to evil [l'idée de la non-résistence au mal]". ${ }^{17}$ Levinas is not Gandhi.

'If self-defence is a problem, the 'executioner' is the one who threatens my neighbour and, in this sense, calls for violence and doesn't have a Face." 18

This declaration, which in my judgement is completely in agreement with Levinas' understanding of ethics and justice, should be considered very carefully. All people have faces; to all people infinite responsibility is due. But under the complicated circumstances under which the question of justice is born, that is, when faced with the contradiction of different equally valid appeals, which in practice excludes contemporaneous obedience, the other might lose his or her face. That means, through the difficult calculation of justice, someone might be sacrificed, that is, someone might be treated as not emitting an imperative prohibiting murder. Such a person might be killed. Under certain circumstances resisting evil, even killing evildoers, might thus be a valid way of obeying the originary imperative: "thou shalt not kill!".

17 ENT 105/EN 115

18 ENT 105. "Si l'autodéfence fait problème, le 'boureau' est celui qui menace le prochain et, dans ce sens, appelle la violence et n'a plus de Visage.” (EN 115). 
If it is considered that this original imperative is the very meaning or sense of all meaning, it should be evident that we are dealing with an extremely important finding about ethics. If killing someone cannot be excluded as a means by which to obey the original sense or significance of one's being that is captured in the prohibition of murder, if killing someone could be under given circumstances the most appropriate way of translating the Saying into the Said, then the means of ethical conduct interferes with the original ethical meaning and as such is part of it. ${ }^{19}$ Levinas is thus mistaken when he claims that the question of the application of ethics is secondary. ${ }^{20}$ If killing someone could be shown to be a valid response to the imperative "thou shalt not kill", how can the fact of responding - practical ethics - not be part of the meaning of the ethical? Rather, the question of the means by which one obeys the contradictory appeals of the others should be considered an essential part of the very meaning of the ethical.

If these conclusions are correct, then surely the competence of the ethical agent for ethical conduct and the means to be deployed in ethical conduct cannot be considered trivial, marginal or of secondary importance in reflection on the ethical. On the one hand it is consenting to an invalid assumption to say that Levinas restricted himself to the ethical origin of meaning, since the practice of ethics interferes, and therefore contributes to what the sense of the ethical is $;^{21}$ on the other hand it is a too facile rejection of the question of practical ethics to pretend that it can simply be reduced to an ethical programme, or a casuistic or a domain-specific deontology - as if these would be the only forms that reflection on the practice of ethics can take.

19 Although arguing his case somewhat differently from what I do here, or did in De l'éthique à la justice, and developing the consequences thereof in a somewhat different manner, Michel Vanni arrived at very similar conclusions concerning the insertion of Levinas' ethics in practice ("En guerre pour autrui", in Internationale Zeitschrift für Philosophie 1, 2004, pp. 78-93). Vanni's essay was published independently from my argument, as I formulated it for the first time in my doctoral dissertation of 2004 (and I discovered the article too late to use in De l'éthique à la justice). This independence of his conclusions, and of course the strength of his argument, should be considered a significant support for my present line of reasoning.

20 This idea will be developed further in Chapter 7, § 2.2.

21 Or as Vanni correctly concludes: "Actually one cannot simply say any more that acts of aggression, withdrawal or contemptuous indifference constitute a covering or a treason of the 'pre-originary' appeal (according to the formula of Levinas). If we don't want to maintain a completely abstract and a-praxical view of this appeal, we should rather say that it leads straightaway to conflict and friction, that it is straightaway situated in the middle of conflict, without being able to claim, by using one or other treason as excuse, that it can be detached from this conflict." "En guerre pour autrui", op. cit. p. 84. 
Perhaps this doesn't mean that Levinas was obliged to work out a philosophy of the practice of ethics, but a restriction to reflection on ethicity (in abstraction from the fact that it cannot exclude reflection on the practice of ethics) could be justified only strategically and not ultimately by the responsibility that the author had for the others - the exclusion of reflection on the practise of ethics would entail a performative contradiction in that the philosophy of ethicity would be practised as if it is not a response to the appeal of the other, of whom some might be threatened by legitimated killing. Furthermore, if it is unacceptable to confront a thinker of the meaning of ethicity with the implications of the practice of ethics, if such considerations need not be of any concern for those working on the meaning of ethicity, then Levinas misunderstood himself when he wrote with indignation about historical events of the era in which he lived and presented his philosophy as a response to it and, besides, his claim to the urgency of ethics as first philosophy ${ }^{22}$ would be simply unintelligible. On the contrary, I take the expression of indignation in Levinas' work to be a clear indication that he assumed, at the very least, that fidelity to the originary meaning of the proximity of the other would fare better in helping the fate of other people (than did whatever was responsible for the catastrophes), in other words, that it had practical relevance and that such relevance was significant for the meaning of the philosophy that he was writing. What I want to claim for the practical realisation of responsibility, or for doing justice to responsibility, is similar to what Levinas claimed for the Rabbinic tradition of commentary on the Biblical verse:

"The expression of signification belongs to its very significance [L'expression de la signification appartient à sa signifiance même].,23

22 LR 78 / EPP 77.

23 NLT 33. With recourse to Levinas' phenomenology of writing in the Judaic writings, Rodolphe Calin has made a subtle attempt to indicate an instance of concrete expression of shared responsibility and thus of the movement of the single responsible subject to a collective of responsible subjects (in Levinas et l'exception du soi. Paris: Presses Universitaires de France, 2005, especially Chapter IX - La communauté inspirée, pp. 331-359). The point of departure of his proposition for such a conception of ethical agents as an "inspired community" is Levinas' coordination between revelation and writing: "if Scripture/Writing [l'Écriture] is revelation, it is in the sense that the speech that reveals and that reveals itself cannot do so without being written [s'écrire], in other words without being inscribed [s'inscrire] in the very texture of the text and in the materiality of the letter, of which the corporeity is nevertheless not that of a signifier that refers to a meaning, but [...] that of the trace: the paradoxical and precarious presence of the one that has radically escaped being and presence." (p. 336). This inscription of the ethical trace gradually exposes itself to the diversity of interpretations in the community of ethical agents; the ethical community being bound together by the incessant reinterpretation of shared re- 
That is to say, just as the repeated commentary on a verse forms part of the meaning of that verse, so the ways in which to obey the originary imperative belong to its very significance. ${ }^{24}$

In the following paragraph, I shall illustrate how far the complications of this negligence of Levinas' can stretch, by reconsidering what the difficult translation of the Saying into the Said may entail.

\subsection{Infinite responsibility and the polysemy of transgression}

In Chapter 1, the presentation of Levinas' political thought culminated in a discussion of a passage in which the radical demandingness of Levinas' ethics for politics has been expressed. I cite this passage again here, with

sponsibility (p. 356). I have three reservations about the possibility of exploiting the insights derived from his study for my question concerning justice in Levinas' work. First, although Calin's use of Levinas' Judaic writings is instructive, it has to be asked why such an attempt is absent from Levinas' philosophy - the reflection on the inspired community still has to be developed into a theory of society searching for justice. Second, whereas the formal phenomenology of writing could suffice to hold together an inspired community, even in isolation from the content of the writing, it is not clear if this formal aspect of writing could be developed for multicultural societies. Furthermore, the content question of distinguishing properly between true and false prophecy or inspiration seems to haunt this formal consideration of writing (see De l'éthique à la justice 320-324, 344-346). Three, it is not certain that the "fragmentation of the infinite" in the plurality of readers or interpreters can do justice to the conflict of interpretations and, by analogy, to the quests for justice and the tragic nature of political action. Underlying all three of these issues is the question concerning the relation between Levinas' philosophy and Talmudic writings - a question that I cannot address here.

24 Whatever else one might think of Husserl's ideas about self-responsibility, in two points at least they seem to be more sophisticated than those of Levinas on responsibility. (1) Husserl considers the fact that the responsible agent is part of a community of responsible agents an indispensable part of reflection on responsibility - the agent is socially constituted and responsibility is always co-responsibility ("Meditation über die Idee eines individuellen und Gemeinschaftslebens in absoluter Selbstverantwortung", in Erste Philosophie (1923/1924), Zweiter Teil: Theorie der phänomenologischen Reduktion, Husserl Gesammelte Werke Band VIII Rudolf Boehm (ed.). Haag: Martinus Nijhof, 1959, pp. 193-202, here pp. 197-198), whereas for Levinas, as argued above, the agent of responsibility is an isolated bearer of an infinite obligation (even though, of course, constituted pre-originally by a plurality of others). (2) For Husserl, vagueness, uncertainty, and the possibility of mistakes and misdeeds remain essential constitutive aspects of responsibility (p. 202), whereas for Levinas the question of the capacity of the agent of responsibility to execute that obligation is never submitted to scrutiny.

This comparison clearly needs to be worked out more carefully in another study. 
a change of accent, because it captures quite correctly the political implications of Levinas' ethics:

"Usually the State is preferable to anarchy - but not always. In certain cases, in fascism or totalitarianism for instance, the political order of the State may well have to be challenged according to the criterion of our ethical responsibility to the other." 25

If you exert yourself to find the greatest realisation of justice "according to the criterion of our ethical responsibility to the other", it might happen that anarchy, ${ }^{26}$ is preferable to the State, that is, to whatever institutionalised legal or normative system that might be in force in a specific context. It would not be too difficult to find examples of such a preferability of undermining the law, of anarchy: one could think of people conspiring to overthrow the Nazi-State or, closer to my home, the armed struggle against Apartheid. Such examples often do not bother us, in fact, they inspire many people as instances of moral excellence, despite the fact that they involve transgression of institutionalised laws, and even when they may involve killing people - hence the relevance of our reflection on killing in the context of Levinas' ethics. Opposing evil, even by violent means, is not excluded by Levinas' ethics, as we have seen above.

If this is the case, it would be of the greatest importance to know when it would be in accordance with "the criterion of our ethical responsibility to the other" to consider anarchy as more preferable to the State. What does Levinas say? According to the citation above, this is in cases of "fascism or totalitarianism, for instance". For instance! My question to Levinas would be: who is to decide how to fill in the blank of his "for instance".

The answer is I. We shall know when and how this blank is to be filled when we understand who is the I that decides when anarchy is preferable to the State. I am the subject subjected in absolute heteronomy to the ethical appeal of the other. This appeal is characterised, as we have seen in Chapter 1, by its infinity and by the fact that it elects me as uniquely, irreplaceably responsible.

Yet, someone might object that my infinite responsibility is limited when the third enters. This is indeed what Levinas believes, and with him a great number of his commentators. But his reasoning on the matter is incorrect. Faced with the infinite appeal of not just one other but with that of numerous others that contradict one another, my responsibility to this particular other

25 "De la phénoménologie à l'éthique", op. cit. 137 (my italics and translation) / "Ethics of the infinite", op. cit. p.66. The argument that follows has been developed in detail in De l'éthique à la justice, Chapter 9, §§ 5-7.

26 "Anarchy" is used here in the usual sense, not as Levinas' an-archy. 
here or that particular other there might be limited, but the sum of my responsibility remains infinite. The State does not limit my responsibility as such and, therefore, in the face of the thirds I have an infinite responsibility to actualise or achieve justice. And nobody can decide in my place what this means. At every moment I am constituted as subject by the question of justice: "who comes before whom?", weighing the demands of these others with those others, and with those efforts of other people to answer the same question and that have been institutionalised in legal and normative systems, including States. In this sense the Levinasian ethical subject is constituted by the plurality of contradicting heteronomous ethical relations as the sovereign power of all politics and justice.

Having arrived at this point, we should ask ourselves about the possible scenarios that could arise from such a political condition of the subject. Of course it could lead me to unsay (dédire) my being by acts of saintly selfsacrifice. Levinas gives an example thereof: people helping others in the event of a natural catastrophe, to a far greater degree than institutionally expected of them. ${ }^{27} \mathrm{He}$ also describes Edmond Jabès' life as being one of "unsaying": ceding or losing his place in the world, rather than persevering in holding his place in it. ${ }^{28}$ But equally congruous with what we have seen thus far in Levinas would be whatever fanatical effort to actualise what I would consider the best justice for a particular society. Nobody protects society against my ideas about justice. Nothing in Levinas' philosophy protects the State against my ideas of how best to answer my infinite responsibility to actualise justice to the point of unsaying myself in saintliness. If politics left to itself contains the possibility of totalitarianism, then saintliness left to itself carries in it the possibility of all sorts of fanaticism. That is why the term "saint" is such an ambiguous one, as are its equivalents: fanatic, kamikaze, terrorist, revolutionary, martyr - all terms that are used to designate people who, rightly or wrongly, consider their own idea of justice to overrule that of one or other State, who consider ethics to be more demanding than the form of justice institutionalised in their particular context. ${ }^{29}$ It should not surprise us to find in Levinas' writings very ambiguous expressions in which the letter of the text expresses equally well a

27 IH 143.

28 PN 63 / NP 93.

29 And while considering the possible turning of the letter against the spirit of the text, one should add to this list the Messiah, if this is nobody other than every person, as Levinas explains, and especially if the Messiah is defined as the "just that suffers for others" (DF 89 / DL 129).

See also my argument in De l'éthique à la justice 397-399. 
possibility of his thought than the spirit of the text: non-resistance to evil, the just war waged against war, or permanent revolt or revolution in the name of the other. ${ }^{30}$ Ethics, because of its limitlessness and because of the irreplaceable position of the ethical subject, could be open towards interpretations of it that would be executed in serious attempts to act in accordance with the ethical appeal, but that would nonetheless be undesirable, or at least, highly ambiguous. ${ }^{31}$

And this does not apply only to me, but to every human being. In Levinas' society man is not a wolf for man, but a prophet and a saint for the other; Levinas' society is the eternal struggle of ideas about how to actualise justice and efforts to do so by everyone - of course never in anybody's own name, but always justified by the reference to the other, the other who justifies one's response to the question of who comes before whom.

Yet, one would not find much in Levinas to support reflection on this dilemma. His project is to reflect on the meaning of the appeal made by the others on me - the meaning of ethics - and not to consider where the contradicting inspirations, that constitute the political subjects, could take them. The real situation in which the ethical subject finds him/herself - "there are always at least three persons..." - seems to be of very limited interest to Levinas. ${ }^{32}$ In any case, any contribution whatsoever from whomever to influence my understanding of the justice to be actualised, will only make up one more element in the big calculation of "who comes before whom?" to which I alone may give the answer.

I shall consider these remarks sufficient to contest an observation made by Jacques Roland:

"I have always thought that the harsh pages 200 to 205 of Autrement qu'être, in the chapter 'From the Saying to the Said or the wisdom of desire', offer (also) the outlines for a philosophical discourse on the political, that hasn't been developed,

30 ENT 105 / EN 115, OB 185 / AE 283, GCM 9-10 / DVI 26-27, respectively.

31 In this way the letter of Levinas' Platonism turns against the spirit thereof and the Platonic supremacy arrogantly claimed by Western culture (in Levinas' criticism thereof - see Chapter 3, §2), becomes telling of the force of an ethical meaning "beyond Being" (according to Levinas' appropriation of the Platonist term): "for Plato, the world of significations [and thus, likewise, the ethical beyond Being $\mathrm{EW}$ ] precedes the language and culture that express it; it is indifferent to the system of signs that can be invented to make this world present to thought. Consequently, it dominates historical cultures. [...] there would exists a culture that consists of depreciating the purely historical cultures and in a certain way colonizing the world [...]" (HO 18f / HH 31, my italics). What is surprising is that Levinas saw with much more clarity the danger lurking in the Western Platonism that he denounces (HO 37 / HH 59), than that of his own re-appropriation of Plato.

32 E\&I $90 /$ EI 85. 
but that could have been in a justified and well articulated manner. Today I understand better that if this has not been the case, it is because the development [of such a philosophical discourse on the political - EW] meets no need from the perspective of the internal balance of [Levinas' - EW] thought.",33

In fact, I defend exactly the opposite thesis. It is not my present objective to question the constitution of the political by the ethical, as Levinas does, but to question the coherence with which he does it and to point out significant concerns about the implications of this perspective. Levinas wrote in the 1990 "Post-scriptum" to his 1934 essay "Some reflections on the philosophy of Hitlerism" that this article

"proceeds from a conviction that the source of the bloody barbarism of National Socialism is not in one or other contingent anomaly of human reasoning, neither is it in one or other accidental ideological misunderstanding. There is in this article the conviction that this source is due to an essential possibility of elemental Evil [Mal élémental] whereto good logics could lead and against which Western philosophy has not secured itself enough. This possibility is inscribed in the ontology of Being, concerned to be [...]". ${ }^{34}$

The task of finding the meaning of ethicity to safeguard Western philosophy against the tyrannical meaning of Being, is Levinas' life work. The aim of my criticism of Levinas is not to question his good will and seriousness, and certainly not the radicalism with which he tackled this problem. What I do believe though, as I have argued here, is that Levinas, in his project of exploring the origin of ethical meaning, did not nearly enough take into consideration the seriousness of the meaning of ethicity as it impregnates practice, that means, politics. This is not a secondary aspect of his research that could be completed afterwards by a willing assistant; it is not a question of tidying up the last remote corners of his thought. It is the very meaning of the ethical that is at stake. I come to the uncomfortable conclusion that the meaning of ethics is originally ambiguous. Ethics left to its own devices carries in it all that is ambiguous about saintliness.

33 Jacques Rolland, "Pas de conseils pour le tyran. Lévinas et la question politique", in Revue philosophique de Louvain 100, Feb-May 2002, pp. 32-64, citation p. 42 (my emphasis).

34 "Post-scriptum", in Quelques réflexions sur la philosophie de l'hitlérisme. Suivi d'un essai de Miguel Abensour. Rivages poche. Petit Bibliothèque: Paris, 1997, citation, p. 25. 


\subsection{Mediation: the irreducible political condition of responsibility}

But the struggle of fanatics of different natures is evidently not where Levinas sees his first philosophy leading us in politics. In rare instances he even indicates a sensitivity for the possibility that the opposition against evil could itself engender evil and therefore cautions that the

"hand that grasps the weapon must suffer in the very violence of that gesture. To anaesthetize this pain brings the revolutionary to the frontiers of fascism." 35

But generally speaking one could consider the possibility indicated of a fanatical slide in the assumption of responsibility for the plurality of others, as a symptom for the lack of attention that Levinas gave to the question (1) of the inevitable recourse to the means (institutional and other) by which the ethical is to be translated into the political and (2) of the mediation of the contradictory ethical appeals in view of the interference of the ethical in the political. It is possible to demonstrate how Levinas sidesteps this task by considering (1) an example of how he neglects reflection on the contextembeddedness of ethical action and (2) an example of how he fails to compare even-handedly the political recourse to means and the prophetic criticism of the side effects of the recourse to certain means, which betrays a weakness in reflecting on the conjunction of the political and the ethical.

(1) Let us, then, first consider the manner in which he often illustrated the dramatic intensity of the ethical constitution of the subject face-to-face with the other by citing a well-know passage from Dostoyevsky:

"Each of us is guilty before all, for all and for everything, and I more than the others."

When Levinas at least once in an interview cites the passage incorrectly as

"[w]e are all responsible for everything and for everybody and before everybody, and I more than all the others", 37

the slide from the novelist's "guilty" to the philosopher's "responsible" is significant in that it reveals the essence of Levinas' conviction concerning the demanding nature of ethics.

35 DF 155 / DL 219. I shall leave out of consideration the question of whether this suffering due to the inevitable violence to be committed is not also the suffering of someone that sacrifices himself/herself for what they consider indisputably just.

36 GCM 84 / DVI 134-135. Levinas' citation corresponds with the translation in the French Pléiades edition of Les frères Karamazov of 1952, p. 310.

37 E\&I 101 / EI 98, translation corrected, my emphasis. We know, of course, that Levinas read Russian, but three pages earlier in the same text he explicitly cites the Pléiades translation. 
"We are all responsible for everything and for everybody and before everybody, and I more than all the others",

according to Levinas. What strikes me as astounding about Levinas' repeated use of these words from the pen of Dostoyevsky - in its correct or adapted version - is that the context in which the novelist places these words is never evoked by the philosopher, even when citing explicitly from the novel. This is despite the fact that the context could help reveal something of the status that the ethical has in the political for Levinas. According to Alexei Karamazov's narration, ${ }^{38}$ the idea was discovered by a dying young man, Marcel, (was it the ultimate meaning of life revealed to him, or was it an idea produced in a state of delirium?) and was taken up some years later by his younger brother, Zenob, as exegesis of the catharsis that he underwent when realising the unacceptability of the violence that he had committed against his servant and the futility of violence in general. So powerful is the realisation of the validity of this idea for Zenob that he decides to give up his military career to become a monk. It is as the starets Zosima that he is encountered from the beginning of The brothers Karamazov. In Book IV, Chapter i, Dostoyevsky describes the scene in which the aged and dying starets gives his last teaching and it is also here that we encounter the cited idea for the first time in the novel. The place of teaching is not the monastery of the city in which the Karamazovs lived, but the hermitage next to it and the people to whom these teachings are addressed are not citizens (in the first place), but monks and priests. All of them, in other words, have sworn oaths of fidelity to a religious hierarchy and some of them are linked by a special tie of absolute obedience to the starets himself (like Alexei, the author of the starets' biography). It is a community constituted by absolute religious obedience and, as such, should be considered an apolitical, or at least a private, setting. In this context, the teaching about one's guilt for everything and everybody is a teaching of saintliness for people that, although they live in the world, do so as not belonging to the world and not obeying the logic that governs the world. It is a teaching that has its application in the domain of the privation of the political.

From these two episodes of the novel it seems then that when the idea of universal guilt (or responsibility) as presented by Dostoyevsky is taken as valid, it would lead one to taking up the frock, or at the very least to convert to a kind of saintliness lived out in this world. Returning from The brothers Karamazov to Levinas, Dostoyevsky helps us to identify the bias

38 Book VI, chapter ii.a of The brothers Karamazov. This is the section to which Levinas refers explicitly when making the citation in OB 146 / AE 228 and he refers to the specific page number in E\&I 98 / EI 95. 
with which Levinas wrote his philosophy. Levinas' ethicity seems to find its origin in a space opened up in the "privation" from the political; ethics is, first and foremost, entre nous, between ourselves, a matter of intimate privacy - yet, he claims that it is this intimate ethical privacy that constitutes the essence of the political, of politics and of the State. ${ }^{39}$

(2) One can measure the unworldliness of Levinas' idea of responsibility for the others (or the neglect in reflecting about the mediation and means of ethics as it signifies in the political), by pointing out the unfairness with which he allows himself to compare State politics and prophecy. In "Human rights and the rights of the other" ("Les droits de l'homme et les droits d'autrui" - 1985) Levinas questions the profundity by which human rights ${ }^{40}$ can install true peace, since these rights have to be defended by the State and the means of the State necessarily complicates the fate of the bearers of rights, since the State and its political order of justice can act only according to the "necessities peculiar to the State":

"Necessities constituting a determinism as rigorous as that of nature indifferent to man, even though justice [...] may have, at the start, served as an end or pretext for the political necessities. An end soon unrecognised in the deviations imposed by the practicalities of the state [la pratique de l'État], soon lost in the deployment of means brought to bear [le déploiement des moyens mis en oeuvre]. ${ }^{, 41}$

And this is when things go well, since the State can also slide into totalitarianism... For this reason, according to Levinas, the defence of human rights has to be assumed also by an instance outside of the State:

"disposing, in a political society, of a kind of extra-territoriality [extraterritorialité], like that of prophecy in the face of the political powers of the Old Testament, a vigilance totally different from political intelligence, a lucidity not limited to yielding before the formalism of universality, but upholding justice itself in its limitations. The capacity to guarantee that extra-territoriality and that independence defines the liberal state and describes the modality according to which the conjunction of politics and ethics is intrinsically possible." ${ }^{, 42}$

To summarise: politics is characterised by proper practice and the means of this practice, which it necessarily uses under the conditions of a rigorous

39 T\&I $300 /$ TI 334.

40 I have elsewhere elaborated on the problems that emerge from the reinterpretation given to human rights in Levinas' later philosophy in terms similar to those deployed in the present Chapter - see "The quest for justice versus the rights of the other?" in In Levinas' trace, Maria Dimitrova (ed.). Sofia: Avangard Prima Publishers, 2010, pp. 101-111.

41 OS 123/HS 167.

42 OS $123 /$ HS 167. 
determinism, inevitably obscure the original finality of justice; prophecy is characterised by an unformalisable vigilance and lucidity concerning justice and the liberal State itself depends on guaranteeing the conditions for the practice of prophecy. What should strike us in this reflection of Levinas' is the perspicacity with which he identifies the risks of the use of the means of politics on the one hand, and on the other hand, when proposing prophecy in response, the question of means simply becomes either immaterial, or is again referred back to the State. What bothers me here is thus not the fact that Levinas draws his inspiration for reflecting on human rights from religious texts, ${ }^{43}$ but that he is not even-handed in his considerations concerning mediation and means when speaking about politics and when speaking about prophecy.

One can identify the same weakness in one of the best know strategies by which Levinas reflects on the "conjunction of politics and ethics". Levinas believes in the to and fro, the balance, between two archetypal ways of conceiving justice: Jerusalem and Athens. ${ }^{44}$ But this is not, as many readers have been tempted to think (and as is perhaps suggested by the passage from Outside the subject, above), a balance between ethics and politics where ethics interrupts or questions politics. Jerusalem is not ethics, and cannot be ethics, because nowhere has ethics a direct influence on politics, nowhere could it impact on or interrupt politics without the mediation of the question of justice. At every stage in the historical development of the Levinasian State every subject - including the prophets - should calculate how best to actualise justice. Acting according to the logics of Jerusalem or those of Athens are just two expressions of this same calculation. The balance between Jerusalem and Athens that Levinas hopes to see, is thus a balance of two ideal types of responses to the question of justice, two interpretations of what the plurality of ethical appeals means in a certain context. If that then is the case, why would this balance hold? What is there in Levinas' philosophy that guarantees this?

Since the originary imperative from the other is purely formal and since its meaning is presented by Levinas as an-archic, one has to come to

43 However, I have shown elsewhere (De l'éthique à la justice 345-346) that if Levinas had given more attention to the evolution of the practice of prophecy in Ancient Israel, he would perhaps have been more careful in his use of this term in his own thought. Yet, given his conviction that nothing of spiritual value can be learned from a historico-critical reading of religious texts, he would not have been predisposed to receive this instruction.

44 BPW 24 / LC 99-100, and see Chapter 1, § 2.2. See also De l'éthique à la justice, Chapter 9, §7, for the point that follows. 
the conclusion that there is nothing in his philosophy that obliges ethical agents to keep this balance, at least, nothing explicit. Implicit in Levinas' philosophy is a categorical imperative that would always curb saintly fanatics' initiative to achieve justice. This imperative is: always act in such a way that your search for justice holds in balance calculating, institutionalising politics (Athens) and subversive prophetic and saintly interventions (Jerusalem). But the an-archy of the Saying makes it impossible to justify this categorical imperative. The balance of Athens and Jerusalem is only one amongst many possible betraying translations of the plurality of Sayings into a just Said and therefore this balance also cannot be proposed as a counter to possible fanatical slides.

If this is not what we read in Levinas, it is because he persists in thinking about what is essentially a political or mediated relation in terms that are private (as illustrated by the text of Dostoyevsky) and unmediated (as indicated in the chosen passage on prophecy). The meaning and sense of all human interaction is ultimately shown to be dependent on this asymmetric relation between the self and the other, but the way in which this disruptive meaning is itself troubled by original contradiction is not what draws Levinas' attention. This seems to me the main problem with thinking responsibility for the plurality of others and therefore political responsibility, with Levinas. The possibility of fanatical slides seem to me a marginal (but real) possibility of a broader problem, namely the lack of accompanying reflection on the inevitable mediation of the plurality of responsibilities and thus the lack of reflection on the competence and means of the agent of responsibility that has to act in a particular context.

\section{After Levinas}

The time has come to take stock of what has been explored and argued, not only in the preceding paragraphs of this Chapter, but also in the preceding chapters of this Part on Levinas' post-anti-humanist humanism. The subtitle of the present book is "After Levinas' humanism" and it has been indicated since the preface that the word "after" is meant here in a positive and a negative sense: positive, by continuing to pursue a philosophical objective in a way that follows significant aspects of Levinas' work and, negative by attempting to find a way out of what is considered an undesirable heritage. In both the positive and the negative aspects of this reception of Levinas, I have attempted to remain true to his text, but 
without any desire to embrace a Levinasian orthodoxy, since I treat his work - as he once said of that of Husserl - as that of a living philosopher. Both of these sides of my reception of Levinas prepare the exploration in Part 3 of the present book in view of a political responsibility for a globalised world. This is the agenda with which I have undertaken the reading of Levinas since Chapter 1.

While the criticisms I have levelled against the political implications of Levinas' philosophy are still fresh after the previous paragraphs of this Chapter, it would probably be prudent to offer a summary of the positive aspects of Levinas' philosophy that I follow through on here. From Levinas' project of philosophising the ethical, I retain (1) the importance of remaining vigilant against all forms of totalitarian tendencies in politics and in social life, (2) to do so from a position that should ultimately be called ethical and that drives the reflection of a non-indifferent philosophising about politics and social life. (3) In this context, ethics refers not to a set of fixed principles for human conduct or for an attempt to program harmless human interaction, but as the significance of human interaction. (4) Thus is taken into consideration the importance that a notion of ethics necessarily has for justice, both in its institutionalised form and in the exercise of power that institutes justice. (5) In all of this, as important as reflection might be, the pre-reflexive level of signification that is inscribed in human praxis plays a decisive role.

These positive elements seem to me to be sufficiently present in the core of Levinas' concern (and sufficiently commented on in Chapters 1, 4 and 5) to justify calling the work done here "after Levinas", in the positive sense of following him. These elements do not form the framework of a theory of political responsibility and need to be developed by other means after they have been confronted with the criticism of Levinas' thought.

The most significant elements of such a criticism that have been pointed out are: (1) even if one concedes to the ethical meaning of the alterity of the other, the infinity of the asymmetry between the self and the other hurtles towards a measureless self-sacrifice of the political subject. (2) Levinas' own attempt at limiting this ethical responsibility in justice, through the confrontation with the plurality of others, not only misses the first point, but is furthermore invalid. (3) On the contrary, nothing is said that could help reflect on the limitation of the initiative that someone could be justified (or someone could justify himself/herself) to take in confrontation with instituted justice and in the name of the responsibility for the others, in view of the transformation or overthrow of such institutions. (4) Such fanatical de- 
viations in politics are the symptom of the absence of reflection of the mediation between ethics and politics and the means by which ethics intervenes in politics; the competence required for assuming the considerable load of responsibility in politics is not submitted to reflection. (5) Although each political agent takes responsibility for all of the others, he/she remains not only the ultimate instance of decision-making concerning the requirements of justice and the means by which to pursue it in a particular context, but also the ultimate instance of the realisation of that justice - in this sense, Levinas' ethical responsibility could be said to be politically irresponsible.

To these points of criticism should be added two more that fall outside of the scope of examination of the present book, but that nonetheless call for some explanation. Without entering into the justification thereof, I state $^{45}$ (i) that Levinas' entire philosophy is subtended by an unjustifiable affirmation that Being is ethically evil and (ii) that the analyses made by Levinas of the alterity of the other do not succeed in supporting sufficiently the ethical nature of that alterity. The reader will immediately notice that especially the last point seriously places the core of Levinas' philosophy in question and it might therefore seem to some readers more coherent to reject Levinas' philosophy en bloc, than to claim that in what I am doing here, I am still in an important way in agreement with Levinas. Thus, even though a "phenomenology" of the alterity of the other is not part of the present project, something needs to be said to justify the continued reflection with Levinas on responsibility.

The conclusion arrived at in De l'éthique à la justice (Chapter 8, § 3.4) is that even if one were to accept all of Levinas' phenomenologically styled analyses of the other, and concede to an alterity of the other, to an alterity that would make of it something non-ontological and even concede to that alterity having a linguistic or sign structure, that tampers with the constitution of the self, then there is still no forceful reason why this alterity should be ethical. The only way in which Levinas succeeds in identifying the alterity of the other as ethical, of calling it an imperative or a questioning of the self, is by secretly introducing a hermeneutics of the alterity of the other where he explicitly claims there could be none. If one then refuses this illegitimate introduction of a hermeneutics of alterity, one will have to accept that the linguistically structured, non-ontological alterity of the other is what I call a hieroglyph: something of which one could be quite sure that it carries a significance, but of which it is impossible to say what that meaning is. This

45 They have been worked out in detail in De l'éthique à la justice, see particularly Chapters 8 and 9. 
doesn't exclude the possibility of it being ethical, but there is no way to affirm this and the philosopher is bound to remain agnostic on this issue.

It should be quite evident that if this is the case, that it touches at the heart of any attempt to take up Levinas' philosophy. What seems to me equally clear is that the ground lost in insight about the passive constitution of the self (by questioning the claim to its ethical constitution) cannot be simply reclaimed by attributing that alterity to the processes of deciphering of Marx, Nietzsche and Freud. ${ }^{46}$ The reason for this is that there is no way to show that the cumulative effect of their theories of suspicious hermeneutics of the subject is an exhaustive account of the passive constitution of the subject. In other words, next to the masters of suspicion, it seems that, at the very least, Levinas exposes the irreducibly hieroglyphic aspect of passive constitution. The implication of this is that there always remains a significant aspect of one's being affected and constituted by the other, of which the meaning might be significant, but which doesn't give itself for a hermeneutics. In this sense there is no foundation to be uncovered about the meaning of the other for the self; the proximity of the other is, as Levinas correctly claims, anarchical.

If this is the case, then the place in which to situate the ethical significance of the other, is not the other, but Levinas' text. When Levinas defines prophetism or inspiration as

"this intrigue of infinity in which I make myself the author of what I hear [cette intrigue de l'infini où je me fais l'auteur de ce que j'entends]", ${ }^{47}$

I suspect that Levinas really hears nothing, or at least nothing decipherable, and that he is the proper author of the ethical meaning of the other. Or to be more precise, it might be that the other has this ethical meaning, but there is no way to affirm this with certainty and any claim to be able to make such an affirmation says more about the claim than about the hieroglyph that is the other. The place of the affirmation of the ethical meaning of the alterity of the other, the place where the uncertainty or agnosticism is solved, is in the text of Levinas.

While this conclusion certainly relativises the force of Levinas' claim, it doesn't have to follow that the texts in which he makes this claim are therefore of no value. In what follows I shall elaborate on what is meant by this statement. However, it needs to be stressed that this is not Levinas' claim -

46 Cf. De l'éthique à la justice 328-331.

47 GCM 76 / DVI 124. See also my discussion of this phrase in De l'éthique à la justice 325-327. 
his philosophy is an exploration of a "strong" alterity in the face of the other, or in the proximity of the other, and of which the philosophical text can only witness ${ }^{48}$ I argue that such a "strong" alterity is a hieroglyph, of which the indeterminacy of its meaning allows for the creation of a "weak" alterity, a suggestion of ethical alterity, through what is written (realising well that, for Levinas, this will mean not much more than a sophisticated rearrangement in the flux of Being). By means of an analogy, I would like to argue that there is something legitimate and even of decisive significance in such an undertaking of creating a "weak" alterity in writing.

Let's consider the central Nietzschean notion of the will to power. Although Nietzsche's anti-Platonism involves denying that there would be a true reality beyond the phenomenal one, he still affirms that the world is - despite appearances or not - the will to power. It is equally true that Nietzsche often presents the notion of the will to power in a dogmatic manner. How is the strong affirmation of the will to power as the intelligibility of the world to be harmonised with Nietzsche's explicit anti-metaphysical stance?

This question could be answered with reference to aphorism 36 of Beyond good and evil, of which the point is encapsulated in the phrase:

"The world viewed from the inside, the world defined and determined according to its 'intelligible character' - it would be 'will to power' and nothing else."

In his interpretation of this aphorism, Paul van Tongeren ${ }^{50}$ insists on the importance of the hypothetical form of the statement ("it would be", "sie wäre..."), and of others from the same aphorism: what seems at first glance to be a metaphysical principle, is a hypothetical conclusion to a series of hypotheses and thought experiments. This hypothetical conclusion is formulated in opposition to metaphysical claims of access to an ultimate

48 I have demonstrated that there is in Levinas no claim that texts can "produce" or "carry" alterity. This has been argued separately for Totality and infinity (De l'éthique à la justice 228-233), for Otherwise than Being (De l'éthique à la justice 287-292), and also for Levinas' presentation of texts of literature in Proper names (De l'éthique à la justice 292-299).

49 Basic writings of Nietzsche. Walther Kaufmann (transl.). New York: The modern library, 1968, p. 238 / "Die Welt von innen gesehen, die Welt auf ihren 'intelligiblen Character' hin bestimmt und bezeichnet - sie wäre eben 'Wille zur Macht' und nichts ausserdem.” Friedrich Nietzsche, Jenseits von Gut und Böse. In G. Colli and M. Montinari (eds.), Kritische Studienausgabe 5. Berlin and New York: De Gruyter, [1885] 1999, p. 55.

50 In my presentation of the notion of the will to power I am guided by Van Tongeren's remarkable book Reinterpreting modern culture. An introduction to Friedrich Nietzsche's Philosophy. Indiana: Purdue University Press, 1999, in particular pp. 154-170. 
reality and thus the hypothetical form is the very performance of the antimetaphysical nature of the notion of the will to power. Seen in this manner, the will to power is not a necessary discovery of the ultimate meaning of the world, but rather a possible name for the world, a possible perspective on the world that opposes other interpretations of the world. It is an interpretation amongst other interpretations of the world, where none can rightfully claim to be anything more than just an interpretation of the world, none can rightfully claim to be the final, authoritative perspective on the world. And since will is a unity only in concept, ${ }^{51}$ the claim that the intelligibility of the world is the will to power is not a claim to the ultimate perspective on reality, but rather an affirmation of the plurality of interpretations. Yet, the weak, hypothetical "epistemological status" of the affirmation of the will to power is sufficient for it to act as a disruptive force of suspicion on the claims of objectivity and truth of other perspectives.

What is of relevance for my recuperation of Levinas is not the theory of the will to power itself, but the form of argument by which it is affirmed. What is required for the philosopher Nietzsche to be able to disrupt contemporary discourse on reality is not a better access to ultimate reality, but a suggestive discursive practice that puts other claims under a perspective of suspicion. It is the philosopher (in this case) that has this anarchical potential. I call it "anarchical" since it doesn't lay claim to having access to an arché or metaphysical principle, yet in the absence of the capacity to gain such a principle, it has the power to disrupt, by shedding doubt through its hypothetical performance.

If I consider it worthwhile to continue reflecting with Levinas in the direction opened up by his philosophy of the ethical alterity of the other - even while remaining agnostic about the ethicity of the other - then it is because I think that that ethicity is situated (at least in its strong affirmative sense) in the text of Levinas and that this is not necessarily a disqualification of his philosophy. When he says that "I make myself the author of what I heard", I say, Levinas could not have been sure of what he heard or learned from the hieroglyph of the other, but made himself nonetheless the author of that undecipherable message. In the absence of the capacity to determine the meaning of the alterity of the other, the strength of Levinas' philosophy seems to me to reside in the doubt that it sheds on the supposition that there is no such ethical alterity or, positively formulated, that his hypothetical idea that the other signifies ethically has sufficient suggestive strength to unsettle any discourse that would simply take the negation of this idea for granted. Without a doubt this is

51 Cf. Basic writings of Nietzsche. op. cit. p. 215 / Jenseits von Gut und Böse, op. cit. p. 32 (aphorism 19). 
not Levinas' own vision about his philosophical achievement or ambition. ${ }^{52}$ However, I would claim that such a reading of his work has at least sufficient performative force to act in an anarchical manner. Levinas' philosophy is then not an anarcheology, ${ }^{53}$ a testimony to an an-archical alterity (in the strong sense), as he would like it to be, but as a discourse suggestive of an an-archical alterity it produces an anarchical event itself (albeit in a weaker sense). By this I certainly do not mean a romanticising of a mysterious ethical force in texts it is not the text that has this disruptive and suggestive quality, but that which is expressed by Levinas in the text. With his hypothesis of the ethical imperative of the alterity of the other, he opens a perspective on reality. Again, even though I claim that the affirmation of the ethicity of the other is created by Levinas' philosophy, it is not exclusively on the basis of his intellectual power or performative brilliance, but also due to the very enigmatic nature of the other, due to the alterity of the other as impenetrable hieroglyph, that this suggestion could gain force. In this sense - and by the purposeful choice of the word "enigma" - the idea of the suggestive force of Levinas' argument is at least not completely foreign to the spirit of Levinas' philosophy.

Levinas' philosophy is of such a nature that it unsettles accepted manners of seeing and thinking and can be considered an un-saying (dédire) thereof. In this, it is appropriate to recall that in more than one instance, Levinas made reference to Nietzsche's discursive practice in order to present his own view of unsaying. Through unsaying - the repeated effort to reduce or re-conduct the Said to the Saying - the philosopher finds a certain lightness with regard to the apparent seriousness of philosophising. In fact, all human expression loses some of its seriousness under the repeated reconduction to what is supremely urgent and serious: the Saying, the imperative to take responsibility for the other. In this it corresponds with the Nietzschean "reduction":

"'reducing' being not by putting in brackets, but by the violence of an unheard-of verb [verbe], undoing by the non-saying [non-dire] of dance ${ }^{54}$ and laughter., ${ }^{45}$

52 As argued in De l'éthique à la justice 228-233, 287-292.

53 OB $7 /$ AE 19.

54 It should be mentioned at least in passing that this phenomenologising appropriation of Nietzsche by Levinas interferes quite remarkably with his much commented and rightfully criticised statement that what is essential about humanity would be the Greeks and the Bible and that all the rest would be merely exotic dance, i.e., frivolous or insignificant. In this Nietzschean reduction, dancing is assigned the lofty task of suspension of the care for Being, and of leading one back to the Saying! In a Levinasian mindset, the excellence of any cultural expression (including Hellenistic and Talmudic studies) would be measured by the degree to which it conforms to dancing, defined in this way.

$55 \mathrm{HO} 65 / \mathrm{HH} 106$, translation modified. 


\section{And likewise,}

"One should have to go all the way to the nihilism of Nietzsche's poetic writing, reversing irreversible time in vortices - up to the laughter which refuses language [jusqu'au rire qui refuse le langage]. ${ }^{, 56}$

True enough, for Levinas this unsaying is first of all due to the unsayability, unutterability or unspeakability (indicibilité) of the Saying $;^{57}$ in the absence of belief in the meaning imposed by the Saying, I place more emphasis on the philosophical (or other) work of unsaying and its suggestive power. Just as no philosophical argument or presentation of the world can remain untouched by the Nietzschean laugh, so it seems to me, no argument or truth, no gnoseology can remain untouched by the suggestion of the decentring imposed by the possible ethical imperative of the face of the other as it is found in Levinas' texts.

It goes without saying that this suggestion of the primordial ethicity could in turn be made suspect, could be submitted to doubt and its weak "epistemological status" be criticised. But such is the nature of debate about ethics. Probably my proposal on the suggestive power of Levinas' texts, by analogy to that of Nietzsche's texts, will not satisfy many of Levinas' readers - if any since, I concede, something important is lost with respect to what Levinas wanted to offer. However, I think it would be reasonable to accept this explanation as justification for continuing to engage with his work and to hold the place of alterity while my reflection on this issue is still "under construction".

It is in the field of tension created between, on the one hand, the completely admirable and justifiable aspects of Levinas (concentrated in the identification of certain elements of a philosophical project of reflection on the ethical and the political) and, on the other hand, the questionable aspects (the failure to recognise the hermeneutical limits to the presentation of alterity and the failure to formulate a plausible and desirable transition from the ethical to the political), that I aspire to make a contribution. The most suitable general term to unite my reflections "after Levinas" is that of responsibility. This notion will have to be explored with its political dimension in mind and with the global world not only as the largest horizon of its desired relevance, but also the practical situation that will condition its realisation. While a fully developed presentation of such a theory of responsibility will not be given in this book, I shall attempt, in Part 3, to elucidate, still in dialogue with Levinas, the requirements for such a project.

$56 \mathrm{OB} 8 / \mathrm{AE} 22$, translation modified.

57 HO 65/HH 106. 



\section{PART 3}

\section{Political Responsibility for a Globalised World}

There is a famous passage in which Derrida describes Levinas' style of argumentation with a lyrical image: it

"proceeds with the infinite insistence of waves on a beach: return and repetition, always, of the same wave against the same shore, in which, however, as each return recapitulates itself, it also infinitely renews and enriches itself."1

From the position of a less gifted reader that nonetheless makes every effort to engage in a thoroughly critical examination of the validity of Levinas' ethics, as I hope should be evident from the preceding Chapters, I often feel more inclined to compare his work with a swarm of bees from which one might succeed in swatting a few, but not without constantly getting stung by others from behind. Emmanuel Levinas developed a particularly innovative and forcefully argued philosophy of ethics. Of the thought provoking and challenging potential of this philosophy the enormous international and interdisciplinary reception that his work enjoys today, could serve as ample proof. Providing adequate responses to whatever objections one might have to a theory of such standing will always be a daunting task. I shall not be so rash as to propose a "solution" to the criticism formulated against Levinas in the previous Chapter. Instead, in cognisance of the magnitude of such an enterprise, I shall use this Part to prepare the ambitious project of enforcing the positive aspects of Levinas' ethics and to explore ways of weakening what have been indicated as undesirable side effects thereof.

1 Jacques Derrida, Writing and difference. Alan Bass (transl.). London and New York: Routledge, 2001, p. 398n7 / L'écriture et la différence, Paris: Seuil, 1967, p. $124 \mathrm{n} 1$ - Derrida refers here particularly to TI. 
The theme of this preliminary discussion will be the question of an ethico-political notion of responsibility for the contemporary globalised world. It has been prepared by all of the preceding discussions. Chapter 1 was devoted to defending the eminently political nature of Levinas' philosophical enterprise in which the responsibility of the self for the other is the centrepiece. In Chapters 2 and 3 an attempt was made to exploit as far as possible some of the means of Levinas' own work to argue for the global horizon for such political reflection. Finally in Chapters 4, 5 and 6, Levinas' own presentation and justification of his thought on the self and the other, as an attempt at uncovering the ultimate nature and sense of such a global political responsibility has been examined under the title of a "humanism of the other human" and the failure of Levinas' ethico-political thought to reflect on the mediations, context, means and consequences of practical obedience to the plurality of others as part of the very meaning of ethicity has been exposed. All of these conclusions should be considered as the essential background to and necessary point of departure for everything written in the current Part. Max Weber, particularly in his capacity as theoretician of responsibility, has been chosen as the appropriate interlocutor through which to augment the explorative power of this Part. A similar role is assigned to two contemporary philosophers that have appropriated significant aspects of Weber's thought on responsibility, namely Karl-Otto Apel and Paul Ricoeur. What these three authors have in common and what opposes the Weberian heritage of thought on responsibility to Levinas, is their conviction that the practical complications of responsible action in a world of uncertainty belongs to the core meaning of ethics. For this reason, confronting Levinas with Weber and his two heirs will help to advance our understanding of the political implications of Levinas' notion of responsibility and to further our own post-Levinasian reflection on responsibility for the contemporary context.

In the three Chapters that follow, a framework for the development of an ethico-political notion of responsibility for a globalised world will be proposed through a three-stage argument. In the first stage, Chapter 7, I shall resume reflection on Levinas' notion of responsibility as it enters the political, where it was left in Chapter 6. Instead of resolving the difficulties created by the contradiction between the plurality of others, the results from my critical reading of Levinas will simply be assumed and submitted to further examination. By means of a detailed comparison between Max Weber's distinction of two ethical-political orientations the ethic of principle and the ethic of responsibility - Levinas' notion of political responsibility, or responsibility that seeks justice, will be magni- 
fied in order to show in more detail what the profile thereof is. On the basis of this profile, I will then attempt, in the second stage of this Part, Chapter 8 , to identify the minimum objectives or requirements for the development of this profile into a theory of political responsibility for a globalised world. Apel's appropriation of Weber's notion of responsibility will serve here as a suggestive parallel. Finally, in the third stage, Chapter 9, the four requirements identified in Chapter 8 will themselves be explored and expanded. Using Ricoeur's practical philosophy, which will be shown to be true to Weber's reflection on political responsibility in pertinent ways, the potential of working on these requirements, in view of a theory of ethico-political responsibility for a globalised world, will be demonstrated and the contours of these requirements will be better mapped out. 



\section{Chapter 7 \\ Levinas and Max Weber on being called for politics}

It is well known that Max Weber's later work, in particular the essay Politics as a vocation, plays a major role in the historical development of reflection on responsibility and notably of a prospective political notion of responsibility. The choice of Weber as the privileged interlocutor of Levinas on political responsibility is not justified by an idea that he would in one way or another bring the desired correctives to the defects of Levinas' ethics. Rather, it seems that Weber's theory of responsibility could serve as a magnifying glass through which the implications of Levinas' ethical notion of responsibility and its implications for political action could be perceived with far greater clarity. Furthermore, Weber's theory will serve to support our reflection on the socio-historical context in which such a responsibility is to have effect and in this way, the comparison of Weber and Levinas will prepare the way for the subsequent explorations of this Part. It is not my ambition to develop a full comparison of Weber and Levinas, but to clarify the issue of responsibility and its social setting by looking at Levinas through the lens of the twin essays Politics as a vocation (Politik als Beruf) and Science as a vocation (Wissenschaft als Beruf).

\section{AN INHOSPITABLE WORLD: DISENCHANTMENT AND POLYTHEISM IN WEBER AND LEVINAS}

These two texts should of course be read together, since it is not possible to appreciate Weber's exposition on responsibility in the first without the socio-historical background provided in the second. The most important 
aspect of the socio-historical background is a twofold diagnosis of contemporary social reality. On the one hand, the complex history of rationalisation that has left (Western) humanity in a disenchanted world governed by calculative and goal-aiming rationality, the execution of which undermines human experience of meaning and the technical implementation of which reduces human freedom like an iron cage. On the other hand, claims to direction giving values grow to a conflicting multitude - to which he refers as a polytheism. Weber takes it as a

"fundamental fact, that so long as life remains immanent and is interpreted in its own terms, it knows only of an unceasing struggle of these gods with one another. Or speaking directly [unbildlich], the ultimately possible attitudes toward life are irreconcilable, and hence their struggle can never be brought to a final conclusion."1

It would evidently make no sense to attribute the detail of Weber's theory of rationalisation to Levinas. ${ }^{2}$ However, it could be pointed out that Levinas shared a number of convictions with Weber and that these are crucial for his understanding of responsibility. The exposition of secu-

$1 \mathrm{SaV} 152$ / WaB 550. On this twofold diagnosis, see Danilo Martuccelli, Sociologies de la modernité, Paris: Gallimard, 1999, pp. 203-216 and Jürgen Habermas, Theorie des kommunikativen Handelns. Band 1. Handlungsrationalität und gesellschaftiche Rationalisierung. Frankfurt am Main: Suhrkamp [1981] 1995, pp. 332-345.

It is probably not inadmissible to clarify a major concern of these two texts of Weber, using a citation from a much earlier intervention, where he exclaimed: "The reason why I react so extremely sharply on every occasion, with a certain pedantry as far as I am concerned, against the amalgamation of 'ought-to-be' with 'what-is' [die Verquickung des Seinsollens mit dem Seienden] is not that I underestimate the question concerning "ought", but exactly the opposite: because I cannot bear it when problems of world-shattering importance, of greatest ideal range, in a certain sense the highest problems, that can move a human heart, are changed here into an issue of technico-economic 'productivity' and made to a subject of specialist discipline [Fachdisziplin], as national economy is." (Gesammelte Aufsätze zur Soziologie und Sozialpolitik von Max Weber, p. 421, pointed out by Willi Oelmüller in "Gibt es überzeugende Orientierungsysteme für unser politisches Handeln?", Diskurs: Politik. W. Oelmüller, et al. (eds.). Paderborn, et al.: Ferdinand Schöningh, 1980, p. 15).

This question of world-shattering importance that fills Weber with so much passion, his concern for "ought-to-be", for how one is supposed to act, for ethics, is identified here by a refusal of the temptation to answer it by the means of scientific disciplines. The reason for this is because of Weber' well-known conviction that the sciences can and should ultimately be neutral with regard to value (wertfrei). This conviction stands in close connection with the theory of the kind of world in which the scientific disciplines as forms of reason have come to being.

2 In the works of Levinas there is not explicit reference to Weber. 
larisation that Levinas developed ${ }^{3}$ has little in common with Weber's reconstruction of the rationalisation of religions, ${ }^{4}$ but it does correspond with Weber in that it is about a description of the contemporary world as disenchanted and rejects a unilaterally positive appraisal of reason and the development of technology ${ }^{5}$ and with it refuses to believe in a certain Enlightenment faith in progress. ${ }^{6}$ That this process leads to a disenchanted world is common to Levinas' ideas of secularisation and Weber's on rationalisation, whatever the different accents of this notion might be for each of them. Although there is no theory of the modern State and bureaucracy in Levinas, he apparently shares Weber's disillusionment in both of them, as is clear when he states:

"For me, the negative element, the element of violence in the State, in the hierarchy, appears even when the hierarchy functions perfectly, when everyone submits to universal ideas. There are cruelties which are terrible because they proceed from the necessity of the reasonable Order. There are, if you like, the tears that a civil servant cannot see: the tears of the Other". ${ }^{7}$

Likewise, although there is no comparable social theory of science in Levinas, he apparently shares Weber's conviction that in the modern disenchanted world the sciences are not capable of giving decisive direction to our choices of actions since, for Levinas, they remain "gnoseologically" oriented (as does Western philosophy) and place the question of ethics second. ${ }^{8}$

The fact that practically all of Levinas' efforts are devoted to the affirmation of one particular direction-giving meaning should not obscure the fact that he was convinced that he lived in a polytheistic world. This should be evident from his elaborations on the "crisis of monotheism" as presented in Merleau-Pontian terms in Humanism of the other (see Chapter 5, above). Even if it is Levinas' contention that there is a unifying point of reconciliation

3 In "Sécularisation et faim", (Emmanuel Lévinas. Cahier de l'Herne. Catherine Chalier and Miguel Abensour (eds.). Paris: Editions de l'Herne, 1991, pp. 19-28) and in "Transcendance, idolatry and secularization" (GDT, 163-166/DMT 190-194).

4 Cf. Wolfgang Schluchter's excellent synthesis in "Die Paradoxie der Rationalisierung. Zum Verhältnis von 'Ethik' und 'Welt' bei Max Weber', in Rationalismus und Weltbeherrschung. Studien zu Max Weber. Frankfurt am Main: Suhrkamp, 1980, pp. 9-40.

5 Making place for an incomplete dialectic between the gains and losses of technological development DF 231 / DL 323, IH 142, commented on in De l'éthique à la justice 145-147.

6 Cf. Danilo Martuccelli, Sociologies de la modernité, op. cit. p. 204.

7 BPW 23/LC 97.

8 OB 64/AE 104. 
of all meaningful action, the manner in which he develops this idea shows some affinities with Weber's theoretical writings on religion. For Weber the diverse religious traditions of theodicy point to the impossibility of harmonising the religious attitude of salvation religions and the factual causality of this world - there is no necessary connection between good action and good consequences; ${ }^{9}$ for Levinas, if the "old-fashioned Judaism is dying off, or is already dead", 10 if the simple religious adoration of God in Judaism has become impossible in the aftermath of the genocide, it is because there is no argument that could put an omnipotent God in the right for these happenings and in this sense, as Levinas said: God "committed suicide at Auschwitz". there is in his philosophical thinking no pre-conceived expectation of a guarantee that well-intended action will lead to good results. In other words, the recognition of the crisis of monotheism amounts to the acceptance of polytheism as a socio-descriptive category. It is in answer to this "polytheism" that Levinas proposes the unique sense (sense unique) that is ethicity.

There is a second, double, way in which Levinas' ethics itself is bound to the idea of polytheism, and this should crystallise from the critical reading of his ethics that I have presented in Chapter 6. On the one hand, the third introduces a contradiction with respect to the ethical appeal of the singular other which means that, on "entering" the political, responsibility equals deciding who should come first - which one of the competing and, in principle, equally valid "gods" should be given priority. The word "god" is appropriate here, since it is the affirmation of the ethical alterity of the other that constitutes Levinas' response to the "crisis of monotheism". The plurality of mutually contradictory, infinite appeals to the responsibility of the subject, could thus be said to represent an ethical polytheism. On the other hand, every ethical subject, once he/she has established what the appropriate way is to cope with the plurality of contradicting claims of the others, has to put through this idea of what justice entails in a social reality of competing claims to what justice entails. And since nobody can claim to directly present the unified appeal of the other, and everybody presents always only ideas of what the compromise between different claims to responsibility entails, it is not realistic to count on a consensus based on the "appeal of the other". Furthermore, it should be noted that one is at a loss for finding any guidance in Levinas' philosophy

$9 \mathrm{PaV}$ 122f / PaB 443f; cf. ENT 188 / EN 194.

10 DF 271 / DL 377.

11 Visage et violence première", interview in La différence comme non-indifférence. Ethique et altérité chez Emmanuel Lévinas. Paris: Kimé, 1995, pp. 129-143, citation p. 135. See also the discussion of "atheism" in Levinas' Judaism, in Chapter 4. 
on either of these two forms of plurality. In this way, the plurality of ethical subjects that compete for the realisation of what they hold justice to entail, amounts to an ethico-political polytheism or a polytheism of justice.

It should be highlighted once again that the picture that one forms of Levinas' ethics - in this case especially in relation to the question of polytheism - depends on the distinction between two levels of his thought: that of ethics and that of politics. If I argue for a polytheism in Levinas' politics, I do not deny his (in my mind, failed) attempt to defend a monotheism in his ethics that is partially based on a critique of social processes through the deployment of the metaphor of a plurality of sacred deities (see Chapter 2).

Whatever the differences might be that distinguish these two authors (despite the indicated similarities), both consider responsibility as the appropriate response for people to this inhospitable world.

\section{LEVINAS: A GESINNUNGSETHIKER OR A VERANTWORTUNGSETHIKER?}

It would be imprudent to equate Weber's and Levinas' notions of "responsibility" simply on the basis of their use of the same (translated) word. In fact, if one considers Weber's presentation of the "two fundamentally differing and irreconcilably opposed maxims [zwei voneinander grundverschiedenen, unaustragbar gegensätzlichen Maximen]" under which "all ethically oriented conduct [alles ethisch orientierte Handeln]"12 may be classified - the ethic of (ultimate) principle(s) [Gesinnungsethik], that insists on the right intention or principle as determining the ethical goodness of an action, and the ethic of responsibility [Verantwortungsethik], that determines ethically desired courses of action by weighing the likely consequences and adopting the appropriate means by which to attain the desired outcome ${ }^{13}-$ it would

$12 \mathrm{PaV} 120 / \mathrm{PaB} 441$.

13 It is not easy to find the appropriate terms by which to translate these Weberian notions in English. Of the uncertainty of the precise meaning of the two notions, Hans Lenk, one of the foremost German specialists of the philosophy of responsibility, writes in Konkrete Humanität. Vorlesungen über Verantwortung und Menschlichkeit. (Frankfurt am Main: Suhrkamp, 1998, p. 138): he suggests that Verantwortungsethik be considered in the case of Weber as equivalent to Folgenethik (ethics of consequences) or Konsequenzethik (consequentialism) and gives Prinzipienethik (ethics of principles) as equivalent to Gesinnungsethik. In what follows, I shall simply translate Verantwortungsethik as ethic of responsibility and follow Lenk's suggestion to translate Gesinnungsethik as ethic of (ultimate) principle(s). The use of "ethic of ultimate ends" for Gesinnungsethik in the translation of Politics as a vocation, seems completely misleading if "ends" refer 
seem at first sight, that Levinas' notion of responsibility stands much closer to Weber's notion of an ethics of principle.

\subsection{The prima facie case for Levinas as "ethicist of principle"}

How strong this prima facie case is, could be indicated with reference to Weber's famous Zwischenbrachtung. ${ }^{14}$ Here the sociologist argues that an ethics of principle is the culmination of a certain history of religious evolution and equates it to an ethic of brotherliness. He devotes a good number of pages to motivate and illustrate his point that

"[t]he religion of brotherliness [religiöse Brïderlichkeit] has always clashed with the orders and values of this world [...].",15

Now, although Levinas' ethics should not be misconstrued as a "religion of brotherliness" or "religious brotherliness", it could be argued that his notion of responsibility corresponds point by point with such a "brotherly ethic"16 or ethic of principle, at least as far as it is negatively situated in relation to the widely accepted values of different life spheres.

to the consideration of outcomes of action; another possible translation for Gesinnungsethik, namely "ethic of conviction" is better and has the advantage of expressing the idea of attitude in Gesinnungsethik, but should perhaps rather be avoided since the ethicist of responsibility also acts out of conviction - this time not convictions regarding context-independent principles, but convictions regarding means and consequences. Furthermore, the option of the translation of "ethic of principle" avoids confusion later when Ricoeur's notion of conviction will have to be distinguished from his interpretation of Gesinnungsethik, even if he translates the latter notion with "éthique de conviction".

Since the aim of examining these notions of Weber (in this entire Part) is to come to a better understanding of what the practical implications of political responsibility are, it is not important to distinguish between a Weberian theory of ethic (with the accent of the description of a habitual way of acting) and, say, a Levinasian theory of ethics (with its accent on the imperative and meta-ethical import); evaluating an ethic of responsibility (as Weber undertakes) simply overlaps with reflection on a justifiable ethics of responsibility (as Levinas attempts), at least in as far as the implications of their insertion in practical contexts is concerned. For this reason I make use of (a theory of the evaluation of) ethic and (a theory of the justification of) ethics as interchangeable notions.

14 Although this text is slightly earlier than $\mathrm{PaB}$ (1919) and WaB (1917) there are numerous points of correspondence in the text that show the closeness with Politics as a vocation.

15 RRW 330/ZB 544.

16 Cf. "It is my responsibility before a face looking at me as absolutely foreign [...] that constitutes the original fact of fraternity." (T\&I 214 / TI 235). 
The five different life spheres with which such a brotherly ethic is explained by Weber to be in conflict are: economics, politics, aesthetics, erotics and the intellectual sphere. Now consider a number of specifications concerning ethics in the work of Levinas. In each case, something is said of the tension between ethicity and the normal logic of the particular life sphere.

(1) Economy:

"The commercial value of services and human labour gives credence to the strong idea of being as totalised and one and (when integrated to the economy and the arithmetic of money) as the order or system that hides or conceals the disorder of the merciless struggles of profit-sharing [intéressement]",

to which Levinas opposes the "axiology of dis-interestedness [désinter-essement] [...] which is the kindness of giving". ${ }^{17}$

(2) Politics:

Whereas the "necessities peculiar to the State" constitute

"a determinism as rigorous as that of nature indifferent to man, even though justice [...] may have, at the start, served as an end or pretext for the political necessities",

Levinas defends the prophetic constitution of ethics as an instance outside of the State that is characterised by

"a vigilance totally different from political intelligence, a lucidity not limited to yielding before the formalism of universality, but upholding justice itself in its limitations". ${ }^{18}$

Likewise, if we consider that Weber discusses the "depersonalisation" [Sachlichkeit] of the bureaucratic State also under this heading, ${ }^{19}$ Levinas' conviction should be again evoked that

"[t]here are cruelties which are terrible because they proceed from the necessity of the reasonable Order. There are, if you like, the tears that a civil servant cannot see: the tears of the Other." 20

(3) Aesthetics:

"before Culture and Aesthetics, meaning is situated in the Ethical, presupposed by all Culture and all meaning." 21

17 "Socialité et argent", in Emmanuel Lévinas. Cahier de l'Herne. Catherine Chalier and Miguel Abensour (eds.). Paris: Editions de l'Herne, 1991, pp. 106-112, citations pp. 109 and 110 respectively.

18 OS 123 / HS 167.

19 RWW334/ZB 546.

20 BPW 23/LC 97. 
It can be conceded that art is a "renewal of the interest for the other", only if it has been recognised first that

"the look of the artist aims at finding novelty, the first contact with. It is not on the level of the relation to the Other that this process is situated, but on the level of the discovery of the world., 22

(4) Erotics:

"The referral to the other is an awakening to nearness, which is responsibility for the neighbour to the point of substitution, which is the enucleation of the transcendental subject. Here we find the notion of a love without eros. ${ }^{23}$

\section{And this notion is clarified elsewhere as}

"love without Eros, charity, love in which the ethical aspect dominates the passionate aspect, love without concupiscence". ${ }^{24}$

(5) Intellectual sphere:

Levinas critiques Western philosophy that

"has never doubted the gnoseological, and consequently ontological, structure of signification"

by calling for the recognition of "a sense somewhere else than in ontology" and by implication, somewhat different from the gnoseological. ${ }^{25}$ Likewise,

"this way of grappling with the perfection of the infinite is not a theoretical consideration in turn in which liberty would spontaneously re-assume its rights. It is a shame that liberty has of itself, when it discovers its very exercise to be murder and usurpation." 26

These references, isolated from their context, certainly do not represent Levinas' often complex (and developing) vision of these aspects of social reality, and I don't ignore the fact that one could therefore evoke a number of passages that would contradict some of those cited here ${ }^{27}-$ in fact, my presentation of Levinas' philosophy on two plains, that of ethics and that

$21 \mathrm{HO} 36 / \mathrm{HH} 58$, translation modified.

22 "Deux dialogues avec Emmanuel Lévinas", in Augusto Ponzio. Sujet et altérité. Sur Emmanuel Lévinas. Paris: L'Harmattan, 1996, pp. 143-151, citations p. 149.

23 GDT 233 / DMT 257.

24 ENT $103 /$ EN 114.

25 OB 64 / AE 104.

26 DEHH 176.

27 See for instance my discussion of Levinas' thought on the economy in De l'éthique à la justice 166-171. 
of politics, could contribute to an explanation of why that is the case. But that is not the issue here. The citations do suffice to make the prima facie case for associating him rather with an ethic of brotherly love and thus with Weber's ethic of principle and to justify my call for vigilance in comparing Levinas' "résponsabilité" with Weber's "Verantwortungsethik".

Without identifying Levinas' ethics with Weber's ethic of principle, Dorando Michelini ${ }^{28}$ has argued that

"the interest of the Levinasian reflection on responsibility lies in a perspective that is diametrically opposed to that of Weber - given that Levinas is not that much interested in drawing up an ethical system to consider ethical actions and decisions, but rather to reflect on the radical origin of all responsibility as answer to the appeal of the other.", 29

Since this articulation, at least of the formal characteristics of Levinas' intention, is perfectly correct, it would be interesting to show how Michelini construes the opposition between the Weberian and the Levinasian perspectives on responsibility.

Whereas direct and indirect consequences of actions are central for Weber, according to Michelini's observation they play only a secondary role in Levinas (meaning probably both secondary in volume discussed and secondary to ethical alterity). In fact,

"unlike Weber and Jonas, Levinas understands ethics and responsibility not from the consequences of human action but from the relation to the other." 30

It is, according to Michelini, probably due to the French philosopher's insistence on the radical alterity of the other and this lack of regard for the consequences of action that it is not simple to formulate a social ethic from a Levinasian perspective. Four weaknesses of Levinas' notion of responsibility could be derived from this general remark. In all of them the absence of a truly Weberian attention to the consequences of action leads to defects in the application of Levinas' ethics: ${ }^{31}$

28 Dorando Michelini, "Ética de la responsabilidad. Modelos de fondamentación y aplicatión" in Concordia 41, 2002, pp. 83-103 (henceforth = EdIR). Despite the fact that the Weber-Levinas comparison forms only a limited part of Michelini's larger project, namely to trace the similarities and divergences between the approaches of Weber, Jonas, Levinas and Apel, I was not able to find any more significant - and no sustained - comparison of Weber and Levinas on the question of responsibility.

29 EdIR 84-85.

30 EdIR 92.

31 EdIR 94. 
(1) The root of Levinasian responsibility is not in the "I" but in the other, which entails a serious undermining of autonomy.

(2) It is an individual responsibility of the I for the other, which provides no significant contribution to social ethics and is thus not capable of contributing towards

"a realistic and minimally objective consideration of the problems of power and the systems of autoaffirmation, like the economy, law or politics". ${ }^{32}$

(3) The notion of a face-to-face responsibility is a-historical, since it doesn't take into account the complex and multiple mediations between the I and the other in everyday life.

(4) Following Habermas, Michelini claims that in situations where multiple ethical options are constituted by complex ideological or cultural differences, rational decision-making depends on inclusive, critical discourse that aims at consensus seeking and that is an indispensable requisite for a justifiable inter-subjective practice. Yet, these are not developed or taken into account by Levinas.

Therefore, despite his effort to find a more radical justification of responsibility, Levinas' version of responsibility is, in Michelini's judgement, not able to help in the solution of contemporary moral problems; ${ }^{33}$ the anarchical and non-reciprocal construal of responsibility

"diametrically contradicts a conception of responsibility conceived as awareness and capacity to moral judgement that is socially and historically formed." 34

Although Michelini doesn't attribute these incapacitating defects of Levinas' philosophy to its religious roots, ${ }^{35}$ his whole presentation of responsibility in Levinas is subtended by the conviction that its religious foundation ${ }^{36}$ is contrasted to Weber's monological, narrowly strategically- and instrumentallybased conception of responsibility. ${ }^{37}$ If one considers that the relation to the

\section{EdIR 94.}

33 This is a criticism often directed at Levinas. Although my own critique of his ethics goes in the same direction, it needs to be stressed that if Levinas was able to provide as little as only a justification for the claim to the tenability of the ethical, he would have rendered an enormous service, not only to the philosophical contemplation of ethics, but also to the quite practical question of how to start speaking about the ethical in a domain of the everyday world, namely philosophy, where the conviction of the death of God reigns. The latter could be considered the most important and difficult of all meta-ethical problems.

34 EdIR 101.

35 EdlR 91.

36 Thus Michelini, EdIR 101.

37 EdIR 101. 
other (the brother, as Levinas says) is central to Levinas' ethics, and connects with it Michelini's interpretation of the religiosity of Levinas' work, then it seems permissible to conclude that Michelini would tend to link Levinas' ethics rather to Weber's ethic of principle or ethic of brotherliness (although he doesn't do so explicitly). Be that as it may, what is important is that Michelini argues for a marked distinction or even conflict between the notion of responsibility in Levinas and in Weber.

Having now shown that a prima facie case could be made for pairing Levinas' notion of responsibility with Weber's notion of an ethic of principle and having presented Michelini's case for a patent distinction between the notion of responsibility in Levinas and Weber, I would like to make the opposite case. I shall not at all attempt to show that Levinas was a Weberian; rather, in accord with the aims set out for this comparison, I shall use Weber's notions of responsibility as a lens through which to magnify certain aspects of Levinas' thought on responsibility.

I have argued above that Levinas shares with Weber significant aspects of the diagnosis of contemporary society (or Gegenwartsdiagnose) of disenchantment and polytheism, with their concomitant experiences of loss of freedom and loss of meaning. Again, in figuring out how to situate Levinas with respect to Weber's notion of responsibility, it will be of utmost importance to distinguish whether one considers the ethical plain of Levinas' thought or the plain of the political implications thereof. I shall argue that if, for the purposes of this examination, we were to accept Weber's categorisation, Levinas would seem to a considerable extent to be an ethicist of ultimate principles (Gesinnungsethiker) on the plane of his ethics. Yet, as argued since Chapter 1, a purely ethical subject never exists - a consequent Levinasian reading would have to concede that the subject is always political - and in his reflection on the political plain and the implications thereof pointed out in Chapter 6, Levinas then seems more an ethicist of responsibility (Verantwortungsethiker) in the Weberian sense.

\subsection{Levinas as political "ethicist of responsibility"}

However, before one could undertake such a comparison between Levinas and Weber, it would be necessary to gain clarity on the exact nature of the categorisation of the ethic of principle and the ethic of responsibility, since this has implications for the manner in which this comparison can be plausibly undertaken. A number of features of Weber's presentation of the two ethical categories in Politics as a vocation would suggest that they are 
categories specifically for political action. The distinction fits into the overall theme of the essay on the nature of the vocation of politics. ${ }^{38}$ The first place in the essay where the question of responsibility is raised consists of a distinction between the responsibility of a bureaucrat or civil servant and the responsibility of a political leader. ${ }^{39}$ Then, after lengthy sociological analyses of the modern State and the different manners in which one could live off or for politics in the State, ${ }^{40}$ Weber reintroduces the question of responsibility by a question that he typifies as "ethical":

"What kind of a person must one be to dare to put his hand on/in the wheel of history?"41

Responsibility, passion and a sense of proportion are the characteristics of such a person - clearly those of a political leader and not of every human being. Besides, from the entire essay it is clear that "responsibility" is the attitude that Weber sees as necessary for someone who operates with the means particular to politics, namely "power backed up by violence". ${ }^{42}$ Even then, when the issue of the inevitable means of politics provokes the question concerning the relationship between ethics and politics ${ }^{43}$ and an ethic that is conscious of the means to be used (responsibility) is opposed to an ethic that insists on the right intention of action (ethic of principle), the theme is clearly still that of a political ethic. Yet, when the distinction between the two kinds of ethics is introduced explicitly for the first time in the essay, Weber unmistakably states

"the fact that all ethically oriented conduct may be guided by one of two fundamentally differing and irreconcilably opposed maxims: conduct can be oriented to an 'ethic of ultimate principles' or to an 'ethic of responsibility'.,44

And at the climax of the essay where Weber sings the praises of a truly mature person's responsibility, assumed to the point of saying figuratively "I can do no other; here I stand", he implores his readers:

38 See also the valuable commentaries of Bradley E. Starr, "The structure of Max Weber's ethic of responsibility", in The journal of religious ethics, 27/3 1999, pp. 407-434 and Wolfgang Schluchter, Wertfreiheit und Verantwortungsethik. Zum Verhältnis von Wissenschaft und Politik bei Max Weber. Tübingen: J.C.B. Mohr (Paul Siebeck), 1971.

$39 \mathrm{PaV} 95 / \mathrm{PaB} 414 \mathrm{f}$.

$40 \mathrm{PaV} 77-115 / \mathrm{PaB} 396-435$.

$41 \mathrm{PaV} 115 / \mathrm{PaB} 435$, translation modified.

$42 \mathrm{PaV} 119 / \mathrm{PaB} 439$.

$43 \mathrm{PaV} 118 / \mathrm{PaB} 439$.

$44 \mathrm{PaV} 120 / \mathrm{PaB} 441$, translation modified, my italics. 
"every one of us who is not spiritually dead must realise the possibility of finding himself at some time in that position., ${ }^{\circ 5}$

Conceded, this is not always everybody's situation, but it could happen to everybody, whereas evidently it could not realistically be expected that the vocation of politics (in Weber's sense) will fall on everybody.

These two uses of Weber's categorisation can't be easily or obviously reconciled. But since the current objective is not to solve a difficulty in Weber's text, but rather to use his text as a lens through which to gaze at Levinas' text, I suggest the following coordination of the two uses. What Weber says about the ethic of responsibility and about the ethic of ultimate principles is intended as insight into the nature of action for the modern world of advanced rationalisation and disenchantment, as he understands it. Even if Weber focuses on the question of politics in the essay under discussion, it should follow that the socio-historical conditions under which any political ethic is to gain its plausibility, are the same as the conditions under which any ethic is to demonstrate its appropriateness. Now, not all fields of ethics have to do with the adoption of the means of the State, the means particular to politics, but in all ethics the question of the preference for principle-guidedness or consequenceguidedness is important in that it confronts pre-established principles with the means appropriate to that field of action. Moreover, if the question about Levinas' stance in relation to these two ethical orientations is posed, it should be borne in mind that all action is for Levinas political (as previously argued). This doesn't mean that it has directly to do with the violent means at the disposal of a State - Levinas' definition of politics is formed by the ethical obligation to the others and the consequent quest for justice - but that it might ultimately lead to an impact on those means.

What, then, is the most appropriate response to our current world and in the face of the other? What is the most fitting ethical orientation in this inhospitable world? Levinas adamantly affirms that the answer is to be sought in a particular understanding of the ethical: the other impacts on the subject as an appeal to limitless responsibility. And it is this originary orientation of all action that exerts its authority without apparent regard for the situation or the mediations of actions, that prompts someone like Michelini to characterise Levinas' thought as a-social and a-historical. ${ }^{46}$ It is thus not only the remarks in which Levinas negatively demarcates his ethics with regard to the inherent rationality proper to the independent life spheres that suggest a

$45 \mathrm{PaV} 127 / \mathrm{PaB} 448 \mathrm{f}$.

46 This aspect of Levinas' thought on ethics has been exposed in Chapter 6 with reference to his use of the famous passage from The brothers Karamazov. 
proximity between his ethical notion of responsibility and Weber's ethic of principle (as indicated above), but the fact that all actions apparently draw their ultimate and decisive meaning from unconditional obedience to the imperative of the other also points in the same direction. However, this holds only so long as the comparison is limited to the plain of Levinas' ethics that considers only the relation between the ethical subject and the other in the singular. But following the repeatedly cited theme of the present book:

"there are always at least three people. [...] As soon as there are three people, the ethical relation to the other becomes political and enters into the totalizing discourse of ontology.,"47

A subject that is "always" obsessed by more than one other will always be political and as such is submerged in the discourse of ontology, in other words, will always have to weigh, calculate, interpret and reflect on the efficiency of actions involving others. From this perspective, from the plain of Levinas' politics, the relationship between his thoughts and an ethic of principle is markedly different. Weber will help us to articulate this difference between Levinas' political thought and the ethic of principle, before we turn in a similar way to an articulation of the resemblance of Levinas' notion of responsibility and Weber's, on the political level.

According to Weber's classification, the calculation of the consequences of action doesn't play an important role in the ethic of principle. ${ }^{48}$ It doesn't have to, since the ethic of principle is fed by a rejection of the irrationality of the world: it assumes that good actions lead to good consequences (even if appearances contradict this assumption) and that there could be no conflict between different duties. ${ }^{49}$ Besides, reflection on the consequences might compromise the fidelity with which one adheres to the intrinsic worth of certain general values or principles of actions. Furthermore, an ethic of principle ignores the fact that sometimes forceful or even violent means have to be adopted to see through what is considered a desirable decision and course of action. Only in extreme cases does principled ethical deliberation embrace the use of evil's means against itself and that is when, from a chiliasticeschatological perspective, violent means are adopted to commit the

"last violent deed, which would then lead to a state of affairs in which all violence is annihilated". ${ }^{0}$

47 "Ethics of the infinite", op. cit. pp. 57-58 / "De la phénoménologie à l'éthique", op. cit. p. 129 (translation modified).

$48 \mathrm{PaV} 120-122$ / PaB 441-443.

49 Cf. Starr, "The structure of Max Weber's ethic of responsibility" op. cit. p. 415.

$50 \mathrm{PaV} 122 / \mathrm{PaB} 443$. 
Levinas' political thought (following the interpretation that I have given thereof in Chapters 1 and 6) stands in stark contrast to this context-blind attitude. Although it is true that, as I have pointed out, the subject of politics is obsessed by the appeal of the other (albeit in the plural) to which, in each case, absolute, unconditional obedience is due, it would not be correct to equate this to an attitude of absolute fidelity to a set of values. The appeal of the other is a void imperative to responsibility and, as pointed out (Chapter $6, \S 2.1$.), the imperative emanating from one other contradicts that of other others, because of its equally and contemporaneously valid, unconditional and all-embracing nature. Levinas is thus very conscious of the fact of contradiction between one's duties. It is exactly for this reason, or from this condition, that the subject as political subject is constituted. And since the political subject is constituted by contradicting equally valid claims to his/her responsibility, means should be devised to compare the incomparable; political subjectivity is born from the fact that there is no set of actions by which to serve all of the interests of all of the others at the same time; something, or someone, inevitably has to be sacrificed - preferably the ethical agent himself/herself in the first place, but calculation will have to determine this. It is here that the socio-historical context of action becomes important. It seems to me that this political condition could lead to "comparing the incomparable" equally possibly by means of hierarchies of values and by calculation of consequences.

However, in the places where Levinas gives an idea of what politics entails, he uses words like comparing, gathering, thinking, equalising, ${ }^{51}$ judging, deciding, ${ }^{52}$ weighing, calculating, and measuring - notions that seem to indicate deliberation on consequences rather than the establishment of values. This is clarified further when Levinas explains that this entails the quest for justice, by means of laws, courts, States, ${ }^{53}$ propositions and communication, ${ }^{54}$ work and technology, ${ }^{55}$ science and commerce, ${ }^{56}$ and philosophy that is charged with introducing a measure in the comparison. ${ }^{57}$ Given these spheres of the realisation of deliberation concerning the just ways of arbitrating the contradicting claims of responsibility, it seems unlikely that a true Levinasian would leave deliberations concerning the consequences of actions out of consideration. In fact, it seems probable that the notion of re-

51 OB 16/ AE 33, GCM 82 / DVI 132.

52 AS 61.

53 ENT 165 / EN 171, GDT 183 / DMT 214.

54 OS 142 / HS 192, OB 134/ AE 211.

55 OB $159 / \mathrm{AE} 248$.

56 OB $161 / \mathrm{AE} 251$.

57 OB 161 / AE 251. On these routes from the ethical appeal to responsibility to domains of the realisation of justice in the sphere of ontology, see De l'éthique à la justice 271-274. 
sponsibility, on the plain of politics, would mean that one would have to stand accountable for the means chosen by which to respond to the appeal of the others. This would be affirmed by the fact that all actions stand forever open to revision and improvement - one would have to evaluate the outcomes of action for their fidelity to respond to the others. That Levinas would count on a happy outcome for whatever is undertaken in the name of the others is excluded. For this, he is too disillusioned with the world. ${ }^{58}$

Now, if it is true that the quest for appropriate ways to respond to the contradicting appeals of the others leads to the adoption of the means of the different life spheres, and if we take into consideration Levinas' suspicion of the inevitable violent inclination of means on the plain of ontology, then it seems unavoidable to conclude that he would have agreed that the "good" could be realised by "evil" means. This becomes evident when we consider his refusal of "non-resistance to evil". 59 And it is here that an unexpected similarity with the ethic of principle crops up on the level of politics. My discussion in Chapter 6 of possible drifts of political radicalism in the frame of a Levinasian ethics, should suffice to support the claim that the radical eschatologically minded seizure of violent means in order to make an end to violence for ever, could not be excluded as a possible outcome of the Levinasian styled calculations of how best to serve the contradicting demands of the others. At least, if it is correct that Weber's presentation of the ethic of principle could be divided into three categories ${ }^{60}$ - religious-acosmic, pacifistic-political and radicalrevolutionary - then the Levinasian seeker of justice will never be religiousacosmic, but might perhaps under certain circumstances share traits with the pacifistic-political (however, Levinas' explicit rejection of non resistance to injustice and violence would tend to exclude this) and it could not be excluded that the radical-revolutionary stance be adopted. ${ }^{61}$ It seems then that in Levinas' political thought, he is quite far from an ethic of ultimate principles, and comes closer to the attitude of an ethic of principles, only to the degree that the ethic of principle itself cedes to the temptation of interfering in the conse-

58 However, one might detect a principled ethical trait in Levinas' fallacious conclusion that the different infinite responsibilities limit each other - this boils down to a form of thinking that good actions will have good consequences (see Chapter 6, $\S 2.2$.). But for Levinas, the limitation of responsibility is not necessarily something good. Furthermore, when Levinas expresses his belief that the individualist and somewhat anarchic ethics of Jerusalem will hold the Athenian doctrine of hierarchy in balance (BPW 24 / LC 99, as was explained and disputed in Chapter 6, $\S 2.3$.), he falls in the ethico-cosmic realist trap.

59 ENT $105 /$ EN 115.

60 According to the exposition in Hans Henrik Bruun's Science, Values, and Politics in Max Weber's Methodology - referred to by Bradley Starr in "The structure of Max Weber's ethic of responsibility" op. cit. p. 416.

61 Cf. discussion of "for instance", in Chapter 6, § 2.2.). 
quences of its action, that is, to have considerations concerning means override (temporarily or by ad hoc justifications and modifications) the ultimate principles. Hence the need to have a look, with Levinas, at the ethics of means and consequences - the ethics of responsibility.

At first glance one could point out a clash between the spirit of Levinas' philosophy and the first three-fold qualifications of responsibility in Weber's essay. $^{62}$ (1) For Levinas the subject of politics is always obsessed by the imperatives of the others; Weber's politician's passion has the meaning of objectiveness (Sachlichkeit). (2) Levinas' is inspired by the other; Weber's is devoted to a cause. (3) Levinas' is forever infinitely responsible; for Weber's the sense of proportion is a decisive quality. However, it can be demonstrated that a categorical opposition between a Levinasian responsibility of "peace and proximity" and a Weberian responsibility of "recourse to violent means and objective distance" would simply be a misrepresentation of the implications of their thought.

To begin with, on the political plain the Levinasian political subject cannot but calculate the consequences of his or her action and therefore also the means necessary to act in particular spheres of life: justice, States, communication, work, technology, science, commerce and philosophy. This has already been argued above. For this reason the drive to gain power, typical for the Weberian politician, may not at all be excluded from the effort of the practical realisation of a Levinasian politics. The reconstruction of Levinas' politics that I have presented (Chapters 1 and 6) seems to be in perfect correspondence with Weber's affirmation that

"[n]o ethics in the world can dodge the fact that in numerous instances the attainment of 'good' ends is bound to the fact that one must be willing to pay the price of using morally dubious means or at least dangerous ones - and facing the possibility or even the probability of evil ramifications. From no ethics in the world can it be concluded when and to what extent the ethically good purpose 'justifies' [heiligt] the ethically dangerous means and ramifications."

It therefore certainly holds for the political implications of Levinas' politics that

"he who lets himself in for politics, that is for power and force as means, contracts with diabolical powers and for his action it is not true that good can follow only from good and evil only from evil, but that often the opposite is true.",64

$62 \mathrm{PaV} 115-116 / \mathrm{PaB} 435-436$.

$63 \mathrm{PaV} 121 / \mathrm{PaB} 442$.

$64 \mathrm{PaV} 123$ / $\mathrm{PaB}$ 444. Cf. my argument concerning a Levinasian justification to kill under certain circumstances, in Chapter $6, \S 2.1$. The characterisation of powers as "diabolical" in the citation from Weber stems from the fact that he attributes this insight (amongst others) to the early Christians; in a secularised form Weber ascribes to this view (cf. PaV 125 / PaB 447). 
This is true also of a Levinasian that, for the sake of the effective realisation of justice, needs associates - the collaborators or followers will have to be incorporated into the desired project, whatever their motivations for collaboration might be - be it as manifestation of what they consider the appropriate response to the appeals of the other, or some or other material, social or psychological gain. ${ }^{65}$ In addition, it would hold to a greater or lesser degree also for any Levinasian political project that

"one of the conditions for success is the depersonalisation and routinisation, in short the psychic proletarianisation, in the interest of discipline". ${ }^{66}$

This would certainly not exclude that a Levinasian project team would always consist of people that contribute to each other's mutual sensitisation to the ethical. ${ }^{67}$ However, it is unrealistic to think that the narrow common motivation - responding to the appeal of the others - would spontaneously lead to a broad consensus on political action. And if there is no guarantee of consensus, then somebody will have to put through his or her idea of what best justice entails at the price of some collaborator's ideas on the same issue and with their collaboration none the less (which does not exclude that the others will simply abandon the project). Yet, reflection on co-responsibility is very far from Levinas' domain of interest.

These are some of the paradoxes to which Levinas' notion of responsibility inevitably leads in the domain of the political; however, it seems unlikely that Levinas would have had the courage to acknowledge with Weber (as I think he should have) that

"[w]hoever wants to engage in politics at all [...] must know that he is responsible for what may become of himself under the impact of these paradoxes" ${ }^{, 68}$

that may endanger the "salvation of the soul" 69 in that sense. Furthermore, although the Levinasian political subject, then, takes the meaning of human action seriously, I am not convinced that Levinas shows sufficiently intimate

"knowledge of tragedy with which all action, but especially political action, is truly interwoven". ${ }^{70}$

But even then, Levinas never uses ethics as a means of justifying action or events, "of being in the right", 71 and always as a manner of pursuing a

$65 \mathrm{PaV} 125 / \mathrm{PaB} 446$.

$66 \mathrm{PaV} 125 / \mathrm{PaB} 447$.

67 Cf. Levinas on "awakening" (éveil) and "sobering-up" (dégrisement) - De l'éthique à la justice Chapter $8, \S 2.1$ "Le dédire et la poursuite de l'authenticité" and $\S 2.2$ "La communauté des philosophes et les livres".

$68 \mathrm{PaV} 125 / \mathrm{PaB} 447$.

$69 \mathrm{PaV} 126 / \mathrm{PaB} 447$.

$70 \mathrm{PaV} 117$ / PaB 437; cf. PaV 121 / PaB 442. 
cause $^{72}$ in full cognisance of the means associated with a domain of action $^{73}$ and with the non rational nature of the world ${ }^{74}-$ all of which are typical of the Weberian ethic of responsibility.

If it is correct then to attribute to the political Levinas at least the implicit recognition that the use of forceful means and reflection on the consequences thereof are indispensable for the quest for justice, it is patent that we do not have to do here with a politics of turning the other cheek. Self-sacrifice, that is, considering oneself as the ultimate means to a specific end, can however never be excluded as political strategy. Turning the other cheek is an attitude of unconditional surrender to the other - but in Levinas' politics the subject's giving to the other is not unconditional, it is conditioned by the calculation of which of the others comes first and of the most effective use the subject can make of himself or herself in that justice. If that consists of self-sacrifice, then the infinite responsibility to the others calls for it, but this would not always be the case. Equally possible is that the political subject accords to himself or herself an important role, for the sake of an efficient response to the others. As pointed out previously, Levinas does not support non-resistance to evil and would therefore certainly agree with Weber's politician that

"thou shalt resist evil [and, if need be - EW] by force, or else you are responsible for the evil winning out." 75

Hence I find it very unlikely that a Levinasian on the political plain would practise truthfulness at all costs, as a principled ethicist would ${ }^{76}$ at least if he or she does, it is not for the truthfulness as such, but for the others. Rather, in the name of the other one might have to lie, obscure, or misrepresent information, exactly because the question of consequences of action is in harmony with the responsible quest for justice.

Responsibility on the political plain probably entails for Levinas, as for Weber, that the results of actions are imputed by the subject to his or her own agency, ${ }^{77}$ whether they were intended or not, adequate for or contradicting of the initial intention. ${ }^{78}$ This could be done only when

$71 \mathrm{PaV} 118 / \mathrm{PaB} 439$.

$72 \mathrm{PaV} 117 / \mathrm{PaB} 438$.

73 Although I have argued in Chapter 6 that Levinas didn't always realise what this implies.

$74 \mathrm{PaV} 123 / \mathrm{PaB} 444$.

$75 \mathrm{PaV} 119-120 / \mathrm{PaB} 440$.

$76 \mathrm{PaV} 120 / \mathrm{PaB} 441$.

$77 \mathrm{PaV} 121 / \mathrm{PaB} 442$.

$78 \mathrm{PaV} 117 / \mathrm{PaB} 437$. 
such an agent is convinced of the desirability of the cause that he or she pursues. Although it is certainly correct to state that Levinas' politics is driven by the plurality of ethical appeals of the others, this does, through the mediating process of calculating what justice entails, mean pursuing a cause, namely the quest for the realisation of that justice (that is of course always in principle open to revision under the appeal of the others). Even here is found a correspondence with Weber's responsibility, since when Weber asserts:

"Exactly what the cause, in the service of which the politician strives for power and uses power, looks like is a matter of faith [Glaubenssache]",

he means that the idea of the end that is to be pursued cannot be given by scientific means, since no form of science can provide that kind of guidance. ${ }^{80}$ And likewise, what Weber calls faith, Levinas develops in the greatest detail in his rendering of one's non-ontological affectedness by the alterity of the other, of which ultimately no phenomenology can give account (i.e., just like faith, the affectedness by the other is a source of motivation that does not draw its resources from knowledge or science). But even if the Levinasian political subject is obsessed by the alterity of the other, he or she is not intoxicated by power as vain politicians are. ${ }^{81}$ This Levinasian subject is rather bound to the cause, not in the sense of being neutral, but in "distance towards one's self", i.e., against vanity ${ }^{82}$ and even - as indicated - to the point of self-sacrifice, if needed. His cause is the others and justice for them. And nobody can replace the bearer of this responsibility in the task of obeying it, just like the Weberian politician cannot reject or transfer his or her responsibility. ${ }^{83}$

Considering the arguments above, it should be clear that the Levinasian political subject shares a number of important characteristics with Weber's responsible politician. On the plain of the political, of the quest for justice, Levinas' philosophy implies something quite similar to Weber's ethic of responsibility.

However, even while affirming this conclusion, the differences should not be obliterated. For Weber, ethics is a serious matter in an era of disenchantment, since it is not possible to give any justification for ethics - for choosing one form of ethics rather than another, and for remaining true to a chosen ethic rather than not. Levinas agrees with this

$79 \mathrm{PaV} 117 / \mathrm{PaB} 437$.

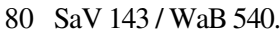

$81 \mathrm{PaV} 116 / \mathrm{PaB} 436 \mathrm{f}$.

$82 \mathrm{PaV} 116 / \mathrm{PaB} 436$.

$83 \mathrm{PaV} 95 / \mathrm{PaB} 415$. 
social critique of ethics, but only provided that one suspends consideration of the face of the other, which for him settles the question of the realness or validity of the ethical. The other of whom the subject is always already a hostage, in the ethical sense that Levinas develops, is not exactly the justification of any particular ethic, but is rather that with reference to which something like justification has meaning at all. At the least, the Levinasian subject is elected to act in response to the others. That is why Levinas could go along with Weber in describing the world as irrational, but ultimately claims, and spends the largest part of his philosophical energy to render credible that "we are not duped by morality" ${ }^{84}$ Since there is no ultimate justification of action for Weber, his subject of responsibility is to be self-responsible (eigenverantwortlich). As a subject of ethics, the Levinasian subject is exactly the opposite of self-responsible: being a subject means exactly being constituted originarily as responsive-responsible to the others that invest the subject's action with the decisive ethical meaning. However, it should be noted that matters are very ambiguous for the Levinasian political subject: this subject always acts by responding to the contradicting appeals of the others, and since nobody can replace that subject in the task of determining what justice entails in this or that context and since nobody can replace that subject in the realisation of that justice, one could get the impression that he or she is de facto responsible to himself or herself for justice. However much this might correspond in form to a political selfresponsibility, for a Levinasian political agent no action is possible that cannot be argued to be done out of responsibility for the other. The fact that the other's opinion of what justice might entail in this or that context is only one amongst many factors to take into account in the decision concerning the demands of justice, doesn't take away from the fact that the subject, in making this decision about justice, remains responsible for the others. In fact, the subject has to act out of responsibility for the other, even if the course of action adopted in the name of justice is executed despite that other's opinion concerning the demands of justice.

The importance of this distinction between Levinas and Weber is accentuated by the fact that there is in Levinas' philosophy no limitation of responsibility for social roles. In contrast, Weber gives at least the distinction between the responsibility of a civil servant and that of the political leader. ${ }^{85}$ But in Levinas' idea of responsibility there can be no limitation

84 T\&I $21 /$ TI 5.

85 If Weber's indication that his discussion in Politics as a vocation is about ethics in politics is taken seriously, one could add that responsibility is attributed to the role 
by role, since any such limitation would amount to an illegitimate restriction of the infinite ethical obligation. Or more accurately, whatever limitation one might assume for oneself or demand of others in the name of justice, can be accepted only as long as these roles are considered the best means to serve the end of justice. Besides, these roles would remain forever open to review. That is why, for Levinas, the political responsibility of the bureaucrat is exactly as demanding as that of the political leader (and of whatever other citizen). Social roles are no limit to responsibility, they are only elements in the calculation and execution of justice.

\subsection{Responsibility elevated to principle or principle elevated to responsibility?}

The distinction between Weber's and Levinas' ethics of responsibility becomes even clearer when a final idea of Weber's concerning responsibility is considered: this entails the combination of the ethic of responsibility and the ethic of principle as it is made by "the mature person" [ein reifer Mensch] ${ }^{86}$ Such a person becomes so conscious of the consequences of a course of action, that in the execution of that responsibility he/she

"reaches a point where he [or she] says: 'I can do no other, here I stand.' [ich kann nicht anders, hier stehe ich]" ${ }^{87}$

This is explicitly a position in which any person - not just political leaders - can find himself or herself. ${ }^{88}$ At this point, Weber relativises his rigid distinction between the "two fundamentally differing and irreconcilably opposed maxims", ${ }^{89}$ by claiming that in the face of the overwhelming possible consequences of one's actions

"an ethic of principle and an ethic of responsibility are not absolute contrasts but rather supplements, which only in unison constitute a genuine person - one who can have the "calling for politics", 90

The combination of the ethic of principle and the ethic of responsibility is thus the summit of human action, and is what is required from those

of political leaders in a sense that cannot be said of other citizens. However, when seen from Weber's remark that the ethic of principle and the ethic of responsibility are general categories of all ethics, this distinction is cancelled.

$86 \mathrm{PaV} 127 / \mathrm{PaB} 448$, translation modified.

$87 \mathrm{PaV} 127 / \mathrm{PaB} 448$, translation corrected.

$88 \mathrm{PaV} 127 / \mathrm{PaB} 448$.

$89 \mathrm{PaV} 120 / \mathrm{PaB} 441$.

$90 \mathrm{PaV} 127 / \mathrm{PaB} 449$, translation modified. 
that want to live for politics. According to Weber, responsibility can and should ideally be elevated to the level of principle ${ }^{91}$ - and this is what he ultimately asks for: the willingness to assume the consequences for the use of the power (of the State, in some people's case), an assumption to the point of "here I stand", i.e., elevating this responsibility to a principle in order to prevent the social order collapsing into "anarchy". 92

This elevation of responsibility to a level of principle follows both from Weber's rejection of cosmic-ethical realism and his definition of the State with reference to the monopoly on the legitimate use of violence. The argument seems to work as follows. The responsible person stands accountable for the foreseen and calculated consequences of his/her action. But since responsibility is acted out in a cosmos where one cannot assume good consequences for good actions, the responsible person will have to also be accountable for unforeseen consequences. Whatever the unforeseen consequences that will accompany the foreseen ones, and independently of (in the sense of ignorant of) the context that is to come, the responsible person will assume those consequences associated with his/her use of powerful means. This has to be accepted in order to guarantee the unified seat of legitimate use of violence in the State and thus to prevent anarchy.

How is Levinas to be situated with respect to this culmination point in Weber's presentation of responsibility? Just as Weber does, Levinas gives a radical thrust to responsibility by linking it to a context-independentness or by ascribing to responsibility a principled weight. Whereas this "principled weight" is in Weber the unconditional accountability for one's decisions regarding the use of power, in other words the principledness of responsibility is effective in the present with a view to the future in order to avoid anarchy, in Levinas this principled weight comes from behind, as it were, by the context-independent validity of the imperative of absolute obligation to the other. But here a significant difference should be noted: whereas Weber's principled responsibility aims at avoiding the fragmentation of the legitimate use of violence, the appeal of the "principle" of the imperative is anarchical. It is anarchical not only in the sense that Levinas explicitly gives to it,

91 It is true that Weber presents the two ethics as supplements of each other, but in the same phrase (cited above) his concern is still clearly with an ethics that is appropriate for the vocation of politics, and for this reason it would amount to a simple contradiction of everything that Weber had said previously of ethics in politics if one were to insist on the flip side of this conjunction, namely that the ethics of responsibility supplements the ethics of principle. That is why I opt for calling thus conjunction "elevating responsibility to a principle".

$92 \mathrm{PaV} 78 / \mathrm{PaB} 397$. 
namely that in the face of the others (in the plural) whatever solution is found to instate justice in society is submitted to eternal correction, revision and questioning in the name of the imperative of the other (and that ultimately ethicity doesn't operate with a foundational logic), it is also anarchical in the sense that I have explained in Chapter 6: the plurality of different requirements of the others explodes this apparent universal rule of obedience to the other into a myriad of conflicting claims. The plurality of ethical appeals that constitute the Levinasian subject as an ethical and responsible subject, each of which holds unconditionally as in the ethic of principle, constitute by their contradiction a political subject that continues to be responsible, has to answer for the others. However, because of the plurality of the others, the political subject has to take responsibility for the consequences of justice even if it may unfortunately contradict the needs or claims of certain individual others. And in the frame of Levinas' thought no limit is set to this responsibility and no reflection accompanies it on the means appropriate for the assumption of this responsibility. The effect of this is (as argued previously) that no justification can be given for keeping Jerusalem and Athens in balance, or in Weberian terms, no justification can be given for protecting the State against the fragmentation of the valid use of violence. Quite the contrary: in final analysis, the Levinasian State has as many instances of the legitimate use of violence as there are ethico-political subjects.

However wide the scope of possible actions a politician can consider as justified by Weber's theory of responsibility, the sociologist's concern about the integrity of the State makes it impossible for the subject of responsibility to put at stake or sacrifice the integrity of the State. This is true, first, in the case of responsibility as the ethic of the broader public and political officials, since no role is assigned to them that would place them in a position from which it would be possible to put the State at risk; second, in the case of the highest holders of political power, sacrificing the State is excluded since their responsibility is the responsibility for the monopoly on the use of violence that constitutes the State and thus the role of political leaders. But this much could not be said of Levinas' subjects of responsibility. Levinas does not take into consideration the entire complex issue of the competence of the ethical agent in matters political and its relation to the use of the array of means deployable in the name of justice. Therefore, the Levinasian political responsibility cannot protect itself against the temptation of attempting to radically undermine a state of affairs judged to be unjust, that is to embrace eschatological or chiliastic violence in order to radically re-found society. In other words (as indicated above), just like an ethic of principles that tempo- 
rarily appropriates for itself the means proper to the exercise of the ethic of responsibility, the fanatical Levinasian subject could place anything and everything at risk, in the name of the calculation of justice, a function for which no expertise or competence is required. Since the competence in responsible calculation of consequences is negligible in importance to the sensitivity to the appeals of the others (which, alas, is a cacophony of mutually contradictory claims), the Levinasian version of the combination of an ethic of principle and an ethic of responsibility resembles less an elevation of the assumption of consequences of responsible action to a principle (as in Weber), and more the elevation of a principled ethics to the assumption of the means of an ethic of responsibility.

In conclusion, it could be derived that there is in Levinas no casuistry or system of ethical rules because of the fact that he shares Weber's conviction that there is no universal rationality that would allow for programming action towards the good, and it might be for this reason that he leaves or abandons the question concerning the calculation of the consequences of action to each particular ethical agent in every particular situation. Levinas implicitly places all of his hope on the spontaneous, unschooled capacity of every ethical agent to obey the imperative from the other and to measure his or her attempts to realise that obedience in sophisticated ways.

That this is a philosophical stance of radical responsibility, cannot be questioned. It deals with a radical plurality of values and doesn't count on the rationality of reality for help; it is backed up by no history of philosophy that would guarantee the ultimate success of ethical conduct. But the political responsibility, the real quest for just action, is constantly held hostage or terrorised by the mercilessly infinite and unconditional imperative of the others.

The gains of this exploration of Levinas through the lens of Weber's notion of political responsibility can be summarised in two essential points: first, it magnifies the political implications of Levinas' theory of responsibility, the contours thereof are mapped more sharply and the potential and limits thereof are thus clearer; second, by indicating the numerous correspondences on essential points between a consequent Levinasian political practice of responsibility and the Weberian politician's responsibility, the way has been opened up to gain more for a reflection on responsibility after Levinas from the tradition of thought on Weber's notion of responsibility. The work of two representatives of the critical appropriation of Weber - Apel and Ricoeur - will be at the centre of the next two Chapters. 



\section{Chapter 8}

\section{Towards a post-Levinasian understanding of responsibility: the Weberian contribution of Apel}

I have argued that there is a significant similarity between Weber and Levinas in their reflection on responsibility. Particularly, Weber's distinction between an ethic of principle and an ethic of responsibility highlighted and clarified the implications of Levinas' notion of responsibility, especially its implications on the political plane. There is a further advantage of this comparison, and of the correspondences that have been indicated, namely that it helps us to better situate Levinas within a spectrum of ethico-political issues. When the debates concerning Weber's position and possible responses to them - in other words, the broad tradition of reflection on responsibility in the wake of Weber - are considered, it could suggest ideas for further reflection on Levinas and thus enrich the resources available for his project on responsibility and justice, albeit in the form of a post-Levinasian theory of political responsibility. In this short Chapter, such inspiration will be drawn from the work of Karl-Otto Apel. Since one could consider this choice of interlocutor as unexpected, a number of remarks of justification and orientation are in order.

\section{JUSTIFICATION: APEL AND THE UNAVOIDABILITY OF RESPONSIBILITY}

In order to engage with a (non exhaustive) series of these thorny political issues in connection with Weber's notion of responsibility, I draw from the later work of Karl-Otto Apel. This does not mean that I consider him the ultimate 
authority on Weber, nor does it imply that I shall advocate his discourse ethics. Rather, Apel is interesting for the current project because of the fact that he, coming from his particular Kantian perspective - a perspective that he himself described in his later work as a species of ethic of principle (Gesinnungsethik) - explicitly attempts to reflect on the shortcomings of his own principled ethical perspective under stimulation of Weber's notion of the ethic of responsibility. Apel is further also important for the current project because since his transformation of metaphysical philosophical approaches to ethics he has attempted to displace the monological approach of the solitary ethical subject with the collective ethical effort - which is exactly one of the deficiencies that I have indicated in Levinas. In the development of his own ethics of responsibility, Apel showed great sensitivity for the means required for ethical action and for the fact that these means should in our era be reflected upon in a global perspective - hence contributing to another deficiency indicated in Levinas. Finally, he seems suitable to use as thought partner for Levinas in reflecting on the Weberian issue of context and means-specific consequences of ethical conduct, exactly because he shares with Levinas (whatever the differences between them might $b^{1}$ ) the desire to anchor ethics in a contextindependent and universally valid justification.

What does Apel teach us when he situates himself in Diskurs und Verantwortung (Discourse and responsibility) explicitly in relation to Weber? ${ }^{2}$ In this re-interpreting and critical appropriation of Weber's notion of responsibility, of which I have shown the correspondences with Levinas', what hints can we get for the direction in which we can think with Levinas against Levinas?

In order to exploit this appropriation of Weber by Apel for our considerations of Levinas, a few remarks have to be made to situate this development in Apel's thought. Why would a philosopher that - at least in his own estimation - disposes of an ultimate philosophical foundation (a Letztbegründung) for ethics, give himself anew over to the task of a fundamental

1 The comparison of Levinas and Apel has thus far not drawn much attention from the scholarly community. However see Michael Barber, "The vulnerability of reason: the philosophical foundations of Emmanuel Levinas and K.O. Apel", in The prism of the self: philosophical essays in honor of Maurice Natanson. Steven G. Crowell (ed.). Dordrecht: Kluwer Academic Publishers, 1995, pp. 93-106. Barber has subsequently attempted to deploy his coordination of Levinas and Apel for an ethical reflection on affirmative action in Equality and Diversity: Phenomenological Investigations of Prejudice and Discrimination. Amherst, New York: Humanity Books, 2001 (see Chapters 5-8). Noteworthy is also the last section of Sophie Loidolt's Anspruch und Rechtfertigung: eine Theorie des rechtlichen Denkens im Anschluss an die Phänomenologie Edmund Husserls. Dordrecht: Springer, 2009.

2 It should at least be noted that there is in this book no reference to Levinas. 
conception of ethics? It is because Apel's Diskurs und Verantwortung is written in response to his realisation of a shortcoming in his established discourse or communicative ethics (Diskursethik), namely when it is confronted with the question of practical application. The problem is, according to Apel, in a profound manner part of the transcendental pragmatic ultimate foundation (transzendentalpragmatische Letztbegründung) of ethics and the discourse ethics that flows from it. Put quite simply, the transcendental pragmatic foundation of communicative ethics relies (for internal reasons that need not be discussed here) on a counter-factual anticipation of an ideal communicative community (kontrafaktische Antizipation einer idealen Kommunikationsgemeinschaft), ${ }^{3}$ but this a priori differs in an essential and practically irresolvable manner (prinzipiellen, faktisch nie völlig aufhebbaren Differenz) $)^{4}$ from the actual communicative community and its historically constituted morality. Now, whereas the detail of this project is not of concern here, it is important to note that Diskurs und Verantwortung is presented explicitly as one of two strands by which Apel considered it important to develop his initial project of re-conceiving philosophical ethics - and consists of reflection on the conditions for the application or gradual realisation of the ideal communicative community in a lifeworld that consists of different real communicative communities. ${ }^{5}$ Without regard for the time that separates the current historical communicative communities and the (never fully attainable) ideal communicative community, the consequences and side effects of the application of the communicative ethics in the present, would render this ethics irresponsible. This problem is seen by Apel as more than merely that of the application of general principles to particular situations; rather, because of the radical historical constitution of the difference between the ideal and real communicative communities, the very reasonability with which it could be expected of people to adhere to discourse ethics is destabilised. This could be illustrated with an example.

"How should one act at the same time in terms of a universalistic moral principle of reciprocity and responsibly, in a lifeworld in which something like legal safety - that is, above all protection against violence, but also corruption-free application of laws - in the State, let alone in international relations, cannot even be guaranteed without exception?"6

3 DV 9.

4 DV 9.

5 Cf. DV 8.

6 DV 242, see DV 139 for a different example. It should be noted that this example immediately places the question of the global dimensions of responsibility in the centre of reflection, since it poses the question concerning the ways in which marginalised regions and groups are interconnected with the rest of the world. 
A second type of reflection on ethics (called Begründungsteil B) is thus required to cope with the historically situated application of communicative ethics ${ }^{7}$ since this dilemma cannot simply be addressed from and by means of the transcendental pragmatic ultimate foundation of ethics, or as Apel recognises,

"a morally sensible new beginning in the sense of the perfectly understandable demand, for example, for the settlement of all conflicts of interest by 'practical discourses' [is] in principle impossible."

At this crucial point, Apel himself presents this challenge to his work in Weberian terms, and this is where Apel becomes interesting for our purposes. ${ }^{9}$ Without a further reflection on the historically contingent application of discourse ethics, the latter will merely lead to irresponsibility:

"it should be clear that the unconditional compliance with the ideal principle of a communicative ethics - 'act in such a way, as if you were a member of an ideal community of communication!' - just as the unconditional compliance with Kant's 'categorical imperative' would come to a principled ethical [gesinnungsethische] maxim, which would 'leave the responsibility to God'.,"10

In order to avoid this, Apel then takes up the challenges in Diskurs und Verantwortung of conceiving the

"historically related application of the communicative ethics as ethics of responsibility". 11

Even if we were to have an ultimate foundation for ethics, it would then be either impotent, or potentially harmful - in any case, irresponsible - to deploy it without consideration for the historical context of action. Or more generally still, the ethical meaning of action cannot be thought of merely in contextindependent terms. And this is exactly the problem that I have pointed out in Levinas (however much his ethics may be different from that of Apel): he seems to have believed that the $a$ priori validity of the ethical affectedness by the other would suffice to express (as good as is humanly possible) the interests of the others. I have argued that this is not necessarily the case. Conse-

$7 \quad$ DV 11.

8 DV 10.

9 One could also trace the essential development of Apel's appropriation of Weber in his interview with Michelini in "Ética del discurso y globalización. La ética ante las coerciones fácticas e institutionales de la politica, el derecho y la economía", in Erasmus, revista para el diálogo intercultural 2/2, 2000, pp. 99-119, see especially p. 100.

10 DV 10, my emphasis, the last phrase quoted is from Weber's PaB.

11 DV 10. 
quently, I could re-formulate my own project in Apelian terms as the quest for a historically situated realisation of the ethicity of the plurality of contradicting others as ethics of responsibility or as political responsibility.

\section{From a Weberian Apel TO A WEBERIAN LEVINAS}

If we then consider what Apel judged the strong and weak points of Weber's theory of responsibility, it would help us to clarify the challenges faced by Levinas' (largely) similar theory of responsibility.

The first major contribution of a historically situated notion of responsibility is that it takes the question of strategy for ethical thought seriously. The fact that an ethics of responsibility would be sensitive to the historical circumstances and means in and by which actions are to be accomplished - the blindness of a principled ethical approach in this regard may do more harm than good - implies that ethics necessarily has to think strategically. ${ }^{12}$ Although the question of strategy is not developed by Levinas, the path from the Saying to the Said and the concomitant insistence on calculation doesn't exclude it. ${ }^{13}$ However, it should be evident that a true Levinasian would always submit a previously adopted strategy to scrutiny under the inspiration of the ethical appeals of the others. One could certainly not find fault with this - as long as one thinks in a context-independent manner about it. But as soon as one thinks about strategy in a strategic manner, it becomes clear that whoever continues to constantly revise an adopted strategy will undermine that strategy and will be an unreliable ally in the "resistance against evil". Or if the question of the efficiency with which one opposed injustice or served the interests of the others is taken seriously - as it should be in calculations about justice - the strategies for the efficient pursuit of justice will necessarily require trade-offs between the appeals of the different others - trade-offs of which Levinas is not able to draw the limits or provide a frame for their ethical reflection. Thus Apel's identification of the issue of strategy supplements our considerations about collaboration and co-responsibility in Chapter 7 (\$2.2). Strategy cannot be given serious thought without taking the other as ethico-political agent seriously and thus strategy and co-responsibility imply each other.

12 Cf. DV 62.

13 See Chapter 7, § 2.2. 
Second, instead of storming into every situation armed with the good will of an ethic of principle in the belief that this will suffice to actualise the integrity of morality in that context, the adherent of an ethics of responsibility à la Apel

"supposes on the contrary, that he/she has to take up the historically given conditions of calculable success for action"

since the

"problem raised hereby encounters its material manifestation, not under the optimal conditions of the evolution of the moral consciousness [...], but under conditions under which moral conduct can often appear as unreasonable to demand [unzumutbar]."14

The reason why, according to Apel, adherents of an ethic of principle find this conclusion difficult to make is because in human history the ethic of principle was the way in which the obligations valid for the intimate circles of orientation (family and neighbourhood) have been generalised and even cosmopolicised. ${ }^{15}$ It should, however, be clear that these principles of intimate relationships cannot simply be applied to modern ethical problems involving either large groups (e.g., classes of society), or modern technical means, ${ }^{16}$ or non-human victims (e.g., the ecosystem). ${ }^{17}$ Therefore,

"[w] hat would be called for in the present crisis of the technico-scientific civilisation on a planetary scale, is [...] something like an ethics of common responsibility of solidarity for humanity in the sense of a communicative negotiation of interests and advice on situations [eine Ethik der gemeinsamen solidarischen Verantwortung der Menschheit im Sinne einer kommunikativen Interessenvermittlung und Situationsberatung]."18

Although I shall not follow Apel in the way he responds to this challenge, I fully subscribe to this estimation of what our times require (as explained above). Apel's appropriation of Weber's notion of responsibility also challenges Levinas: reflection on ethics cannot circumvent the question of the context of ethical action since this is part of the very meaning of the ethical (which Levinas never recognised or conceded) and this would hold even if Levinas' idea about the ethical meaning of the face of the other is accepted as it is. Consequently, it is impossible to take the manner in which the context-specifics of ethical action contrib-

\footnotetext{
14 DV 242.

15 DV 23.

16 Apel clearly draws on Jonas here.

17 Cf. DV 23.

18 DV 23-24.
} 
ute to the constitution of the meaning of the ethical seriously without reflection on the nature of the means by which ethical agents act. This involves, of course, the entire spectrum of technical and institutional means from the smallest to those that constitute the global dimension of human existence. ${ }^{19}$ This also means that we have to reflect on our contemporary situation that differs greatly from the situation known to and described by Weber. Furthermore, the context-specifics, the technical means and the scale of responsibility, necessarily entail re-affirming the bearing of co-responsibility on responsibility (see previous point).

But, third, Apel makes his approach to Weber very cautiously. When he criticises Weber's notion of responsibility, it has almost always to do with the manner in which it is demarcated from the ethic of principle, and the socio-historical implications of this distinction. After all, Apel doesn't abolish his a priori (deontological) ethics. An ideal politician needs both a true consciousness of responsibility and a fundamental ethical orientation for political decision-making. ${ }^{20}$ Exactly this ethical orientation is absent from Weber, or rather, pushed back to a domain outside of public debate and scrutiny - a fact that is implicitly recognised by Weber in his schematisation of ethical orientations as either an ethic of principle or an ethic of responsibility (according to Apel's reading). In this, Weber would be a typical representative of what is, according to Apel, the major ailment of Western normative thought, namely the

"dualism, or to be precise, the complementarity of value-neutral rationality and the irrational choice of ultimate axioms of judgement". ${ }^{21}$

Apel explains that Weber is one of the "co-founders of that system of complementarity of the Western ideology [Komplementaritätssystems der westlichen Ideologie]" according to which

"the praxis in the public domain of life - in the spheres of politics, law and science has to be regulated exclusively from the value-neutral rationality of science and technology, and thus the guidelines for goals and judgement have to derive from agreements in the sense of democratic majority decisions. In contrast, morality just as religion - has to be exclusively a private matter.",22

19 Here the concern for the largest, global range of reflection on political responsibility - expressed especially in Chapter 3 - and that of the inevitable reflection on the means of responsible political action - introduced especially in Chapter 6 - are thus re-introduced from another angle.

20 Cf. DV 39-40.

21 DV 56.

22 DV 56-57. 
Hence Apel's characterisation of public or political decision-making in the frame of Weber's thought on responsibility as irrational. ${ }^{23}$ This inherent irrationalism of political responsibility would then be at the origin of the tradition of criticism against what is considered to be Weber's decisionism.

This criticism of Apel's is aimed at a Weberian responsibility as practised under normal circumstances and that entails isolated political decision-making in the face of the particular needs of a situation. However, even though the entire thrust of Apel's ethico-political reflection is aimed at "saving" politics from this "irrationalism", he doesn't deny that in extreme cases or borderline situations (Grenzsituationen) one could still be forced to that kind of decision. But as far as Apel is concerned, this is only a valid manner of responding to highly exceptional circumstances. ${ }^{24}$ This important concession to what he considers to be irrationality is given a very specific place within his description of the requirements for a new theory of responsibility, the thrust of which I have fully supported - I cite the same passage, this time fully:

"However, what would be called for in the present crisis of the technico-scientific civilisation on a planetary scale, is much more than an ethics of existential borderline situations - an ethics that could even possibly [womöglich] depend on irrational final decisions. What is called for is something like an ethics of common responsibility of solidarity for humanity in the sense of a communicative negotiation of interests and advice on situations.",25

Apel thus acknowledges for all his transcendental pragmatic foundation of discourse ethics, some form of ethics that would be more than, but not excluding, ${ }^{26}$ an ethics of existential extreme situations, which can arrive at responses to those exceptional situations, only by means of ultimately non

23 Cf. DV 40.

24 In the current study, I shall not enter into the detail of the thorny issue of exception in its relation to the debates concerning decisionism. My reader will not be surprised to hear that I find a certain form of decisionism - a decisionism of application, but not a decisionism of foundation - one of the possible manifestation of Levinas' ethics (for the distinction see Eckard Bolsinger "Was ist Dezisionismus? Rekonstruktion eines autonomen Typs politischer Theorie", in Politische Vierteljahresschrift 39/3, 1998, pp. 471-502, here p. 472). I have indicated one way in which to consider Levinas' ethics in relation to Schmitt's thought on political theology and sovereignty in "The State and politics in a post-colonial, global order. Reconstruction and criticism of a Levinasian perspective", in SA Publiekreg / SA Public Law 24/2, 2009, pp. 352-369, here $§ 5$.

25 DV 23-24, I emphasise "even possibly".

26 Apel says explicitly of this kind of situational ethics that it "doesn't meet the requirements of the moment", but adds: "although it is by no means obsolete, as the borderline situations of solitary decision definitely exist (situations in which everyone has to choose his/her gods, as M. Weber said [...])" (DV 23). 
reason-bound decisions - i.e., under these circumstances a Weberian responsibility without any recourse to a deontological ethics or to an ethic of principle would be in order. Under such circumstances, the enormity of the context overrides the authority of the principles and the responsibility has to be elevated to a principle. ${ }^{27}$ Such situations cannot be avoided, but the dilemma that they bring to light should not be generalised either, according to Apel. Now, this poses a challenge to my criticism of Levinas' politics, since (as shown in my commentary on the fatal "for instance" from the Kearney interview in Chapter 6, § 2.2.) "sometimes" a Levinasian politics can find recourse to very extreme means and might (as I have shown above in comparing his responsibility to Weber's ethic of principle) even develop into an eschatological violence. And here, in the current discussion of Apel's appropriation of Weber, Levinas seems to have found an unexpected ally: from one of the most serious representatives of a contemporary re-actualisation of deontological ethics, comes the recognition of exceptional states in which a priori, universal principles have to cede to considerations of the circumstances and a communicative ethics makes way for an ethics of extreme situations.

\section{FOUR OBJECTIVES FOR A THEORY OF POLITICAL RESPONSIBILITY}

A number of important impetuses for further reflection concerning the deployment of a Levinasian responsibility, and responsibility in general, in its political dimension could be derived from Apel's project, as it has been shown to fit with Levinas and Weber at the same time. Apel's appropriation of Weber's ethics of responsibility, or rather, his recognition that there is something indispensable in a consequentialist responsibility to complete his principled ethical re-appropriation of a Kantian deontology could show what the challenges are that one faces when reflecting "after Levinas" on political responsibility in a globalised world. Both the positive elements of Apel's evaluation of Weber's ethics of responsibility and the negative criticism thereof, present us with important categories for asking what a theory of responsibility should be able to do and what it should look like. I have argued above (Chapters 6 and 7) that Levinas cannot but recognise

27 As I have explained above, and as explained by Apel with reference to Weber's remark about the connection between the ethic of responsibility and the ethic of principle (in "Ética del discurso y globalización.” op. cit. p. 101.) 
that the consequences of ethical conduct have ethical meaning, namely that considerations regarding the consequences belong to the essence of the moment of decision making in the face of the plurality of others. Practically all of the traits that Levinas' theory of responsibility shares with that of Weber follow from this finding. Now, just as I have magnified the implications of Levinas' notion of responsibility for the domain of the political by looking at it through the lens of Weber, we can now amplify a number of requirements for re-conceiving responsibility after Levinas, by looking at it through the lens of Apel.

First, if the consequences of ethical action participate in the very meaning of the ethical, then it is impossible to avoid thinking about ethics not exclusively in terms of the meaning of the face of the other (or in terms of transcendental pragmatics, in the case of Apel), but also to think strategically. All of this seems to me in line with Levinas' recognition that, in the face of the plurality of others, one should compare the incomparable and act accordingly. Not thinking strategically would amount to clinging in a principled ethical manner to a cosmic-ethical realism that has centuries ago already been problematised convincingly by the world religions. ${ }^{28}$ In other words, since there is in Levinas no such necessary correlation between action that is done in response to the appeal of the others and the beneficial outcomes of those responses, the subject has to think strategically. Strategic thinking necessarily means not obeying all of the others completely, but having to prioritise and ultimately to make sacrifices in the name of the maximisation of justice.

Second, if an ethics of responsibility is then an ethics of consequences and therefore of strategy, then Weber's description of responsibility is too simple. Or more precisely, whereas Weber devotes a lot of attention to describing at least the contemporary social conditions under which one will have to take up responsibility if one has the vocation for politics, his Politics as a vocation is insufficient to unpack the different forms of responsibility that one could assume or be made to take up in different spheres of social and political reality. Reflection on these different forms and dimensions of responsibility ${ }^{29}$ is,

28 Cf. PaV 123 / PaB 444.

29 By "forms and dimensions of responsibility" I shall henceforth refer to the typical distinguishable configurations through which responsibility is socially integrated. These types might be more or less stable roles and more or less distinguishable, depending on historical circumstances; the forms and dimensions also involve the roles and competences of the subject of responsibility in society, which in turn impacts on the sphere of influence, the circle of people, things and events that are influenced, the scales of competence, the nature of activities, relationships between people, etc. Usually the forms and dimensions of responsibility refer to the 
however, indispensable for a general theory of responsibility - of which Levinas aspired at least to uncover the justification (and even if this general theory implies a generalisation of the political to the entire social reality ${ }^{30}$ ). Taking the forms and dimensions of responsibility seriously, means thus to engage with the inevitable strategic nature of responsibility and the embeddedness thereof in a historical context and a network of possible means, and can therefore not simply be assimilated to an enthusiasm for technocratic solutions (see also point three, below). Whoever has to think strategically about responsibility, necessarily has to think of the different conditions under which one has to be responsible and the forms of responsibility that one should carry. Even if, from a Levinasian point of view, all such roles remain forever open to critical intervention from the side of ethics, from whence they would always seem like a limitation of infinite responsibility and an alibi to shake off or shift over

distinguishable aspects of temporality (prospective, retrospective), subjectivity (individual- or co-responsibility), conditionality (formal, informal, legal, contractual), modality (responsibility for action, for failing to act or preventing someone from acting), and so forth. The point here is not to work out these forms and dimensions, but to integrate thought on them in a project of reflection on responsibility in its political nature after Levinas. Expositions regarding the forms and dimensions of responsibility can be found in most introductions to the philosophy of responsibility; see particularly Hans Lenk's detailed presentation "Typen und Dimensionen der Verantwortlichkeit", in Konkrete Humanität. Vorlesungen über Verantwortung und Menschlichkeit, op. cit. pp. 261-284.

It would be misguided to reduce the formal aspect of responsibility to that of the contractual obligations of the stereotypical bureaucrat (as is all too often done). The person that is unexpectedly confronted with someone in need and the liberation fighter can equally be shown to be informed by certain pre-existing forms of responsibility as they play out their responsibility outside of an institutional framework and it would not be correct to consider their attempts at responsible action (supererogatory or transgressing) as simply formless. What is at issue in the discussion of forms of responsibility is not to predetermine responsible action independently of the situation of action (it cannot be done), nor to eliminate conflict between the multiple roles that every person holds (it cannot be done) - the issue is that responsibility action cannot exist without it.

I am not ignorant of the fact that such considerations about the forms and dimensions of responsibility would, in Levinas' mind, largely be considered derivatives of originary responsibility and for this reason not only secondary, but also mere translations and therefore already treasons against originary responsibility. My point is that even if this is accepted, the practical execution (translation) of originary responsibility on the level of politics (that is, in principle, all action) participates in the meaning of the originary imperative and that one therefore must consider the whole when reflecting on political responsibility.

30 Let it be repeated here that I share, with Levinas, Ricoeur's conviction that the political is not merely one amongst different spheres of social life, but a unifying aspect of them. However, this does not mean that the entire social existence could be reduced to or exhaustively explained in political terms. 
responsibility, these roles of responsibility should be considered indispensable in the execution of responsibility, also in the execution of a truly Levinasian responsibility. The person that exposes or denounces all the sacrifices made in respect to the legitimate appeals of the others and all the limitations or compromises made to infinite responsibility by remaining true to the rules of specific roles of responsibility, might well be ethically in the right, but also risks undermining the strategy necessary for effective service to the others. Furthermore, such reflection on the strategy, conditions and roles of responsibility would necessarily entail reflection on co-responsibility ${ }^{31}$ - a notion that is completely absent from Levinas, since if nobody can respond in my place to the appeals of the others, the sharing of responsibility could, at best, be a secondary derivative of my own responsibility, at worst, another alibi to shirk my duty towards the others. The consequence of my arguments concerning possible fanaticism derived from a Levinasian ethics (Chapter 6, § 2.2.) should show that a defect in reflecting on co-responsibility thoroughly could equally do violence to the interest of the others. Furthermore, it seems to me under the current conditions of the disenchanted polytheistic world impossible to conceive of co-responsibility between different ethical agents - for a context that demands strategic thinking, acting and sacrifice - without negotiation between the relevant partners concerning strategy and sacrifice, in fact concerning everything entailed in ethical conduct. Negotiation between ethical partners would not have a foundational pretence here, but it does seem an indispensable component in the execution of ethical conduct - at least when ethics in a context larger than just the very narrowest of interpersonal relations is concerned. That such negotiation could take different forms conjugating different degrees of participation, engagement, consultation with specialists, concessions, reason and pressure seems undeniable. However it does seem that there are limits to such negotiations that could not be transgressed without putting the collaborative ethical endeavour at risk. ${ }^{32}$

31 It is probably more prudent to understand co-responsibility (Mitverantwortung) as "shared responsibility", rather than "collective responsibility", as distinguished by Iris Young (in "Responsibility, Social connection, and Global labor justice", in Global challenges. War, self-determination, and responsibility for justice. Cambridge and Malden: Polity, 2007, pp. 159-186). She defines shared responsibility as "a personal responsibility for outcomes or the risks of harmful outcomes, produced by a group of persons. Each is personally responsible for outcomes in a partial way, since he or she alone does not produce the outcomes; the specific part that each plays in producing the outcome cannot be isolated and identified, however, and thus the responsibility is essentially shared." (p. 179).

32 The passage from Levinas to different forms of dialogical or discourse ethics is opened in this way and will have to be elaborated on in future reflection. 
Third, if the consequences, strategy and roles of responsibility are essential elements of an ethics of responsibility, then the socio-historical and cultural context of the ethical decision making becomes extremely important, since consequences, strategy and roles are all equally constituted by historically contingent processes. Consequently, this means that responsibility cannot be contemplated without considerations to the historically contingent means by which that responsibility is to be realised; strategy and roles are determined by the means that are available for responsible action and reflection on consequences is necessarily reflection on means. Therefore means - whether conceived in terms of technology, systems or institutions - are a constituting factor of responsibility. Furthermore, in the era in which we live, the global extent and influence of means of action as well as of the context of action, should be considered the ultimate horizon, as Apel correctly pointed out and as I have shown the implications of Levinas' reflections on totalitarianism and the postcolonial order to be. ${ }^{33}$ Also, the question of the means at one's disposal for action, would necessarily lead to considerations concerning the sustainability of their use and thus about ecology. ${ }^{34}$ At the same time, none of these reflections about means and the consequences of their use could be imagined without the recourse to expertise. These include not only the sciences and law (including the law-enforcement systems), but also insight into the nature of action, means and consequences so as to avoid the moralism engendered by context-ignorance. ${ }^{35}$

33 See Chapter 3. This is also an essential aspect of Bernasconi's conclusion concerning the re-conception of ethics for the current globalised world: "If globalisation means to live in a world in which the notions far and near, foreigner and neighbour, do not have the same meaning for us as before, since they can be seen to belong to the same sphere, then the hunger of those that are pushed to the remotest periphery, represent the fundamental point of reference" in "Globalisierung und Hunger", in Im Angesicht der Anderen. Levinas' Philosophie des Politischen. Pascal Delhom and Alfred Hirsch (eds.). Zürich and Berlin: Diaphanes, 2005, pp. 115-129, citation p. 125.

34 I state this as a very minimum entrance to the question of an ethics of ecology. Other, non-anthropocentric approaches would of course award a much more prominent place to the responsibility to non-human forms of existence. Although I do not ignore the importance of these kinds of considerations, they are not my concern here.

35 That this introduces at the same time the risks involved in technocracy and expertocracy has been forcefully argued by such authors as Habermas and Slama. But my point is that responsibility asks for engagement with these problems. Similarly an engagement with the complexities of agency (as in the thought of Ricoeur, which will be focused on in the next Chapter) should enforce one's vigilance against moralism. 
Fourth, (linking with the first point) the fact of being responsible for different others at the same time necessitates strategic thinking about ethical action and hence about sacrifice. One cannot merely do the right thing - one has to decide what the best course of action is. One has to weigh, or as Levinas says, compare the incomparable. But this means that, in certain historical circumstances, ethical agents might consider radical means of answering the appeal of the others to be the appropriate thing to do - they might consider the appeal of the others, as they hear it, to override the institutionalised organisation of matters as it is in place in their field of action. They would, in other words, feel themselves ethically obliged to obey the appeal of the others, rather than the laws or rules in force - not, perhaps, out of a lack of respect for the law, but out of a conviction that the urgency of the appeal of the other requires an exception. Responsibility is an ethics of uncertainty; as an ethics of consequences it keeps itself open to unforeseen or unforeseeable realisations of itself, even if it is driven by context-independent imperatives. In fact, responsibility is an ethics of equity, in the sense that it always has to consider the possible conflict between the "letter" and the "spirit" of its obligation. As shown in Apel's concession, it is not possible to avoid limit situations, and under these extreme situations the normal response makes way for exceptional responses. This could entail abandoning one's reflection on the circumstances and simply executing the rule; it could equally be to follow one's interpretation of the circumstances to the detriment of the rule. But one thing is clear - one has to decide: not only on what one is going to do, but on whether and to what degree the context of action constitutes an exception. The pair decision-exception thus makes an integral part of a proper theory of responsibility. And it makes a significant difference if one reflects on responsibility by starting from the question of the exception, or if one interprets the exception as the last outgrowth of the common everyday practice of responsibility. Ultimately, reflection on the exception joins a meditation on evil. ${ }^{36}$

In these four points I hope to capture the task of a theory of responsibility "after Levinas". The requirements for such a theory of responsibility might not be entirely new - my use of Weber and Apel to make this point should be ample recognition of this fact. ${ }^{37}$ However, what is new, as far as I can

36 Of which I find Levinas' presentation very unsatisfactory - cf. De l'éthique à la justice 60ff. A much more convincing reflection on evil (in which a chapter is also devoted to Levinas) is Richard Bernstein's Radical evil. A philosophical interrogation. Cambridge: Polity, 2002.

37 From the vast literature on politics and responsibility, the following deserve to be singled out: Kurt Bayerz (ed.), Verantwortung: Prinzip oder Problem?. Darmstadt: Wissenschaftliche Buchgesellschaft, 1995 and Ludger Heidbrink and Alfred 
see, is the double claim that (1) all of these are necessary consequences of reflecting on the implications of Levinas' responsibility as it takes effect on the level of the political and (2) that they are not secondary derivatives of the primary meaning of ethics, but part of the very meaning of ethics, if one thinks the implications of a Levinasian responsibility through. Yet, most of this is largely, if not completely, absent from his thought.

These requirements, this task, are what our study of Levinas leaves us with. It would simply be foolhardy to attempt to work that out in the current context. Instead, these four requirements will be developed in Chapter 9 with the help of our last interlocutor, Paul Ricoeur. 



\section{Chapter 9}

\section{Ricoeur's contribution \\ to a notion of political responsibility \\ for a globalised world}

Having in the two previous Chapters first sharpened the contours of the implications of Levinas' notion of responsibility and its political deployment and then outlined the four basic tasks for the further elaboration of a general theory of political responsibility in Levinas' wake, it is important in a third movement to consider the possible implications of such a fourfold progression in the reflection on post-Levinasian responsibility. The interlocutor chosen to aid me in magnifying the implications of the task of further developing the notion of political responsibility is Paul Ricoeur. He is used here not in order to hold him up as the bearer of the ultimate solution to this task not least because the theme of responsibility is left in a somewhat undecided state in his work. Rather, the complex manner in which he integrates aspects of both Weber and Levinas' notions of responsibility makes him suitable to help explore the potential of the subsequent restructuring of Levinas' responsibility for our current purposes. The aim is thus not to present a comparison of Ricoeur and Levinas, but to inquire into the magnifying potential that we can obtain from Ricoeur's ethico-political thought for our project of a political responsibility for a globalised world. At the same time, this exercise would already suggest a number of ways by which my concerns, born of a critical examination of Levinas, can be pursued by different means. I shall therefore not attempt an exhaustive presentation of Ricoeur's ethico-political thought, but only elaborate on possible contributions that his work could make to a fuller understanding of the requirements that crystallised from my Levinas-Weber-Apel reading. 
If Ricoeur is well suited for this task, it is not only because of the inherent merit of his work, but also because it is fairly natural to place him in the line of my Weberian exploration. Although it would obviously not be correct to reduce his political thought to his Weberian heritage, it can be argued that an examination of the way in which Ricoeur received Weber and the place accorded to that reception in his own thought, would give a valid and fruitful entry to Ricoeur's ethico-political thought. Consequently, Ricoeur's contribution to the project of a post-Levinasian theory of political responsibility will have to start with a clarification of his orientation in political philosophy and his appropriation of Weber $(\S 1)$. This can be done best through an examination of a selection of his texts from the late 1950s. However, the accent in this study is on Ricoeur's "Little ethics" and the elaborations on it in the 1990s (to which the discussion will go over in $\S 2$ ). A brief overview of the "Little ethics" is needed to map the terrain in which the subsequent reflection on political responsibility will be placed $(\S 3)$. Having thus prepared the exploration, Ricoeur's contribution to the four requirements for a theory of political responsibility - as developed in Chapter 8 - will be proposed ( $\$ 4)$.

\section{RicOEUR'S POLITICAL PARADOX AND APPROPRIATION OF WEBER}

It is well known that the essay "The political paradox" (1957) marks an important moment in the formation of Ricoeur's political philosophy. While he wrote texts of political philosophy before that, and even texts in which themes from the 1957 essay were anticipated, Ricoeur himself explains retrospectively that

"[i]t is true that my subsequent reflections in political philosophy have stemmed from this initial text."

The figure of the political paradox is a recurrent theme that structures Ricoeur's political thought over many decades, and it is clear that when in the late 1980s and 1990s he develops his "Little ethics" (petite éthique), he is still concerned with an examination and deepening of the idea of the political paradox. $^{2}$

The repeated use of the expression "the political paradox" might mislead one to think that an unequivocal definition can be given for it. Yet, it

$1 \quad \mathrm{C} \& \mathrm{C} 95 / \mathrm{CC} 147$.

2 Cf. RF 80. 
would be more exact to refer to the expression "the political paradox" as a pattern of interpretation of which the interpretational potential is gradually discovered and explored, as Ricoeur develops his reflection on the political. A definition of "paradox" from one of Ricoeur's later texts might be helpful to come to a first approximation of the figure of the political paradox. A paradox is

"a situation in which two contrary theses equally oppose being refuted and, as a result, require being preserved or abandoned together,"3

and in contradistinction to an antinomy, where two theses do not belong to the same discursive universe, in the paradox they do. Of course, I do not maintain that this is the exact definition that Ricoeur had in mind when he drafted the 1957 essay, but rather that this definition suffices to clarify this dominant pattern of research in Ricoeur's political philosophy.

This research pattern, this situation of thought stuck between two opposing theses, concerns the specificity of the political or of political power. ${ }^{4}$ The difference and relation between the two theses could be profiled in a number of ways: the paradox concerns the political and politics, the form and force of politics, ${ }^{5}$ the power of willing to live together and the legitimate recourse to violence by the power of domination, ${ }^{6}$ the horizontal and the vertical political dimensions, ${ }^{7}$ the legislative and the executive powers, ${ }^{8}$ the rationality particular to the political and the foundational violence thereof, ${ }^{9}$ the encompassing nature of the political with respect to the different spheres of society and the encompassed nature of politics as one amongst the spheres of society (englobant-englobé). ${ }^{10}$

In order to make my way towards a more detailed presentation of this paradox and to align this presentation with my general strategy for this Part of the book - namely to reflect on political responsibility with Max Weber's essay on Politics as a vocation as stimulus - another important characteristic

3 RTJ 19, 73/ JII 27, 86.

C\&C 96/ CC 148, 149.

OAA 257 / SA 299.

C\&C 99/CC 153.

C\&C 99/CC 152.

C\&C $105 /$ CC 161.

9 C\&C 96, 98/CC 149, 151.

10 C\&C 103, 104 / CC 159, 160. See also Bernard Dauenhauer's recapitulation of the dimensions of the political paradox in Paul Ricoeur. The promise and the risk of politics. Lanham, et al.: Rowman and Littlefield publishers, 1998, pp. 211-212, which draws on Ricoeur's "Fragilité et responsabilité", in Eros and Eris. Contributions to a hermeneutical phenomenology. Paul van Togeren et. al. (eds.). Dortrecht, et al.: Kluwer, 1992, pp. 295-304. 
of its development by Ricoeur needs to be mentioned: next to a series of other authors, Weber is assigned an important role in the elaboration of the political paradox. The very first time that the notion of the political paradox appears (at the beginning of the essay "The political paradox") it is presented in terms that could be said to reflect a Weberian agenda:

"Techniques change, human relationships evolve depending upon things, and yet power unveils the same paradox, that of a twofold progress in rationality and in possibilities for perversion."

Since Weber's work on the Protestant work ethics, the adjective "Weberian" may be applied to any idea of a history of increasing rationality and its dark flip side, emblematically referred to as the "iron cage". Even if Weber is not referred to by name, and no facile identification of Ricoeurian and Weberian terms is intended, the resonance of the Weberian theme in Ricoeur is undeniable. Yet, the importance of Weber for Ricoeur's political paradox is not so much in the development of the form of the paradox, than in the particular place designated for Weber in the paradox. Ricoeur repeatedly uses Weber's definition of political power as the monopoly on the ultimate recourse to legitimate violence, as the precise formulation of the vertical power of politics, of the executive power of domination. Not only does this serve (in 1957) to explore the particular nature of political evil, but consequently, it serves implicitly to launch the question concerning the nature and constitution of legitimacy and the question concerning the limitation of that power. Let's then see how Ricoeur presents his political thought in this key text.

When we turn to "The political paradox", it is clear that Ricoeur is concerned with arguing for the irreducible particularity of political rationality and political harm or evil ( $\mathrm{mal}$ ). The paradox resides in the fact that these two particularities oppose each other, but can be reflected on only together:

"This paradox must be retained: that the greatest evil adheres to the greatest rationality, that there is political alienation because the political is relatively autonomous."12

This paradox is theoretically indissoluble, but can be responded to by a practical solution. What then is the autonomous rationality of politics? What is the nature of the particular alienation or evil of politics? And how could this practical solution be clarified?

The Greeks, and Aristotle in particular, taught us the meaning and significance of the fact that human beings are essentially, and not accidentally, political beings. The rationality of the political is derived from this: a politi-

11 HT 248/HV 295.

12 HT 249/HV 296, translation modified. 
cal being, that strives to live well, aims at the good through life in the State. Political rationality is a teleological rationality that aims at "contributing to the humanity of people", ${ }^{13}$ by living together in a State, as citizens, and by practising virtues of participation in power. One acquires these virtues by living in the State and they not only define the individual as citizen, but make the individual into a human being. The rules and means of other spheres of social interaction (e.g., economy) are deemed subservient to, or at least neatly distinct from, the teleology of politics. ${ }^{14}$ The tyrant is a secondary phenomenon of the political and can be understood and judged only in the light of the inherent rationality and autonomy of the political.

Ricoeur finds a second essential component of the particularity of the political in Rousseau's social contract:

"The great, invincible idea of the Social Contract is that the body politic is born of a virtual act, of a consent which is not an historical event, but one which only comes out in reflection." 15

Unlike the case with Hobbes' notion thereof, this consent to the social contract is not an exercise by which freedom is exchanged for security, but the entry of individuals into a civil existence by an act whereby all consent to the law ${ }^{16}$ and thus constitute - again, retrospectively and in reflection - the State, and through the State constitute the citizens as free and equal. ${ }^{17}$ Whatever the subsequent abuses of the law by powerful interest groups in the State may be, the contract is the truth of politics and the reality of the State. ${ }^{18}$ For Ricoeur, Rousseau essentially continues the teleology of Aristotle:

"In the two cases, with the Telos of the State and the generating pact of the general will, it is a matter of manifesting the coincidence of an individual and passional will with the objective and political will, in short, of making man's humanity pass through legality and civil restraint."19

Hegel's notion of the State as reasonable organisation of individual freedom would be an extension of the same idea. ${ }^{20}$

But even if this is so, the political (le politique) never appears in history detached from politics (la politique); the political may show itself retrospectively in reflection as reasonable organisation, but politics has to cope with

\footnotetext{
13 HT 250 / HV 297, translation modified.

14 HT 265 / HV 315.

15 HT 251 / HV 299.

16 HT 252 / HV 299.

17 HT 252 / HV 300.

18 HT 252 / HV 300.

19 HT 253 / HV 301.

20 HT 254 / HV 302.
} 
uncertainty and has to make decisions in anticipation of an uncertain future, moreover, it has to do so by using political power and the means particular to politics. ${ }^{21}$ These means are characterised by "the monopoly over legitimised physical constraint [le monopole de la contrainte physique légitimé]". 22 Whereas this "legitimacy" refers the force of political power back to the end and form of the political, the relation between the monopoly on violence and its legitimacy differs in intensity from case to case. Politics, in contradistinction to the political, ${ }^{23}$ is defined by power and by the means of its exercise and it is here that the possibility of political evil takes root. This finding occasions a new formulation of the political paradox: however the means, the power, of politics may be used, it remains the instrument of the "historical rationality of the State", ${ }^{24}$ that is to say that the political, detached from the power of politics, remains powerless, without effect; yet, the quest for the good life through the State can be realised only by the means of the State that carry in themselves the potential of evil use of the monopoly on the use of violence. Or, formulated negatively,

"on the one hand, the meaning of power resides in the desire of a plurality of people to live together; on the other hand, power dispossesses, nevertheless, all those that do not exercise power from the capacity to decide., ${ }^{, 5}$

The political can realise itself only through politics, yet politics has shown itself often to be an unreliable partner: the power and even violence that is needed to constitute the political can spend itself on the undermining of the political - this is the political paradox. At the same time, the denunciation

21 HT 255 / HV 303. "From the political to politics [Du politique à la politique], we move from advent to events, from sovereignty to the sovereign, from the State to government, from historical Reason to Power." (HT 255 / HV 303, translation modified).

22 HT 255 / HV 303, translation modified; no explicit reference made to Weber by Ricoeur.

23 Here Ricoeur refers explicitly to Politics as a vocation when he defines politics as "the sum total of activities which have for their object the exercise of power, therefore also the conquest and preservation of power. Step by step, politics will encompass every activity whose goal or effect will be to influence the division of power." (HT 255 / HV 304). Cf. Also "The State is that reality that down to the present has always included murder as condition for its existence, its survival and first its institution." (HV 288, my translation).

Note that here Ricoeur does not adopt the categorisation of Arendt where the political as the desire to live together is itself the source of political power and politics is defined in Weberian terms as the recourse to certain forms of the exercise of power (C\&C $99 /$ CC 152f).

24 HT 256/HV 304.

25 Marc Crépon, "Du 'paradoxe politique' à la question des appartenances", in Paul Ricoeur (Cahiers de L'Herne), Myriam Revault d'Allonnes and François Azouvi (eds.). Paris: L'Herne, pp. 307-314, citation p. 309. 
of political evil becomes unintelligible if the human quest for the good through political being is not presupposed in that critique.

A long procession of political thinkers throughout human history may have denounced events in which the sovereign parades as sovereignty itself, but even so, a perfect harmony between the political and politics is unattainable. ${ }^{26}$ However, it would be too simple to merely classify political power as evil, because the means of political action belong radically to the human being as a political being. The evil of political power, is the evil of the human being as political being. ${ }^{27}$ Human beings can no more rid themselves of the dilemma of the use of political power, than from their essence as political beings. ${ }^{28}$ Although Ricoeur doesn't do so in this text, he subsequently regularly mentioned the fact, when referring to Weber's presentation of politics and the unavoidable constitution of power by violent means, that Weber presented this picture of politics in an address made to naive pacifist students. ${ }^{29}$ Ricoeur too rejects this political naivety as can be derived from his insistence in the essay "The political paradox" on the fact that his exposition of the evil of politics is motivated by a quest for lucidity and an attempt to remain politically vigilant. $^{30}$

This lucidity and vigilance are of considerable importance in making the transition from the theoretical to a practical reflection on the political paradox, since whereas there is no theoretical (dis-)solution of the political paradox - the two theses can be maintained only together - there is a practical solution to it. This practical solution of the paradox consists of allowing the State enough power to do its beneficial work, but setting limits to that power, or practising an "ethic of limited violence [éthique de la violence limitée]". ${ }^{31}$ In more concrete terms:

"the great problem of democracy concerns the control of the State by the people", which means

"to devise institutional techniques especially designed to render possible the exercise of power and render its abuse impossible. ${ }^{, 32}$

26 Cf. HT 259/HV 308.

27 HT 261 / HV 310.

28 Cf. HT 261 / HV 311.

29 E.g., LI 235.

30 HT 261 / HV 310, 311, respectively.

31 HT 262 / HV 312, my emphasis. This is a crucial expression, since it is in practically the same terms that Ricoeur, two years later, suggests the coordination of the ethic of principle and the ethic of responsibility be interpreted in Weber (see discussion below). It also corresponds with the terms in which the nature of the political paradox was posed in its first use (see above).

32 HT 261f / HV 311 and see HT 264 / HV 314. 
How then does Ricoeur see the question of a political ethics of limited violence - this thoroughly Weberian question of realism with regard to the means of politics? If the paradox of the political is a universal structure, in other words if it is independent of historical contingencies of particular political forms, then it follows that there would always be at least the possibility of institutional dispositions of the State that would surpass the interest of a power group within the State. One example is of particular importance here: the universal intention of liberal politics since the 18th century surpasses the contingent form of what socialists would call the bourgeois State. ${ }^{33}$ The "universal" aspects of liberalism would be: (1) the independence of judges with regard to the State, (2) the possibility of access for citizens to sources of information and science that are generated independently from the State, and this includes the freedom to form a public opinion, which in turn depends on the freedom of the press, (3) the settlement of differences in interests between the State and the work force, even if it means recourse to strikes, and (4) the control exercised by a democratically organised citizenry to negotiate the tension between long-term planning and continual discussion. Hence Ricoeur's conclusion that if the term "liberalism" is to retain any credit it stands for a formulation of the political paradox from the perspective of liberty:

"either that the State founds freedom by means of its rationality, or that freedom limits the passions of power through its resistance.",34

The final considerations of Ricoeur's exposition of the political paradox clearly battles with the question of the inevitable use of the violent means that define the State, ${ }^{35}$ and thus attempts to accompany reflectively the Weberian issue of a political ethic of responsibility. Although Ricoeur draws the terms describing this issue from Weber (amongst others) and Politics as a vocation in particular, in the essay on "The political paradox" he doesn't make mention of the notion of an ethic of responsibility and thus the question of how he would articulate the different concerns recorded by Weber in the opposition between the ethic of responsibility and the ethic of principle remains in suspense.

33 HT 267/HV 317-318.

34 HT 270/HV 321.

35 As he does in a text of the same year in "State and violence" (HT 234ff / HV 287ff). Although Weber is never mentioned in this essay, he is even more present by implicit illusions to the most important aspects of his political thought. 
For a response to this question one could perhaps turn to the curious little essay "Ethics and politics" (1959), ${ }^{36}$ written shortly after "The political paradox" as commentary on the then recently published French translation of Politik als Beruf..$^{37}$ My choice of the word "curious" is deliberate. One could safely say that the six pages of simple exposition are successful as introduction to the paper of Weber, but that it is otherwise uneventful. One notes that the question of legitimate violence is central in this exposition, as it is in "The political paradox" and "State and violence" (also of 1957) and that this violence is the means of the State and its defining characteristic. That violence is organically fused with the political suffices to evoke the question concerning an ethics of politics - which Weber does with his distinction between an ethic of principle and an ethic of responsibility. These derive their meaning not only from the historical conditions in and for which Weber wrote, but also from the more general characteristics of politics in the modern era. Weber's question, then, is to understand what a person is to be like, who lives under these conditions for politics (and not merely of politics). Such a person has to have a passionate devotion for the cause, a cool reflective vision of the state of affairs and then also responsibility (as we have also seen in Chapter 7). And it is here that Ricoeur's fairly uneventful commentary becomes interesting. Without commenting on the detail of the ethic of principle and the ethic of responsibility, Ricoeur first insists that Weber shows a lot of respect for the ethic of principle of the Gospel and for the imperative of responsibly taking on the consequences of action by oneself this twofold respect prohibits Weber from taking pleasure in the thorny conflicts associated with political decision-making. Then, having posed this twin respect of Weber for the two political ethics, Ricoeur claims that Weber doesn't call for a rejection of the ethic of principle, since it is exactly because of the fact that the ethic of principle is "impregnable" (inexpugnable) ${ }^{38}$ that there is a problem (supposedly of the ethical orientation of political decision making). Furthermore, Ricoeur reads Weber to mean that

"for souls that are not dead, there is always a moment that can neither be planned, nor stipulated, when the ethic of principle blocks the person that acts according to the rule of responsibility and suggests, as Socrates' demon that said always no: 'Up to here, but no further [Jusqu'ici, mais pas plus loin].' It is not said either that this contradiction is without solution; it is rather a test [épreuve] in all the meanings of the word - and this test makes a choice inevitable."39

36 LI 235-240.

37 This is as far as I know, the only lengthy commentary of Ricoeur on this paper of Weber.

38 LI 240.

39 LI 240. 
This citation in which we find Ricoeur's reading of the coordination between the two ethics of politics of Weber is curious for a number of reasons.

(1) First, instead of declaring the ethic of principle a possible, but inappropriate ethic for contemporary politics (as Weber does), Ricoeur sees it playing an equal but different role from the ethic of responsibility in political decision making.

(2) Second, instead of elevating the ethic of responsibility to a level of principle (as I have shown Weber does), responsibility is bound in a tension with the ethic of principle that has its own independent role to play.

(3) Third, this role of the ethic of principle does not consist of shying away from or refusing to contemplate and assume the consequences of action (as Weber defines the ethic of principle), instead, the ethic of principle is redeployed as setting limits to the ethic of responsibility, that means in fact that the ethic of principle now consists of embracing the ethic of responsibility that contemplates and assumes the consequences of action within the limits set to it by the ethic of principle, in order to set those limits to it. This new role assigned to the ethic of principle is enforced by two further improvisations. On the one hand Ricoeur equates it with the Socratic "no"; one could perhaps see it as the negation that is the root of deontological thinking (see discussion below). On the other hand Ricoeur renders the words, attributed legendarily to Luther, in a very odd manner: "Jusqu'ici, mais pas plus loin" - not only does he not follow Julien Freund's translation (even though his paper was written to celebrate the new translation!), but also, although in meaning Ricoeur's translation corresponds with the Freund translation, it is an incorrect rendering of "ich kann nicht anders, hier stehe ich" (by which Weber cites Luther, but inverts the two halves of the phrase, $\mathrm{PaB} 448)$. Gerth and Mills translate: "Here I stand; I can do no other" (PaV 127); I translate it somewhat freely as "This is my position and it is impossible for me not to hold it" or "This is what I think is to be done and I shall not budge on it", but Freund translates it as: "Je ne puis faire autrement. Je m'arrête là!",40 ("I can do no other. I stop here!") and Ricoeur then: "Jusqu'ici, mais pas plus loin" ("Up to here, but not further"). This translation clearly serves the purpose of assigning an independent role to the "no" of principled

40 Max Weber, Le savant et le politique. Julien Freund (transl.). Raymond Aron (intro.), Paris: Plon, 1959, p. 199. The more recent translation by Catherine ColliotThélène reads very similarly: "Je ne peux faire autrement, je m'arrête ici." in Max Weber, Le savant et le politique. Une nouvelle traduction. Paris: La Découverte, 2003, p. 204. 
ethics. $^{41}$ This "no" is presented in Ricoeur's reading of Politics as a vocation as the pronouncement of a practitioner of the ethic of responsibility that has equally internalised the ethic of principle, understood as the setting of limits to the range of actions responsibly assumable. However, the words of Luther, in the mouth of Weber, seem rather to speak of assuming or the consequences and undesired side-effects of one's action.

(4) Fourth, while affirming that there is no theoretical solution to this conflict of ethical orientations (as Weber also does), Ricoeur claims that there is a practical solution possible (just as he claimed for the response to the political paradox). Since this solution is practical, cannot be dictated before-hand and thus constitutes a test (épreuve), it would be in order to call this an exercise of phronésis between the "excess" of political power and the "deficiency" of the moral prohibition. The phronetic choice is the moment of the exercise of power within certain limits; it is the practical manifestation of an "ethic of limited violence" as Ricoeur says in 1957. It is also this that Ricoeur identifies as the heart of the vocation of politics in the last sentence of his 1959 essay. In other words, if the vocation of politics consists of practising the ethic of limited violence, then it also consists of practically responding to the political paradox, notably by effecting control over the exercise of State power.

41 On reflecting about how to interpret the relation between the two kinds of political ethic, identified by Weber, Raymond Aron, in the introduction to the first French translation, concedes that there exists a veritable "antinomy" between the two forms of ethic. However, he thinks it nonetheless reasonable to expect that "in the majority of cases, prudence would suggest a reasonable compromise" ("Introduction" in Le savant et le politique, op. cit. p. 46). Compromise is of course necessitated by the conflicting nature of political interaction. Whereas the adherents of an ethic of principle refuse to engage with this conflict, the responsible political agent does engage with the conflict, yet, not without sometimes being forced to pronounce the principled ethical "no": "There is no responsible person who will not, one day or another, be forced to say 'no', whatever the price of it might be, weil er nicht anders kann, because he can not do otherwise." (p. 46).

Like Ricoeur, Aron identifies the voice of the ethic of principle with saying "no". Although Aron is not very clear on the coordination of the two ethics, he seems to believe that under extreme circumstances the ethic of responsibility transforms into an ethic of principle where the responsible agent is forced to say: "No, I don't budge, whatever the price". In this Aron is closer to Weber than Ricoeur. Ricoeur's "no" rather says: "here I yield, in order not to sacrifice what is of absolute value, to gain what is merely of great value". For this reason it seems implausible to identify Aron as the inspiration behind Ricoeur's peculiar reading of this point in Weber. 
In expounding his reading of the coordination between the ethic of principle and the ethic of responsibility, Ricoeur is manifestly quite far from the text of Weber, in fact, one learns in it much more about the thought of Ricoeur than of the thought of Weber. ${ }^{42}$ For the purposes of my argument this is a very valuable discovery: Ricoeur appropriated Weber's thought on politics and responsibility in such a manner that he could, as it were, read his own philosophical project from the text of Weber. And it is striking that the schema of realistic use of political power and violence, challenged by a deontological prohibition and thus requiring the arbitration of practical wisdom, as derived here from a reading of Politics as a vocation, will be the basic framework for reflecting on the normativity of political action in Ricoeur's "Little ethics" of the 1990s.

Let us, in conclusion, develop this point: what do we learn about Ricoeur's political thought from the emergence of the notion of the political paradox and the Weberian appropriation accompanying it? The political can be understood only under the figure of a paradox. Human beings striving for their fullest accomplishment through political existence need political force and even violence to constitute and realise this political existence; at the same time it is the means of political life that carries the possibility of evil abuse of that power. One could refer to the two dimensions of this paradox

42 In as far as a later text can be called to witness for an earlier one, the essay "Tasks of the political educator" (1965) (in Political and social essays. David Steward and Joseph Bien (eds.). Athens: Ohio University Press, 1974, pp. 271-293 / LI 241-257) confirms this rendering of Ricoeur's appropriation of Weber. Speaking of the difficult connections between politics and ethics, and thinking now more on an institutional level than an individual level, Ricoeur clearly states: "I want to say at once that I adopt as a working hypothesis, and I add as a personal guideline, a most fruitful distinction which I borrow from the great German sociologist of the beginning of this century, Max Weber." He is equally clear about what it is that he derives from Weber: "I am convinced, in fact that the health of a collectivity rests ultimately on the justness of the relation between these two ethics. On the one hand the ethic of principle is supported by cultural and intellectual groups and by confessing communities, including the churches, which find here and not at all in politics proper - their true point of insertion. On the other hand, the ethic of responsibility is also the morality of force, of methodological violence, of calculated culpability." (Political and social essays, op. cit. pp. 287-288 / L1 253, translation modified). What social health needs, then, is to maintain these two ethics in "a lively tension [...]. For if we reduce the ethic of principle to the ethic of responsibility, we will sink to political realism and Machiavellism, which results from the constant confusion of means and ends. But on the other hand if the ethic of principle pretends to a kind of direct action, we will sink to all the illusions of moralism and clericalism. The ethic of principle can only operate indirectly by the constant pressure which it exerts on the ethic of responsibility and power." (Political and social essays, op. cit. pp. 287-288 / LI 253-254). 
as the horizontal and the vertical aspects of the political. Whereas the horizontal aspect is presented in 1957 especially with the aid of Aristotle, Ricoeur will do so in the 1990s with the aid of Arendt ${ }^{43}$ - political power is seen as constituted by the will or desire to live together (vouloir vivre ensemble) that represents the teleological aspect of human social action. The deontological force of the contract theory, presented by Ricoeur in 1957 with reference to Rousseau, will in the 1990s be developed through a series of studies on Rawls. But the deontological moment of reflection on the political is provoked in particular by the drifts in the use of means of political action, that is, the means associated with domination, which is the vertical aspect of the political. Ricoeur still presents this vertical aspect in the 1990s with recourse to Weber's definition of politics as the monopoly on the legitimate use of violence. ${ }^{44}$ Even though the political will to live together and the eventual use of violent means by politics are fatally joined, Ricoeur will still insist on and elaborate his conviction that the political stretches beyond the sphere of politics and encompasses the other spheres of social action. ${ }^{45}$ The practical negotiation between the teleological and the deontological moment of ethics is a central concern for Ricoeur in the 1990s. Accordingly, the practice and limitation of politics through discussion ${ }^{46}$ takes an important place, amongst others, in Ricoeur's debate with discourse ethics. Also the reflections on the just extends the thought about the settlement of disputes, of conflicting claims. All of these points could serve to support Ricoeur's (implicit) claim that in his "Little ethics" and the elaborations on it, he was providing "a sufficient anchorage" for his previous and contemporary work on the paradoxes of political power (RF 80). And inversely, as will follow from the ensuing discussion, accepting the political paradox is a condition for the intelligibility of responsibility in its political dimension.

In order to make the transition from the 1950s to the 1990s and to enforce the legitimacy of the claim that Ricoeur is (amongst others) occupied with the Weberian concerns that I have formulated earlier, I shall find my point of entry to the "Little ethics" from a marginal essay of 1991.

43 On this, see Ricoeur's reading of Arendt, with the telling title: "Power and violence" of 1989 in LI $20-42$.

44 OAA $194 /$ SA 227.

45 LI 288, TJ 92 / JI 141, C\&C 101 / CC 156.

46 OAA 257-262 / SA 300-305. It should be noted that his exposition of discussion follows directly from a reference to the political paradox and Weber's concern about politics' defining recourse to legitimate violence in Politics as a vocationsee OAA 257 / SA 299. 


\section{FROM THE POLITICAL PARADOX TO ITS INTEGRATION IN THE “LITTLE ETHICS”}

The "Postface au Temps de la responsabilitê"47 could be considered a minor text in Ricoeur's work of the 1990s, not least because it is written as an overview and interpretation of a collection of essays by other authors. Consequently, in this text Ricoeur's concern is first with presenting the opinion of the authors of the book. However, at certain places his own voice comes through very clearly. In categorising the contributions to the book in two kinds, with regard to the way in which the notion of responsibility is treated in them, Ricoeur discusses first the opposition between a logic of responsibility and a logic of obedience, ${ }^{48}$ before turning to the opposition between an ethic of responsibility and an ethic of principle. ${ }^{49}$ The reason why I would like to comment on these latter few pages is that they neatly take up the question of the Weberian opposition between an ethic of responsibility and an ethic of principle where we left it at the end of the 1950s. However a number of terms that are crucial for Ricoeur's political and normative thought in the 1990s are attached to this pair - in such a way that I may claim that we find here, through a few remarks on the Weberian ethical categories, a small entrance to Ricoeur's later political thought.

First Ricoeur insists on the problematic nature of the distinction: does the categorisation of an ethic of responsibility and an ethic of principle mean that responsibility goes without principle or conviction? Likewise does it deny that principle or conviction ${ }^{50}$ invests people with responsibility? Having questioned the absoluteness of this opposition, Ricoeur advances by maintaining the close relationship between these opposed ethico-political approaches and reflection on the political. The close tie is due to the fact that the domain of the exercise of political power is a scene of conflict - between pragmatic political engagement and idealistic moral conviction. It is important to note that Ricoeur claims that this is a commonly acknowledged insight at least since Sophocles' Antigone, because it is exactly by means of a commentary on Antigone that Ricoeur introduces the notion of the tragic nature of action in Oneself as another, where it will be explored under the three dimensions of conflict (institution, autonomy, respect) in the ninth study (entitled "The self and practical wisdom: conviction").

47 LI 271-294.

48 LI $284 f f$.

49 LI $286 f f$.

50 For the sake of clarity, it needs to be recalled here that I consistently render Weber's Gesinnungsethik by ethic of principle, and thus also when commenting on Ricoeur's use of the term in the French translation as "éthique de conviction". 
It should, however, immediately be pointed out that the notion of principle (Ricoeur uses "conviction") as Ricoeur comments on it in the "Postface" and where "principle" denotes, in accordance with Weber's initial usage "an 'idealistic' invocation of moral values, without consideration for the consequences", 51 differs markedly (1) from its use in 1959 and 1965 where, without a clear definition it denotes a positive contribution of non-political intellectual, cultural and religious discourses to the health of a collective by remaining in constant tension with the political morality of force and violence $^{52}$ and (2) from its use in Oneself as another where conviction, together with argumentation, keeps the difficult balance between teleology and deontology. But as in 1965, Ricoeur here agrees with Weber that an idealist ethics of principle - that is not willing to face up to what defines the exercise of political power, namely the ultimate recourse to violence - is not worthy of our human reality. Rather, whoever wants to engage with the reality of political action and decision making is, according to Ricoeur, immediately caught up in the paradox of the political ${ }^{53}$ and thus he makes the link with his earlier political philosophy explicit. It is only when one enters this paradox of the "fragile conjunction" between the form (constitution and State of law in so far as they express the will to live together) and the force (origin and use of violence) of political action ${ }^{54}$ that one is confronted with the "tragedy of action" and hence, one might add, with the need for a practical solution of the paradox.

In fact, this paradox manifests itself also beyond the political sphere in all matters pertaining to the use of power in action and where the choices about the use of power are in effect political. ${ }^{55}$ To be quite clear, Ricoeur specifies that

"After all, the political is not a separate or additional sphere, but the place where decisions are made on the scale of those historical communities that are the nation States. The same problems will arise on the level of supra-state, European or global authorities." 56

This declaration is evidently of great concern for the current project, first because it states the terms of a general notion of the political dimension of action beyond the social sphere of politics, and secondly, because it already affirms the global reach of this principle.

54 Cf. OAA 257 / SA 299.

55 LI 288.

56 LI 288. 
Closely tied to this is the affirmation of the need for a restriction of responsibility by something - for which the name ethics of principle is at least a suitable place-holder - that would prevent the reflection on the use of means in responsibility slipping into a brutally one-sided calculation of efficiency. In fact, responsibility should be rooted in a "conviction" (or principle), of which Ricoeur now gives his own circumscription, namely "the obligation to help the fragile [périsable]". ${ }^{57}$ This re-definition of conviction is remarkable, not only because it clearly rejects the ethic of principle (or ethic of conviction) understood as "an 'idealistic' invocation of moral values, without consideration for the consequences" (as he did just before), but also as its new content embraces two ideas that are very relevant for the current project. First, the idea of "obligation" that is the key notion for the morality, for deontology, as part of Ricoeur's "Little ethics" between teleology and practical wisdom. In fact, if he here says that responsibility has to be moderated by conviction that has the form of obligation, he refers (and I guard against a too facile identification of the structures of the argument in the different loci of Ricoeur's work) to the coordination of the teleological and the deontological for which the conflict of practical ethical conduct calls. Second, this reading is reinforced when one considers that a few pages earlier, Ricoeur carefully appropriates Jonas's notion of responsibility, but particularly that part in which the Jonasian categorical imperative of responsibility is foregrounded as the appropriate way to respond to the new dimensions of human fragility:

"if the human being has become the fragile par excellence, the main moral maxim becomes the exercise of moderation, restraint and even of refraining from action.",58

Again the idea of limiting the scope of adoptable courses of action by a rule of conduct (maxime) is clear (even though it is done here, following Jonas, under the name of "responsibility" and not "conviction"!). One might at this point recall that in Ricoeur's 1959 essay the value of the ethics of principle was exactly said to be its force of saying "no!" in the face of the exigencies of political efficiency. ${ }^{59}$ The character of negativity, or rather the force of interdiction, we shall see, is the beginning of the moral order of obligation, since morality responds primordially with a "no!" to the violence committed by some against (the fragility of) others; but the interdiction implies already the ethical from which the "no!" of moral indignation draws it strength. ${ }^{60}$

57 LI 289.

58 LI 284.

59 LI 240.

60 OAA 221 / SA 258. A simple illustration of how this "no!" impregnates the power of the State can be found in "La justice, vertu et institution" (in La sagesse 
The specificity of the political is then this conflict between responsibility (as the effort to give form to the political by the means of politics) and conviction (or principle) of controlling the spontaneity of political action by the demand to help the fragile. Subsequently, if one wants to understand human action in its political dimension, beyond the sphere of politics, by taking into account ethical considerations (in as far as they can be shown to be philosophically credible) and the very nature of political action in whatever form, this short passage from Ricoeur's "Postface" makes a series of important suggestions. As normative should hold, not only considerations about obligation and interdiction, but equally reflection on where obligation and interdiction draw their strengths from; this should be done in full realisation of the tragic nature of human action. It is to these questions that we shall turn now.

\section{Political action between capacities AND CONFLICT}

From the earlier Ricoeur, we have seen that the central figure of thought of his political philosophy - the political paradox - is formulated, amongst others, by an appropriation of Weber's definition of the State as having a monopoly on the legitimate use of violence and of the idea of responsibility consisting in the sober use of the (ultimately, violent) means associated with political power. From the later Ricoeur, we have seen that this Weberian distinction and coordination is appropriated, albeit through a reinterpretation thereof, to set out the need for the limitation of or the control over the use of these political means. From this perspective one could consider Ricoeur's central notion of the political paradox as a manner in which he positions himself in the extension of a Weberian thought on political power and responsibility, more precisely, with respect to the half of the paradox which has to do with the inevitable recourse to the means of political power and for the question of its control, which is the question of the practical solution to the paradox.

pratique. Autour de l'oeuvre de Paul Ricoeur. Jeffrey Barash and Mireille Delbraccio (eds.). Amiens: Centre régional de documentation pédagogique de l'académie d'Amiens, 1998, pp. 11-28) where Ricoeur explicitly recognises the Weberian definition of the State by its monopoly on public violence (p. 12), but when it comes to the question of the death penalty, he insists: "But one thing is sure and that is that the State may not behave like the executioner and that there should be a kind of restraint, namely that State should prohibited itself [s'interdit] to act like a murderer." (p. 16). 
However suitable Weber's thought might be in the development of these key aspects of Ricoeur's political philosophy, it always has to be situated within a broader development of his political thought. The simplest way to show this is to point out that the first half of the political paradox hardly comes into view when one focuses only on the Weberian side of the paradox. This first half of the paradox is represented by the political, the essence of which is elaborated on in the larger ethico-political theory by the teleological formula: "aiming at the 'good life' with and for others, in just institutions". ${ }^{61}$ This formula encapsulates what Ricoeur calls ethics or the ethical (l'éthique) and it is only in the confrontation between ethics and what he calls morality or the moral (la morale) (that, without being identical to it, takes the place of Weber's ethic of principle), that a contextsensitive ethics of prudence can be deployed. With some reservations, that will be formulated later, it is the latter that gives us the best picture of what a Ricoeurian notion of political responsibility would look like.

The core of his ethico-political theory, first expounded in Oneself as another (published in 1990, and then further developed in essays during the decade that followed and of which most have found their way into the two volumes of Le juste), ${ }^{62}$ takes form by a reflection on action in which Ricoeur, not completely unlike Levinas, ${ }^{63}$ confronts this question of action by redirecting it to the question of the agent: Who is it that aims at the good life with and for others in just institutions? Therefore, in order to

61 OAA 172 / SA202.

62 An exposition of the philosophy of these books that cover the same terrain as the present subsection is Olivier Abel's Paul Ricoeur. La promesse et la règle. Paris: Editions Michalon, 1996. See also the presentation and appraisal of Ricoeur's "Little ethics" in Fred Dallmayr's "Ethics and public life. A critical tribute to Paul Ricoeur" in Paul Ricoeur and contemporary moral thought. John Wall, Willam Schweiker and W. David Hall (eds.). New York and London: Routledge, 2002, pp. 213-232.

63 Despite this similarity it is clear from the outset that Ricoeur's philosophical anthropological approach to the agent of ethico-political action differs considerably from Levinas' metaphysical or ontological approach. The most significant aspect of this difference is probably the importance attributed to pure passivity by Levinas and the accent in Ricoeur on capacities and self-esteem. Ricoeur captured this difference in a letter to Levinas (25 June 1990) by saying: "If there is between you and I some disagreement, it is to be situated exactly at the point where I maintain that the face of the other could be recognised as source of questioning [interpellation] and of injunction only if it turns out possible to arouse or to awake a self esteem [understood in terms of 'solicitude for others and justice for everybody' EW] (published as "L'unicité humaine du pronom je", in Ethique et responsabilité: Paul Ricœur. Jean-Christophe Aeschlimann (ed.). Neufchâtel: Editions La Baconnière, 1994, p. 37.). However a detailed comparison of the two theories of subjectivity is not the issue here. 
provide us with the orientation needed for our current exploration, a number of remarks are in order concerning the agent, the capable human being (l'homme capable), both in his/her capacities and in his/her constitution. This consideration of (and for) the capabilities of the agent will form the background to what I want to draw from Ricoeur in the project for a theory of responsibility "after Levinas". The competence of political agents to determine and execute responsible action in sensitivity for the normative restriction of efficiency, but also in cognisance of the complexity of praxis seem already to be major components of this theory (whereas, as argued before, they are neglected by Levinas). But in order to show how Ricoeur could be useful in this regard, the entry of the ethical and the moral on the scene of the agent's existence has to be presented as well. These two issues the capable agent and the ethical - represent the two axes of the chart on which Ricoeur's ethico-political reflection can be mapped out: ${ }^{64}$ the horizontal axis being the dialogical constitution of the self and the vertical axis representing the hierarchy of predicates applicable to action and to agents - "ethical", "moral" and "prudent". Lets recall the main traits of these two axes in turn, before exploring their intersection in more detail. ${ }^{65}$

Saying that one could represent the constitution of the self on a horizontal axis entails that the self, in isolation and in the singular, is for Ricoeur only an abstraction of the person that is continually constituted by others. These are the nearby others, the "you", but also the anonymous others, "he or she" or "everyone". This triad of first, second and third person should thus be seen as a relation of dialectical constitution of the self. ${ }^{66}$ Furthermore the constitution by an interpersonal alterity of the second person and an institutional alterity of the third person ${ }^{67}$ should be considered equally original. At the same time the agent requires the mediation of the others in order to develop and actualise his or her capacities into powers, which in turn find their realisation or deployment in similar relations to the others. ${ }^{68}$ The capacities in question here are those of speaking, acting and suffering, narrating about oneself, and presenting oneself as a subject of ethical imputation. It is only

64 Cf. TJ xii / JI 13.

65 There are a number of core aspects of Ricoeur's approach that I shall not look at here: the "epistemological status" of claims about the ethical agent (the entire issue of attestation), the language pragmatics in which Ricoeur's argument is embedded, the problematisation of the is/ought-dilemma by Ricoeur and the justification of discourse on the ethical, the detail of the dialogical constitution of the self. It is only the limits of the current use of Ricoeur that could justify such a thematic restriction.

66 RTJ $60 /$ JII 72.

67 TJ $5 /$ J 34.

68 TJ 5/JI 33-34. 
by the deployment of these four kinds of capacities that someone can identify himself or herself (each time as a "self", rather than a direct introspective and free standing "I") and show esteem for himself or herself. In fact by deploying its capacities the self shows its care ${ }^{69}$ for its life, and for that of others, and is situated in the force field of desire and lacking that stretches towards the accomplished or good life. ${ }^{70}$ This teleological directedness of the self is not so much a description of the normal human inclination to the good (but does at least not exclude such inclinations), but rather an optative through which it is affirmed that a life would indeed be good in which the self would care for himself/herself with and for the others in just institutions. ${ }^{71}$ It should already be added here that while the telos of teleology is the good, what this good entails is a matter of uncertainty ${ }^{72}$ and thus the issue of uncertainty will infiltrate the "Little ethics" from the beginning.

Let's look at the essence of the activation of self-esteem through the four capacities. This always happens through relationships and interactions of reciprocity or of recognition with the nearby others, that is, in solicitude $^{73}$ and/or through institutions with everybody, that is, in justice. ${ }^{74}$ It is, furthermore, important to emphasise that Ricoeur is especially concerned with the distributive mode of justice, which allows him to visualise the institutions (that are responsible for just distributions) in a very broad way:

"every institution as a schema of distribution, of which the portions that have to be distributed are not only goods and merchandise, but rights and duties, obligations and tasks, advantages and disadvantages, responsibilities and honours." ${ }^{, 75}$

Distribution as a function of institutions includes sharing, participation and distinction. ${ }^{76}$ If the deployment of capacities always involves selfesteem, solicitude of others and just institutions, it could be shown to be the case in all four of these capacities.

Through the first capacity, that of speech, a person identifies himself or herself by engaging in speech acts in exchange with interlocutors and by adopting the institution of language (that is sharing and participating in

69 LI 259, LII 208.

70 TJ xi / JI 16.

71 Cf. LI 259.

72 LI 178.

73 LII 205.

74 LII 206.

75 LII 206.

76 OAA 200 / SA 233; prendre part as Ricoeur says in LI 180, presenting a vision of social participation not unlike that of Norbert Elias. 
its existence) that belongs to nobody in particular, but of which a distinct use is made at that moment. Or: someone says something about something to somebody ${ }^{77}$ in a certain language. The same pattern marks the deployment of the second capacity, that of acting. By acting, the self identifies himself/herself in interaction with other people and these actions take shape under the social institutions of the "rules of the game" or different kinds of measures of excellence with which all actions comply to a greater or lesser degree and that help us to identify them as ways of participating in the myriad of social practices and playing certain roles, ${ }^{78}$ Or: someone does something (or undergoes something) in interaction with somebody, according to standards of excellence that constitute practices.

The capacity of narration, as third in the series of four, foregrounds the temporal development of the agent of speech and action. By narrating his or her existence, the agent establishes his or her identity. This happens once again in a dialectical implication of the others with whom one's life-narrative is shared or entangled and through which the constitutional triad unfolds. These other narratives include those of the institutions with whom one interacts and even fictive narrations. Furthermore, through narration a dialectic of identity as sameness (idem, immutability) and identity as selfness (ipse, selfhood) is worked out.

In all three of these capacities of the agent, care (for the self, the nearby others and the just institutions) gave a distinct teleological directedness to the parallel threefold realisation thereof. This is only partially true for the fourth capacity, that of self-assignation of imputability. In order to get the full picture of this capacity, one has to return for a moment to the capacity of action. Whenever one considers the interaction of people, there are often not only active agents, but also those that passively undergo action. Action often entails the power of some over others and thus the possibility and reality of the infliction of harm. ${ }^{79}$ Here the "no" of prohibition and its imperative expression, the obligation, are called for, ${ }^{80}$ since the infliction of harm is an attack on the very capacities of the other and it is these that are truly worthy of respect in a person ${ }^{81}$ and that one has to recognise to have self-respect. The ethics of teleo-

77 LII 212.

78 LII 215-216.

79 LII 216.

80 OAA 218 / SA 254. As Ricoeur explains in RTJ 235 / JII 271, the moral plane of reflection is needed because of the potential for conflict for which ethics, by the sole resources of teleology, cannot provide the necessary arbitration.

81 LI 163. 
logical valuation of action in self-esteem has to be doubled by a deontological valuation in self-respect. In other words, the capable agent has to identify himself or herself through the considered application of the predicates "good" and "obligatory" on actions and retrospectively on their agents and himself or herself as the person that makes the judgement. ${ }^{82}$ The fourth capacity is, then, special in the sense that it includes the other capacities: it is as capable of self-identification as the person that utters speech, as the actor of action and as the protagonist-narrator of narrations that one could be considered worthy of self-esteem and self-respect. ${ }^{83}$ Therefore, this capability of ethics in the true sense of the word, is also deployed in the interpersonal dimension (e.g., in agreements and promises) and with others in just institutions, the latter including especially all the institutions of law, up to the international level.

With this last capability, we have also started to present the vertical axis of Ricoeur's ethico-political theory, which concerns the attribution of evaluative predicates on three levels. The first level of ethical judgement is the teleological and is encapsulated in the formula: the desire for the good life, with and for the others, in just institutions. If it is accepted that the discussion of the teleological dimension of ethics as given above suffices for our present purposes, the second level can be presented in more detail.

For Ricoeur the deontology is the moral aspect of the attribution of evaluative predicates and concerns the aspiring of the teleological towards the good under the regime of the moral law, that is, the formalisation of obligation by which the optative essence of teleological directedness is submitted to restriction. ${ }^{84}$ Detached from teleological concerns, the moral refers to the universalistic ambition of obligation. ${ }^{85}$ Hence Ricoeur's predilection for the Golden rule as formulation of morality as prohibition against the infringement on the dignity of the other: "do not do unto others what you would not have them do to you". 86 The indignation with which this imperative or rather prohibition responds to violence is rooted in the reciprocal recognition of self-esteem in solicitude (and mutatis mutandis in just institutions). ${ }^{87}$ Here, on the moral level, one can see again the relatedness of the self to the others. This relatedness is not merely a supplement to the selfrespect for the autonomy of the moral self; rather the respect for the others as

82 TJ $4 /$ JI 32.

83 TJ $4 /$ JI 33.

84 OAA 204 / SA 238.

85 OAA 238 / SA 276.

86 Cf. elaboration OAA 219/SA 255.

87 Cf. OAA 222 / SA 258. 
an end goal in itself is co-constitutive of self-respect. Just as self-esteem is complemented by solicitude and justice, so personal autonomy (and selfrespect) is complemented by communitarian and cosmopolitan autonomy. ${ }^{88}$ Or, one could equally say that the moral obligation is complemented by the formal norm and by legality. The latter represents the institutional incorporation of deontology as nourished by the contractualist tradition of political theory and where justice refers to procedural formalism. ${ }^{89}$

However, when considering the question: "what then shall we do in this situation?" one is immediately confronted with the tragedy of action: the tension between the singularity of particular cases and the generality of obligation, the conflict between obligations and the complexity of life in society. ${ }^{90}$ Thus one is forced to the third level of ethical judgement of action, that of prudence or practical wisdom. This is not a third independent source of evaluative reflection, but emerges from redirecting the formalism of morality back to ethics under the conflicting circumstances of the situation of ethical praxis. ${ }^{91}$ If practical wisdom requires the relativisation of the universality of the moral imperative, because of the historically particular circumstances of action or because of the particular claims of certain people, then this does not mean abandoning the moral imperative in order to embrace a flat arbitrariness, ${ }^{92}$ but to keep the tension between the ethical and the moral. Or in a later reformulation of the relation:

"On the one hand, we can take morality as the plane of reference in relation to which a fundamental ethic that is anterior to it and an applied ethics that is posterior to it are defined. On the other hand, we can say that moral philosophy in its unfolding of private, juridical, and political norms constitutes the transition structure that guides the movement from the fundamental ethics to applied ethics, which gives moral philosophy visibility and readability on the plane of praxis.",93

88 RTJ 237 / JII 273, similarly OAA 238 / SA 277.

89 But here, the correct coordination of contractual thinking - the inspiration of Arendt or Rousseau on the one hand and Rawls on the other - is important. See Abel, Paul Ricoeur. La promesse et la règle. op. cit.: "Before being this procedure of reciprocal regulation that will play an important role in the second approach to justice, the contract is thus the act through which a common will is instituted. In this sense, just as in Rousseau the social contract is an implicit and retrospective pact that has not taken place but that is the presupposition of all political existence, the real contract has to be rediscovered incessantly together like a forgotten project that precedes all our rules. The political is nothing other than the rootedness of institutions in this fictitious pact." (p. 53).

90 RF 81.

91 OAA $250 /$ SA 291.

92 OAA 241 / SA 280.

93 RTJ 56-57 / JII 68. 
However it is then formulated, the power with which this dialectic between the ethical and the moral is played out in practice, is carried by conviction that effects the mediation in coordination with argumentation. ${ }^{94}$

But the insistence on the conflicting and tragic nature that this mediation can take on, doesn't mean that all situations are of the nature of distress, but that prudence exactly creates space for reflection on it and that the possibility of tragedy in ethical decision making always has to be taken into account. For the conflict that arises then in the situation of practical application, a practical solution has to be found (like in "The political paradox"), and this not only in self-reflection, but in consultation with others and in engagement in public debate. 95 Furthermore, since "the principles of justification of a moral or legal rule leave the problems of application intact" tion" is a notion of interpretation, the tradition that mediates the application of universal norms to particular situations should constantly be submitted to interpretation in prudent reflection. ${ }^{97}$

This synopsis suffices to map out the terrain in which Ricoeur works out his ethico-political theory. A self that can identify himself or herself as the capable agent of speech, action, narration and imputation, is constituted by the other - those close by, but also by everybody - and in interaction with the others these capacities can be deployed. This is the horizontal axis. Driven by the desire for a flourishing or good life, but already under the impression of the problem of conflict and violence, the self seeks the realisation of the good life under examination of the universal and formal obligation, but also in full cognisance of the complexity of the situations of application. This is the vertical axis. The ideas interpreted in this synopsis represent the indispensable orientation for the subsequent detailed exploration of a number of aspects of this theory, within the framework of my own project.

\section{Responsibility, PRUdence, COLLABORATION, EQUITY}

Having presented the broad schema of Ricoeur's ethico-political thought, we can now enter some of the detail thereof, equipped with my own project as agenda for this exploration. This will be done in three movements: first, a number of clarifications with regard to the situation of Levinas' ethics in re-

94 OAA 287 / SA 334

95 OAA 257-262 / SA 300-305.

96 RTJ 243 / JII 279.

97 RTJ 243f / JII 280. 
lation to Ricoeur's framework will be presented; second, the uncertainty concerning the exact place and function of the notion of responsibility in Ricoeur's "Little ethics" needs to be focused on in order to highlight that there is no short-cut for adopting Ricoeur's insight for this project and; third, it will be argued how this theory of Ricoeur's can be expected to contribute to the elaboration of my project and provide pointers in the development of a political notion of responsibility for a globalised world.

\subsection{Remarks on the resources: Levinas and Ricoeur}

As declared earlier, the intention of introducing Ricoeur in this study about Levinas and responsibility is not to work towards a comparison of the two authors. ${ }^{98}$ Instead, the question is how Ricoeur can help to give an improved grasp on my project of a political responsibility after Levinas. This doesn't mean that the value that such a confrontation between Ricoeur and Levinas could have for the current theme is denied, but simply that it falls outside of the current thematic and strategic delimitation.

However, although I shall thus not enter into the detail of the profound philosophical arguments concerning, especially ontology, alterity and the constitution of the subject, my strategy of using Ricoeur to enhance my post-Levinasian project necessarily involves at least an implicit confrontation between the "resources" or most fundamental thought of these two philosophers. For that reason, I consider it desirable to at least give an account of the structural differences between the two philosophies. I shall do this

98 The comparison between the two philosophers has naturally been the subject of exploration and dispute. The contributions of Patrick Bourgeois and of Richard Cohen in Ricoeur as another. The ethics of subjectivity. (Richard Cohen and James Marsh (eds.). Albany: State University of New York Press, 2002) are worthy to be highlighted as valuable, since they represent two strong, opposing answers to the question concerning the correctness of Ricoeur's interpretation of Levinas and with it the relation between Levinas and Ricoeur. It should be clear that my reading of Levinas and Ricoeur is much closer to that of Bourgeois than to that of Cohen: the formidable scope of enterprise and the strength of the sovereignty of the Levinasian political subject (as I interpret it) seems to me to be the consequence of the strong emphasis on exteriority of the other as regards the ethical (emphasised in Bourgeois' mostly approving reading of Ricoeur's interpretation of Levinas). And if in "accepting the role of solicitude in human existence, Ricoeur has developed a place within interiority that really allows a response to the face of the other." ("Ricoeur and Levinas: Solicitude in reciprocity and solicitude in existence", in Ricoeur as another, op. cit. pp. 109-126, here 122) then he also allows for taking the opinion of the other about matters ethical seriously and thus taking the other as agent of ethics seriously - to a point I doubt possible in Levinas. 
by highlighting a number of significant divergences of Levinas with respect to the framework of Ricoeur that has been presented above.

(1) In Ricoeur's development from the first person to the second and third person, the self is doubly constituted by the other and this on the plane of reciprocity. In Levinas the priority of the second person other is indisputable in the absolute asymmetry between the self and the other; this asymmetry is so radical that, on the level of ethics the other overwhelmingly defines the self. Furthermore, not only is the place of the third person other underdeveloped in Levinas, but there is no clear indication of the relation between the other and the thirds, or their irrelation is simply expressed as contradiction. ${ }^{99}$ However, on the level of politics this contradiction is the resource of a fraternity of eternally asymmetrical relations.

(2) Ricoeur presents the triangular unfolding of the identity of the self in relation to the other as the expression of the different dimensions of selfesteem and thus of esteem for the life of the self and of the others with whom it is directly and institutionally linked. This teleological moment of the self would, for Levinas, be equal to the conatus, the perseverance in the ontological identity and as long as the alterity of the other is not sufficiently recognised, the affirmation regarding the constitution of the self by the other risks sliding into the identitary or indifferent force of participation with all of the potential violence lurking within it, as discussed in Chapter 2.

(3) There is in Ricoeur a dramatisation of the coordination between teleological ethics and deontological morality - both find their realisation in the dialectical relation to each other that is expressed in practical wisdom. Levinas fuses the teleological (that is condemned as inevitably conspiring with the dark side of ontology) and the deontological (in the sense of the unconditional imperative emanating from the other and the negativity of that imperative in the "thou shalt not kill!"') in the double, ontologicalethical, constitution of the subject, and of which the ambiguity of ageing (discussed in Chapter $1, \S 2.1$. and Chapter 5, $\S 3$ ) is the easiest manifestation. $^{100}$

99 Didier Frank convincingly argues that Levinas reduces the complex relationship (the political) to the simpler one (the face-to-face) and tries to derive the complex from the simple. This should be regarded a considerable weakness in his approach to the political. Cf. Didier Frank (L'un-pour-l'autre. Levinas et la signification. Paris: Presses Universitaires de France, 2008) p. 237.

100 I am fully aware that these are not Levinas' terms and that I present him with the tools borrowed from another artisan. This could be allowed at least for the strategic purposes outlined in this Chapter. 
(4) Even though there is no development of practical wisdom in Levinas, his description of the constitution of the quest for justice (cf. Chapter 7, §2.2) sufficiently marks the place in his philosophy where that should be situated. For Ricoeur reflection on ethics culminates in a reflection on practical wisdom.

(5) Whereas in Ricoeur, situations of tragedy necessitate a recourse to the ethical despite the validity of the moral, in Levinas the law is to be challenged by what is even more moral than the law, namely that for which the unspeakable imperative "thou shalt not kill!" holds the place.

(6) Whereas the question of the capacity of the self is central for Ricoeur and finds its culmination in imputation, the self in Levinas is always elected, independent of whatever capacity; this election is simply imposed or assumed passively. But this difference on the level of the constitution of the subject has implications for the political situation of the subject. Strictly speaking, every Levinasian subject is isolated in his or her responsibility for the others, in the sense that nobody can be responsible in the subject's stead. Furthermore, this responsibility draws all of its resources from a constitution independent of that of the life in a State. For Ricoeur, on the other hand, the question of the form of the State and the respect due to the others are ultimately rooted in the capacities of the citizens. ${ }^{101}$

(7) Since, for Ricoeur, ethical agency is constituted in relationships of reciprocity and recognition and mediated institutionally, ethical action can be coordinated between different agents or executed alone. For Levinas nobody can take my place and any collaboration can only be understood as and accepted in as far as it is an extension of my irreplaceable obedience to the other. Any reciprocity or recognition is already an expression of the attempt to answer in responsibility the appeal of the others. Consequently, all initiatives at institutionalising and mediation of ethical conduct would, for Levinas, merit at least a healthy dose of suspicion.

101 "On the contrary, an anthropology that makes a place for the notions of the capability to act, dispositions, development, realisation, can give account of the fact that the capabilities that we quite rightly consider as immediately worthy of respect can flourish only in societies of a certain form, and thus their development is not possible in simply any political society. And yet, if the individual becomes human only under the condition of certain institutions, then the obligation to serve those institutions is itself a condition for the continued development of a human agent." (LI 163). And one should add that this central position accorded to capacities and institutions in turn implies the significance of the technologies associated with the capacities and institutions (which is not the same as adopting a technocratic approach to politics). 
(8) For Ricoeur the force behind the improvement of justice is the force of the political, of the will to live together. By contrast, for Levinas, the force for the improvement of justice resides in the individual agent's orientation by the ethical imperative and the plurality of these imperatives, which result in the strength to override or call to greater justice the legal system that is in force at a certain place and time.

In these points the most salient differences in the ethico-political profile of Levinas and Ricoeur are sketched. This should suffice to contrast them with respect to their deepest philosophical orientations in matters ethical and the political thought that is nourished by these orientations, which lead to the divergent contributions they would make to a debate about political responsibility. In accordance with the demarcation of the present study, I remain as far as possible agnostic regarding the ultimate philosophical issues presupposed by the work of Levinas and Ricoeur, in order to devote my attention to matters that ensue from it. For this reason it is important to insist that the point at which Ricoeur enters this project is not on the level of the debate of the ultimate philosophical concerns, but limited to the level of the elaboration of the four requirements for a political notion of responsibility (see Chapter 8 ), that were already a step away from Levinas' own thought.

Now, whereas the notion of responsibility is evidently a key notion in his thought, thus far nothing has been said about Ricoeur's contribution to the question of responsibility (accept, of course his commentary on Weber's notion thereof). The reason for this temporary exclusion needs to be explained. It is necessary to give a review of the complicated attitude of Ricoeur with regard to the notion of responsibility, since it is only by doing so that I can complete the justification for the stated manner in which I shall attempt to make his thought useful for the current project.

\subsection{Ambiguity concerning Ricoeur's use of the notion of responsibility}

It would certainly be too simplistic to understand the thrust of my argument as replacing a defective Levinas with a correct Ricoeur. This cannot be the case, not only because of the manner in which I inscribe my reflection in the continuation of central aspects of Levinas' thought (see end of Chapter 6), but also because Ricoeur, in the development of his ethicophilosophical theory, attempted to incorporate important aspects of Levinas' thought into his own and therefore it seems incorrect to schematise the re- 
lationship between the two philosophers as that of two mutually exclusive alternatives. ${ }^{102}$ There is a further significant reason why one could not simply open Ricoeur's work and draw from it a theory of responsibility in its political dimension and this is the uncertainty concerning the status of the notion of responsibility in Ricoeur's later thought.

It seems that in the later work of Ricoeur there are at least three somewhat divergent uses of the notion of responsibility.

(1) It is, first of all, used as synonymous for "imputability". The fourth question by which to enquire about the identity of the capable agent "who is the moral subject of imputation?", 103 is sometimes simply formulated as "who designates herself as the morally responsible author of her acts?". ${ }^{104}$ Likewise, Ricoeur would claim that without a subject that could have self-esteem through being capable of acting intentionally and of initiating action, there would be no "responsible subject". ${ }^{105}$ And with a different emphasis and some reservations, Ricoeur explains that only in so far as a subject is capable of situating his or her action under the obligation to conform to rules and to assume the consequences of action, can that subject be called responsible. ${ }^{106}$

(2) In spite of Ricoeur having equated responsibility and imputability, he immediately then opens a gap between the two notions. If responsibility is to be taken as a synonym for imputability and if imputation means first of all the capacity to assume on one's account an action, then responsibility means first of all Zurechnungsfähigkeit, the capacity to have an action placed on one's account as it were, that is, not "to respond to" in the first place, but giving an account of one's actions or admitting to having authored them. ${ }^{107}$ But this means that there is also another meaning of responsibility, in which the "responding to" is dominant and in this sense is not the same as imputation. In "The concept of responsibility. An essay in semantic analysis" "108 this difference despite the similarity between imputability and responsibility is worked out by tracing the historical development by which "responsibility" as a notion branched off from "imputability". "Responsibility" changed from simple

102 See again Bourgeois, "Ricoeur and Levinas: Solicitude in reciprocity and solicitude in existence", op. cit. pp. $122 \mathrm{f}$.

103 OAA $169 /$ SA 199.

104 TJ $23 /$ JI 55.

105 LII 205.

106 RTJ 82 / JII 96.

107 RTJ 82-83 / JII 97.

108 TJ $11-35 /$ JI $41-70$. 
attribution (that is, imputation) to obligation (especially in law), and from there the explosion of its use filled it with ambiguity in law (withdrawal of the meaning of imputation and inability in the tendencies of attribution of penalty and culpability for those that commit mistakes). A proliferation of meanings also developed in moral philosophy. The latter entails a shift in the object of responsibility (e.g., from responsibility for one's actions to responsibility for the other, in Levinas) or the unlimited extension of the scope of responsibility (e.g., for future generations, as in Jonas) and in both of these cases there is increased emphasis on prospective responsibility, rather than on retrospective responsibility (of which imputability is a species) and a consequent undermining of the component of the identifiability of the subject of responsibility (due to the lapse of time between consequence and initial action, or due to the complexity of the causal network that makes the calculation of what responsibility is taken for very hazy). When Ricoeur then concludes that the subject of responsibility becomes ungraspable (insaissable) and diluted (dilué $)^{109}$ we have arrived very close to the opposite of the initial idea (in point 1.) of responsibility as the capacity of imputation. In fact, the prudence that Ricoeur proposes as corrective to the (legitimate) issues expressed in the new moral philosophies of responsibility, depends on a stronger emphasis and valuation of the capacity of imputation. In this sense this course of examination presented by Ricoeur doesn't amount to a plea for the abolition of the moral theories of responsibility, but for a considerable rethinking of them, starting by anchoring them anew in the agent that is capable of imputation.

(3) Between these two extremes of convergence (synonymy) and divergence (or firm distinction), is a third, positive place accorded to the notion of responsibility in Ricoeur's ethics. In the conclusion to the "Little ethics" and, in fact, to the first nine studies of Oneself as another ${ }^{110}$ Ricoeur recapitulates the contribution of the three ethical studies not only to the reflexive identification of the self by ethical judgement, but to the entire set of capacities of the capable human. If Ricoeur explains the title of the book right from its first pages by the threefold question concerning the identity of the "who?", then the conclusion following the ninth study provides a comprehensive answer that can be given only once the entire course of the exploration of the capacities of speech, action, narration and ethico-moral judgement has been followed through. Let it be recal-

109 TJ $34 /$ JI 69.

110 OAA 291-296/SA 337-344. 
led that the threefold question concerning the "who?" consists of (1) the question concerning the reflexive identity of the self (soi) through mediation by speech and action, (2) the question about the dialectical identity of sameness (identity-idem) and selfness (identity-ipse) and (3) the question regarding the dialectical identity of selfness through alterity. ${ }^{111}$ The exploration of ethics provides answers to these three questions while at the same time drawing on the three other capacities (speech, action, narration) and in this sense recapitulates the entire movement of the response to these three questions concerning oneself as another. ${ }^{112}$ For each of these three answers a name could be given to encapsulate the response that is only possible to give once the fourth, the ethical, capacity has been reached. The encapsulating term for reflexive self-identification is imputation, the term for the dialectical identity of sameness and selfness is responsibility, and the term for the identity emerging dialectically from the self and the other is recognition. Imputation designates the self as capable of attributing statements or actions to himself/herself through the mediation of the ethico-moral predicates (good, obedient, just, prudent, etc.). ${ }^{113}$ Recognition

"is a structure of the self reflecting on the movement that carries self-esteem toward solicitude and solicitude toward justice. Recognition introduces the dyad and plurality in the very constitution of the self."

Between the two, responsibility refers to the continued selfidentification or "self-constancy" [maintien de soi-même ${ }^{115}$ that remains in dialectical tension with the mere duration of empirical sameness of the ethical agent through the vicissitudes of time and the adventures of ethics that it entails. Ricoeur elaborates on this by examining the temporal aspects of responsibility. The prospective or future aspect of responsibility refers to assuming the future consequences (intended or not) of actions; the retrospective or past aspect of responsibility refers to the assumption of actions (committed by oneself or not) or the recognition of debt. But "[h]olding oneself responsible now, is

111 Cf. OAA 1-4/SA 11-15.

112 We have seen a similar movement at work in one of the texts used to introduce the question of the identity of the ethical agent and his/her capacities: "Approches de la personne" (LII 203-221) and "Who is the subject of rights" (TJ 1$10 /$ JI 2-40).

113 OAA 291, 293 / SA 338, 340.

114 OAA $296 /$ SA 344.

115 OAA 295 / SA 343. 
[...] accepting to be held to be the same today as the one who acted yesterday and who will act tomorrow". ${ }^{116}$ Furthermore,

"this responsibility in the present assumes that the responsibility of the consequences to come and that of a past with respect to which the self recognises its debt are integrated in this non-pointlike [non ponctuel] present and in a sense recapitulated in it." 117

Even if the notion of responsibility proposed here by Ricoeur includes imputation (described previously), it is certainly non-synonymous with it, in fact it rather represents a further development the idea of imputation. Likewise, one could consider recognition as an extension or further development of the notion of responsibility.

Instead of attempting a superficial conflation or harmonisation of these three uses of "responsibility" by Ricoeur, or even worse, making a choice between them, I shall take a step back in order to situate the issue at stake in each of them within the broader framework of Ricoeur's ethico-political theory, that I approach from the point of view of the political paradox. Since such an approach is justified by nothing more than the aims of the current project, my point is obviously not to propose a "rectification" of Ricoeur's use of "responsibility", but just to examine the ways in which he could be said to contribute to the construction of my own development on "responsibility".

Three things are sure about this "practical solution" to the uncertain position of the notion of responsibility in Ricoeur, and with them I shall proceed on my alternative approach to finding Ricoeur's contribution on responsibility. First, accepting the first sense of responsibility as imputability is the condition for thinking with Ricoeur about matters ethical; second, the third sense should be considered as an expansion of the meaning of the first and with this statement the question of the further expansion of the use of the term in a Ricoeurian frame is opened; third, it could be accepted that the second sense is concerned with theoretical problems in contemporary theories of responsibility ${ }^{118}$ and could thus be considered a negative contribution to considerations on the use of the term. All three of these statements affirm that Ricoeur's ethical theory remains the major stake of the use of the term "responsibility" and hence for current purposes it could be acceptable to refer the issue of the polysemy in Ricoeur's use of it back to the frame of his ethics sketched earlier.

As stated, in what follows certain aspects of Ricoeur's ethics will be discussed in greater detail, notably from the perspective of the political paradox.

116 OAA 295 / SA 242, translation modified.

117 OAA 295 / SA 243.

118 Cf. also RTJ 159 / JII 185. 
The reader will recall that I have shown that the political paradox could be presented as a reformulation of Weber's concerns in the paper in which he developed his theory of political responsibility. This is the perspective in which I want to bind all considerations about responsibility, since it is the perspective from which I have tried to develop a project for political responsibility out of Levinas.

Let us now consider some of the aspects of Ricoeur's contribution to the developed fourfold project of political responsibility. ${ }^{119}$

\subsection{Towards a political responsibility for a globalised world}

For the sake of clarity, let it be recalled that the notion of "political", as it is used here, concerns something broader than one of the spheres of social reality. In fact, it includes all human relationships, with the possible exceptions of (aspects of) close interpersonal relationships. The political refers to the broad power of the will to live together (Arendt) and is the furthest implications of the teleological aim of human life. But the power of the political is necessarily bound up with the political paradox: in order for political power to realise itself, it has to adopt means appropriate to that realisation (see Weber on the means of the political), but those means carry at the same time in them the possibility of their violent use and misuse. The political paradox is thus a form of the tragedy of human action. Since this is the case, the question concerning the limitation or control of these means has to be asked, and in Ricoeur's reinterpretation of the ethics of principle this entails the affirmation of the obligation of restraint. The assumption of the use of political means and the consequences thereof, that Weber designated as an ethic of responsibility, has to be placed under control by the force of obligation - Ricoeur's reformulation of the relationship between Weber's ethic of responsibility and ethic of principle turns out to be the tension between the teleological and deontological sides of his "Little ethics". But this tension doesn't resolve the political paradox, instead it continually calls for a practical response to it, which is reflected on by Ricoeur under the term of practical wisdom or prudence. If the summit of responsibility is for Weber the coordination of responsibility and principle by elevating responsibility to a principle, then for Ricoeur the summit of ethical

119 For an exposition of political responsibility on Ricoeur's own terms, see Bernard Dauenhauer, Paul Ricoeur. The promise and the risk of politics, op. cit. Chapter 8: "Political responsibility". Although Dauenhauer gives full recognition to the fact that, in Ricoeur, the political extends beyond the sphere of politics, his presentation thematises mainly responsibility for or in connection with the political sphere. 
action is the practical solution of the eternal tension between the ethical and the moral in practical wisdom. The way in which Ricoeur opts to think through this complex issue that leads up to prudence situates the "who?" of this practical wisdom in the centre. He also refers to this being as a person or the subject of law or again the capable human. With my Weberian perspective on Ricoeur, it may be permissible to call it the agent of political responsibility.

Central to the motivation for seeking in the Ricoeurian agent of political responsibility an ally in reflection on political responsibility after Levinas, is the fact that Ricoeur engages with the capability of the agent and consequently also facilitates reflection on the means of agency (whatever the status of the capability and the nature of the means might be). Let it be recalled here that a number of problematic issues with the ethical subject in Levinas seemed to necessitate this continued reflection on responsibility that I undertake in this Chapter: behind all of the insufficiencies concerning reflection on coresponsibility, the complexity of application to a practical context and the mediatedness of action, is the blind-spot concerning the nature and dimensions of the competence of ethical agents. One could be perfectly ethically constituted as Levinas has it, but fatally clumsy in subsequently translating that ethical constitution into appropriate action. This is of course not to say that an acquisition of certain skills and knowledge programmes an agent to more ethically acceptable conduct, but simply to recognise that the practise of ethics is not at all without relevance for the meaning of the ethical. If Ricoeur, then, draws our attention to the capacities of ethical agents, it will neither be to ignore the role of the other in the constitution of that agent, nor to establish a set of requirements for effective ethico-political agency, but to open the discussion of ethics to a reflection on who the agent is or how the capacity to act ethically is constituted. By referring the question about ethics to a philosophical anthropology of human capabilities (to Ricoeur's homme capable), an approach is adopted in which the competence of the ethico-political agent is taken seriously, since capacity immediately implies the distinction between degrees of capability, and thus of excellence or the lack of it or of sufficiency in it. This means that if we are from the outset concerned about the capacity of ethical agency that it will facilitate reflection on: (1) strategy, calculation and sacrifice; (2) the distribution of roles, the dimensions of responsibility and coresponsibility; (3) the context of action and its institutional and instrumental dimensions in particular and (4) the dilemma of the exception and equity - in short, the four objectives for reflection on a notion of political responsibility "after Levinas", as outlined in Chapter 8. This insistence on the capability and excellence of the ethical subject doesn't mean that the meaning of "for the other" is interfered with or compromised, but simply that we cannot merely 
be concerned about the "that" of ethical agency, without this implying the importance of the question of "how?" or "what?" of excellence. Ethical action is not an all-or-nothing matter; excellence doesn't exclude the possibility of the fairly good sufficing in certain circumstances. This conviction is of course Aristotelian. But this shouldn't surprise us, since the entire discussion concerning Ricoeur headed for a re-appropriation of phronésis.

How would reflection on the phronetic capacity of ethical agency contribute to the four objectives set out above? In answering this question I do not only confront the four objectives that crystallised from my Levinas-WeberApel reading with the insights gained in this Chapter from Ricoeur, but simultaneously formulate my view - in as far as it can be developed in the present book - on the development of a theory of political responsibility for a globalised world.

The first point on the agenda is that of strategy. If the question regarding strategy arises from the affirmation of the importance of competence and means for ethics, then it is rooted deeper still in the rejection of cosmic-ethical realism. The positive formulation of this rejection is in the affirmation of tragedy, of "the unavoidable nature of conflict in moral life". ${ }^{120}$ Ricoeur's entire effort in moral theory could be considered as an attempt to show how this crucial recognition of tragedy in human action calls for ethical reflection that is appropriate for practice, while avoiding both arbitrariness and univocity. ${ }^{121}$ Only a practical wisdom that engages with the situation or context of its realisation, while remaining informed about consideration that transcends the mere factual particularity of the situation, can accomplish this task. Therefore, responsibility, in order to be responsible, has to be more than the name for ethicity, but has to anticipate the consequences of its practice, which in turn implies the question of the optimisation of those consequences in terms of obedience to the meaning of the ethical. That is why applied ethics (les éthiques) cannot be understood as mechanical application of context-independent principles to situations, as a blind casuistry. ${ }^{122}$ Instead applied ethics is ethics as it applies itself through phronetic engagement with the situation. That is why applied ethics cannot be considered as separate from ethical reflection; its distinction from ethics resides in the specialist insight that it generates concerning specific contexts or cases in which the ethico-moral dialectic has to realise itself, just like the political that strives to realise itself through politics.

120 OAA 243 / SA 283.

121 OAA 249/SA 290.

122 "We can say that moral philosophy in its unfolding of private, juridical, and political norms constitutes the transition structure that guides the movement from the fundamental ethics to applied ethics, which gives moral philosophy visibility and readability on the plane of praxis." (RTJ 57 / JII 68). 
Responsibility thus benefits equally from reflection on ethicity and by reflection on its practical realisation. But this reflection is always done in the face of practical conflict and not as a programming of action towards inevitable success. Responsibility is practice in the face of moral conflict - the incomparable has to be submitted to comparison as Levinas so aptly says, which implies the need for prioritisation and even sacrifice. The practical solution of ethical situations of conflict, through responsible action, affirms and, in this sense, maintains the conflict associated with the situation, while attempting to show itself as prudent response to it. That prudent responsibility is sacrificing responsibility should be considered an inevitable concession. ${ }^{123}$ However, while affirming the inevitable role of calculation in the assumption of responsibility and the tragic dimensions it can assume in certain cases, we must avoid regarding the conflict involved in responsibility as evenly spread over all situations of responsibility, lest we risk contaminating the entire notion of responsibility with an unremitting pathos of the sole agent agonising in every act of decision making. Because responsibility is serious, it strives to realise itself strategically, which may allow for division, formalisation and variation in complexity and collective assumption (all, evidently, in varying degrees, depending on the context).

Responsibility is not one. The demands of strategy naturally differentiate responsibility out into different forms and dimensions of responsibility which are in turn inevitably bound up with institutions, means and other dimensions of the context of action. These have been indicated to be the second and third points on the agenda for an alternative notion of responsibility. One could perhaps say that responsibility doesn't simply concern a "here I am, responsible for others", but that it has the form of someone being responsible for other people (for the consequences of what is done or not done to them), in ways determined by different social roles, within certain institutional frameworks, where the competent use of certain means will be required and where the specifics of each of these elements may be submitted to revision according to the circumstances of its application.

That responsible people are responsible as members of societies seems to be the primary lesson to be derived from Ricoeur's extension of the aim of the good life to political existence - and to this should be added that one should at least count with the other members of society as probable agents of responsi-

123 But Martha Nussbaum is correct, at least in principle, to call for the claim that loses out in the phronetic decision to be kept in play; the fact of its being cancelled as the decisive claim through a practical decision doesn't take away from its initial validity in the tragic conflict between competing claims. See her "Ricoeur on tragedy: teleology, deontology and phronesis", in Paul Ricoeur and contemporary moral thought, op. cit. pp. 264-276. 
bility (which is not the same as to claim that all members of society devote their lives in responsibility to others). If one wants to avoid thinking of oneself as the last bastion of ethics (which is the hallmark of fanaticism ${ }^{124}$ ), in other words, if one simply seriously engages with the question of efficiency of responsible action, one would naturally be lead to the issue of co-responsibility. And this in turn entails taking other people seriously as agents of responsibility. They have to be taken seriously, not only because one has to collaborate with them, but also because one is constituted as an ethical agent in numerous ways by the others.

In fact, the plurality of agents of responsibility in society do not simply act in a haphazard and uncorrelated fashion - they interact and this interaction is supported and conditioned by an array of institutions by which actions are correlated. In Ricoeur's broad use of the notion of institution structure is given to interaction by language and different social practices. Institutions are the mode of living together of others that are not close by (although the relationship with the "you" is not completely without mediation from institutions) and they pre-exist the life of the individuals that are involved in them. In fact institutions are that by which one becomes human in the way that one does and it is through institutions that one acquires the capacity to act, ${ }^{125}$ possibly responsibly. They are all characterised by a "teleology that regulates action", ${ }^{126}$ where regulation refers to the distribution of roles (including privileges, obligations, control over goods, etc.) by which people participate in the institution. ${ }^{127}$ In this manner institutions are societal structures by which equality of distribution (i.e., proportionate equality) could be aimed at, even though it should also be counted amongst the traits of institutions that they do not succeed in distributing goods, obligations, risks, etc., justly. ${ }^{128}$

In his presentation of social institutions, Ricoeur doesn't only prepare his reflection on justice (which will be focused on below), but he has a clear social theoretical objective, namely to overcome the opposition between the sociologism of Durkheim and the social individualism of Weber. ${ }^{129}$ This social theoretical aspect of the theory of institutions is of considerable importance for reflection on responsibility, since it contributes to a fair understanding of what human action and interaction in general, and therefore responsi-

124 But also of saintliness. However, the point is here to confront the ambiguity of saintliness, rather than to dispute the possibility of saintliness having laudable consequences.

125 OAA 254 / SA 296.

126 LII 215.

127 OAA $200 /$ SA 233.

128 Cf. LII 207.

129 OAA 200 / SA 234, LI 180 
ble action in interaction with others, entail on a social theoretical level. Since the agent of responsibility is always constituted by participation in institutions, he/she always has to take these forms of mediation into account in interaction with the third: not only to know one's own capacity of action, but also to gain insight into the network of social interactions that distributes the consequences of one's action. As true as it might be that injustice lurks in all forms of institution, so it is true that it is not possible to do away with all aspects of institution at the same time - one needs the benefits of institutionalised interaction and one's institutional constitution in order to counter, for instance, systemic injustice. As such, institutions are not only a major aspect of the socio-historical context on which one has to act, but an aspect that mediates the context to agents of action and interaction.

If one is then constituted by institutions that impose a certain form and coordination on action as interaction with other agents of responsibility, it seems inevitable to give serious consideration to the question of coresponsibility. In a situation where interaction is regulated by the institutional distribution of roles and everything that is associated with it, one could, first, identify the respective forms of excellence involved in the practice of certain roles and, second, differentiate different forms and dimensions of responsibility that fit with these roles and their capable execution. ${ }^{130}$ Again, this doesn't suppose that all institutions are just, or that the capacities acquired by playing all roles are good. But when all competence is condemned as conspiracy with injustice, one leaves the bearer of responsibility without any means. Under normal circumstances (I shall question this term in the Conclusion) some practices can be considered acceptable means of supporting other people.

The roles and dimensions of responsibility, then, stand for the acceptance of certain limits, qualifications or specialisations of responsibility, when considered under the perspective of interaction and co-responsibility. Often roles are the incarnation of certain principles laid down for the bearers of office. This is the original sense in which the term responsibility was used as an ethico-political term. In this sense role-associated responsibility has a deontological character. However, even this deontology can be confronted with conflicting demands in particular situations that would necessitate a hermeneutics

130 More of the detail concerning competence, excellence and the constitution of practices and their interrelation can be read in OAA 175f / SA 206f and LI 163. This reflection, which evidently engages with such neo-Aristotelian philosophies of virtue as that of Alasdair MacIntyre, clearly has important implications for the consideration of the relationship between ethics and means, which will be turned to shortly. 
of prudence - as Ricoeur's numerous studies on medical ethics sufficiently illustrate.

Whether in the form of restricted roles of responsibility or a certain prudent adaptation to the demands of practical dilemmas, responsibility has to reckon with the demands of compromise. ${ }^{131}$ But the recognition of coresponsibility makes it possible to introduce expertise and negotiation into the process of compromise. Expertise has the potential to prevent responsible agents rushing into decisions in domains where they have no competence. But expertise is only one of the forms in which consultation, discussion or exchange of views forms part of negotiation or dispute. This conflict of opinions regarding what should be done crosses the entire field laid bare by the political paradox, by the tension between the will to live together in just institutions and the means by which this is to be realised. There is no reason to adopt an overly irenic image of what this entails. Discussion is a form of conflict by which decisions are made that cannot be settled by scientific or dogmatic means. ${ }^{132}$ And these decisions are in principle forever open to revision. On a more radical level, even the aims and form of discussion and the legitimisation of power could be submitted to revision. ${ }^{133}$ In extreme cases the very nature of dominant practices can be challenged, that is, justice could be questioned in the name of equity - to this I shall turn in a while.

But before doing so, I need to stress a last aspect of Ricoeur's contribution to the issues of the roles of responsibility and the context of its application. This concerns the ultimate extent of the context of action and thus the ultimate horizon for deliberation about responsibility. It seems that Ricoeur would agree that this ultimate horizon is the entire humanity. He insists on the fact that

"human action takes on its first meaning only when it is crowned by the activities relating to the quest for a good government, whether it be that of the city, the nation of humanity as a whole."134

Elsewhere he refers to the extension of justice over the entire humanity as ideal, ${ }^{135}$ which takes form in reflection on the international order. ${ }^{136}$ The de-

131 Of the particular character of compromise in Ricoeur, Abel gives a valuable articulation in Paul Ricoeur. La promesse et la règle. op. cit. pp. 104-106.

132 OAA $258 /$ SA 300.

133 OAA 258-261 / SA 301-304.

134 LI 162.

135 LI 182, and I see no reason why this should not be taken literally, since Ricoeur also says: "The citizen that results from this institutional mediation can only wish that all humans would enjoy in the same manner this political mediation, which, apart from being one of the necessary conditions noted by a philosophi- 
velopment of reflection on justice to this scale is in any case made inevitable by the emergence of an increasing number of post-national or supra-state institutions, amongst which are those that have legislative powers. ${ }^{137}$ The conditions of this global extent of ethico-political reflection are referred to in his "Postface au Temps de la responsabilitê"138 where Ricoeur evokes development, technology, geopolitics, and the threat to the environment or the economy - that can be taken as indications of the will and need to transcend the national boundaries in political reflection. ${ }^{139}$ This implies that the teleological optative aiming at the good life in just institutions, as well as the imperative against injustice and their dialectic in prudent decisions of justice should all be considered, ultimately, in their global dimension. This is implied in the very definition of the ethical, since justice

"adds to solicitude, to the extent that the field of application of equality is all of humanity". 140

If the universal claim of the moral imperative through human rights cannot rid itself of its particular formulations, then this is an indication that the dispute (referred to above) concerning these "universals" has to be conducted on a global scale, since

"only a discussion on the concrete level of cultures could say - after a long history that is still to come - which claimed universals will become the recognised universals". ${ }^{141}$

The fourth point on the agenda for a reflection on political responsibility after Levinas concerns equity. Responsibility seems to me an appropriate term

cal anthropology for the transition of the capable human being to a real citizen, also becomes a sufficient condition thereof." (LI 40).

136 LI 193. The passage in question is devoted to the idea of a "just distance".

137 TJ $93 /$ JI 142.

138 LI 272f, 275f, 277, 286, 288.

139 See also Fred Dallmayr's reflections on the global relevance of Ricoeur's ethico-political thought in "Ethics and public life." op. cit. pp. 214, 228-229.

140 OAA 202 / SA 236. One could also consider who the everybody (chacun) is that constitutes the political dimension of the ethical teleology. Could this "everybody" be limited by membership of political institutions (in the narrow sense of "political"), like citizenship? Would it not be more coherent to consider the "everybody" with whom one would live in just institutions as all those with whom one has or could have an institutionally mediated relation (in the large sense)? This would mean that "everybody" is incorporated into the ethical teleology by all de facto exchanges, whatever the nature thereof might be. Whatever Ricoeur's opinion on this matter might be, this conclusion leads immediately to the dimension of globalisation and the texture of social ties as they are mediated technologically.

141 LI 268. 
through which to approach the question of equity, since responsibility is an ethics of uncertainty, ${ }^{142}$ compromise and sacrifice. By acknowledging this, the idea is not to celebrate tragedy, but to do justice to ethics. Equity concerns exactly justice, its credibility and its desirability or commendability, ever since the fifth book of the Nicomachean Ethics. Keeping justice just, in other words keeping the socio-historically contingent institutionalised expression of justice true to the originary signification of the ethical, is Levinas' concern in his attempt to coordinate ethics and justice. In this sense Levinas could be said to contribute to a theory of equity. But it was also the interference of the ethical in the domain of justice that posed problems in Levinas' philosophy (see Chapter 6).

Ricoeur is eminently aware of the need to accompany reflection on justice with reflection on equity, and to accompany reflectively, in turn, equity as far as possible. As far as possible, since equity represents, for Ricoeur, a species of ethico-political conflict. In order to grasp the contribution that he could make to the question of equity in a notion of political responsibility, one has therefore first to recall how he understands justice. The just, says Ricoeur,

"faces in two directions: toward the good, with respect to which it marks the extension of interpersonal relationships to institutions; and the legal, the judicial system conferring upon the law coherence and the right of constraint". ${ }^{143}$

This is a precious schematisation, first, because it systematises the double position that Ricoeur accords to reflection on justice (namely at the same time in teleology and in deontology), second, because it underscores the inevitable recourse of justice to the means of its realisation and, third, because it links justice to the tension inherent in the political paradox between the horizontal will to live together and the inevitable vertical exercise of force. As a result, the concerns reaped from Ricoeur's reading of Weber's notion of political responsibility (notably the legitimate use of violence and the control over it) could be located here. ${ }^{144}$ At the same time, through the analyses of the teleological and the deontological perspective on justice (that will not be retraced in detail here), one is inevitably guided towards the conflict be-

142 Compare this with what Ricoeur writes about practical wisdom in the preface to The just: "the just in the final analysis qualifies a unique decision made within a climate of conflict and incertitude." (TJ Xxi / JI 24). As such, practical wisdom is a model for responsibility.

143 OAA 197 / SA 231.

144 There is an explicit return to the notion of the political paradox as well as Weber's definition of the political in terms of the monopoly on the legitimate use of violence in the subchapter concerning conflict and institutions in the ninth study of Oneself as another (OAA 257 / SA 299). 
tween justice as the good and justice as legality and thus to the repetition of the question of justice in the sphere of prudence or practical wisdom. It is only when reflection on justice has covered this long trajectory that it can elevate itself to the status of equity. ${ }^{145}$

The conflict concerning justice, to which prudent consideration has to bring arbitration, arises especially from the fact that the qualitative heterogeneity of goods to be distributed is equalised out by the legal process of distribution that imposes a quantitative homogeneity. Ricoeur sees especially two versions of this: conflict concerning the primary social goods, and the contextualist or communitarian form of claims that limit the universalism claimed for rules of justice. ${ }^{146}$ Hence the intricate confrontation of Ricoeur with Walzer and Boltanski and Thévenot on the one hand, ${ }^{147}$ and with Habermas and Apel on the other hand. ${ }^{148}$

But instead of entering these debates, I aim directly at the core of the question of equity. Ricoeur identifies this core by his answer to the double question: why would political practice be the site of specific conflicts and in what way do these conflicts refer us to the ethical meaning (le sens éthique) of justice? ${ }^{149}$ Ricoeur gives his response to this double question, his interpretation of the constitution of the question concerning equity, by taking recourse to the political paradox. ${ }^{150}$ There is a conflict particular to the practice of politics because of the fact that the hierarchy of domination of politics (la politique) tends to cover and obscure the power of politics (le politique), yet the purely horizontal power of politics can generate no truly political action without the vertical structures of political domination. ${ }^{151}$ Since Ricoeur rejects the Hegelian solution of the State "erected as a superior agency endowed with self-knowledge", ${ }^{152}$ he counts on the plural or public dimension of phronésis. ${ }^{153}$ This prudent dispute by which the horizontal and vertical dimensions of political conflict are arbitrated is played out on three levels of radicality (alluded to above). The prudent way to dispute justice is to descend gradually through the discursive modes of political practice:

\footnotetext{
145 OAA 250/SA 291.

146 OAA 251f/SA 293.

147 See especially "The plurality of instances of justice" (TJ 76-93 / JI 121-142).

148 See especially "The universal and the historical" (RTJ 232-248 / JII 267-285).

149 OAA 256/SA 298.

150 OAA $256-257$ / SA 298-299.

151 OAA 257/SA 299.

152 OAA 256/SA 298.

153 OAA 261 / SA 304.
} 
"[1] from that of institutionalized political debate in pluralist democracies to [2] that of discussion about the ends of good government (security, prosperity, equality, solidarity, and so on), and finally [3] to the level of the legitimation of democracy itself' ${ }^{154}$

One can gauge the importance that this three-storey presentation of the prudent solution to conflict in matters of justice would have for reflection on political responsibility by considering how it responds to the weakness concerning equity in the implications of Levinas' theory of justice (which was a major point of Chapter 6). ${ }^{155}$ (1) One can be engaged in these different levels of dispute of justice only if the other is recognised - at the very least in the capacity of opponent - as valuable in the struggle to find what one could consider as greater justice. In this way the charge of responsible changes brought to justice as legality, in the name of justice as the good, is placed on the shoulders of many. (2) The way in which one participates in such a struggle and the way in which one thus recognises the other as responsible agent, changes from one level of radicality to another. This entails the assumption of roles and dimensions of responsibility appropriate for each of the respective levels of dispute. In other words, the very challenge of justice in the name of equity is tied up with the institutional distribution of roles of responsibility - this role-bound responsibility is shed only gradually, which means at the same time assuming other roles with other responsibilities. (3) The exposition of the levels of conflict indicates an appropriate degree of polemics determined by the degree of conflict. At the same time it is implied that certain capacities would allow for responsible participation in the dispute at each of the levels. (4) All three of these levels of dispute represent ways of calling justice to greater justice, by referring legality to the aim of the good life in just institutions. As manifestations of public phronésis they serve to arbitrate between the teleological and deontological dimensions of justice, but evoke already the question of the $e x$ ception: every challenge to the generality of the law, with recourse to the particularity of specific cases, in other words every appeal to equity, calls for arbitration. Furthermore, with every level of dispute, the extent and the stakes involved are increased, but the alternative of all-or-nothing is postponed to the very last. And even if that point is reached, equity remains another name for justice and this becomes pertinent in the face of the failure of the law to do justice. That is why equity as justice refers to the very last reaches of the appeal to it, to a long trajectory of arbitration:

154 OAA 284-285 / SA 330, discussed in OAA 257-262 / SA 300-305.

155 It should also be considered that the three levels of dispute discussed here are typical of the domain of politics, but that similar structures for the institutionalisation, conducting and even generation of dispute in other domains could be explored. Ricoeur's studies on medical and legal ethics testify to this fact. 
"Equity $[\ldots]$ is another name for the sense of justice, when the latter traverses the hardships and conflicts resulting from the application of the rule of justice."156

Or inversely:

"there would not be a problem of equity in unique situations unless there were a general problem of justice capable of universal recognition."

In all of this, I do not suggest that Levinas' take on justice excludes such reflection, but only that there is no way in which his thought on ethics could enable him to introduce it and that the reflection on the practical recourse to equity is not of secondary importance to the meaning of ethics.

In this consideration about disputed justice, it stands out that the prudent arbitration of conflicts (the comparison of the incomparable as Levinas would say) remains the culminating point in the attribution of the predicate "just". Thus the just could be called the "good" (in the teleological perspective) or the "legal" (in the deontological perspective) or "the equitable" when the just concerns the exercise of judgement in a particular situation. Equity, says Ricoeur, is

"the figure that clothes the idea of the just in situations of incertitude and of conflict, or, to put it a better way, in the ordinary - or extraordinary - realm of the tragic dimension of action". ${ }^{158}$

Furthermore, this reflection on the tragedy of action and the response of practical wisdom necessitates reflection on the conscience, as the ultimate seat of arbitration:

"It is at this stage that the moral conscience, as an inner forum, one's heart of hearts, is summoned to make unique decisions, taken in a climate of incertitude and of serious conflict." 159

This "climate of incertitude and of serious conflict" is where the reflection on the intensifying dispute of justice in the name of equity leads; these are situations where the intensity of uncertainty places particular pressure on the individual conscience:

"When the spirit of a people is perverted to the point of feeding a deadly Sittlichkeit, it is finally in the moral consciousness of a small number of individuals, inaccessible to fear and to corruption, that the spirit takes refuge, once it has fled the now-criminal institutions." 160

156 OAA 262/SA 305.

157 RTJ 247 / JII 284.

$158 \mathrm{TJ}$ xxiv / JI 27.

$159 \mathrm{TJ} \mathrm{xxi} / \mathrm{JI} 24$.

160 OAA $256 /$ SA 298. 
We have to examine Ricoeur's position on this problem, since it was the recourse to ultimate means by the isolated individual that has been shown to have a dark side in Levinas' ethico-political thought.

In order to examine Ricoeur's contribution to this locus of the problem one has to step outside of the "Little ethics" in Oneself as another to the discussion of the "great kinds" in the tenth Study, where the conscience is discussed under the heading of the self and the other. ${ }^{161}$ One should, to start with, shed all illusions concerning a supposed clarity of the conscience:

"Conscience is, in truth, that place par excellence in which illusions about oneself are intimately bound up with the veracity of attestation." 162

\section{Furthermore:}

"left to its own judgment, conscience will never be rid of the tendency to confuse good and evil, and [...] this very confusion remains the fate of conscience left solely to itself.", 163

Since this is the case, the exploration of the conscience should resist the temptation of a self-celebrating auto-justification of the conscience ${ }^{164}$ and rather take the humbler way of dispersing the alternative of a good and bad conscience. The reinterpretation to which Ricoeur submits the triad of ethics, morality and prudence in terms of alterity, points to an understanding of the conscience as attestation-injunction. This means that what is indicated by the metaphor of the voice of the conscience is the passively undergone injunction to live well with and for the others in just institutions and to which the bearer of conscience attests through self-esteem that expresses itself in the optative: my I live well with and for the others in just institutions. ${ }^{165}$ Formulated briefly, in Heideggerian parlance,

"[c]onscience, as attestation-injunction, signifies that these 'ownmost possibilities' of Dasein are primordially structured by the optative mood of living well, which mood governs in a secondary fashion the imperative of respect and links up with the conviction belonging to moral judgment in situation."

And ultimately this judgement in a particular situation and the decisions ensuing from it rest with the individual that is called by the conscience:

161 The philosophical register in which this is done, is one that I have been avoiding in this book, but that is evidently not irrelevant to the current thematic. However, it is not the present objective to enter the debate about the "great kinds".

162 OAA 341 / SA 394.

163 OAA 345/SA 397.

164 OAA $347 /$ SA 400.

165 OAA $351 /$ SA 405.

166 OAA 352 / SA 406. 
"it is always alone that, in what we called the tragic character of action, we make up our minds. In measuring up to conviction in this way, conscience attests to the passive side: 'Here I stand! I cannot do otherwise!' [Ici je me tiens! Je ne puis autrement!]."

In these words we have arrived at, what is for Ricoeur, the narrowest and ultimate space of conflict and arbitration. We recognise, of course, the words of Luther, cited by Weber to express the climax of his exposition on political responsibility and that has been our companion throughout this Part. One would also recall that Ricoeur had, quite early on, appropriated these words to express the need to submit the exercise of political domination to control, to set a limit to what politics may allow itself to do. By returning to these words even if it is without an explicit reference to Weber - Ricoeur deepens the implications of their meaning within his ethico-political theory. The ultimate seat of responsible decisions concerning the political is the individual conscience. However, unlike the case in Levinas, the injunction recorded by the conscience is immediately captured by the self-esteeming self that is called to live the good life with and for the others in just institutions, which means that the recognition of the other as affected conscience is even in the extreme cases, not far away. Also, the space for reflection concerning the means and appropriateness of their use in response to the injunction, is already implied in the injunction. But at this point one enters the debate about the status of alterity on a level about which I remain, for the present study, agnostic.

Yet, it should be stated unambiguously that for Ricoeur too, the ultimate decision concerning the situation of exception, the exceptional character of such a situation and the concomitant compromises and even sacrifices that have to be made, reside with the individual capable agent as inspired by the call of the conscience. This is the conscience of which Ricoeur has acknowledged from the outset that it is

"that place par excellence in which illusions about oneself are intimately bound up with the veracity of attestation", 168

and that

"left to its own judgment, conscience will never be rid of the tendency to confuse good and evil, and that this very confusion remains the fate of conscience left solely to itself', ${ }^{169}$

For this reason, Ricoeur's presentation of the conscience doesn't amount to a self-justification of a good conscience. 


\section{CONCLUSION}

For a "good enough" justice

Through the preceding Chapters I have searched for a way in which to think with Levinas, but also "after" Levinas. My attempt has consisted of a series of exercises by which, next to the central theses of his thought, detailed exegesis of marginal aspects of Levinas' work and explorations of inherent tensions in his work have been combined and subsequently submitted to amplification in confrontation with authors from the Weberian tradition, in order to gain a passage to a refigured conception of political responsibility for a globalised world.

The trajectory was launched by an insistence on the primordial political nature of the responsibility presented and advocated in the thought of Levinas. Responsibility is not only the name for ethicity, but it is at the same time a wisdom that is "urgent" and that by its very nature seeks its realisation in the fragile existence of people that are all too often exposed to different sorts of violence. Responsibility is political, because it is concerned with the fate of the plurality of others and the responsible agent always has to coordinate and prioritise the relative urgency of the others' respective contemporaneously valid appeals to that agent's responsibility. This political dimension is proper to all responsibility, whether practised in the framework of the social sphere of politics or not. In fact, political responsibility is called for in all domains of human interaction and also on the scale of all human interaction. This holds from the local to the global scale of all matters that would solicit or complicate the execution of responsible action; the ultimate horizon for reflection on political responsibility is the global scale of humanity, with the intricate relations of States and other global role players, of cultural and interest groups. Reflection on the history of colonisation and decolonisation throws this horizon of responsible action into relief. 
The perspective from which Levinas' response to these challenges to responsibility has been presented is that of a humanism of which the root is not an essence of the human being, but the ethical obligation imposed by the other. This theme finds expression in certain writings prepared for a Jewish setting and where it furthermore resonates in a Jewish cultural politics by which Levinas reinterprets Jewish particularism in order to give it a new pertinence for the socio-political and intellectual situation of the Diaspora Judaism in France. The humanism of the other is given full philosophical expression in the book in which the major concerns of Levinas' work - the decisive origin and sense of all meaning in the context-independent ethical imperative imposed by the other on the self are gradually developed in the form of thinking of his later period.

It is particularly the political implications of this thought of Levinas that is critically examined. Whereas the good intention and seriousness with which Levinas confronts the issue of responsibility cannot be questioned, it seems that there are possible unexpected and undesirable sideeffects that could be engendered by his radical and limitless understanding of responsibility. More important than this probably marginal (but even so, serious) slide, is that the difficulty that Levinas' ethics has in dealing with the profound contradiction between the appeals of the plurality of others, with the unlimitability of responsibility and with reflecting upon the competence and means appropriate for responsible (in other words political) action within a particular historical context are exposed.

When these aspects of the political implications of Levinas' theory of responsibility are carefully studied, the marked difference between responsibility considered on the level of ethicity and responsibility considered on the level of its political enactment becomes clear. It is the wager of the third Part of this book that the range of political implications of responsibility should be developed and submitted to further reflection. This has been prepared by identifying Levinas' double "polytheism", consisting, first, of the impossibility of finding an ultimate arbitration between the conflicting claims of different cultural (and other) perspectives (for which he proposes ethics as unifying meaning) and, second, of the annoying fact that the political agent is always confronted by a multitude of conflicting and incommensurable claims to his/her responsibility from the side of the others, which has to be arbitrated in a world where the agent of such arbitration will constantly be in conflict with other similar agents regarding the best arbitration. Once this is recognised, Levinas' notion of responsibility turns out to be much closer to Weber's than one would believe when considering only the first philosophy of the ethical meaning of the single 
other. In fact, by amplifying the political implications with the aid of Weber, one can identify the importance of thinking about the consequences of action embarked on in responsibility. The consequences of action and the means adopted to realise justice contribute to the meaning of the ethical.

By analogy with Apel's recognition that even a deontological theory inevitably has to incorporate reflection on the consequences of responsibility, a four-fold programme for subsequent reflection on political responsibility has been outlined, consisting (at least) of elaborations (1) on strategy and sacrifice, (2) on forms and dimensions of responsibility and coresponsibility, (3) on the context and means of responsible action and, finally, (4) on the confrontation of responsibility with its limits in equity and the question of the exception. These four elements have been clarified with the help of Ricoeur, represented from the perspective of his appropriation and reinterpretation of Weber's ethic of responsibility. The complex constitution of practical wisdom in Ricoeur's ethico-political thought shows itself to be suitable to elaborate the intricate web of considerations that has to be held in tension when thinking about political responsibility. Whereas this trajectory suffices to indicate how I think responsibility in its political dimension can be thought after Levinas, a full development of such a theory of responsibility will have to be the project for another book.

My critic will not have failed to notice that, with respect to the difficult, unconditional and self-sacrificing justice of Levinas' ethics, the way forward that I propose for reflection on political responsibility entails a certain abatement. And since this abatement is associated with the effort to think realistically about the insertion of responsibility as ethicity in the world of its practical effectuation, one might be tempted to attribute an extreme cynicism to this project. But is the darkest cynicism not rather to be found in Levinas that condemns the entire tendency of politics, in fact, of Being itself, as a flux of violence? Is it not perhaps facile to criticise my moderation with respect to Levinas' position when the latter advocates the unconditionality of demanding responsibility against a pitch dark night of violence? Whereas I see no reason to adopt a rosy view of politics and its potential, the absolute denigration of human history makes the appeal to eschatology - that, after all has to be mediated, realised, by people - possible and thus the negative effects of the recourse to ultimate means can be written off against the account of the allpervasive evil ontology. If, on the contrary, one wants to maintain the seriousness of responsibility, but at the same time remain vigilant with respect to the recourse to ultimate means and heroism, one does a favour to the concerns of Levinas to pull them into a Weberian sphere of 
thought, in as far as this means integrating considerations regarding the means and consequences of responsible action, as they can be identified for a specific moment in history, into the very meaning and understanding of what responsibility is.

I could state my position somewhat differently. It is not my intention to evacuate the radicality attributed by Levinas to responsibility, but to accompany that radicality reflectively as far as possible, since that radicality cannot be assumed to be an a priori good when put to political action. It would be a caricature to suppose that such a reflective accompaniment would entail taming responsibility by a programme that would remedy the fallibility of ethical agents. Rather, it should be recognised that the fallibility of responsible agents and the complexity of the world in which they have to act, submit them to an unfortunate degree of incompetence. The human condition of responsibility is one of meagre moral luck. That is why the reflective accompaniment of responsible action will always be something of what Marquard called the competence to compensate for incompetence. This compensation for our moral un-luck means, in a world where it cannot be assumed that action out of good intentions will lead to desirable consequences, that one does better to recognise that there is an interval between the ethical constitution of the agent of responsibility and the exceptional, tragic and totally self-sacrificial exercise of that responsibility. If it can be conceded that there are situations that do call for the ultimate self-sacrifice, it seems nonetheless ill-advised to construe all forms of responsibility as derivatives of that exceptional manifestation of responsibility. Rather, prudent responsibility requires adaptation of the demands and forms of responsibility in correspondence with the degree of instability of the context in which responsible action has to be deployed. Equity is the figure under which different degrees of questionability of a state of justice can be challenged, in a way appropriate to that situation.

But is it not true, then, that there might be situations that are so exceptional and where the social institutions of responsibility are destabilised to such a degree, that it is incumbent on the individual agent of responsibility - despite his/her lack of skill or insight into the situation - to take whatever measures available to oppose a state of injustice? As hard as my criticism of the possible fanatical slide in a Levinasian ethics might be, I cannot see how the possibility of such "states of exception" can be ignored. Both Apel and Ricoeur have been indicated to affirm as much. This is also the central problem in Arendt's troubled reflections on personal responsibility. ${ }^{1}$ It is for this reason

1 See Hannah Arendt, Responsibility and Judgment. Jerome Kohn (ed.). New York: Schocken Books, 2003. Considering the case of Nazi Germany, Arendt is con- 
that I have described the dramatic self-sacrifice towards which the Levinasian political agent may head as ambiguous: political saints are not only known throughout history for having sown chaos and destruction through their fanatical pursuit of justice; other saints have also faced the most adverse circumstances in the most praiseworthy manner - for other people and at the expense of their own lives. This ambiguity seems to me possible to recognise only if one doesn't abandon Being as such to pitch-black evil, but sees it in its shades of grey, as it were, and thus realises that the intensity of action that drives the two extreme possibilities of this ambiguity apart, is only gradually arrived at as the call for responsibility approaches regions of increasingly complex, troubled and unstable action, and where the call for equity gives increasing credibility to considering the exception reasonable.

Yet, there is no neutral vantage point from which to judge the gravity of exception of historical situations. Because of this fact, the fragility ${ }^{2}$ of responsible agency is amplified by the obscurity of what could be called evil; calling the exception is ultimately a manifestation of the inscrutability of the ultimate ground for the choice between good and evil. ${ }^{3}$ This fact is exacerbated by the tragedy that evil can masquerade as the ultimate good, for instance the ultimate good of the exception that, under extreme cases, one cannot simply refuse. For this reason one might ask if it is not better to adopt a stance towards the exception and equity that

vinced that "there exist extreme situations in which responsibility for the world, which is primarily political, cannot be assumed because political responsibility always presupposes at least a minimum of political power." (p. 45). Hence, assuming personal responsibility under conditions in which all customary rules have broken down (pp. 26-27) means two things. First, it entails responding to the negative counsel of the conscience that prohibits one as an individual from engaging in certain activities if one wants to be able to live with oneself henceforth (p. 44) - this powerless refusal to collaborate or consent being the trait of moral, rather than political action. Second, under the "marginal situation in which moral propositions become absolutely valid in the realm of politics is impotence" (p. 156), and judgement, for Arendt, functions without any pre-established procedure. But even here, one does well to compare Arendt's notes on "Civil disobedience" (in Crises of the Republic. San Diego, et al.: Harcourt Brace and Company, 1969, pp. 51-102), which is a neat argument for justice as equity, in other words for calling the law to greater justice in the name of the spirit of the law. Civil disobedience is thus already a fairly radical questioning of a state of justice, but not so severe that one could say that the actors of civil disobedience act out of absolute powerlessness and personal responsibility and thus completely apolitically.

2 Cf. Paul Ricoeur, "Fragilité et responsabilité", in Eros and Eris. Contributions to a hermeneutical phenomenology. Paul van Togeren et. al. (eds.). Dortrecht, et al.: Kluwer, 1992, pp. 295-304.

3 I take the formulation of this phrase from Richard Bernstein's Radical evil. A philosophical interrogation. Cambridge: Polity, 2002, p. 235. 
might be called that of a good enough justice, in a way comparable to what Winnicott calls a "good enough" mother. This is not an attempt to tackle political matters with tools from family psychology, but simply to adopt the idea of "good enough" as opposed to "perfect". The good enough mother doesn't do everything by the book as the perfect mother does (and the latter consequently risks suffocating her child by her care). "Good enough" is a figure of real and constant, demanding devotion, but where the relationships in which one is involved and the historical development thereof are given due recognition. The perfect justice might be the cleanest in theory, but can be quite messy in practice; a good enough justice accepts compromise to various degrees in common circumstances and while it doesn't exclude the dramatic exception, it doesn't live constantly under the pressure of tragedy. It is true that "good enough" would be a hermeneutical concept and it might be that finally it says not much more than prudence. Therefore, in order to have the advantages of prudence, of a serious devotion to practice that is nonetheless not insensitive to contingent circumstances, such prudence has to be given its proper place in ethical reflection. That is why it should be included in a thorough theory of responsibility. 


\section{Bibliography}

\section{Abbreviations}

\section{Levinas}

ADV L'au-delà du verset. Lectures et discours talmudiques. Paris: Editions de Minuit, 1982.

AE Autrement qu'être ou au-delà de l'essence. (livre de poche) Dortrecht: Martinus Nijhoff, [1974] 1986.

AS Autrement que savoir. Les entretiens du Centre Sèvres. Paris: Editions Osiris, 1988.

AT Altérité et transcendance. Montpellier: Fata Morgana, 1995.

CdC Carnets de captivité et autres inédits. Levinas Oeuvres 1. Paris: Grasset, 2009.

DE De l'évasion. Montpellier: Fata Morgana, 1982.

DEHH En découvrant l'existence avec Husserl et Heidegger. Paris: Vrin [1967] 1998.

DL Difficile liberté. Essais sur le judaïsme. Paris: Albin Michel, 1976.

DMT Dieu, la mort et le temps. Paris: Grasset, 1993.

DSAS Du sacré au saint. Cinq nouvelles lectures talmudiques. Paris: Editions de Minuit, 1977.

DVI De Dieu qui vient à l'idée. Paris: Vrin, [1982] 1992.

EE De l'existence à l'existant. Paris: Vrin, [1947] 1998.

EI Éthique et infini. Paris: Fayard, 1982.

EL Emmanuel Levinas. Essais et entretiens avec François Poirié. Lyon: Actes Sud, [1987] 1996.

EN Entre nous. Essais sur le penser-à-l'autre. Paris: Grasset, 1991.

EPP Éthique comme philosophie première. Paris: Rivages Poche, [1982] 1998. 
HH Humanisme de l'autre homme. Montpelier: Fata Morgana, 1972.

HS Hors sujet. Montpellier: Fata Morgana, 1987.

IH Les imprévus de l'histoire. Préface de Pierre Hayat. Fata Morgana: Montpellier, 1994.

LC Liberté et commandement. Montpellier: Fata Morgana, 1994.

NP Noms propres. Montpellier: Fata Morgana, 1975.

SMB Sur Maurice Blanchot. Montpellier: Fata Morgana, 1975.

TA Le temps et l'autre. Paris: PUF, [1947] 1998.

TI Totalité et infini. Essai sur l'extériorité. (livre de poche) Paris: Kluwer Academic, [1961] 1998.

\section{Levinas in English translation}

A\&T Alterity and transcendence. Michael Smith (transl.). London: Athlone Press, 1999.

BPW Basic philosophical writings. Adriaan Peperzak, Simon Critchley and Robert Bernasconi (eds.). Bloomington and Indianapolis: Indiana University Press, 1996.

BV Beyond the verse. Talmudic readings and lectures. Gary Mole (transl.). Bloomington and Indianapolis: Indiana University Press, 1994.

CPP Collected philosophical papers. Alphonso Lingis (transl.). The Hague, et al.: Martinus Nijhoff Publishers, 1987.

DF Difficult freedom. Seán Hand (transl.). London: Athlone Press, 1990.

E\&E Existence and existents. Alphonso Lingis (transl.). The Hague: Martinus Nijhoff, 1978.

E\&I Ethics and infinity. Conversations with Philippe Nemo. Richard Cohen (transl.). Pittsburg: Dusquesne University Press, 1985.

ENT Entre nous. Thinking-of-the-other. Michael Smith and Barbara Harshav (transl.). London: Athlone Press, 1998.

GCM OfGod who comes to mind. Bettina Bergo (transl.). Stanford, California: Stanford University Press, 1998.

GDT God, death, and time. Bettina Bergo (transl.). Stanford, California: Stanford University Press, 1993.

HO Humanism of the other. Nidra Poller (transl.). Urbana and Chicago: University of Illinois Press, 2006.

LR The Levinas reader. Seán Hand (ed.). Oxford: Basil Blackwell, 1989.

NTL Nine Talmudic readings. Annette Aronowicz (transl. and intr.). Bloomington and Indianapolis: Indiana University Press, 1990. 
OB Otherwise than Being or beyond essence. Alphonso Lingis (transl.). The Hague, et al.: Kluwer Academic Publishers, 1991.

OS Outside the subject. Michael Smith (transl.). Stanford, California: Stanford University Press, 1994.

PN Propernames. Michael Smith (transl.). London: Athlone Press, 1996.

T\&I Totality and infinity. An essay on exteriority. Alphonso Lingis (transl.). The Hague, et al.: Martinus Nijhoff Publishers, 1979.

TO Time and the other. Richard Cohen (transl.). Pittsburgh: Duquesne University Press, 1987.

\section{Jean-Paul Sartre, Martin Heidegger and Louis Althusser}

EH Jean-Paul Sartre, L'existentialisme est un humanisme. Paris: Nagel, 1946.

W Martin Heidegger, Wegmarken (Heidegger Gesamtausgabe, Vol. 9), Frankfurt am Main: Vittorio Klostermann [1967] 1996.

PM Louis Althusser, Pour Marx, Paris: F. Maspero, 1965.

\section{Jean-Paul Sartre, Martin Heidegger and Louis Althusser in English translation}

P Martin Heidegger, Pathmarks. William McNeill (ed.). Cambridge: Cambridge University Press, 1997.

E\&H Jean-Paul Sartre, Existentialism and humanism. Philip Mairet (tranl.), London: Methuen, 1968.

FM Louis Althusser, For Marx. Ben Brewster (transl.). London: Verso, 1979.

\section{Max Weber}

PaB "Politik als Beruf" (1919), in Gesammelte politische Schriften, Postdamer Internet-Ausgabe (following the "Marianne-Ausgabe"), http://www.uni-potsdam.de/u/paed/pia/index.htm (1999), pp. 396-450.

WaB "Wissenschaft als Beruf" (1917), in Gesammelte Aufsätze zur Wissenschaftslehre, Postdamer Internet-Ausgabe (following the "Marianne-Ausgabe"), ibid., pp. 524-555.

ZB "Zwischenbetrachtung: Theorie der Stufen und Richtungen religiöser Weltablehnung", in Gesammelte Aufsätze zur Religionssoziologie, Vol. 1, Tübingen: J.C.B. Mohr (Paul Siebeck), pp. 536-573. 


\section{Max Weber in English translation}

$\mathrm{PaV}$ "Politics as a vocation", in From Max Weber: essays in sociology. H.H. Gerth and C. Wright Mills (transl.). London: Routledge, 1991, pp. 77-128.

$\mathrm{SaV}$ "Science as a vocation", in From Max Weber: essays in sociology. H.H. Gerth and C. Wright Mills (transl.). London: Routledge, 1991, pp. 129-156.

RRW "Religious rejections of the world and their directions" [1915], in From Max Weber: essays in sociology. H.H. Gerth and C. Wright Mills (transl.). London: Routledge, 1991, pp. 323-359.

\section{Karl-Otto Apel}

DV Diskurs und Verantwortung. Das Problem des Übergangs zur postkonventionellen Moral. Frankfurt am Main: Suhrkamp, 1988.

\section{Paul Ricoeur}

CC La critique et la conviction. Entretien avec François Azouvi et Marc de Launay, Paris: Calman-Lévy, 1995.

HV Histoire et vérité (third edition). Paris: Seuil, 1967.

JI Le juste 1. Paris: Esprit, 1995.

JII Le juste 2. Paris: Esprit, 2001.

LI Lectures 1. Autour du politique. Paris: Seuil, 1991.

LII Lectures 2. La contrée des philosophes. Paris: Seuil, 1992.

RF Réflexion faite. Autobiographie intellectuelle. Paris: Esprit, 1995.

SA Soi-même comme un autre. Paris: Seuil, 1990.

\section{Paul Ricoeur in English translation}

C\&C Critique and conviction. Conversations with François Azouvi and Marc de Launay. Kathleen Blamey (transl.). Cambridge: Polity Presss, 1998.

HT History and truth. Charles Kelbley (transl.). Evanston: Northwestern University Press, 1965.

OAA Oneself as another. Kathleen Blamey (transl.). Chicago and London: University of Chicago Press, 1992.

TJ The just. David Pellauer (transl.). Chicago and London: University of Chicago Press, 2000.

RTJ Reflections on the just. David Pellauer (transl.). Chicago and London: University of Chicago Press, 2007 
All other texts of these authors are listed in the bibliography below. Were no specification otherwise is given, translations are my own.

\section{General biblography}

Abel, Olivier 1996: Paul Ricoeur. La promesse et la règle. Paris: Editions Michalon.

Apel, Karl-Otto and Michelini, Dorando 2000: "Ética del discurso y globalización. La ética ante las coerciones fácticas e institutionales de la politica, el derecho y la economía", in Erasmus, revista para el diálogo intercultural 2/2, pp. 99-119.

Arendt, Hannah 1969: "Civil disobedience", in Crises of the Republic. San Diego, et al.: Harcourt Brace and Company, pp. 51-102.

2003: Responsibility and Judgment. Jerome Kohn (ed.). New York: Schocken Books.

Barber, Michael 1995: "The vulnerability of reason: the philosophical foundations of Emmanuel Levinas and K.O. Apel", in The prism of the self: philosophical essays in honor of Maurice Natanson. Steven G. Crowell (ed.). Dordrecht: Kluwer Academic Publishers, pp. 93-106.

2001: Equality and Diversity: Phenomenological Investigations of Prejudice and Discrimination. Amherst, New York: Humanity Books.

Bayerz, Kurt (ed.) 1995: Verantwortung: Prinzip oder Problem?. Darmstadt: Wissenschaftliche Buchgesellschaft.

Bernasconi, Robert 1990: "One-way traffic: the ontology of decolonization and its ethics", in Ontology and Alterity in Merleau-Ponty. Galen A. Johnson and Michael B. Smith (eds.). Evanston: Northwestern University Press, pp. 67-80.

1992: "Who is my neighbor? Who is the other? Questioning 'the generosity of Western thought", in Ethics and responsibility in the phenomenological tradition. The ninth annual symposium of the Simon Silverman Phenomenological Center. Pittsburgh: Duquesne University, pp. 1-31.

2005: "Globalisierung und Hunger", in Im Angesicht der Anderen. Levinas' Philosophie des Politischen. Pascal Delhom and Alfred Hirsch (eds.). Zürich and Berlin: Diaphanes, pp. 115-129.

Bernstein, Richard 2002: Radical evil. A philosophical interrogation. Cambridge: Polity. 
Bolsinger, Eckard 1998: "Was ist Dezisionismus? Rekonstruktion eines autonomen Typs politischer Theorie", in Politische Vierteljahresschrift 39/3, pp. 471-502.

Bourgeois, Partick 2002: "Ricoeur and Levinas: Solicitude in reciprocity and solicitude in existence", in Ricoeur as another. The ethics of subjectivity. Albany: State University of New York Press, pp. 109-126

Calin, Rodolphe 2005: Levinas et l'exception du soi. Paris: Presses Universitaires de France.

Castells, Manuel 1998: End of millennium, Oxford: Blackwell.

Caygill, Howard 2002: Levinas and the Political, London and New York: Routledge.

Ciocan, Cristian and Hansel, Georges 2005: Levinas concordance. Dortrecht: Springer.

Cohen, Richard and Marsh, James (eds.) 2002: Ricoeur as another. The ethics of subjectivity. Albany: State University of New York Press.

Crépon, Marc 2007: "Du 'paradoxe politique' à la question des appartenances”, in Paul Ricoeur (Cahiers de L'Herne). Myriam Revault d'Allonnes and François Azouvi (eds.). Paris: L’Herne, pp. 307-314.

Dallmayr, Fred 2002: "Ethics and public life. A critical tribute to Paul Ricoeur" in Paul Ricoeur and contemporary moral thought. John Wall, Willam Schweiker and W. David Hall (eds.). New York and London: Routledge, pp. 213-232.

Dauenhauer, Bernard 1998: Paul Ricoeur. The promise and the risk of politics. Lanham, et al.: Rowman and Littlefield publishers.

Derrida, Jacques, L'écriture et la différence, Paris: Seuil, 1967.

2001: Writing and difference. Alan Bass (transl.). London and New York: Routledge.

Descombes, Vincent 1979: Le même et l'autre. Quarante-cinq ans de philosophie française (1933-1978). Paris: Minuit.

D'Hondt, Jacques 1968: "La crise de l'humanisme dans le marxisme contemporain", in Revue internationale de philosophie 85-86, pp. 369-378.

Dostoïevski, Fiodor 1952 : Les frères Karamazov (Pléiades) Paris: Gallimard.

Eisenstadt, Shmuel 2000: "Multiple modernities", in Daedalus 129/1, pp. 1-29.

Eze, Emmanuel 1997: "Introduction: Philosophy and the (post)colonial", in Postcolonial African philosophy. A critical reader. Emmanuel Eze (ed.). Oxford and Cambridge, Mass.: Blackwell, pp. 1-21. 
Frank, Didier 2008: L'un-pour-l'autre. Levinas et la signification. Paris: Presses Universitaires de France.

Freud, Sigmund [1917] 1924: "Eine Schwierigkeit der Psychoanalyse", in Gesammelte Schriften von Freud, Vol. 10: Totem und Tabu: Arbeiten zur Anwendung der Psychoanalyse. Leipzig, et al.: Internationaler Psychoanalytischer Verlag, pp. 347-356.

Garin, Eugenio 1968: "Quel 'humanisme'? (Variations historiques)”, in Revue internationale de philosophie, 85-86, pp. 263-275.

Gellius, Aulus [1927] 1982: The Attic nights, Vol. 2. Loeb classical library. London: William Heinemann.

Greisch, Jean and Rolland, Jacques 1993: "Présentation", in Emmanuel Lévinas. L'éthique comme philosophie première. Paris: Cerf, pp. 7-10.

Habermas, Jürgen [1981] 1995: Theorie des kommunikativen Handelns. Band 1. Handlungsrationalität und gesellschaftliche Rationalisierung. Frankfurt am Main: Suhrkamp.

1991: "Zu Max Horkheimers Satz: "Einen unbedingten Sinn zu retten ohne Gott, ist eitel”, in Texte und Kontexte, Frankfurt am Main: Suhrkamp, pp. 110-126.

Hamrick, William S. 2003: "Doing justice to responsibility", in Human Studies 26/3, pp. 401-407.

Heidbrink, Ludger and Hirsch, Alfred (eds.) 2007: Staat ohne Verantwortung? Zum Wandel der Aufgaben von Staat und Politik. Frankfurt and New York: Campus Verlag.

Heidegger, Martin [1927] 1993: Sein und Zeit. Tübingen: Max Niemeyer Verlag.

[1962] 1988: Being and time. John Macquarrie and Edward Robinson (transl.). Oxford: Basil Blackwell.

Hirsch, Alfred 2005: "Vom Menschenrechte zum ewigen Frieden. Grenzgänge zwischen Kant und Levinas", in Im Angesicht der Anderen. Levinas' Philosophie des Politischen. Pascal Delhom and Alfred Hirsch (eds.). Zürich and Berlin: Diaphanes, pp. 229-244.

Homer, Sean 2004: "Humanism and antihumanism", in Encyclopedia of modern French thought. Christopher John Murray (ed.). New York and London: Fitzroy Dearborn, pp. 331-334.

Husserl, Edmund 1959: "Meditation über die Idee eines individuellen und Gemeinschaftslebens in absoluter Selbstverantwortung", in Erste Philosophie (1923/1924), Zweiter Teil: Theorie der phänomenologischen Reduktion, Husserl Gesammelte Werke Band VIII. Rudolf Boehm (ed.). Haag: Martinus Nijhof, pp. 193-202. 
Irele, Abiola 1998: "African philosophy, Francophone", in Routledge Encyclopedia of Philosophy. E. Craig (ed.). London: Routledge.

Janicaud, Dominique 2001: Heidegger en France, Vol I: Récit. Paris: Albin Michel.

Keck, Frédéric 2005: "Causalité mentale et perception de l'invisible. Le concept de participation chez Lucien Lévy-Bruhl", in Revue philosophique 3, pp. 303-322.

Jordaan, Eduard 2009: “Cosmopolitanism, freedom, and indifference: a Levinasian view”, in Alternatives 34, pp. 83-106.

Kambouchner, Denis 2009: "Lévi-Strauss and the question of humanism (followed by a letter from Claude Lévi-Strauss)", in The Cambridge companion to Lévi-Strauss. Boris Wiseman (ed.). Cambridge, et. al.: Cambridge University Press, pp. 19-38.

Kebede, Messay 2004: Africa's quest for a philosophy of decolonization. Amsterdam and New York: Editions Radopi.

Lacroix, Jean 1968: "L'humanisme de Marx selon Adam Schaff", in Revue internationale de philosophie 85-86, pp. 379-386.

Lenk, Hans 1998: Konkrete Humanität. Vorlesungen über Verantwortung und Menschlichkeit. Frankfurt am Main: Suhrkamp.

Levinas, Emmanuel 1984: "Ethics of the infinite", in Dialogues with contemporary Continental thinkers. The phenomenological heritage. Richard Kearney. Manchester: Manchester University Press, pp. 49-69.

1988: "La vocation de l'autre", in Racismes. L'autre et son visage. Grands entretiens réalisés par Emmanuel Hirsch. Paris: Cerf, pp. 91-102.

- 1991: "Socialité et argent", in Emmanuel Lévinas (Cahier de l'Herne). Catherine Chalier and Miguel Abensour (eds.). Paris: Editions de l'Herne, pp. 106-112.

1994: L'intrigue de l'infini. Marie-Anne Lescouret (ed.). Paris: Flammarion.

1995: Visage et violence première", in La différence comme non-indifférence. Ethique et altérité chez Emmanuel Lévinas. Paris: Kimé, pp. 129-143.

1996: "Deux dialogues avec Emmanuel Lévinas", in Sujet et altérité. Sur Emmanuel Lévinas. Augusto Ponzio. Paris: L'Harmattan, pp. 143-151.

1997: "Post-scriptum”, in Quelques réflexions sur la philosophie de l'hitlérisme. Paris: Rivages poche.

1997: "De la phénoménologie à l'éthique”, in Esprit 234, pp. 121140. 
Lévy-Bruhl, Lucien 1949: Les carnets de Lucien Lévy-Bruhl (with a preface by Maurice Leenhardt). Paris: Presses Universitaires de France.

Loidolt, Sophie 2009: Anspruch und Rechtfertigung: eine Theorie des rechtlichen Denkens im Anschluss an die Phänomenologie Edmund Husserls. Dordrecht: Springer.

Marion, Jean-Luc 2000: “D'autrui à l'individu”, in Emmanuel Lévinas. Positivité et transcendance. Paris: PUF (Epiméthée), pp. 287-308.

Martuccelli, Danilo 1999: Sociologies de la modernité, Paris: Gallimard.

Mende, Dirk 2003: "Brief über den 'Humanismus'. Zu den Metaphern der späten Seinsphilosophie", in Heidegger-Handbuch. Leben-WerkWirkung. Dieter Tomä (ed.). Stuttgart and Weimar: Verlag J.B. Metzler, pp. 247-258.

Merleau-Ponty, Maurice 1960: Signes. Paris: Gallimard.

- [1966] 1996: Sens et Non-sens. Paris: Gallimard.

Michelini, Dorando 2002: "Ética de la responsabilidad. Modelos de fondamentación y aplicatión", in Concordia 41, pp. 83-103.

Nietzsche, Friedrich [1885] 1999: Jenseits von Gut und Böse. In G. Colli and M. Montinari (eds.), Kritische Studienausgabe 5. Berlin and New York: De Gruyter.

1968: Basic writings of Nietzsche. Walther Kaufmann (transl.). New York: The modern library.

Nussbaum, Martha 2002: "Ricoeur on tragedy: teleology, deontology and phronesis", in Paul Ricoeur and contemporary moral thought. John Wall, Willam Schweiker and W. David Hall (eds.). New York and London: Routledge, pp. 264-276.

Oelmüller, Willi 1980: "Gibt es überzeugende Orientierungsysteme für unser politisches Handeln?", in Diskurs: Politik. W. Oelmüller, et al. (eds.). Paderborn, et al.: Ferdinand Schöningh.

Renaut, Alain 1993: Sartre. Le dernier philosophe. Paris: Grasset and Fasquelle.

Ricoeur, Paul 1992: "Fragilité et responsabilité", in Eros and Eris. Contributions to a hermeneutical phenomenology. Paul van Togeren, et al. (eds.). Dortrecht, et al.: Kluwer, pp. 295-304.

1974: Political and social essays. David Steward and Joseph Bien (eds.). Athens: Ohio University Press.

1994: "L'unicité humaine du pronom je", in Ethique et responsabilité: Paul Ricœur. Jean-Christophe Aeschlimann (ed.). Neufchâtel: Editions La Baconnière. 
1998: "La justice, vertu et institution", in La sagesse pratique. Autour de l'oeuvre de Paul Ricoeur. Jeffrey Barash and Mireille Delbraccio (eds.). Amiens: Centre régional de documentation pédagogique de l'académie d'Amiens, pp. 11-28.

Rockmore, Tom 1995: Heidegger and French philosophy. Humanism, antihumanism and being. London and New York: Routledge.

Rolland, Jacques 1997: "L'humain dans l'homme. Quelques notes", in Esprit 234, pp. 111-120.

— Jacques 2002: "Pas de conseils pour le tyran. Lévinas et la question politique", in Revue philosophique de Louvain 100, pp. 32-64.

Rosenzweig, Franz 1984: "Atheistische Theologie", in Der Mensch und sein Werk. Gesammelte Schriften, Vol. 3, Zweistromland. Kleinere Schriften zu Glauben und Denken. Reinhold and Annemarie Mayer (eds.). Dordrecht: Martinus Nijhoff, pp. 687-697.

Sartre, Jean-Paul [1956] 1964: "Le colonialisme est un système", in Situations V. Colonialisme et néo-colonialisme. Paris: Gallimard, pp. 25-48.

Schluchter, Wolfgang 1971: Wertfreiheit und Verantwortungsethik. Zum Verhältnis von Wissenschaft und Politik bei Max Weber. Tübingen: J.C.B. Mohr (Paul Siebeck).

1980: "Die Paradoxie der Rationalisierung. Zum Verhältnis von 'Ethik' und 'Welt' bei Max Weber', in Rationalismus und Weltbeherrschung. Studien zu Max Weber. Frankfurt am Main: Suhrkamp, pp. 940.

Serres, Michel 1967: "Analyse symbolique et méthode structurale", in Revue philosophique de la France et de l'étranger 171, pp. 437-452.

Soper, Kate 1986: Humanism and anti-humanism. London, et al.: Hutchinson.

Starr, Bradley 1999: "The structure of Max Weber's ethic of responsibility", in The journal of religious ethics 27/3, pp. 407-434.

Vanni, Michel 2004: "En guerre pour autrui", in Internationale Zeitschrift für Philosophie 1, pp. 78-93.

Van Tongeren, Paul 2000: Reinterpreting modern culture. An introduction to Friedrich Nietzsche's philosophy, West Lafayette: Purdue University Press.

Vattimo, Gianni 1983: "La crise de l'humanisme", in Exercises de la Patience 5, pp. 19-30.

Weber, Max 1959: Le savant et le politique. Julien Freund (transl.). Raymond Aron (intro.), Paris: Plon. 
2003: Le savant et le politique. Une nouvelle traduction. Catherine Colliot-Thélène (transl.). Paris: La Découverte.

Wolff, Ernst 2007: De l'éthique à la justice. Langage et politique dans la philosophie de Lévinas (Phaenomenologica 183). Dortrecht: Springer.

2007: “Giving up your place in history. The 'position' of Levinas in philosophy and Jewish thought", in Journal for Semitics 16/1, pp. 180-193.

2009: "The State and politics in a post-colonial, global order. Reconstruction and criticism of a Levinasian perspective", in SA Publiekreg / SA Public Law 24/2, pp. 352-369.

2009: "Responsibility in an era of modern technology and nihilism. Part 2. Inter-connection and implications of the two notions of responsibility in Jonas", in Dialogue. Canadian Philosophical Review 48/4, pp. 841-866.

2010: 'Le mal, le destin et l'éthique. Lévinas et le Voyage au bout de la nuit", in Études littéraires 41/2, pp. 133-145.

2010: "The quest for justice versus the rights of the other?", in In Levinas' trace. Maria Dimitrova (ed.). Sofia: Avangard Prima Publishers, pp. 101-111.

Young, Iris 2007: "Responsibility, Social connection, and Global labor justice", in Global Challenges. War, Self-determination, and responsibility for Justice. Cambridge and Malden: Polity, pp. 159-186. 
Der Mensch im Netz der Kulturen Humanismus in der Epoche der Globalisierung/ Being Human: Caught in the Web of Cultures Humanism in the Age of Globalization

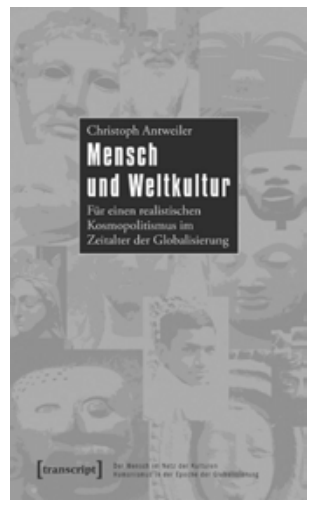

Christoph Antweiler Mensch und Weltkultur Für einen realistischen Kosmopolitismus im Zeitalter der Globalisierung 2010, 326 Seiten, kart., 29,80€, ISBN $978-3-8376-1634-7$

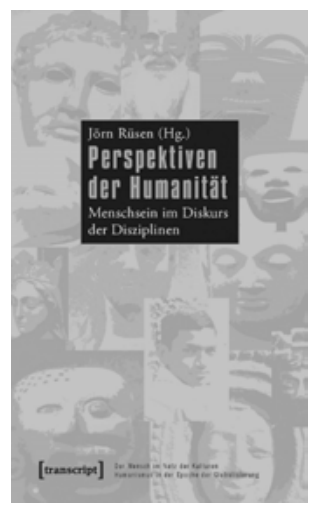

JÖRN RÜSEN (HG.)

Perspektiven der Humanität

Menschsein im Diskurs der Disziplinen

20I0, 454 Seiten, kart., 32,80€,

ISBN 978-3-8376-I4I4-5

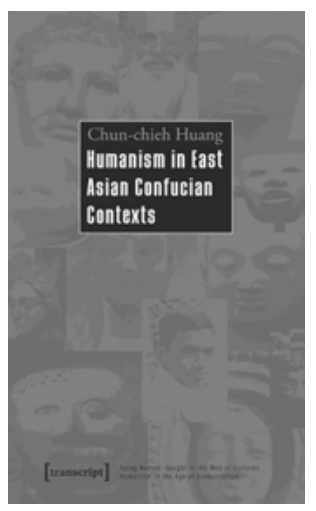

Chun-chieh Huang

Humanism in East Asian Confucian Contexts

2010, I68 Seiten, Hardcover, 25,80€,

ISBN 978-3-8376-I554-8

Leseproben, weitere Informationen und Bestellmöglichkeiten finden Sie unter www.transcript-verlag.de 
Der Mensch im Netz der Kulturen -

Humanismus in der Epoche der Globalisierung/

Being Human: Caught in the Web of Cultures Humanism in the Age of Globalization

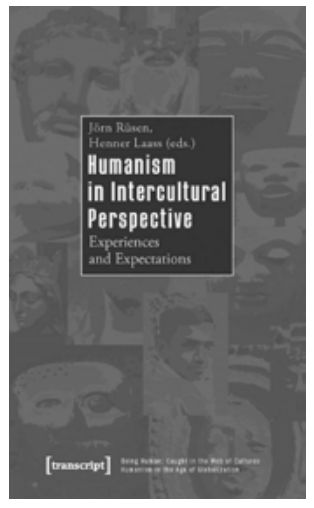

Jörn RÜSEn, Henner LaAss (eds.)

Humanism in Intercultural Perspective

Experiences and Expectations

2009, 280 Seiten, kart., $34,80 €$,

ISBN 978-3-8376-I344-5

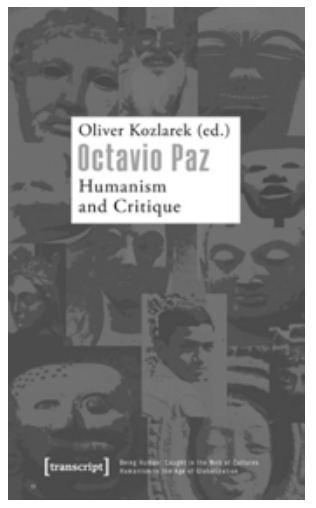

Oliver Kozlarek (ed.)

Octavio Paz

Humanism and Critique

2009, 266 Seiten, kart., 32,80€,

ISBN 978-3-8376-I304-9

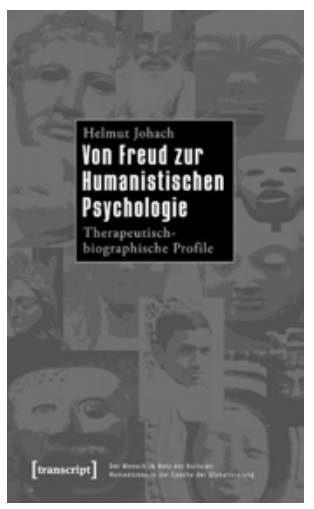

HeLmut Johach

Von Freud zur Humanistischen Psychologie

Therapeutisch-biographische Profile

2009, 340 Seiten, kart., 29,80€,

ISBN 978-3-8376-I294-3

Leseproben, weitere Informationen und Bestellmöglichkeiten finden Sie unter www.transcript-verlag.de 
Der Mensch im Netz der Kulturen -

Humanismus in der Epoche der Globalisierung/

Being Human: Caught in the Web of Cultures Humanism in the Age of Globalization

\author{
Carmen Meinert (ed.) \\ Traces of Humanism in China \\ Tradition and Modernity \\ 20Iо, 2I0 Seiten, kart., 26,80€, \\ ISBN 978-3-8376-I35I-3 \\ Carmen Meinert, \\ HANS-BERnd ZöLlner (EDS.) \\ Buddhist Approaches \\ to Human Rights \\ Dissonances and Resonances \\ 2010, 248 Seiten, kart., 29,80€, \\ ISBN 978-3-8376-1263-9 \\ Gala Rebane, Katja Bendels, \\ Nina Riedler (Hg.) \\ Humanismus polyphon \\ Menschlichkeit im Zeitalter \\ der Globalisierung \\ 2009, 288 Seiten, kart., 29,80€, \\ ISBN 978-3-8376-II72-4
}

Leseproben, weitere Informationen und Bestellmöglichkeiten

finden Sie unter www.transcript-verlag.de 